\title{
The Making of the Tuoba Northern Wei: \\ Constructing Material Cultural Expressions in the Northern Wei Pingcheng Period (398-494 CE)
}

by

Chin-Yin Tseng

Merton College

A thesis submitted in partial fulfillment of the requirements for the degree of Doctor of Philosophy

University of Oxford

Michaelmas Term, 2012

Faculty of Oriental Studies

The Oriental Institute, Pusey Lane

Oxford, OX1 2LE 


\section{Acknowledgements}

I am proud to have been a student of Professor Dame Jessica Rawson. Her extraordinary energy and vivacious spirit make her the best mentor anyone could have ever wished for. To her, I express my deepest gratitude and respect.

I would also like to thank Professor Helena Hamerow, Dr. Dirk Meyer, Dr. Peter Ditmanson, Dr. Robert Chard and Dr. Frances Wood for their valuable suggestions and advice during my transfer and confirmation interviews as well as in the final viva.

This thesis required access to archaeological sites and to the Yungang grottoes that would not have been made available without the help of local scholars at Datong, Shanxi province. My heartfelt appreciation goes to Director Cao Chenmin and Wang Yanqing from the Datong Museum, Director Liu Junxi from the Datong Archaeological Institute, Director Dr. Huang Jizhong and Li Xueqin from the Yungang Grottoes Research Institute, as well as Yin Xian, editor of the journal Beichao yanjiu.

In Beijing, Professor Zheng Yan from the Central Academy of Fine Arts shared with me important insights into Northern dynasty tombs. My colleague Zhang Jingping from Tsinghua University has been my sounding board since the inception of this thesis.

My fellow academic brothers and sisters, Wu Hsiao-yun, Deng Fei, Chen Xin, Neil Coomber and Sascha Priewe, shared with me words of wisdom and helped me find my way through the world of academia over countless cups of coffee and tea. Chen Yi, Chen Xuan, Liu Yan and Li Chen have been my most cherished companions on this arduous journey. It is thanks to them that I have been able to keep a smile on my face through all my frustrations and apprehensions; always looking forward to our next hot-pot gathering.

Finally, and most importantly, I dedicate this thesis to my beloved parents. I owe everything that I have achieved today to their unconditional love and unwavering support, giving me strength through every stage of my life. 


\title{
The Making of the Tuoba Northern Wei: \\ Constructing Material Cultural Expressions in the Northern Wei Pingcheng Period (398-494 CE)
}

\author{
Chin-Yin Tseng \\ Merton College \\ A thesis submitted in partial fulfillment of the requirements \\ for the degree of Doctor of Philosophy \\ University of Oxford \\ Michaelmas Term, 2012
}

\begin{abstract}
The Tuoba's success in the making of the Northern Wei as a conquest dynasty in fifth century northern China will be argued in this thesis as a result of their ability to cross between the traditions and practices of the Chinese sphere and those of the Eurasian steppe, through the construction of a "dual presence" in the Pingcheng period (398-494 CE). A negotiation of material culture in this formative phase of state-building allowed for new notions of kingship, dynastic identity, and representations of daily life to be (re)created. This was manifested separately through the application of mountain-side stone sculptures, tomb repertoires, as well as the conception of Pingcheng as a capital city. The material cultural expressions explored in this thesis reflect significant changes in the socio-cultural atmosphere at this point in history. In effect, these ritual, funerary, and commemorative discourses wove together to create new notions of "Chineseness" in fifth century northern China. In the following discussion, we will come to recognize the Tuoba's maintenance of a "dual presence", not only as "Son of Heaven" to the conquered subjects, but also carrying over practices that befit a Khagan in the Central Asian tradition, as an act of ingenuity.
\end{abstract}




\section{Table of Contents}

Acknowledgements ......................................................................................................i



Table of Contents ................................................................................................... iii

Chapter 1: Introduction.........................................................................................................1

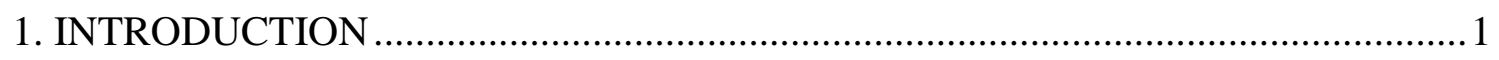

2. HISTORICAL AND MATERIAL SOURCES ................................................

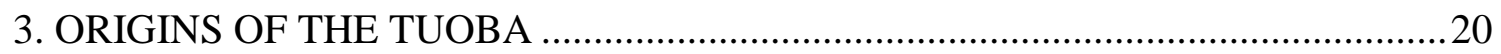

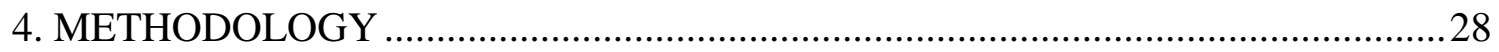

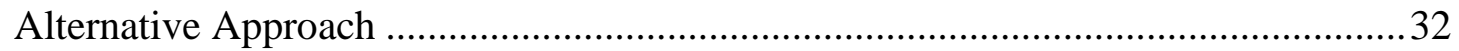

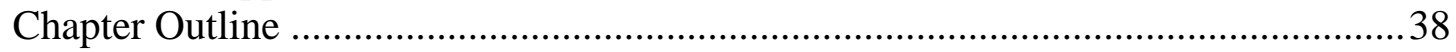

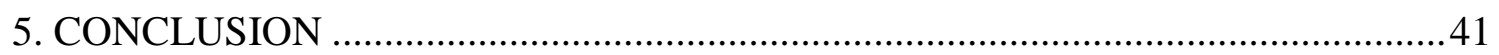

Chapter 2: Pingcheng and the Rituals of Empire ........................................42

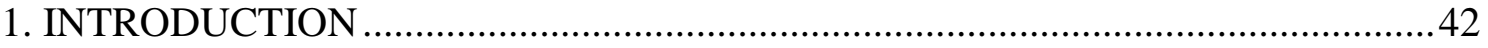

2. THE TUOBA SEAT OF POWER: PHYSICAL AND CONCEPTUAL .....................47

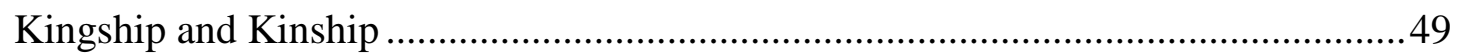

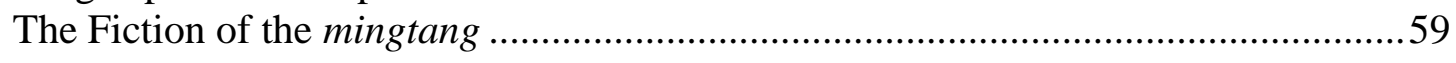

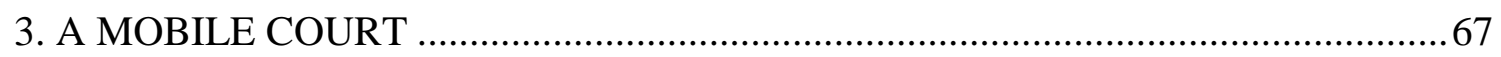

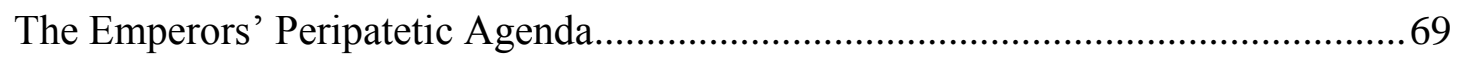

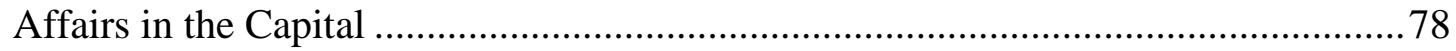

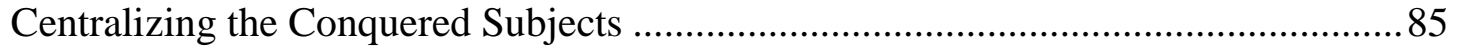

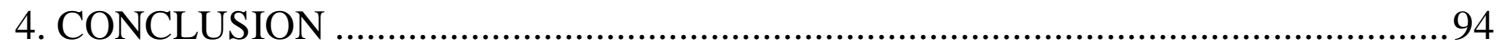

Chapter 3: Yungang and the Tuoba Kingship ..............................................96

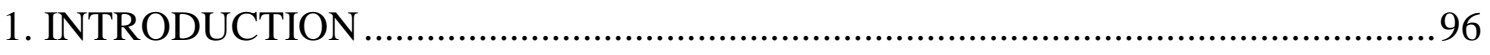

2. A NEW IMPERIAL MONUMENT: THE FIVE CAVES OF TAN YAO ............... 104

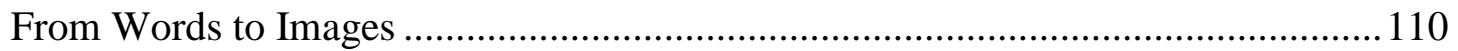

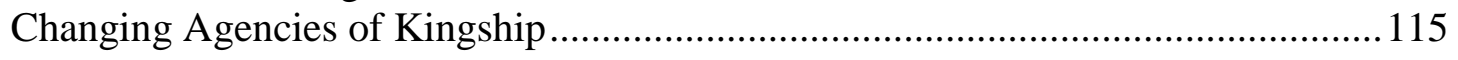

3. A NEW IMPERIAL APPROACH: THE CAVES AS ENGAGING SPACES ........119

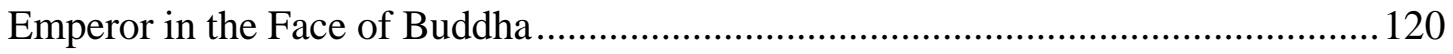

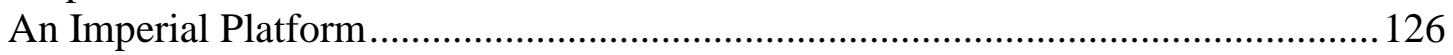




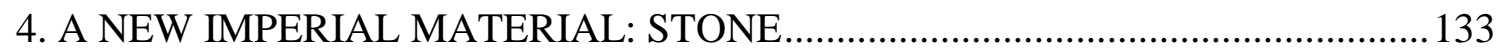



Materializing Kingship through the Restoration of Buddhism .............................. 146

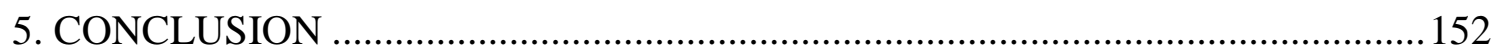

Chapter 4: Life and Death of the Northern Wei Elite..................................154

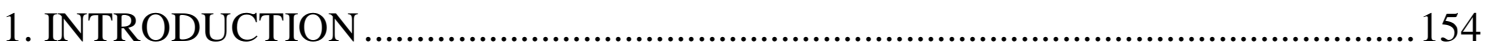

2. CASE STUDY I: SHALING M7 OF LADY PODUOLUO .................................... 164

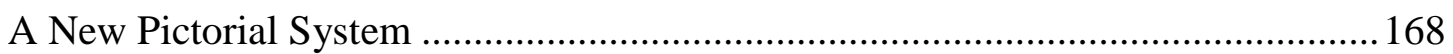

East Wall: Positioning Lady Poduoluo in Her Household ...................................... 176

North and South walls: Remembering Lady Poduoluo in Leisure and Ranks .......... 185

3. CASE STUDY II: YANBEI SHIYUAN M5 OF SONG SHAOZU ........................... 191

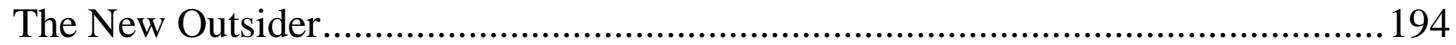

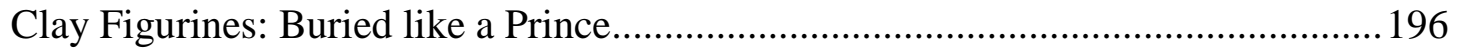

Stone Sarcophagus: Appeals of a New Fashion .....................................................207

4. CONCLUSION: READING THE TOMBS ..................................................... 218

Chapter 5: The Many Faces of the Tuoba .........................................................222

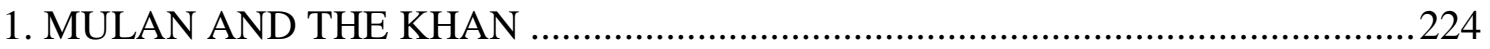

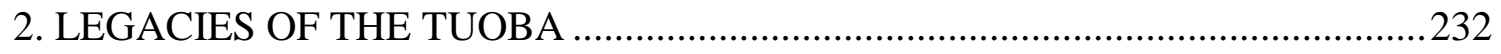

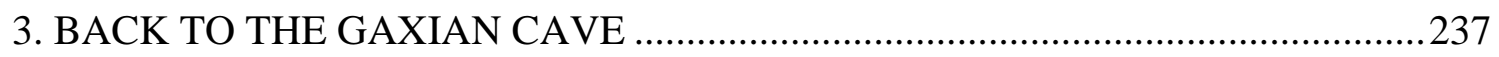

Appendix A: Northern Wei Emperors of the Pingcheng Period..............242

Appendix B: Figures .................................................................................................243

Appendix C: Bibliography .......................................................................................316

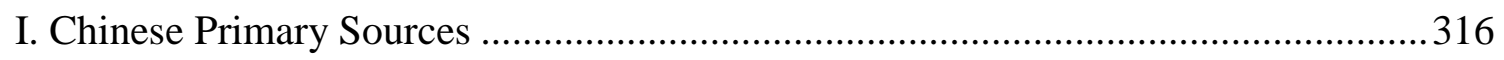

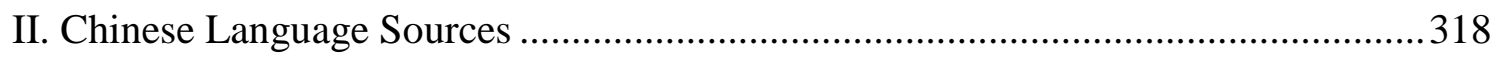

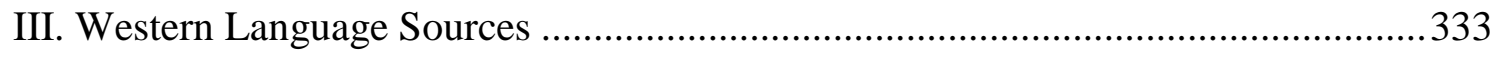






\section{Chapter 1: Introduction}

昔黃帝有子二十五人，或内列諸華，或外分荒服。

昌意少子，受封北土，國有大鮮卑山，因以爲號。

其後, 世為君長, 統幽都之北, 廣漠之野, 畜牧遷徙, 射獵為業, 淳樸為俗, 簡易為化，不為文字，刻木紀契而已，世事遠近，人相傳授，如史官之紀錄焉。 黃帝以土德王, 北俗謂土為托, 謂后為跋, 故以爲氏。

In antiquity, the Yellow Emperor had twenty-five sons. Those who stayed at home became the ancestors of the Chinese people; those who went abroad scattered in the wilderness. The youngest son, Ch'ang-i, was given the northern lands containing Ta Hsien-pi Mountain. ${ }^{2}$ From this he took his name. For generations, his descendants were made chieftains in charge of the lands to the north of $\mathrm{Yu}-\mathrm{tu},{ }^{3}$ where, in the vast wilderness, herding and hunting formed the basis of life. The customs were pure and unsophisticated; the culture plain and simple. The people were without any written script, and contracts were sealed by notching a piece of wood. Details of both the recent and remote past were passed down by word of mouth just as historical records are in China. Since the Yellow Emperor ruled through the virtue of 'earth', and northerners call the earth ' $\mathrm{T}$ ' $\mathrm{o}$ ' and the ruler ' $\mathrm{Pa}$ ', the people took the name ' $\mathrm{T}$ 'o-pa'.

--- Wei $s h u^{4}$

\section{INTRODUCTION}

The Tuoba 拓跋/托跋 ${ }^{5}$ ruling house that unified northern China under the dynastic name of Wei 魏 (most commonly known as the Northern Wei 北魏, $386-534$ CE) ${ }^{6}$ (fig. 1a, b)

\footnotetext{
${ }^{1}$ Wei shu, juan 1, p. 1.

${ }^{2}$ Ta Hsien-pi Mountain, or Da Xianbei Mountain 大鮮卑山, has been identified to be the Daxing'an Mountain Range 大興安嶺 in northwestern Heilongjiang province; see Lin Lüzhi 1967, pp. 143-144.

${ }^{3}$ Yu-tu, or You-du 幽都, is the traditional name for the area to the north of the bend in the Yellow River; see Holmgren 1982, p. 79.

${ }^{4}$ English translation after Holmgren 1982, p. 51.

${ }^{5}$ Tuoba, also known as T'o-pa or Tabgatch, was a nomadic clan of the Xianbei 鮮卑 people active in northern China as early as the second century. The Xianbei first appeared in Chinese records in $45 \mathrm{CE}$. Upon the collapse of the second Xiongnu confederacy, when it was split into the Northern and Southern Xiongnu, the former became the object of campaigns by the Chinese and the latter settled within the loop of the Yellow River. By 87 CE the Xianbei struck a heavy blow at the Northern Xiongnu, and although they began challenging the Chinese authority within ten years, despite the initial clashes, the Xianbei raids on Chinese settlements along the northern frontier were infrequent and of far less trouble than the other nomadic groups; see Holmgren 1982, p. 7. The structure and origins of the Xianbei varied from that of the Xiongnu state. The Xianbei consisted of nomads and forest tribes from the Manchurian Liao River region, with an egalitarian
} 
between the fourth and sixth centuries was a clan of the Xianbei 鮮卑 group active in the steppeland beyond China's northeastern frontier as early as the Han 漢 dynasty (202 BCE - $220 \mathrm{CE}$ ). Since they conquered and ruled over the Chinese-speaking arena as a minority through military prowess, the Tuoba's state-building success has generally been viewed as the result of an active Sinicization effort by these "outside" rulers - a complete political and social acculturation into the so-called Han Chinese mainstream. However, the success of the Northern Wei as a conquest dynasty tells a much more complex story. In fact, as will be argued in this thesis, it was through the construction of a "dual presence" in the Pingcheng period (398-494 CE) that the earlier phase of the Northern Wei crossed back and forth between the traditions and practices of the Chinese sphere and those of the Eurasian steppe. This was manifested in the application of mountain-side stone sculptures, tomb burials, as well as in the reification of the notion of a capital city. Consequently, a negotiation of material culture allowed the Tuoba to (re)create notions of kingship, dynastic identity, and representations of daily life, which were particular to fifth century northern China.

The application of a "dual presence", as a mechanism adopted by the Tuoba in the making of the Northern Wei state, can be seen as having derived from the form of dual organization employed by their cousins and also predecessors, the Murong Xianbei 慕容

political structure and close contact with sedentary regions within Manchuria. The steppe border to the west of the Liao River was the eastern wing of the nomadic imperium; east of the Liao River, although only narrowly connected to China proper, was always closer to the Chinese in culture and organization; see Barfield 1989, pp. 9, 85-87, 104.

${ }^{6}$ To differentiate from the earlier Wei state (220-265 CE) established by Cao Cao, also known as the Cao Wei 曹魏, the Tuoba's Wei dynasty has been referred to as the Northern Wei 北魏, Later Wei 後魏, and the Tuoba Wei 拓跋魏.

${ }^{7}$ This term was suggested by Professor Jessica Rawson in our discussions on how to better position the Tuoba between traditions and practices of the Central Plains and those of the steppeland where they originated from. 
鮮卑, in their administration of the successive Yan 燕 states in the fourth century. ${ }^{8}$ (fig. 2)

In the "mixed states" of the northeastern frontier (or Manchurian frontier), where the bipolar world of the nomadic steppe and the agrarian Chinese settlements collapsed and merged, the steppe nomads, forest tribes and frontier Chinese gave rise to a new type of state structure under the Murong rulership. ${ }^{9}$ As emphasized by Thomas Barfield, the dual organization that the Murong developed in these circumstances, which was later inherited by their cousins - the Tuoba, allowed for a separate administration for the steppe tribal peoples and the Chinese. The steppe peoples were controlled by a military organization in which discipline and centralization replaced the originally loose tribal confederations; the Chinese subjects were ruled under the employment of Chinese bureaucrats and institutions. ${ }^{10}$ It was then the responsibility of the ruling dynasty to integrate the two spheres and to combine the strengths of Chinese-styled civil administration with the power of steppe based military forces. The civil and military commands were combined in the hands of the sovereign who theoretically had power over both sectors, developing into what I will later explore as the "dual presence" of the Tuoba's imperial façade.

While Barfield's discussions of the dual organization is centered on the political features of the Yan states, this thesis will focus on the "dual presence" as expressed in the different forms of material and visual representations that converged at the Northern Wei capital of

\footnotetext{
${ }^{8}$ The Murong Xianbei of the northeast (present-day southern Manchuria and northern Hebei province) was a semi-sedentary group of people who lived in a mixture of forest villages, agricultural communities and nomadic camps. Due to the mixed nature of their economy and the possession of a relatively stable geographic base, the Murong were adept at combining nomadic armies with a Chinese-styled administration. This remained a characteristic feature of the series of the four Murong Xianbei states, namely the Former, Later, Southern, and Northern Yan states; see Lewis 2009, p. 74.

${ }^{9}$ In these "mixed states" consisting of separate peoples who converged in the frontier zone, the dominant group was not predetermined, but in general, it was the forest or steppe peoples who took command because the Chinese living in the border region were less inclined to create their own states, which would have had to compete with the established dynasty in China proper; see Barfield 1989, pp. 104-105.

${ }^{10}$ Such a combination was not as powerful militarily as a centralized steppe confederacy nor administratively as effective as a native Chinese dynasty, but it was a potent combination in times of disunity, and offered the best hope of stability; see Barfield 1989, p. 104.
} 
Pingcheng 平城 (present-day Datong, Shanxi province). Temporally speaking, the focus is on the early dynastic rule of the Tuoba between $398-494$ CE, when Pingcheng was the seat of the Northern Wei court. The Pingcheng period was the second of three phases undertaken by the Tuoba as they advanced into the Central Plains. The initial pre-dynastic court of the Tuoba was first established in Shengle 盛樂 (present-day Helinge'er, Neimenggu province) in $385 .{ }^{11}$ Subsequently in 398 , the Tuoba moved southeast to Pingcheng (fig. 3), where the first Northern Wei emperor was also proclaimed in that same year. ${ }^{12}$ After a century of making the northern frontier the seat of power in the Northern Wei, ultimately this inward move ended with relocating the capital to Luoyang 洛陽 in the Chinese heartland in 494, marking the final phase of the Northern Wei dynasty until its dissolution in 534.

The fifth century Northern Wei Pingcheng period witnessed a change in the form of interaction between the Eurasian steppe and the Chinese sphere. Traditionally in the earlier Qin 秦 $(221$ - 207 BCE) and Han (202 BCE - 220 CE) periods, the bipolar world between the Xiongnu 匈奴 ${ }^{13}$ confederacies of the Mongolian central steppe and the Central Kingdom repeated a cyclical pattern of the former's violent raiding followed by extortion demands on the latter in return for a limited period of peace. ${ }^{14}$ This "outer frontier"

\footnotetext{
${ }^{11}$ At this time, the Tuoba referred to their realm as the state of Dai 代國, and it was in the following year (386) that the realm name was changed to the state of Wei 魏國.

${ }^{12}$ Previous Tuoba sovereigns were referred to as the King of Dai 代王 and the King of Wei 魏王. It was with the move to Pingcheng that the Wei dynasty was proclaimed and that Tuoba Gui 拓咙珪 made himself the founding emperor.

${ }^{13}$ The Xiongnu were the first people in the Mongolian steppe to have adopted the imperial confederacy, which became a stable form of nomadic state; see Barfield 1989, p. 8. This organization based on a confederacy was employed by the Xiongnu between approximately $200 \mathrm{BCE}$ to $150 \mathrm{CE}$.

${ }^{14}$ Barfield argued that the steppe tribes of Mongolia played a key role in frontier politics without becoming conquerors of China. It was Manchuria, mostly due to its political and ecological circumstances, that became the breeding ground for foreign dynasties when native dynasties in China proper collapsed in the face of internal rebellions; see Barfield 1989, p. 11.
} 
strategy, a term developed by Barfield, took advantage of the nomads' ability to suddenly strike deep into China and then retreat before the Chinese had time to retaliate. ${ }^{15}$ The building of the Great Wall by the First Emperor Qin Shihuang 秦始皇 (r. $221-210$ BCE) and the Han Emperor Wudi's 漢武帝 (r. 141 - 87 BCE) establishment of the commandaries along the Hexi corridor (namely Wuwei, Zhangye, Jiuquan, and Dunhuang), after having repelled the Xiongnu beyond the Lop Nor (in present-day southeastern Xinjiang) in $111 \mathrm{BCE}$, were defensive measures against the continuing threat from the steppe.

In this sense, the Chinese emperors were not unlike their Roman counterparts, who took military and diplomatic steps to maintain a guarded frontier between them and the European barbarians in the first century CE, along a line more or less marked by the Rivers Rhine and Danube. ${ }^{16}$ The story of these empires, both east and west, was rooted in the construction of a boundary between Us and Them, denigrating those across the frontier as the barbarian "others" to highlight the superiority of the imperial state. Incidentally, the Xiongnu "other" of the Chinese Central Kingdoms and the Scythian "other" of the Graeco-

\footnotetext{
${ }^{15}$ This "outer frontier" strategy had three major elements: violent raiding to terrify the Han court, the alternation of war and peace to increase the amount of subsidies and trade privileges granted by the Chinese, and the deliberate refusal to occupy Chinese land even after great victories; see Barfield 1989, p. 49. ${ }^{16}$ At the beginning of the first millennium, imperial Europe was defined by the reach of the Roman legions, which stretched out from the Mediterranean basin as far north as the River Danube and as far east as the River Rhine. Beyond these frontiers were the European barbarians who occupied some of the Central European uplands and most of the Great European Plains. Temperate Europe was largely Germanic dominated, though there is no reason to suppose that the entire population of this vast area was culturally homogenous or even that it spoke the same language. On the other hand, Scythia was a catch-all term for inhabitants of the eastern parts of the North European Plain, stretching from the River Vistula and the fringes of the Carpathian Mountains to the Volga and the Caucasus. Frontier security demanded a proactive response from the imperial state, and Rome had maintained a military superiority along its European frontiers, backed up by aggressive diplomacy; see Heather 2009, pp. 3, 6, 82 .
} 
Roman world were both nomadic peoples of the Eurasian steppe sandwiched between the two civilizations. $^{17}$

As we shall see in the case of the Tuoba, being "outsiders" themselves, the creation of the Northern Wei was founded on a "pull" policy that actively drew together the Sino-centric and the steppe-centered world orders. The negotiation of material culture as a wrestling of power, raised by Chris Gosden, was carried out in the Pingcheng period through a changing pattern of the consumption of material goods with attached cultural values. ${ }^{18}$ These, in turn, produced new notions of interaction and encounter between the incomers and local Han Chinese. As life in the Pingcheng period was marked by a constant reworking of foreign and native "forms" and "meanings" in the application of visual and material systems, the Tuoba acted as patrons and facilitators in the negotiation that contributed to creating what we now know of as Chinese culture. Stone sarcophagi in the imitation of a timber hall (fig. 59) and murals depicting banquet scenes in an open-air setting (fig. 55b) came to exist as the norm in funerary assemblages of the elite tombs in northern China. As the image of the Buddha appeared on the mountain sides in the form of larger than life-sized stone sculptures (fig. 18), a new notion of imperial commemoration and a new type of material medium were both put into practice.

Population movement across the frontier undoubtedly generated interaction between groups of people that came to converge and share in a cultural milieu. This new Northern

\footnotetext{
${ }^{17}$ In the Greek geographical and ethnographic tradition, Scythia was often portrayed as a chill wilderness, the archetypal "other", the mirror image of Greek civilization. Every imaginable type of uncivilized behavior was ascribed to the inhabitants of this world; see Heather 2009, p. 6.

${ }^{18}$ Gosden emphasized on the consumption of new forms of material culture that destabilizes those of older values, rather than the creation or exchange of these resources; see Gosden 2004, pp. 4-5.
} 
Wei "middle ground" 19 at Pingcheng would have been derived from resources brought by all parties to the encounter, but not identical to that of either group. In this process, new patterns of conception and activities were produced, creating sets of material repertoire and social practices that formed a particular Northern Wei habitus. ${ }^{20}$ As defined by Pierre Bourdieu, this is a set of socially learned dispositions and practices that are acquired through the activities and experiences of everyday life. Identities of the groups of people who converged in Pingcheng were bound together, and in turn, reconstructed within this habitus. Out of this mélange, a particular discourse of the Northern Wei emerges in a Foucauldian sense, creating new representations of the imperial power, patronizing foreign images of the Buddha alongside traditional Chinese ritual buildings. Such constrasts took forward dynastic narratives away from the standard narrative. ${ }^{21}$ As such, the system of power relations construed from the vocabulary of this discourse allowed the Tuoba rulers to manipulate their imperial agency behind the façade of a "dual presence". ${ }^{22}$ They were sovereigns, not only as the Son of Heaven to the conquered Han Chinese in northern China,

\footnotetext{
${ }^{19}$ The "middle ground" is where incomers and locals formed a new way of living through a working relationship between the two parties, and based on cultural repertories brought by all parties to the encounter; see Gosden 2004, pp. 30-32, 82-113.

${ }^{20}$ Habitus is a principle which binds together objective structures and social practices. In this manner, habitus can be defined as a system of dispositions, developed by individual agents in response to the objective conditions it encounters. These dispositions include acquired patterns of conception, behavior, and taste, the result of the internalization of cultural or social structures through the experience of an individual or a group. Practices produced by the habitus are determined by the embodiment and internalization of past conditions which have produced the principle of their production; see Bourdieu 1977, pp. 78-87. This is helpful to our understanding of how identity was (re)-constructed by both the Tuoba and the Han Chinese in the Northern Wei. Coming from distinct traditions, these two groups of people each had their own set of cultural and material repertoire which managed to coexist within Pingcheng, constructing a new Northern Wei identity from which we are to extract the practices and concepts involved in its creation.

${ }^{21}$ Language is one of the media through which thoughts, ideas and feelings are represented in a culture, but so are visual images when they are used to express meaning. In essence, any sound, word, image or object which functions as a sign, and is organized with other signs into a system capable of carrying and expressing meaning is a language. These language systems work as discourses, which are ways of referring to or constructing knowledge about a particular topic of practice; see Hall 1997, pp. 1, 6, 19.

${ }^{22}$ As explained by Foucault, there is no power relation without the correlative constitution of a field of knowledge, nor any knowledge that does not presuppose and constitute at the same time, power relations; see Foucault 1977, p. 27. As such, the combination of discourse and power becomes a power/knowledge complex that not only assumes the authority of "the truth" but has the power to "make itself true"; see Hall 1997, p. 49.
} 
but also continued to practice in ways that befit a Khagan in the steppe Central Asian tradition.

In effect, this thesis puts forth an alternative approach to understand the relations and interaction between the steppeland and the Chinese sphere in the early Northern Wei period. Set in a period commonly referred to as the Six Dynasties or the Northern and Southern Dynasties, ${ }^{23}$ between the unified empires of the Han (202 BC-220 CE) and the Tang 唐 (618-907 CE), this was a time when China was marked by political division between the nomadic non-Han regimes of the north and the émigré-led southern courts. As Albert Dien so aptly puts it, whereas a division into regional states in Europe is taken for granted, the lack of a central state in China is considered abnormal and transitional throughout Chinese history. ${ }^{24}$ The Chinese historiographical tradition has long been grounded in the concept of the maintenance of a lineage, which is why such a period of disunity seems disconcerting in the traditional Chinese historiographical context. This thesis intends to provide a new viewpoint into this period, as a time when the Chinese sphere received strong material cultural injections from the outside world, placing

\footnotetext{
${ }^{23}$ The term Six Dynasties is derived from the number of states during this period that located their capitals in what is now modern day city of Nanjing, since capitals established before this time had been in the north, primarily in modern day Xi'an or Luoyang. The movement of non-Han peoples into northern China and the establishment of northern states forced the Han émigré to seek refuge in the south; see Dien 2007, p. 1. In assessing the various terms applied to this period of Chinese history between the Han and the Tang, Mark Lewis discards the traditional practice of periodization by modern Chinese scholars of calling this the Wei, Jin, and Southern and Northern Dynasties (Wei Jin Nanbeichao 魏晉南北朝) as well as the Western alternatives of the Age of Disunion or the Early medieval period. While the former assumes that Chinese unity under a single regime is the normal state of affairs, the latter imposes a Western template on Chinese history. For this reason, Lewis adopts a modified term, the Northern and Southern Dynasties, for recognizing that the political world of nearly four centuries was defined by this split between the drainage basins of China's two major rivers - the Yellow River in the north and the Yangzi River in the south, which marked the historical significance of this period; see Lewis 2009, p. 1.

${ }^{24}$ Dien explains that the reason to why unity was treated as a natural state of equilibrium in China is due to the lack of blood aristocracy, which limited those leaders at regional levels around whom opposition to the central state would coalesce and make claims for regional independence. Instead, the political system finds its equilibrium in centralization of power, its viability rested on control of an army and general acceptance by the population, which puts unity as the priority to ensure a successful statehood; see Dien 2007, pp. 2, 11-12.
} 
Pingcheng as the central node in this network. It is within this greater picture of movement and ingenuity that the Tuoba emerged from the northeastern steppe into our sources.

\section{HISTORICAL AND MATERIAL SOURCES}

To properly place the Tuoba within their historical and social context, this thesis will consult both textual and material sources that produce a vivid narrative of the cultural material expressions of the Northern Wei Pingcheng period. Though the variety of textual sources is not entirely limited to that of dynastic history, the understanding of Northern Wei history has been heavily dependent on such traditional texts. ${ }^{25}$ Even though there are abundant material remains, they have generally been treated as no more than secondary sources that corroborate the picture of the Northern Wei as presented in the dynastic history of the Wei shu 魏書 (Book of Wei). ${ }^{26}$ Through the juxtaposition of text and material

\footnotetext{
${ }^{25}$ As Denis Twitchett pointed out in his study of the Tang, a modern historian who is concerned with the earlier periods of Chinese history is heavily dependent on textual materials within the standard dynastic histories; see Twitchett 1992, p. 3. This was even more valid of the Northern Wei, a period with less available poetry and other forms of literary prose than that of the Tang dynasty. However, it must be recognized that these standard histories were rarely of single authorship as they may appear to be. They are often products of royal commissions, having gone through a sifting process by which a "normative" history came into being through the selection and elimination of historical events deemed appropriate by the ruling authority. While dynastic histories may not be the most unbiased or reliable records for some of our research purposes, those of the Northern and Southern Dynasties in particular reflect viewpoints of the reigns and rulers under which the works were produced, since the authors were writing about the very regimes in which they had once lived in; see Xiang Shiling 2004, p. 604.

${ }^{26}$ This thesis will follow the edition of Wei shu published by Zhonghua shuju 中華書局 in 1974, which contains one hundred and fourteen juan in total. By the Northern Song, twenty-nine juan of the Wei shu were already missing, and the Northern Song block print edition edited by Liu Shu 劉恕, between the reigns of Emperor Shenzong (1070) and Emperor Huizong (1111-1118), was not widely circulated. By Southern Song in the reign of Emperor Gaozong (1144), Liu Shu's edition of Wei shu was re-block printed in Sichuan. Unfortunately, both editions are no longer available. The edition of Wei shu that has survived was also a block print edition of Southern Song, with additions made in the Yuan and Ming dynasties, thereby receiving the name of "three dynasties edition" (sanchao ben 三朝本). Following this are the Nanjing Guozijian 南京 國子監 edition of Ming dynasty Wanli reign (1597), the Beijing Guozijian 北京國子監 edition also of the Wanli reign, Jiguge 汲古閣 edition of late Ming, Wuyingdian 武英殿 edition of Qing dynasty Qianlong reign (1739), Jinling shuju 金陵書局 edition of Qing Tongzhi reign (1872), the Baina 百衲 edition published by Shangwu yinshuguan 商務印書館, as well as the current commonly used Zhonghua shuju punctuated edition, which takes on variations from all previously mentioned editions.
} 
culture, this thesis hopes to elicit some of the subtleties in which the realities of life in fifth century northern China strayed from the standard historical narrives.

The Wei shu covers the years 386 to 550, spanning across the dynasties from Northern Wei to the Eastern and Western Wei. Written by Wei Shou 魏收 (507-572 CE), ${ }^{27}$ who served under the three successive northern regimes of Northern Wei, Eastern Wei 東魏 (534-550 CE), and Northern Qi 北齊 (550-577 CE), the Wei shu was completed in 553. The biased nature of the historiography of standard histories is well recognized by scholars working with textual sources. The Wei shu is no exception. Commissioned by Emperor Wenxuan 文宣帝 (r. 550-559 CE) of the Northern Qi, and written by a member of the Northern Qi court, the historiography of the Wei shu recognizes orthodoxy in the Eastern Wei/Northern Qi lineage of rulership in the post Northern Wei period. It relegates the Western Wei 西魏 (535-556 CE)/Northern Zhou 北周 (557-581 CE) line as the illegitimate regime. However, since the founders of the subsequent Sui 隋 (581-618 CE) and Tang 唐 (618-907 CE) dynasties came from elite families of the Northern Zhou, the Wei shu's bias against this line of dynastic heritage became the very reason why this text was ill-received in the Sui and Tang. ${ }^{28}$

\footnotetext{
${ }^{27}$ For the biography of Wei Shou, see Bei shi, juan 56, pp. 2023-2039.

${ }^{28}$ This allegiance to the Eastern Wei/Northern Qi regime as the legitimate successors to the Northern Wei state was the very reason for the Chinese neglect of the Wei shu in later periods, beginning with the Sui and Tang dynasties. Since the founders of both the Sui and Tang dynasties, Yang Jian 楊堅 and Li Yuan 李淵, came from elite families of the Northern Zhou, they traced the succession of their regimes back to Northern Wei through Northern Zhou, thereby discrediting Wei Shou's history which had been compiled under the supervision of Zhou's enemies, the Gao family of Northern Qi. Several histories for the Northern Wei were commissioned by the Sui, but while the first was judged unsatisfactory, the second was never completed. Another attempt in the Tang was also abandoned. Private histories were more successful, but most were soon lost, and Wei Shou's work remained the chief and official source for the period; see Holmgren 1989, pp. 3-8.
} 
Despite having lived through the periods that he wrote about, Wei Shou's access to sources on the pre-dynastic history of the Tuoba was still limited. This is reflected in the much abbreviated structure and mythical content of juan 1 of the Wei shu. ${ }^{29}$ Nonetheless, the Wei $s h u$ contains references from other contemporary texts that have not survived, making it the most comprehensive and authoritative textual account of Northern Wei history. ${ }^{30}$ Moreover, it contains atypical treatises on social economic policies, such as land rent and tax levies, ${ }^{31}$ not to be found in other dynastic histories, as well as a dedicated treatise on Buddhism and Daoism (Shi Lao zhi 釋老志). ${ }^{32}$ These anomalous aspects of the Wei shu are clear indications of the peculiar nature of the Northern Wei, a regime in which religion and social wealth assumed prominent roles as new instruments of rulership adopted by the Tuoba. This was necessitated by the fact that having taken part of the Chinese arena as outsiders, the Tuoba needed new claims to a legitimate rulership over a territory where they were in the minority. As will be further explored in this thesis, the Tuoba had constructed narratives out of material sources that were in no way simple imitations of those materials deployed by rulers of previous or contemporary Chinese regimes.

\footnotetext{
${ }^{29}$ Jennifer Holmgren noted that in particular the opening paragraphs of the Wei shu rely heavily on Chinese mythological traditions. Claiming descent from the Yellow Emperor, as descendents of his sons who had went abroad into the wilderness, Wei Shou plots the entire Tuoba pre-dynastic history onto Chinese prehistoric mythologies, following a traditional historiography; see Holmgren 1982, pp. 17-18, 51.

${ }^{30}$ Early reference texts for the Wei shu included Deng Yuan's Guo ji 國記 (also known as Dai ji 代記) from the pre-dynastic period commissioned by Emperor Daowu 道武帝 (Tuoba Gui 拓跋珪, r. 386-409 CE) in 402, Cui Hao and Gao Yun's Guo shu 國書 commissioned by Emperor Taiwu 太武帝 (Tuoba Tao 拓跋奉, r. 424-452 CE) in 439, the initial dynastic records compiled by Li Biao and Gao You under Emperor Xiaowen 孝文帝 (Tuoba Hong 拓跋宏, r. 471-499 CE) in 482, and Cui Hong's Shiliuguo Chunqiu 十六國春秋 of late Northern Wei in 504. James Ware provides a brief discussion on some historical sources that were available at Wei Shou's time and how Wei shu was received in later periods, see Ware 1932. Though having received much criticism for what some refer to as biased and preferential treatment of the Tuoba regime and the Northern Wei, Jennifer Holmgren is convinced that Wei Shou's Wei shu is a careful and highly accurate account of the Northern Wei period and ranks with some of the better official histories to have been produced under other dynasties; see Holmgren 1989, p. 8.

${ }^{31}$ Wei shu, juan 110 , pp. 2849-2866.

${ }^{32}$ Wei shu, juan 114, pp. 3025-3055. Completely annotated by Tsukamoto Zenryū and translated into English by Leon Hurvitz in the 1950s, this final chapter of the Wei shu has formed the foundation of many studies, including those of Buddhist art, iconology, and Buddhism as a school of thought in the West, which will be later discussed; see Tsukamoto 1961.
} 
English scholarship on the Wei shu consists of several translations along with historical discussions on the historiography of the text. The history of the Wei shu has been undertaken by Jennifer Holmgren ${ }^{33}$ and James Ware, ${ }^{34}$ who have both also produced translations of parts of the text of their interest. While Holmgren's annotated translation of the first juan of the Wei shu dealt with early Tuoba history in the pre-dynastic period and the Tuoba's rise to state-hood, Ware's focus was on the treatise on Buddhism and Taoism of juan $114 .{ }^{35} \mathrm{~A}$ second translation of this same treatise was later provided by Leon Hurvitz $^{36}$ who was a student of Tsukamoto Zenryu and had worked with the latter to provide a complete and annotated translation of juan 114. These works have formed the foundation for most of Western historical studies of the Tuoba, indicating that interest in the Tuoba Northern Wei generally fall under one of two aspects, either the religious aspects of the Northern Wei state or the Tuoba's nomadic origins.

Apart from the Wei shu, parts of Northern Wei history are also covered by contemporary textual sources from the south, including the Song shu 宋書 (Book of Song) ${ }^{37}$ by Shen Yue 沈約 (441-513 CE) and the Nan Qi shu 南齊書 (Book of Southern Qi) ${ }^{38}$ by Xiao Zixian 蕭

\footnotetext{
${ }^{33}$ See Holmgren 1982 for both the history of the Wei shu and the translation of the first juan of the Wei shu.

${ }^{34}$ See Ware 1932 for a discussion of the sources available to Wei Shou when writing the Wei shu. Ware also looked at how Wei shu was received by the author's contemporaries, as well as the later history of the Wei shu when it became obscured and missing in several chapters, which had to be filled with content taken from other histories compiled in later periods.

${ }^{35}$ Ware's translation of this treatise was divided into two parts. The initial paper published in T'oung Pao was a translation of the first section of the treatise that looked at Buddhism in the Northern Wei; see Ware 1933a. The following paper published in the Journal of the American Oriental Society is on the second section of the treatise which covered Taoism in the Northern Wei, along with the subject of Taoism in the Sui shu 隋書 (Book of Sui); see Ware 1933b.

${ }^{36}$ For the complete English translation of the treatise see Hurvitz 1956.

${ }^{37}$ In the Song shu, the chapter on the northern nomads falls under the heading Suolu zhuan 索虜傳 (Biographies of the Suo Captives), seeing that an alternative name for the northern nomads given by the Southern Song was Suotou 索頭. The chapter on the Suo captives opens with the statement that the Suotou captives went by a clan name of Tuoba, and their ancestry could be traced to descendents of the Han general Li Ling, who had surrendered to the Xiongnu; see Song shu, juan 95, pp. 2321-2359.

${ }^{38}$ In the Nan Qi shu, it is straight-forwardly under the heading Weilu zhuan 魏虜傳 (Biographies of the Wei Captives). Though the term "captives" is used when referring to the northerners, it does not suggest in any
} 
子顯 (487-537 CE). As official histories written by contending regimes, the denigrating nature of these southern accounts in reference to the Northern Wei is to be expected, but at times they turn out to be more detailed and colorful since they were intended as caricatures of the Tuoba. A good example is the Wei shu's brief mention of the construction of the Dong gong 東宮 (Eastern Palace), residence of the crown prince, in the seventh month of the first year under the Yanhe reign (432 CE). ${ }^{39}$ Alternatively, Nan Qi shu provides a more vivid, though intentionally derogatory, description of this Eastern Palace along with mention of the members involved in palatial activities. ${ }^{40}$ In fact, according to Southern Qi observations, this Eastern Palace of the "illegitimate" (wei 僞) crown prince was located in the eastern parts of the city, with four doors, tiled roof, and elevated structures at the four corners of the building, while the prince's concubines lived in humble households built out of earth. The servants and maids, who added up to over a thousand people, were all involved in the making of fabric and brocade to be sold, along with alcohol. At the same time, they raised animals and grew vegetables on palace grounds, all to be sold for profit. Despite the rather disparaging terms used to describe the northerners and their lifestyle, this southern viewpoint provided a vibrant scene of palace economic activity that the Wei $s h u$ had neglected to mention.

In the Tang 唐 dynasty (618-907 CE), Li Yanshou 李延壽 digested all of the above sources, and produced two comprehensive histories of the Northern and Southern

\footnotetext{
way that the people mentioned in the biographies were captives taken by the south. Instead, the word $l u$ 虜 had turned into the normative term, by this time, which southerners use derogatively towards the northern nomads. In the chapter on the Wei captives, Nan Qi shu explains why these northern nomads were being referred to derogatively as Suotou, although it was recognized in the south that they were of the northern Xianbei people and went by the clan name Tuoba. It is said that these northerners let their hair down loose and in wearing their gowns, they wrap the left side over before the right, which was exactly opposite to standards set by Western Zhou of a proper gentleman; see Nan Qi shu, juan 57, pp. 983-1001.

${ }^{39}$ Wei shu, juan 4, p. 81.

${ }^{40}$ Nan Qi shu, juan 57, p. 984.
} 
dynasties in 659, the Bei shi 北史 (History of the North) ${ }^{41}$ and the Nan shi 南史 (History of the South) ${ }^{42}$ Most of the accounts on the Northern Wei included in the Bei shi were taken straight from the Wei shu, with particular additions and eliminations at the author's discretion from a retrospective viewpoint. First of all, the biographical section focused on families that continued to remain prominent in the Tang, and ancestors of newly risen important Tang households were added back as part of Northern Wei history. Secondly, the treatises, a distinguishing feature of the Wei shu, were discarded to follow the standard structure of other dynastic histories. The same was true of edicts issued by Northern Wei emperors that were originally kept on record in the Wei shu. Finally, content regarding the Tuoba's early history, when they practiced the relocation of households and animals from conquered territories, as well as accounts of frontier rebellions of other nomadic groups, have all been deleted from the Bei shi. Evidently, these illustrate the different approaches to historiography taken by Wei Shou and Li Yanshou, but most of all, they emphasize the latter's desire to reconstruct the rise of the northern regimes, from which the Sui and Tang took as their dynastic origins.

It was these standard histories that provided grounding for the study of the Tuoba and the early history of this nomadic group, before archaeological reports of Northern Wei excavations became available. While the texts may provide an orthodox account of normality and consistency in the tradition of Chinese historiography, material culture has turned out to be better indicators of changes within a society, particularly of changes in social practices and material traditions. The development of archaeological fieldwork in

\footnotetext{
${ }^{41}$ Bei shi covers the years 386-618 CE, spanning across the dynasties of Northern Wei and the subsequent Eastern Wei/Northern Qi, Western Wei/Northern Zhou, and into the Sui.

${ }^{42} \mathrm{Nan}$ shi begins with the first year of the Song (420 CE), first regime of the southern dynasties, and finishes in 589 with the fall of the Chen, last regime of the southern dynasties. It covers 170 years of southern history in total.
} 
the post-1949 era has provided a new range of material culture to enrich the understanding

of a people and a period previously obscured by the lack of sources.

Before 1949, the Japanese team headed by Seiichi Mizuno and Toshio Nagahiro was the main source of archaeological reporting in and around Datong, Shanxi province in the 1930s and 40s. They produced extensive reports on the Yungang grottoes 雲崗石窟 ${ }^{43}$ located to the west of Datong (fig. 4), as well as preliminary surveys of the Pingcheng city $\operatorname{site}^{44}$ (fig. 5) and the Yonggu mausoleum 永固陵 of Dowager Empress Feng (441-490 CE) on Fang Mountain 方山, north of the city (fig. 4). ${ }^{45}$ These formed the foundation of Pingcheng studies, which had developed more recently among local Datong scholars, first in 1995 with the discovery of a possible mingtang 明堂 (Hall of Brightness) site (figs. 12, 13), ${ }^{46}$ followed by the finding of the Caochangcheng 操場城 Northern Wei palace site in

\footnotetext{
${ }^{43}$ See Mizuno and Nagahiro 1952-1956 for the complete reports on Yungang grottoes, located west of Datong city of the Wuzhou Mountain 武州山. In the 1930s and 40s, Japanese scholars took advantage of their wartime access into northern China for extensive research on the Buddhist grottoes, a subject they have most fervently pursued down to this day. After many years of fieldwork in China, Seiichi Mizuno and Toshio Nagahiro compiled a detailed report of sixteen volumes, with a complete archaeological survey of Buddhist cave temples at Yungang. This report continues to serve as a foundation in the studies of Yungang, with complete cave by cave details in text and plates.

${ }^{44}$ While surveying Yungang, Japanese scholars found it necessary to work out a plan of Pingcheng, capital of Northern Wei at the time, in order to better understand the significance of what took place at Yungang. It was an accidental discovery of several pillar bases behind the modern day railway station of Datong which Japanese scholars identified as a site of the former Pingcheng palace to the north of the city. A strip of elevated land that runs in an east-west direction north of the railway station was identified as the north wall of the city; see Mizuno and Nagahiro 1952-1956, vol. 16, pp. 19-22.

${ }^{45}$ Yonggu mausoleum enjoys a prime geographical location north of Datong, at the point where two rivers merge into the Ruhun River 如渾河 (modern day Yu River 御河) that then flows south through the city. The site was officially excavated by archaeologists from the Datong museum in 1976; see Datong shi bowuguan and Shanxi sheng wenwu gongzuo weiyuanhui 1978, pp. 29-33. It was first surveyed by the American team headed by Carl Whiting Bishop with A. D. Wenley in 1925. Bishop and Wenley began investigating the Fang Mountain mausoleum in 1925, with Bishop as lead archaeologist, but due to his illness and early retirement from the site, the preliminary survey was finished by Wenley. Years later at Bishop's request, literary sources were related to the site to ascertain whether any connections could be established on historical ground, bringing forth a paper published by Wenley; see Wenley 1947. In the 1930s, Mizuno and Nagahiro had also conducted a further survey of the Yonggu mausoleum; see Mizuno and Nagahiro 19521956, vol. 16, p. 19-22. After 1949, archaeological work on the Yonggu mausoleum was picked up again in the 70s by Su Bai's team from Peking University; see Su Bai 1977b, pp. 38-46.

${ }^{46}$ The excavation of the mingtang remains was led by scholars at the Datong museum; see Wang Yintian, Cao Chenming and Han Shengcun 2001, pp. 26-34. In another paper, Wang Yintian uses remains of the
} 
2004 (fig. 6). ${ }^{47}$ With the Pingcheng palace more accurately located, the city's north wall has also been re-evaluated. What Mizuno and Nagahiro had previously determined as the north wall of Pingcheng is now considered to be the northern "Great Wall" of the Tuoba. Enclosing the pass between the Baideng Mountain 白登山 to the northeast and the Leigong Mountain 雷公山 to the northwest, this northern wall formed a screen that protected the capital of Northern Wei from northern invasions (fig. 6). ${ }^{48}$

On the other hand, tomb burials of the Northern Wei came to light later than the city sites, with excavations beginning in 1958. Since then, tombs of the Tuoba have been discovered across the provinces of Neimenggu, Shanxi, Henan and Ningxia, encompassing over 40 sites, and still counting. ${ }^{49}$ The majority of Northern Wei Pingcheng period tombs are located in the vicinity of Datong, Shanxi province. Based on what has been published, there are several concentrated tomb clusters in the eastern, southeastern, and southern suburbs of Datong.

Southeast of Datong, on the east bank of the Yu River 御河 and south of Baideng Mountain (present-day Mapu Mountain 馬鋪山), is a well-established burial site with

Northern Wei city wall in Datong and the platform basis of the Yungang grottoes as cross references to establish the dating of the mingtang. This was done based on the rammed earth foundations that correspond in thickness and building method, as well as the masonry of the stone wall; see Wang Yintian 2000, p. 159. Several years later, Han Shengcun published a separate report in 2005, reiterating the significance of this discovery; see Han Shengcun 2005, pp. 37, 43.

${ }^{47}$ In 2004, Cao Chenming of the Datong museum made a breakthrough in the study of Pingcheng by locating Northern Wei debris and site remnants in the northern part of Datong, south of the current railway station, which has been named the Caochangcheng 操場城 site; see Cao Chenming 2004, pp. 9-12. From these newly discovered cultural layers, Cao determined that the Northern Wei palace site was further south than had been previously suggested by the Japanese team in the survey report. The pillar bases found by the Japanese were approximately 1500 meters north of Caochangcheng and that area does not contain enough Northern Wei debris underground to suggest any palatial activities; see Cao Chenming 2004, p. 10.

${ }^{48}$ Cao Chenming 2004, p. 10.

49 Although published in 2007, Sun Wei's database on Tuoba tomb burials ends with the 2001 Haila'er site of Hulunbei'er city. Indeed, between 2001 and 2007, several Northern Wei tombs in Shanxi province known to the author of this thesis had already released archaeological reports, though unmentioned in Sun Wei's work; see Sun Wei 2007, p. 4-5 
several Northern Wei tombs of high social status. These include tombs of Sima Jinlong 司 馬金龍 (d. 484), ${ }^{50}$ Yuan Shu 元淑 (d. 508), ${ }^{51}$ Gao Kun 高琨, ${ }^{52}$ Song Shaozu 宋紹祖 (d. 477) of the Yanbei shiyuan 雁北師院 cluster, ${ }^{53}$ the earth pit tomb at Qijiapo 齊家坡, ${ }^{54}$ Shaling 沙嶺 cluster, ${ }^{55}$ and the Yingbin dadao 迎賓大道 cluster ${ }^{56}$ It is from this area, in the southeastern fringes of the city, that many of the more distinguished and identified Northern Wei tombs have been found with exquisite burial objects that provide rich visual and material sources.

In the eastern suburbs are the tomb clusters of Anliuzhuang 安留莊 ${ }^{57}$ and Hudong 湖東 ${ }^{58}$ as well as an individual brick chamber tomb at Xiashenjing 下深井. ${ }^{59}$ Without dating or inscriptions from which tomb occupants could be identified, these have been determined to be Northern Wei burials based on the iconography and stylistic patterns in designs found on tomb objects. The same is true for the tomb clusters in the southern suburb of Datong, including the Huaxianchang 化纖厰 cluster, ${ }^{60}$ Nanjiao 南郊 cluster, ${ }^{61}$ Jinshumeichang 金

\footnotetext{
${ }^{50}$ See Shanxi sheng Datong shi bowuguan and Shanxi sheng wenwu gongzuo weiyuanhui 1972 for the archaeological report on the Sima Jinlong tomb.

${ }^{51}$ See Datong shi bowuguan 1989 for the report on the Yuan Shu tomb in the eastern suburbs of Datong.

${ }^{52}$ The excavation report for the Gao Kun tomb was never released, but the closest that we have to an account is a study of the epitaph from this tomb; see Wang Yintian 1989.

${ }^{53}$ See Liu Junxi and Zhang Zhizhong 2001 for the brief excavation report on the Song Shaozu tomb. For the full report on the Yanbei shiyuan tomb cluster, including the tomb of Song Shaozu; see Datong shi kaogu yanjiusuo 2008.

${ }^{54}$ See Wang Yintian and Han Shengcun 1995 for the excavation report on the Qijiapo site.

${ }^{55}$ See Datong shi kaogu yanjiusuo 2006a for the excavation report on the Shaling tomb.

${ }^{56}$ See Datong shi kaogu yanjiusuo 2006 c for the excavation report on the Yingbin avenue tomb cluster.

${ }^{57}$ Excavated in 1994, no official report has yet been released. It is briefly mentioned in the footnote of the 2004 report on the Hudong site, that the Datong municipal archaeology institute had conducted the excavation of the Anliuzhuang site in 1994, uncovering more than 20 Northern Wei tombs, but the information is still being processed; see Shanxi sheng Datong shi kaogu yanjiusuo 2004, p. 26.

${ }^{58}$ See Shanxi sheng Datong shi kaogu yanjiusuo 2004 for the excavation report on the Hudong tombs.

${ }^{59}$ See Datong shi kaogu yanjiusuo 2004 for the excavation report on the tomb at Xiashenjing.

${ }^{60}$ No official report has been released on this site.

${ }^{61}$ Excavated in 1988, a brief report was released in 1992; see Shanxi sheng kaogu yanjiusuo and Datong shi bowuguan 1992. The final book on the Nanjiao cluster was published in 2006; see Shanxi daxue lishi wenhua xueyuan, Shanxi sheng kaogu yanjiusuo and Datong shi bowuguan 2006.
} 
屬鎂厰 cluster, ${ }^{62}$ Zhijiabao 智家堡 cluster, ${ }^{63}$ Qilicun 七里村 cluster, ${ }^{64}$ Datong Erdianchang 大同二電廠 and Nanjiao Maxinzhuang 南郊馬辛莊 cluster. ${ }^{65}$ As of now, only one tomb has been discovered west of Datong, which is that of Feng Heyao 封和突 (d. 504) near Xiaozhancun 小站村. ${ }^{66}$

The most recent archaeological discoveries of the Pingcheng period have been published in December of 2011, a rather serendipitous timing, as they provide valuable resources for the study of the application of murals and architectural sets undertaken in chapter four of this thesis. These reports are on three single-chambered brick tombs found respectively to the northeast, south, and the far eastern suburbs of Datong city, namely the tombs at Wenyinglu 文瀛路, ${ }^{67}$ Yunbolilu 雲波里路, ${ }^{68}$ and the burial of Yuchi Dingzhou 尉遲定 州. ${ }^{69}$

Despite the extraordinary number of burials in and around Datong, scholars have yet to integrate these materials into the greater parameters of Pingcheng or Tuoba studies. In fact, even archaeological reports appear rather thin and preliminary, establishing little information, apart from providing a description of the tomb contents. One main problem of

\footnotetext{
${ }^{62}$ See Han Shengcun, Cao Chengmin and Hu Ping 1996 for the excavation report on the Jinshumeichang tomb cluster.

${ }^{63}$ One report is on the three sections of painted coffin boards found at the Zhijiabao tomb cluster site; see Liu Junxi and Gao Feng 2004; another report is on the murals found on the inside surfaces of a stone sarcophagus also found in the area; see Wang Yintian and Liu Junxi 2001.

${ }^{64}$ See Datong shi kaogu yanjiusuo 2006b for the excavation report on the Qilicun tomb cluster.

${ }^{65}$ The cluster was named after the electricity generator which was about to be constructed on the site where the Northern Wei tombs were uncovered in 2008, approximately one kilometer north of Maxinzhuang in the southern suburbs of Datong. No official excavation report has been released except for an article which appeared in the Zhongguo wenwu bao; see Zhang Qingjie 2008.

${ }^{66}$ See Datong shi bowuguan and Ma Yuji 1983 for the excavation report on the Feng Heyao tomb at Xiaozhancun.

${ }^{67}$ For the excavation report on the tomb at Wenyinglu, see Datong shi kaogu yanjiusuo 2011c.

${ }^{68}$ For the excavation report on the tomb at Yunbolilu, see Datong shi kaogu yanjiusuo $2011 \mathrm{~b}$.

${ }^{69}$ This tomb has been dated to $457 \mathrm{CE}$, as identified by the inscriptions on the stone blocking the tomb entrance. For the excavation report on the tomb of Yuchi Dingzhou, see Datong shi kaogu yanjiusuo 2011a.
} 
these excavation reports is the arbitrary designation of "remains" to "cultures". Upon uncovering a lacquer screen with Chinese figure paintings in the Sima Jinlong tomb, the artifact is by default an index of the degree to which Sinicization had progressed, or the extent to which Han culture was preserved, among the elite of Northern Wei (fig. 7). ${ }^{70}$ Alternatively, the existence of unusual and foreign items or motifs is mostly overlooked, or at best being designated as "foreign objects" in the reports. ${ }^{71}$

What the archaeologists failed, or possibly even refused, to acknowledge is the likelihood that these so called "foreign objects" were not at all foreign to the people living in Pingcheng at the time. On the other hand, some of the objects designated in the reports as belonging to "mainstream Chinese culture", even when found in the tombs of Han Chinese elite, could very well had been simple tokens of remembrance that bonded them with their ancestors, without any contemporary relevance or direct affiliation. ${ }^{72}$ Rather, finding out why these anomalous objects were among particular tomb repertories, and the significance of their being present, would be the more meaningful track to follow. As will be explored in chapters two and four, the notion that the separation of "form/design" and "meaning", in their capacity to take on different cultural affiliations, becomes a useful framework for us

\footnotetext{
${ }^{70}$ The excavation report's discussion is centered on the continuation of artistic style from the Warring States period and that of the Eastern Han as represented on this lacquer painted screen; see Shanxi sheng Datong shi bowuguan and Shanxi sheng wenwu gongzuo weiyuanhui 1972, pp. 28-29. For a separate study on the Sima Jinlong painted lacquer screen of this same perspective; see Lü Wenping 2007, pp. 38-40, 44. See also Dien 1992, p. 47 for Albert Dien's argument against this methodology.

${ }^{71}$ An example of this would be the copper tent hook uncovered from the Shaling tomb. According to the excavators, this copper tent hook has a dragon-shaped tip, with a hole in its body for fastening ropes, and the tail end of the hook is hollowed out to be inserted with a shaft. There are bits of wooden chips that remain in this shaft hole. As one of the few objects kept in this mural tomb, the copper tent hook obviously came from the steppe tradition. This piece was found in the northwestern corner of the tomb chamber, and my assumption is that three more were buried with the tomb occupant, representing the four corners of a tent that this chamber was supposed to represent for the deceased to reside in. Nonetheless, the report contains only a brief description of the hook's proportions, without venturing into the meaning of burying this copper hook as a part of the tomb repertoire; see Datong shi kaogu yanjiusuo 2006a, p. 6.

${ }^{72}$ For example, bronzes that contain archaic designs could function as physically present references to earlier generations of a family and would have also reminded later generations of their achievements; Rawson 2006a, pp. 57-69.
} 
to understand how new meanings can be endowed upon borrowed objects, institutions, and traditions. $^{73}$

Having looked at the dynastic histories and archaeological reports that provide the dominant sources for this study, several questions naturally follow in constructing a background for understanding the Tuoba. Who were these people? Where did they come from? What can we find out about their activities before entering into the Chinesespeaking world? Answers to these questions will provide a better context for us to further explore the ways in which material cultural were (re)created and applied in the Northern Wei Pingcheng period, as well as the discursive agencies that these visual expressions would have empodied.

\section{ORIGINS OF THE TUOBA}

One exhibit in the Datong Museum (Datong, Shanxi province) is a group of glazed clay figurines in military formation dated to the fifth century Pingcheng period (fig. 8). These Tuoba warriors are dressed in heavy cloaks that drape to the ground and are covered from head to toe in garments and armor. They are nothing like the Han figurines uncovered from Yangling 陽陵 (north of modern day Xi'an, Shaanxi province) of Emperor Jing, Liu

\footnotetext{
${ }^{73}$ Jessica Rawson used the hill censers (boshanlu 博山爐) that became popular among the elite in the Han dynasty as an example of how, in borrowing new materials from Central and Western Asia, the Han accommodated them within a completely local context. This is most prominently demonstrated in the case of the conical lid on top of the silver incense burners that belonged to a tradition that extended from Iran to Egypt and further westwards to Greece, Etruria and Rome and eastwards to the Scythians as well as parts of the northwestern Indian subcontinent. While the form of the conical lid was most probably borrowed from the west, the exact shape of the Chinese censers and the meanings behind the shape - rendered by the Han as a mountain - were certainly local. Rawson further established that the Chinese-speaking world did not take over the conical lid turning it into a mountain-peak until the Han could fit this particular form into their ideological or cosmological framework. It was the Han preoccupation with the concept of a systematic universe, together with the tradition of linking immortal figures with specific mountain peaks, that the hill censer was adapted as a new form of expression for new concepts; see Rawson 2006b, pp. 78-82.
} 
Qi 劉啓 (188-141 BCE) (fig. 9). Some riding on horses and others marching in heavy footsteps, these people do not bear features of the Han Chinese. Neither do they reflect the “foreigners”, also known as $\mathrm{Hu}$ ren 胡人 (fig. 10), ${ }^{74}$ who were often found portrayed in clay figurines by this time. Who were the Tuoba? How did they originate from the northeastern steppe and manage the transition to being sovereigns in the Chinese heartland between the fourth and sixth century CE?

Ma Changshou's ethnic study of the Wuhuan and Xianbei peoples in 1962 is representative of Chinese ethnic studies in the earlier half of the twentieth century. He followed a traditional Chinese textual approach, using events of the Wei shu to trace out migratory routes of Tuoba ancestors across the Mongolian steppe before they established the pre-dynastic Tuoba state of Dai. ${ }^{75}$ Particularly, he relied heavily on the first juan of the Wei shu, the preface of which contains the bibliography of Tuoba ancestors, who had led the clan through previous conquests, up to Emperor Daowu 道武帝 (Tuoba Gui 拓跋珪, r. 386-409 CE), founding emperor of the Northern Wei dynasty (Appendix A). ${ }^{76}$ Nonetheless,

\footnotetext{
${ }^{74}$ The term Hu ren remains fluid throughout Chinese history, applied as a generic name for the mounted nomads of the northern steppe. They had entered in Chinese historical record in the fourth century BCE under a generic name of $\mathrm{Hu}$ 胡. With the founding of the Qin dynasty in $221 \mathrm{BCE}$, the Hu became differentiated in the Chinese records, with three major nomadic groups emerging along the northern frontier: The Yuezhi in the west, the Xiongnu in the Ordos region, and the Donghu on the eastern flank; see Barfield 1989, p. 32. As introduced in Sima Qian's Shi ji, Hu 胡 was originally a self-prescribed term used by the Xiongnu in their correspondences with the Han emperor; see Han shu, juan 94, p. 3780. In later periods, the term was applied onto different groups of northern and western nomads by the Han Chinese to differentiate between the civilized "us" and the barbaric "other". However, under conquest dynasties ruled by nomadic people, the term Hu ren continued to be in use, only targeting a different group of people as the uncultured, those from Central Asia who appeared foreign even to the nomads.

${ }^{75}$ Ma Changshou 1962, p. 222. See also Jennifer Holmgren's study on the early history of the Tuoba for cross-referencing, as both scholars attempted to trace the migratory routes and the activities of the Tuoba based on the first chapter of Wei shu; see Holmgren 1982.

${ }^{76}$ This preface to the Wei shu runs from 1.1 to 1.14 in the Zhonghua shuju edition published in 1974 with 114 scrolls in total, which will be the edition used in this study. Ma Changshou pointed out that while he does not agree with dynastic histories contemporaneous to Wei shu, such as Nan Qi shu or Song shu of the southern dynasties, that describe Tuoba as descendents of a Xiongnu woman and the captured Han general Li Ling for a sense of superiority that the Tuoba are of half Han blood, Wei shu itself should be given more credit as a reliable source of Tuoba history. Ma acknowledged that preface of the Wei shu was based on legends passed down through an oral tradition. Nonetheless, he strongly felt that there must be a reason for
} 
while claiming that his history of the Tuoba was constructed based on recovering details from the Wei shu, on the question of Tuoba origins, Ma had arbitrarily determined them to be descendents of Xianbei fathers and Xiongnu mothers. ${ }^{77}$ In doing so, he completely disregarded the fact that there is no mention of this specific lineage of the Tuoba in the Wei $s h u$, nor any other contemporary dynastic histories.

Ma Changshou's view was based on the accounts of the Hou Han shu 後漢書 (Book of Later Han), in which it is said that a branch of the Dong $\mathrm{Hu}$ 東胡 (Eastern $\mathrm{Hu}$ ) remnants fled to the Xianbei Mountain to escape Xiongnu invasion in the Western Han (206 BCE $9 \mathrm{CE}$ ); these people took the name of the mountain and became known as the Xianbei. ${ }^{78}$ For the purposes of defining their lineage, they are also referred to as the Dongbu Xianbei 東部鮮卑 (Eastern Xianbei), having branched off from the Dong $\mathrm{Hu} .{ }^{79}$ In $48 \mathrm{CE}$, the Xiongnu state went through its first split between the north and south, triggering a series of political changes across the Mongolian steppe. This drew the Dongbu Xianbei from the Manchurian northeast to fill the power void that had emerged in the former heartland of the Xiongnu (fig. 3), where they formed the first, yet short-lived, Xianbei confederation in

\footnotetext{
certain legends to pass down instead of others, and Ma accepted these collective memories as credible accounts for historical background. It is in this light that Ma chose to base his study of pre-dynastic Tuoba history on the Wei shu; see Ma Changshou 1962, pp. 221-222.

${ }^{77}$ According to Ma Changshou, ancestors of the Tuoba Xianbei were a group that originated from the upper streams of Heilongjiang. When the Xiongnu moved west across the steppe, they migrated to the central, western, and southern parts of the steppe to fill in the power void. In the mean time, they merged with Xiongnu remnants to have descendants that took on the name Tuoba Xianbei; see Ma Changshou 1962, pp. 160-161. The specificities of Xianbei fathers and Xiongnu mothers is pointed out because according to Ma Changshou, the reverse, namely Xianbei mothers and Xiongnu fathers, gave birth to the Tiefu branch of the Xiongnu; see Ma Changshou 1962, p. 3.

${ }^{78}$ Hou Han shu, juan 90, p. 2985.

${ }^{79}$ According to Ma, the Xianbei could be divided into the Dongbu Xianbei 東部鮮卑 (Eastern Xianbei) and the Tuoba Xianbei. Ma took the Dongbu Xianbei as an important constituent of the Dong Hu that fled east to the Xianbei Mountain after being invaded by the Xiongnu in Early Han. In other words, this term applied to all other Xianbei people other than the Tuoba clan, which emerged later in his view; see Ma Changshou 1962, p. 160.
} 
modern day Hulunbeier region. ${ }^{80}$ According to Ma, in this process of migrating from the Daxing'an mountain range (situated within modern day Heilongjiang province) south to Hulun Lake, the Tuoba clan had yet to emerge in historical accounts. Ma speculated that it was after the Dongbu Xianbei's westward move across the Mongolian steppe, when they mixed with remnants of the Xiongnu during the long migration, that descendants of the two peoples became ancestors of the Tuoba Xianbei. ${ }^{81}$ It was by this logic that he came to the conclusion that the Tuoba clan had branched out of the Dongbu Xianbei at a later date, which explains the lack of references to the Tuoba in Han texts. ${ }^{82}$

Lin Wo's study in 1989 had access to archaeological reports that were unavailable in Ma's time. ${ }^{83}$ Of most importance was the ancestral dedication found inscribed inside the Gaxian Cave 嘎仙洞, a cave discovered in 1980, located in the northern section of the Daxing'an Mountains in present-day Neimenggu province. ${ }^{84}$ In light of this new discovery, the northern section of the Daxing'an Mountains has been confirmed to be the Da Xianbei shan 大鮮卑山 (Greater Xianbei Mountain) attributed to in the preface of the Wei shu,

\footnotetext{
${ }^{80}$ The Xianbei formed a second confederation with the Tuoba clan as its main component after having assisted the Han in driving off the Northern Xiongnu from the Chinese frontier in 91 CE. Unlike the Southern Xiongnu or the Wuhuan who accepted a subsidized existence subordinate to the Han, the Xianbei headed a new nomadic confederacy to fill in the void left by the dissolution of the former Xiongnu confederacy, one that posed an even greater threat to the Later Han by the second half of the second century CE. For a more detailed account of the rise of the Xianbei in consolidating power on the steppe, see Keay 2008, p. 171. During the Sixteen Kingdoms, the Xianbei states separately emerged based on the various clans that constituted the original confederacy, such as the Yan state of the Murong and the Dai state of the Tuoba; see Ma Changshou 1962, p. 226.

${ }^{81}$ Ma Changshou 1962, p. 228.

${ }^{82}$ Ma Changshou 1962, p. 6.

${ }^{83}$ Lin Wo 1989, p. 79.

${ }^{84}$ For the excavation report of the cave chamber and its preliminary studies, see Mi Wenping 1981; also Lin Wo 1989, p. 79. A 1980 discovery of the cave located in the northern section of the Daxing'an mountain range 大興安嶺 (also known as the Gaxian dong 嘎仙洞 by local inhabitants) has been treated as a landmark in the study of the Tuoba by Chinese archaeologists and historians, who believe that it is the missing piece to early Tuoba history and confirms the exact location of Tuoba origins. They came to this conclusion through the engravings found inside the cave chamber, which bears the date of the fourth year in the Taiping Zhenjun reign 太平真君 (443 CE) and contains the prayers presented to Tuoba ancestors by Emperor Taiwu as recorded in the $L i$ zhi 禮志 (treatise on rites) section; see Wei shu, juan 108, pp. 2738-2739.
} 
from which the ancestors of the Tuoba Xianbei claimed to have taken their name. ${ }^{85}$ On the other hand, the Xianbei Mountain mentioned in the Hou Han shu, where remnants of the Dong $\mathrm{Hu}$ had fled to, has been identified to be within the southern section of the Daxing'an Mountains. Before the discovery of the Gaxian Cave, these two mountains had been thought of to be the same entity but with a slight variation in names. Lin used this new finding to make the separation between Xianbei Mountain and the Greater Xianbei Mountain as two distinct locations, thereby giving credit to the Tuoba Xianbei's independent origins, one that did not necessarily derive out of the Dongbu Xianbei.

With this new discovery, Lin Wo overturned previous views to propose that the Tuoba may have originated separately from the Dongbu Xianbei, and that they could have even had a longer history except having been obscure to Han historians as a result of their location off to the northeast. ${ }^{86}$ Though without substantial evidence, Lin Wo further hypothesized that when the Dong $\mathrm{Hu}$ scattered upon Xiongnu invasion, the group that headed for the Xianbei Mountain did not end up there by chance, but possibly to seek out their distant cousins in the northeast, since they were all members of the different Xianbei clans. ${ }^{87}$ A recent study by Sun Wei provided archaeological evidence that supports this new hypothesis, recognizing the Tuoba as the Beibu Xianbei 北部鮮卑 (Northern Xianbei), a separate clan from the Dongbu Xianbei, with distinct features in their material remains. ${ }^{88}$

\footnotetext{
${ }^{85}$ Wei shu, juan 1, p. 1.

${ }^{86}$ According to the preface of Wei shu, the Tuoba recognized that they were unaccounted for in ancient Chinese texts. It explains that this was due to the fact that their ancestors, the descendants of Shijun 始均 (one of the early Tuoba chieftains), did not associate with the Chinese in the south, unlike the Xiongnu 匈奴, Shanrong 山戎, Xianyun 獫狁 and Xunyu 獯嗣, who were violent and aggressive, harmful to those in the central plains since the Xia, Shang and Zhou dynasties, down to Qin and Han; see Wei shu, juan 1, p. 1. ${ }^{87}$ Lin Wo 1989, p. 81.

${ }^{88}$ The study done by Sun Wei on the archaeological remains of the Xianbei is a recent attempt at understanding this group of people and its various clans through exploring the features of their material remain; see Sun Wei 2007, pp. 1-10.
} 
Although we do not have sufficient information on the Tuoba's exact origins in relation to the rest of the Xianbei people, it is best to avoid viewing the Tuoba as necessarily descendants of nomadic groups historically known to the Han Chinese. First of all, this limits the possibility of ethnic variety on China's northern frontier, suggesting that only those nomadic groups accounted for in Chinese historical texts could have existed. In line with this Sino-centric perspective, having remained unknown to the Han, the Tuoba inevitably had to be related to the Xianbei and Xiongnu, two of the most commonly mentioned northern peoples in Han texts. At the same time, it denies the potential ambition and innovative spirit attributed to the Tuoba for having become sovereigns in the Chinese arena, something that even the Xiongnu did not succeed in achieving. An alternative view would accept the basic conclusions that the Tuoba was another clan of the Xianbei that had long been active in the Daxing'an Mountains, while allowing for the possibility that they had then come into contact with the Dongbu Xianbei upon the latter's arrival. ${ }^{89}$ As such, this thesis will recognize that the Tuoba most likely had a separate experience in the Manchurian frontier, which will continue to be rewritten by further studies as new materials appear.

Though the addition of archaeological materials complemented previous understanding of Tuoba origins gained from textual sources, one issue remains inconclusive. The language spoken by the Tuoba before establishing themselves as rulers of northern China and adopting the Sinitic monosyllables is still a much contested issue. Even Chinese ethnologists who have delved into the search for Tuoba origins are content with drawing up the conclusion that they spoke a Xianbei tongue, one which had a written script that has

\footnotetext{
${ }^{89}$ Lin Wo 1989, p. 84.
} 
not survived in any existing texts. ${ }^{90}$ The forms of speech and script used in the Xianbei language are yet to be confirmed. In fact, without new textual sources to shed some light on this issue, it appears that scholars are generally satisfied with regarding the Xianbei tongue as an Altaic language.

In the West, scholars have long attempted to reconstruct and analyze the fragmented vocabulary of the Tuoba preserved in Chinese sources, such as the Wei shu, Song shu and Nan Qi shu. ${ }^{91}$ The Tuoba's native tongue was formerly assumed to be Tungusic, ${ }^{92}$ along with the rest of the northern peoples collectively known as the Dong Hu. ${ }^{93}$ Then in 1960 , Gerald Clauson argued that the Xiongnu, the Xianbei (except for the Yuwen and Khitan clans), and the Rouran were all Turkic-speakers. ${ }^{94}$ This assertion was later overturned by Louis Ligeti, who provided an alternative hypothesis that the Dong $\mathrm{Hu}$ were protoMongols and not Turkic, based on cross-referencing linguistic evidence. ${ }^{95}$ On the other hand, Peter Boodberg used Chinese phonetic pronunciations found in historical texts as approximations of the Tuoba tongue. He then matched these pronunciations conveyed in Chinese to various possible languages with similar meanings. Boodberg eventually traced the etymology of the Tuoba vocabulary as being essentially Turkic, with a mixture of Mongol elements, which he called Turco-Mongol. ${ }^{96}$ From the above conclusions, it

\footnotetext{
${ }^{90}$ Lin Wo 1989, p. 103

${ }^{91}$ See Boodberg 1979, p. 222; also Pulleyblank 1983, pp. 452-453.

${ }^{92}$ The Tungusic languages (also known as Manchu-Tungus, Tungus) are spoken by the Tungusic people in Eastern Siberia and Manchuria, considered as part of the Altaic language family, along with the Turkic and Mongolic languages.

${ }^{93}$ Pulleyblank attributed this to a chance similarity in modern Chinese pronunciation of Dong $\mathrm{Hu}$ and the Altaic Tungus, an assumption he believed to have no real foundation; see Pulleyblank 1983, p. 452. The modern Chinese pronunciation of Dong Hu, which in the Mongolian language is known as Tünghu, had various reconstructions in the Old Chinese of the Warring States Period (476-221 BCE), when the Dong Hu people were first accounted for in Chinese texts, and the Chinese transliterations end up very close to that of the word Tungus in pronunciation.

${ }^{94}$ Clauson 1960, p.122.

${ }^{95}$ See Ligeti 1970, pp. 265-308 for his hypothesis on the Tuoba and the language spoken by them.

${ }^{96}$ Boodberg claimed that though etymologies given by late imperial Chinese historians for nomadic names are often fanciful, they should not be unjustly discounted as they provide phonetic hints as to the original
} 
appears that the debate about whether the Tuoba tongue was more Tungusic, Turkic or Mongolic in the Altaic languages will remain ongoing. ${ }^{97}$

Finally, although the Tuoba emerged on the horizon of fourth century steppe politics as unifiers and rulers of northern China for the following century and a half, in organization and structure, they cannot be understood without reference to the political model set up by the Murong Yan states. ${ }^{98}$ The Tuoba were one of the most westward clans of the Manchurian Xianbei tribes, ${ }^{99}$ which made them the most nomadic in nature, as they remained closer to the steppe tradition than their cousins to the east of the Liao River, who had started assuming the responsibility for ruling cities and governing farmers as the region was narrowly connected to China proper. Upon the fall of Luoyang in $311 \mathrm{CE}$, which marked the collapse of the Western Jin dynasty (265-316 CE), a weakened central order invited the various nomadic tribes on the northern frontier to try their hand at moving into the Chinese arena. Border polities like the Former Yan (337-370 CE), Western Yan (384-394 CE), Later Yan (384-409 CE), Southern Yan (398-410 CE) of the Murong survived through the chaos as a result of their dual organization structure, stressing defense and internal organization, while others failed because of their inability to administer their conquests. As such, the successive Murong states that began with the Former Yan in 337 and ended with the Southern Yan in 410 maintained a strong control over northeastern China throughout the fourth century. The Murong's system of the dual organization and

word. The term Turco-mongol was used by Boodberg when referring to the Tuoba vocabulary in Boodberg 1979 , pp. 232, 237-238.

${ }^{97}$ The language of the Xianbei people continues to be undefined, though the reasons for suggesting Turkish and Mongol have been quite substantiated. Nonetheless, there are also those scholars, such as Liu Xueyao, who remain more cautious and suggest that the Xianbei may have had their own language system, apart from the broad classification of the Ural-Altaic, and should not be assumed to be identical with any other known languages; see Liu Xueyao 1994, pp. 83-86.

${ }^{98}$ Barfield went as far as claiming that the Tuoba would not have been able to succeed without the adoption of the Murong's innovation of the dual organization framework; see Barfield 1989, p. 118.

${ }^{99}$ The exception being the Tuyuhun 吐谷渾 who had moved entirely out of the region. 
the officials who knew how to make it work were eventually all inherited by the Tuoba with the Northern Wei's control of the entire northeastern region of China and southern Manchuria by the year 410 .

\section{METHODOLOGY}

The Pingcheng period, which marks the earlier phase of the Northern Wei dynastic building, was a time when the Tuoba and the subjects of this new regime were forced to respond to the inevitable demands that resulted from the encounter of two cultural spheres on the Chinese-Eurasian steppe frontier. Whereas originally, opposition was derived from the demarcation between the nomadic peoples and the Han Chinese, with the transition of the Tuoba into the Chinese arena, creating a unified northern China under one nomadic rulership, a reconfiguration of Us and Them was deemed necessary. ${ }^{100}$ The concept of "being Chinese" and the construct of a "Chinese state" in the Tuoba Northern Wei could be better explored through a study of the systems of material culture and population interaction that converged at Pingcheng.

A study of the Northern Wei Pingcheng period based on textual sources will most likely continue to present a monolithic historical progression characteristic of the Chinese historiographical approach. This is especially true when it comes to the study of conquest

\footnotetext{
${ }^{100}$ In most historical instances, imperial attention to the frontier may have served domestic political needs more than external military requirements. Much like the Roman view of the barbarian, provided by Guy Halsall, they were primarily people who lived beyond the political limits of, and were opposed to, Roman rule. At the surface level, it would appear that the Roman concept of the barbarian was derived from that of the Greeks, which in the first instance, referred to someone who spoke an unintelligible language, including the Romans themselves. Upon appropriation of this word from Greek vocabulary, in the early days of the Roman Empire, a new meaning emerged; see Halsall 2007, pp. 45-46.
} 
dynasties. ${ }^{101}$ These were the regimes established by peoples of non-Han Chinese origin from the steppe, seen to be characterized by an ethnic and cultural division between the ruling minority and the conquered majority. In the words of Jennifer Holmgren, Chinese attitude towards conquest regimes "has alternated between benign indifference about their foreign origins, silent embarrassment, and vituperative hostility". ${ }^{102}$ Scholars of Chinese history are keen to see all dynasties as part of a single tradition embracing the Han Chinese majority, not just in the ethnic composition, but also in terms of cultural superiority and political governance. This is to maintain the Sino-centric appearance of a unified dynastic heritage in the flow of Chinese history, a linear progression through which all outsiders were assimilated into a so-called Chinese civilization. ${ }^{103}$

Here, I would like to turn to the famous debate on the contention over the use of the term "Sinicization" as a defining characteristic of the Manchu's success in building a successful Qing 清 dynasty (1644-1912 CE). Evelyn Rawski has argued against a Han-centric interpretation of China's history as it emphasized on the process of assimilation of the nonHan Chinese into a conceived notion of "Han culture", which was indeed an intellectual construct of the early twentieth century, thus excluding the contributions of different groups of people to what has known to be the Chinese civilization. ${ }^{104}$ Her viewpoint was a strong reaction against P. T. Ho's statement in 1967 that "the key to its [Qing] success was

\footnotetext{
${ }^{101}$ In a paper by Jennifer Holmgren on conquest dynasties that emerged in the course of Chinese history, she points out the importance of historical legitimacy when it comes to differentiating the recognized conquest dynasties of Northern Wei, Liao, Jin, Yuan and Qing, from other states founded by non-Han peoples within or along China's northern frontier. When we automatically think of Liao and Jin as a part of Chinese dynastic successions, though as outside conquerors, why is the contemporary state of Xi Xia invariably ignored, when it also had a stable administrative center within the Chinese frontier? Holmgren's answer is the ability to gain dynastic legitimacy; see Holmgren 1989, pp. 8-11.

${ }^{102}$ Holmgren 1989, p. 2.

${ }^{103}$ This is a gravely misleading assumption that is gradually being recognized and rectified as scholars move away from the concept of a linear development to using the notion of a multi-directional network in understanding the history of this region within the present-day boundaries of China.

${ }^{104}$ Rawski 1996, pp. 832-836.
} 
the adoption by early Manchu rulers of a policy of systematic Sinicization”. ${ }^{105}$ Rawski proposed in 1996 that the success of the Qing, in terms of empire building, lay in the Manchu's ability to use their cultural links with the non-Han peoples of Inner Asia and to differentiate the administration of the non-Han regions from the administration of the former Ming 明 dynasty (1368-1644 CE) provinces. ${ }^{106}$ She was then countered by Ho, who claimed in 1998 that the idea of "Sinicization" should be applied in a broader sense that "transcend[s] the narrow confines of interethnic relations and embraces the evolution of the whole Chinese civilization". ${ }^{107}$ By emphasizing on the whole of Chinese civilization, P. T. Ho was clearly justifying the Sinicization concept by steering it away from being a Han-centric notion in order to include other ethnic groups in this process, which can be interpreted as a more politically correct statement. However, in light of the current discussions on the Tuoba Northern Wei, I would argue that it is precisely his focus on the idea that Chinese civilization could be interpreted as a process of "evolution" that should be challenged. Instead, our emphasis should be on the different choices made by the historical players and to understand the reason behind them.

The Chinese view of the Mandate of Heaven, which conferred legitimacy upon a regime, was devolved upon only one dynasty at the time, and invariably upon the most successful. Success, in this sense, was defined in terms of the regime's durability, geographic location and extent, as well as its degree of cultural conformity to Chinese ideals. ${ }^{108}$ As such, the

\footnotetext{
${ }^{105}$ Ho 1967, p. 191.

${ }^{106}$ Rawski 1996, p. 831.

${ }^{107}$ In his discussions on the perennial significance of the forces of Sinicization, P. T. Ho recognizes that the Chinese term Han hua 漢化 is not entirely correct, since the process had begun to operate well before the Han dynasty came into being, thus the more appropriate term should be Hua hua 華化. Nonetheless, he stresses the importance of using the concept of Sinicization in understanding the evolution of Chinese history, particularly in light of the term's new relevance to the notions of Westernization and modernization that contemporary China is currently engaged in; see Ho 1998, pp. 151-152.

${ }^{108}$ Holmgren 1989, p. 10.
} 
Northern Wei had been deemed fit, albeit a "foreign" rulership, for the title of a conquest dynasty in Chinese historiography, based on its temporal, spatial, and cultural success visà-vis its contemporary competitors. However, with the recent growing emphasis on the study of material objects, owing to increasing archaeological findings, I would suggest that an exploration of the material cultural negotiations would provide a more vibrant and complex insight into the Tuoba's success with the Northern Wei. As Matthew Canepa remarked, searches for notions of "original" or "pure" cultural structures are a dead-end. Rather, the more productive approach for understanding cross-cultural interaction requires an understanding that "cultures are not unitary monoliths but dynamic interrelated systems continually recreated by daily or general human practice". 109

Despite the political instability and warfare during the Northern and Southern dynasties, it was a time of innovation and new accomplishments. As pointed out by Dien, in terms of the material culture that emerged from this period, "there is a continuity of development building upon the Han foundations and leading into the accomplishments of the Sui and Tang". ${ }^{110}$ While the continuity should be noted and given due credit, we also need to recognize that, under the Northern Wei, the Tuoba introduced new materials and new ways of thinking about the application of visual forms. I will turn to explore the many practices that enable us to ask questions beyond identifying the "cultural provenance" of a specific type of object or visual representation. ${ }^{111}$ Pingcheng, as the Tuoba's seat of power, may have contained the buildings and institutions that appeared to be essential to a Chinesestyled capital city, but a breakdown of the sovereign's activities in and out of the city reveals the peripatetic nature of these Northern Wei emperors. While architectural sets of

\footnotetext{
${ }^{109}$ Canepa 2010, p. 9.

${ }^{110}$ Dien 2007, p. 13.

${ }^{111}$ Canepa 2010, p. 9.
} 
columns, niches and arches decorated with half-palmette scrolls in stone originated from the Classical world with regional adaptations in the Buddhist centers of Central Asia, it was at the Yungang grottoes and decorated on the stone sarcophagi in the Pingcheng elite tombs that they took on new meanings. By combining old traditions/objects with new practices/applications, visual representations and material forms were (re)created and (re)interpreted in the Northern Wei Pingcheng period.

\section{$\underline{\text { Alternative Approach }}$}

In order to move away from a linear model in understanding the making of the Tuoba Northern Wei, I would like to raise a new perspective, one that treats fifth century Pingcheng as the both the geographical and temporal site of convergence, where several pulses of outside stimuli produced the different types of material culture to be examined in the following chapters. These visual and material injections can be viewed as having arrived at Pingcheng in waves of contact that originated as far west as Western Asia, and through a more direct contact with parts of Central Asia. Mountain-side sculptures, houseshaped stone sarcophagi, murals depicting open-air banquets, and the frequent progresses of the emperor himself, were all practices that traveled eastward from these distant lands, picking up regional variations along the way through local exchanges.

This process of adoption followed by adaptation is most pertinent in the novel application of architectural sets with the profuse use of arches, niches, and columns carved out of stone as we shall see in the caves of Yungang in chapter three and on the stone sarcophagi in the tombs of the Pingcheng elite in chapter four. Jessica Rawson looked to the Hellenistic buildings in Western Asia as the ultimate source of these architectural elements that appeared at Yungang, complementing the display of figures for religious and imperial 
purposes. Since an immense area lies between the Mediterranean coast and China, the relay stops in this movement of material cultural repertoire are based on the principal cities of the Parthians and the Kushans along the trade route that shared a common interest in the construction of monumental stone buildings. ${ }^{112}$ As such, the architectural sets that arrived in northern China had its origins from Hellenistic spheres but also took advantage of the Buddhist "techno-complex"113 in the Central Asian kingdoms, which were then transferred via Liangzhou (present-day Gansu province) to Pingcheng with the flow of Buddhist teachings. In this context, Liangzhou and Pingcheng were no more than two nodes on the eastern end of this network.

As a node, we can also understand Pingcheng as what Chris Gosden called a "middle ground", within which frequent contact brought about a negotiation of material culture. ${ }^{114}$ Whereas conventional models saw only two possibilities for power to be exercised by one group of people onto another, namely through acculturation or cultural and physical destruction, Gosden raised a third working relationship between incomers and locals. He termed this the "middle ground", where a new way of living is derived from the systems of practice and culture that all parties bring to the encounter. ${ }^{115}$ Gosden treated access to, and

\footnotetext{
${ }^{112}$ Modern boundaries suggest divisions that did not exist in the third and second centuries BCE, but in fact, Egypt, Greece and Western Asia had been in contact through trade and warfare over many centuries; see Rawson 1984, pp. 38-39.

113 The notion of a "techno-complex" is borrowed from Stuart Piggott's discussion of the chariot packagedeal, that the supply of horses, training and breeding of stock, as well as the skills of an adequate driver would all have had to be acquired when we consider the introduction of chariots into China; see Piggott 1992, pp. 45-48. In the context of this thesis, I look at the range of activities, peoples, and objects that were introduced into China along with Buddhist teachings as a "techno-complex" that would have been adopted by the Tuoba. This term will be dealt in more detail in chapter three.

${ }^{114}$ In Gosden's typology of forms of colonialism, the "middle ground" offers the greatest amount of experiment and creativity between the groups of people involved. It involves an accommodation and regularized relations through a working understanding of others' social relations. The result is often a creation of new modes of difference, not acculturation, and it is difficult for any party to sustain fixed categories of difference; see Gosden 2004, p. 26.

${ }_{115}$ The example that Gosden used to demonstrate the "middle ground" model is the North American fur trade of the sixteenth and seventeenth century, between Native Americans and Europeans in eastern Canada, which brought hundreds of thousands of Europeans to the region. By 1621, the zone between the St.
} 
creation of, new material forms as ways of destabilizing older values and exercising power over the people who are joined together by these practices. This view allows us to put aside the question of who had agency on whom, because everyone involved in this process of negotiation did. Systems of culture and the values attached to material objects are central to these negotiations, the material culture being the point at which aesthetic, social and belief values converged.

It was here, at the "middle ground", where the creation and consumption of stone sculptures, house-shaped sarcophagi, murals of outdoor banquets, nomadic-dressed clay figurines, and representations of military processions embodied a set of social practices and dispositions that could be treated as a Pingcheng habitus. ${ }^{116}$ The various groups of people involved in this encounter, including the Tuoba, Han Chinese, and other frontier people who took part in life at Pingcheng, were bound together through this habitus, from which a new identity emerged to redefine the notion of "being members of the Northern Wei state". In this process, narratives of shared memory became essential building blocks of group identities that bound particular collectives together, ${ }^{117}$ and it is through this process that new classification of outsiders and insiders were created. While existing social

\footnotetext{
Lawrence and the Hudson River was one of regular interaction between Native American and European groups. Native Americans attached particular sets of values to material culture. For example, sets of religious beliefs were attached to colours and objects that manifest these colours, of which red, white/sky blue-green and black were most important. These values which adhered to local objects were extended to European trade items with increasing contact between the two cultural systems. Consequently, Europeans were assimilated into the network of local relationships through the significance of the trade items they brought with them. This "middle ground" denotes a complexity of material and cultural forms that took on continuous stimulus over the years of European fur trade in eastern Canada. It was necessitated as a pragmatic alliance between groups of people in creating an elaborate network of economic, political, cultural, and social ties to meet the demands of deriving profit from the fur trade, which was shared by all participating groups; see Gosden 2004, pp. 83-89.

${ }_{116}$ Daniel Miller referred to habitus as the underlying unconscious order of the cultural environment to which we adapt to. He called culture our second-nature, that which we habitually act on without thinking, and it is precisely this entire system of things, with their internal order, that define us as the people we are; see Miller 2010, p. 53.

${ }^{117}$ Collective memories could be selectively reconfigured, discarded, or passed down. They are usually strengthened, relived, or preserved through some type of medium. These could be artifacts, iconography, texts, or collective activities; see Wang Mingke 2006, pp. 27, 31-33.
} 
and cultural systems were retained for further use, there was a necessary destabilization of older values. Consumption of, and the ability to create, new systems of visual and material repertoire with cultural and political cache, redefined the new Northern Wei identity.

Throughout this study, notions of social identity, for those of Han Chinese and non-Han origins, along with various concerns of how one could maintain separate private and public affiliations in a fluid society like that of the Northern Wei, will be demonstrated as being negotiable. This thesis will treat social distinction of groups of people as necessitated by the pursuit of interest and the protection of resources in every society. Nonetheless, as necessitated by the pursuit of interest and the protection of resources in every society, Fredrik Barth defines identity as no more than a strategy for personal advancement. When circumstances change, making one group identity more advantageous than another, the individual will necessarily switch allegiance, a condition of group identity characterized by Barth as an "evanescent situational construct, not a solid enduring fact". 118

It is here where Michel Foucault's definition of discourse as systems of thoughts composed of ideas, attitudes, beliefs and practices that systematically construct the worlds of which they speak becomes a useful tool for us to understand how identities in the Northern Wei were constructed and expressed. Discourse, treated as a system of representation, is regulated by rules and practices that produced meaningful statements in a particular historical period. ${ }^{119}$ What would have simply been Buddhist sculptures inside cave temples became an innovative medium at Yungang that combined imperial ancestral

\footnotetext{
${ }^{118}$ Barth 1969, p. 9. Also refer to Richard Jenkins's definition of identity as the human capacity, rooted in language, to know "who's who" and "what's what". Jenkins looked at why a threat to one's identity is often more serious than we would normally give it credit, since it is in actuality a threat to one's social interests; see Jenkins 2008, p. 5.

119 Hall 1992, p. 291.
} 
commemoration together with a new visual manifestation of kingship in the hands of the Tuoba in the fifth century. Foucault further argued that discourse constructs the topic, defines, and produces the objects of our knowledge. Since discourse governs the way that a topic can be meaningfully reasoned about, it is the key to our understanding of the power-knowledge relations that shape the social dynamics. ${ }^{120}$ The pictorial depictions of musicians and dancers in Han Chinese garment on the inside surface of the house-shaped stone sarcophagus of Yanbei Shiyuan M5 demonstrate a striking difference in the tomb occupants' cultural affiliation when set beside the clay figurines in nomadic headgear and garb that were placed outside the sarcophagus. Found within the same tomb, these two types of representations may suggest an alternating discourse in expressing the tomb occupants' public and private social relations, as members of the Pingcheng elite. Essentially, while Foucault does not deny that things can have a material existence in the world, he remains strong by the notion that "nothing has any meaning outside of discourse". ${ }^{121}$ In this thesis, I am simply replacing the traditional textual discourse with expressions constructed out of the material world of fifth century Northern Wei and the practices conducted within this particular social system.

As we will see in chapter four, the murals, figurines, and other tomb furnishings together created different discourses for the Pingcheng elite, not necessarily based on their ethnic origins, but reflective of their new social standings. Within a particular burial context, the application of the visual and material repertoires also allowed for the tomb occupants to move between public and private spheres using different methods of representation. On a more conceptual level, the Tuoba sovereigns made use of these same discursive

\footnotetext{
${ }^{120}$ In Foucault's words, "there is no power relation without the correlative constitution of a field of knowledge, nor any knowledge that does not presuppose and constitute at the same time, power relations"; see Foucault 1977, p. 27.

${ }^{121}$ Foucault 1972, p. 32.
} 
representations to manipulate their imperial agency, either in practicing rituals of the court as the "symbolics of power" as discussed in chapter two, or in the expression of kingship through the sculptures at Yungang as discussed in chapter three. ${ }^{122} \mathrm{I}$ argue that it was precisely this ability to manipulate the discourses to serve specific agendas that the Tuoba were able to put on as many imperial façades as they saw fit.

As a response to this particular social and cultural milieu of the Northern Wei Pingcheng period, a phenomenon appeared which I will refer to throughout this thesis as the notion of a "dual presence". This term has a two-fold application, describing both the identity of the people and the agency of the material forms. With their steppe origins, the Tuoba Northern Wei presided over a vibrant region where the Chinese sphere and the Eurasian steppe converged. The Tuoba sovereigns and members of the elite households shared in maintaining the "dual presence" by juggling between identifying themselves with certain cultural practices of the Eurasian steppe and at the same time adjusting to particular traditions of the Chinese arena. Further, in the application of funerary repertoires in the Pingcheng burials, there emerged a practice of working with a mélange of material forms. At the same time, new meanings were generated out of preexisting traditions, since in effect the function of objects does not reside in their forms. Rather, it is dictated by the pathways as determined by the activities and practices of the human agents involved. ${ }^{123}$

\footnotetext{
${ }^{122}$ Clifford Geertz developed the argument that the rituals of rulers, which can also be referred to as the "symbolics of power", are not mere ephemera, but are central to the structure and working of any society. The very thing that the rituals and ceremonies are supposed to conceal - that majesty is made, not born - is demonstrated by it; see Geertz 1983, p. 124.

${ }^{123}$ Walker and Lucero 2000, p. 133.
} 


\section{Chapter Outline}

The emperors' hunts, progresses and ancestral worships that manifest private and public spectacles became an integral part of the structure of power that defined Pingcheng as the capital of the Northern Wei. In chapter two, the rituals of an empire will be extended beyond the limits of a traditional context of sacrificial worships, to include the mobility of the Tuoba sovereigns and the Northern Wei court as they became ritualized through routine practice. As such, a ceremonial consciousness remained the central element in the many discursive expressions that were produced from these practices. ${ }^{124}$ Access to these rituals determined the ownership of imperial discourse, and thereby the control over the agency of kingship. Furthermore, apart from keeping themselves mobile, throughout the century of the Pingcheng period, the Tuoba's practice of relocating population and resources from conquered areas suggested that with each military conquest, regional networks of skills, materials, and technology were also transferred wholesale to the capital. As the various cultural spheres converged to create new social practices and discourses of imperial rituals, the activities in and out of Pingcheng embodied the notion of a seat of power that the Tuoba had conceived for their new realm.

In chapter three, the Yungang grottoes will be explored, no longer in a traditional Buddhist context, but as the embodiment of a new imperial commemorative tradition that represented new notions of kingship. With the creation of larger than life sized stone sculptures, Yungang was an imperial monument that combined a Chinese interest in commemoration of ancestors with the Western application of images. Being a "teaching by images", the Buddhist "techno-complex" brought with it an entirely new package of visual designs and material forms from as far west as Western Asia, which was fully explored, as

${ }^{124}$ Cannadine 1987, p. 12. 
a new set of cultural vocabulary for this to happen. ${ }^{125}$ As such, the impact of Buddhism on the visual culture of China is an example of how new practices and ways of seeing the world could be introduced and integrated into a host culture. ${ }^{126}$ Moreover, under the Northern Wei statehood, the conflict of loyalties between monastic and state power was resolved by merging the two identities in the entity of the emperor, as he came to be regarded as a Buddha incarnate. ${ }^{127}$ Finally, the combination of stone sculptures, mountainside carvings, and decorative architectural sets produced a new type of discourse through which the Tuoba sovereigns could convey their imperial agencies.

Chapter four is structured around two case studies - the tomb of Lady Poduoluo at Shaling M7 and that of Song Shaozu at Yanbei Shiyuan M5. The two tombs contain very different types of materials for us to work with. Shaling M7 is a fully decorated mural tomb, and Yanbei Shiyuan M5 is filled with objects and figurines. These two distinct repertoires produced different sets of narratives that construct the practices, aspirations, and social affiliations of the tomb occupants. Together, they created a context in which the social identities of a person could be (re)constructed through the application of the different types of visual and material repertoires. ${ }^{128}$ The representation of these murals, figurines, and tomb furnishings not only contains human agency, they are the very discourses that

\footnotetext{
${ }^{125}$ See Rawson 1984, pp. 34-52 for a detailed account of how architectural styles and scroll motifs from the Near East traveled to the eastern limits of their influence, culminating in Yungang during the Northern Wei. ${ }^{126}$ Canepa compared this impact that Buddhism had on China to the taste for Classical visual culture among the empires of post-Hellenistic Iranian nomads and other exchanges between the Byzantine, Islamic and Western European worlds; see Canepa 2010, p. 14.

${ }^{127}$ Similarly, when the Byzantine Iconoclast emperors failed in their attempt to control the powerful religious forces in the state by opposing the centrifugal enthusiasm for images, once more emperors turned to claim divine support, legitimizing their own position by representing themselves in visual art in conjunction with divine personages; see Cameron 1987, p. 135.

${ }^{128}$ In her study of the sixth-century stone tomb furniture, Bonnie Cheng proposed that any analysis that tries to assign specific objects to strands of cultures based on the ethnic, religious or social identity of the deceased could reduce the distinctive cultural characteristics and obscure the constitutive nature of identity and the creativity inherent in the process of exchange in cross-cultural interaction; see Cheng 2010, pp. 84-85.
} 
narrated the lives and practices of their consumers. ${ }^{129}$ Rather than an examination of single artifacts or of categorical types, this chapter will look at the entire tomb space as a functional group, providing a setting and context to which the performances and narratives were played out. ${ }^{130}$ In this discussion, the notion that the "form/design" of any given object or visual representation may be borrowed while new "meanings" could always be endowed by the current consumers and patrons will be constantly referred to. ${ }^{131}$

Lastly, chapter five brings together all of the ideas explored in this thesis through three vignettes. The story of Mulan, snippets of the Northern Wei legacies, and the ancestral dedication at the Gaxian Cave all show us how these different narratives embody an active construction of identity through social practice. In fifth century northern China, at the crossroads of colliding networks of practices, visual representations and material forms, the people who shared this habitus were exposed to an increasingly diverse set of cultural variables. Instead of trying to identify all that we have encountered to one "coherent" culture or another, this final section acknowledges the reconfiguration of traditions in the Northern Wei Pingcheng period as an act of ingenuity.

\footnotetext{
${ }^{129}$ This discussion is situated within Merlin Donald's framework of mimetic, mythic, and theoretic modes of activity and thought; see Donald 1993, p. 2-3. These three categorical modes of activity and thought are renamed by Jessica Rawson as performative, narrative, and theoretic modes. In her study of Chinese burial patterns as sources of information on thought and belief, Rawson found Donald's modes of performances and narratives in Chinese tomb material culture. She viewed it as a convention for all humans to intentionally design our own settings and the artifacts we use. This is for the purpose of making the objects intelligible to the creators and also for the viewers to similarly interpret them; see Rawson 1998, p. 107.

${ }^{130}$ For the approach used to treat objects in functional sets as opposed to linear typology, see Rawson 1998, pp. 113-119.

${ }^{131}$ Put in a slightly different way, Canepa pointed out that although an art object, architectural form, or ornamental motif had no meaning outside the uses of its original patron, consumer, or viewer, visual material itself could introduce new ways of seeing to a host culture; see Canepa 2010, p. 14.
} 


\section{CONCLUSION}

As new patterns of practice and discourse emerge from our sources, they reflect significant changes in the socio-cultural atmosphere of northern China at this point in history. The Yungang grottoes, tomb burials, and the idea of Pingcheng as the Northern Wei capital will be separately treated in the following chapters as critical social systems from which practices and identities particular to the Northern Wei were produced. Together they testify to the dialectic between existing constraints and actual practices that conceptualizes the relationship between individuals and society, as a result of tradition, the routine of daily life, and individual motivations. ${ }^{132}$ In this study of the Tuoba's conquest and the pursuant making of the Northern Wei, these ritual, funerary, and commemorative discursive representations wove together to create new notions of "Chineseness" in fifth century northern China.

${ }^{132}$ Walker and Lucero 2000, p. 131. 


\section{Chapter 2: Pingcheng and the Rituals of Empire}

敕勒川，陰山下，

天似穹盧, 籠蓋四野。

天蒼蒼，野茫茫，

風吹草低見牛羊。

Chile plains, ${ }^{134}$ at the foot of the Yin mountain; ${ }^{135}$

The sky is like a domed yurt, giving cover to all corners of the earth.

The dark-green Heaven is vast, and the wilderness is boundless;

When the wind blows the grass bends low, and there the cattle and sheep appear.

---“The Chile Song",136

\section{INTRODUCTION}

Before settling into Pingcheng 平城 (present-day Datong, Shanxi province), the Tuoba had roamed the Manchurian forests and the Mongolian grasslands (fig. 3) with the Heaven as their domed yurt and the great wilderness as the expanse of their realm. This was the life that they were familiar with, an idyllic one most vividly presented in "The Chile Song". The year 398 marked a watershed moment in the course of the Tuoba history. The decision to establish a dynastic regime under the name of Wei 魏 $^{137}$ coincided with the permanent relocation of the capital to Pingcheng, at the discretion of Emperor Daowu 道武帝 (Tuoba Gui 拓跋珪, r. 386-409). Needless to say, the many changes brought about a new way of

\footnotetext{
${ }^{133}$ Chinese text taken from the Yuefu shiji 樂府詩集 compiled by Guo Maoqian 郭茂倩 in the Song dynasty (960-1279CE), which remains as the earliest existing text on "The Chile Song"; see Yuefu shiji, juan 86, pp. 1212-1213. However, “The Chile Song” was first mentioned in the Bei Qi shu 北齊書 (Book of Northern Qi), written by Li Baiyao 李百藥 in 636, in which the song was attributed to Hulü Jin 斛律金, a general of the Eastern Wei 東魏 (534-550 CE). It is said that he had written it during a battle against the Western Wei 西魏 (534-556 CE) in 546, in order to raise the morale of the Eastern Wei troops; see Bei Qi shu, juan 2, p. 23. ${ }^{134}$ In present-day Neimenggu, near the area occupied by the Tumed Banner that spans the borderland of Hohhot and Baotou.

${ }^{135}$ The Yinshan mountain range runs in a east-west direction and is located in the middle part of present-day Neimenggu.

136 Author's trans.

${ }^{137}$ Other variations include the Tuoba Wei, Later Wei, or more commonly as the Northern Wei.
} 
life for the Tuoba, but exactly how much of their old lifestyle had to be given up in this process? Or, had it? When these new rulers of northern China were given the chance to build a capital from ground up, what did they hope to convey through establishing a more permanent seat of power at Pingcheng? How was the "dual presence" of the Tuoba Northern Wei maintained and manifested in the ways in which the Tuoba court was conceived?

As a result of limited archaeological findings on the city remains at present-day Datong, existing scholarship on Pingcheng tends to focus on two aspects: 1) the construction of the mingtang 明堂 (Hall of Brightness) and other corresponding ritual buildings in the year 486, as these are currently the only palatial sites to be discovered of Northern Wei Pingcheng; ${ }^{138}$ 2) the Pingcheng period as a political phase in the Tuoba's pursuit for dynastic stability and regime legitimacy during the formative period of the Northern Wei. ${ }^{139}$ What both lines of inquiry ultimately share in common is that they assume an urgency for the Tuoba to adopt Chinese court practices and to adopt the traditional dynastic institutions of their predecessors.

This assumption stemmed from the Chinese historiographical tradition of being intimately linked to the exercise of power as a state institution since the founding of the Qin dynasty in 221 BCE. As Lothar von Falkenhausen incisively pointed out, Chinese historiography is "beholden to a notion of uninterrupted cultural, ethnic and historical continuity, as well as unity, [and] it propounds a unilinear sequence of events and is prone to disregard divergent

\footnotetext{
${ }^{138}$ See Xiong 2003, 31-92; Steinhardt 1990, pp. 78-80; Wang Yintian 2000, pp. 153-166; also Han Shengcun 2005 , pp. 37, 43.

${ }^{139}$ See Zhang Jinlong 1997, pp. 3-19; Holmgren 1989, p. 2; Liu Jingcheng 1995, pp. 58-71; Lu Yaodong 2006; Li Ping 2000; also Barfield 1989, pp. 118-120.
} 
(e.g. local) traditions." ${ }^{140}$ It is this preoccupation with the notion of a "continuous historical experience" that constituted the background of traditional Chinese historiography, to the extent of impacting archaeological studies. ${ }^{141}$ Within this type of discourse, the layout of the dynastic capital becomes the most definitive marker of heritage from an archaeological perspective, often relying on the descriptions of capital planning contained in the Wei shu. In effect, existing scholarship on Pingcheng presents it as a more or less static entity that was no different from any other Chinese capital, focusing on its physical components rather than exploring the role it served on the part of the Tuoba's strategization in the Northern Wei state-building. ${ }^{142}$

In light of this current state of research, the following discussion attempts to shed a new light on Pingcheng as the Northern Wei capital by exploring another set of textual data. Also relying on the Wei shu, rather than looking at descriptions of the city, I will use the annual activities of the Tuoba court to piece together an account of the court life at Pingcheng, and most importantly, the Northern Wei emperor's relationship to the city. The mobile rhythms of Tuoba imperial life dictated that the emperor travelled frequently out of Pingcheng, and a pattern emerges as to the time of the year, as well as to the various purposes for which the emperor would return to the capital. I intend to apply this new

\footnotetext{
${ }^{140}$ Falkenhausen 1993, p. 840. However, in a later work by Falkenhausen published in 1995, he acknowledged that while a nationalist interpretive framework remained basic to the pursuit of history and archaeology in China, a new regionalist paradigm had emerged in the interpretation of archaeological data. Whereas until the late seventies, all of Chinese civilization had been perceived as originating from a narrowly circumscribed area along the middle ranges of the Yellow River, in the eighties and early nineties, a new model was adopted, triggered by important discoveries in various provinces which became more difficult to accommodate into the earlier mononuclear framework. As a result, a more pluralistic view of the foundation of the Chinese civilization is being welcomed; see Falkenhausen 1995, pp. 198-200.

${ }^{141}$ Falkenhausen attributed this linear-historiographical phenomenon to the importance of Chinese historiography as a state institution in dynastic traditions. When Sima Qian completed the Shi ji 史記 (Records of the Grand Historian) in 91 BCE, he had first extended the scope of his enquiry to what he regarded as the beginnings of civilization, constructing a historical narrative proceeding from mythical cultural heroes and sage rulers to the three pre-imperial dynasties - the Xia, Shang and Zhou, down into the historian's own time; see Falkenhausen 1993.

${ }^{142}$ See Gu Hongfei 1995; Yin Xian 2002; also Steinhardt 1990, pp. 78-80.
} 
insight into the Northern Wei court to construct an "active" life of Pingcheng, one that might allow us to see an entirely different city within its relatively "static" shell.

Furthermore, the physical and institutional aspects of Pingcheng will be treated as a strategic move by the Tuoba in adopting a "dual presence" in their conception of a capital for the Northern Wei dynasty. In fact, this deliberate act of assuming a façade of an orthodox Chinese capital began literally from day one of the Tuoba's dynasty-building, with the establishment of a palace, an ancestral temple and a sheji 社稷 altar (Altar of the Earth and Harvests) in the seventh month of the year 398, immediately after Pingcheng was made the capital. ${ }^{143} \mathrm{~A}$ series of large scale constructions of palatial, ritual, and ancestral buildings occupied the new sovereigns throughout the Pingcheng period, all the way up to 494 with the relocation of the capital to Luoyang 洛陽, Henan province. This near obsessive persistence in unceasingly equipping the Northern Wei capital with every conceivable institutional element for close to a century reflects not just the whims of a single ruler, but the result of a long-term dynastic agenda that facilitated the Tuoba's smooth transition into the Chinese sphere.

We can understand the Tuoba's establishment of power in Pingcheng as being derived from two types of rituals of the empire: a system of state ceremonies with a focus on ancestral dedications and the progresses of a peripatetic rulership. Separately, they reveal two distinct imperial discourses on the Northern Wei state-building process. The former positions the sovereign as a representation of the entire state, both at the moment and over

${ }^{143}$ Wei shu, juan 2, p. 33. 
historical and future time. ${ }^{144}$ As another type of ceremonial form by which the sovereign could take symbolic possession of his realm, the peripatetic nature of the Tuoba reminds us of the ways in which the earlier period of the Holy Roman Empire was ruled without a capital city, as the emperor governed through his household, which continually moved throughout the realm. ${ }^{145}$ The empire was only in full strength wherever the emperor was situated, and it was through his frequent appearances in the various parts of the empire that the emperor himself was to be respected.

In a way, the progresses of the Tuoba were also much like those undertaken by Henry VIII, ${ }^{146}$ designed to consolidate the realm and, at the same time, consisted of pleasurable entertainments. ${ }^{147}$ Intrinsic to early Northern Wei imperial rule, these progresses also reflected the individual political and social circumstances of each year. Though disparate in nature, the juxtaposition of these two features of the Tuoba rulership in the Pingcheng period gives us a new understanding of how they were able to jointly create an imperial expression that fulfilled the needs of the new sovereigns in a burgeoning empire. From an examination of these two discourses, we shall see that "the very thing that the elaborate mystique of court ceremonial is supposed to conceal - that majesty is made, not born - is demonstrated by it". ${ }^{148}$

\footnotetext{
${ }^{144}$ In Michelle Gilbert's study of the Ghanian kingship, the person is seen to have resulted from the conjunction of his matrilineage and his father's line of affiliation. Thereby, a person's primary social identity, conceived of in terms of "blood", comes from these groups; see Gilbert 1987, p. 303.

${ }^{145}$ Berman 1983, p. 483.

${ }^{146}$ Royal progresses locate the society's center by stamping a territory with ritual signs of dominance, not unlike animals marking a territory through the spreading of its scent; see Geertz 1983, p. 125. The "progress" is recognized as an important instrument of Tudor government, and became a mark of the reigns of Henry VIII and Elizabeth I; see Samman 1995, p. 59; also Cole 1999, pp. 1-4.

${ }^{147}$ Samman sees the progresses of Henry VIII as a part of the transitional period between the typical "medieval" style progresses that were designed for the consolidation of the realm and the pleasure progresses with spectacular entertainments which characterized Elizabeth's reign; see Samman 1995, p. 73.

${ }^{148}$ On the subject of symbols of power, Geertz argues that at the political center of any complex society, there is both a governing elite and a set of symbolic forms expressing the fact that it is in truth governing. This is the motivation behind the imperial reliance on rituals and ceremonies, as the elite justify their existence and actions; see Geertz 1983, p. 124.
} 
As such, the politics of a capital city is perfectly played out at Pingcheng. In "form" and "design", the city was equipped with every element a capital city in the Chinese tradition would have needed. ${ }^{149}$ Ultimately, the city was intended as a message to the Northern Wei subjects, as well as to their southern neighbors, that the Tuoba were just as qualified as their predecessors to rule over China, having mastered the terms of the game. However, a closer look at the imperial life in Pingcheng brings out the frequent roaming of the Tuoba rulers. Shuttling between the capital and the detached courts and hunting grounds to the north, in the span of a year, the sovereign returned periodically to Pingcheng for the New Year or annual ritual sacrifices. Compared with their more sedentary imperial predecessors, the Tuoba's relationship to Pingcheng was closer to the practice of a peripatetic ruler, preferring a mobile court in their desire to maintain a semi-nomadic existence. It was at Pingcheng where the notion of a capital, its position as the central seat of power of the Northern Wei, as well as the agency it was expected to convey as a part of the Tuoba's imperial discourse, took on a whole new "meaning". Together, these features of Pingcheng reveal to us the many faces strategically assumed by the Northern Wei emperor.

\section{THE TUOBA SEAT OF POWER: PHYSICAL AND CONCEPTUAL}

It is rather fitting that our knowledge of the physical layout of Pingcheng is mainly derived from the Northern Wei geographer Li Daoyuan's 麗道元 ( 470-527 CE) account in his monumental work of the Shuijing zhu 水經注 (Commentary on the Waterways Classic). Correspondingly, the sole surviving pictorial plan of Northern Wei Pingcheng (fig. 11) is

\footnotetext{
${ }^{149}$ Murata Jiro had put forth the notion that the city plan of Ye 鄴 (present-day Hebei province), capital of the state of Wei (220-265 CE) in the Three Kingdoms period, which had been visited by Emperor Daowu six months before establishing the Northern Wei capital at Pingcheng in 398, was very influential in shaping the newly designated imperial city; see Murata 1981, pp. 71-76.
} 
from the Qing 清 dynasty illustrated geographical study known as Shuijing zhu tu 水經注

圖 (Illustrated Commentary on the Waterways Classic) by Yang Shoujing 楊守敬, dated to 1905 CE. ${ }^{150}$ Indeed, the city of Pingcheng was positioned right between the two branches of the Ruhun River 如渾水 (now renamed the Yu River 御河). The Ruhun River branched off just north of Pingcheng, to the south of Fang Mountain 方山, splitting into two waterways that run parallel in a north-south direction, flanking the city right between the two river branches. In the words of Li Daoyuan:

如渾水又南, 分爲二水, 一水西出南屈, 入北苑中, 歷諸池沼, 又南誙虎圈 東, 魏太平真君五年, 成之以牢虎也。。。其水又南屈, 逕平城縣故城南。

一水南逕白登山西。。。其水又逕寧先宮東, 獻文帝之為太上皇, 所居故宮 矣。。。其水又南逕平城縣故城東。。。其水自北苑南出, 歷京城内, 河幹 兩湄, 太和十年累石結岸, 夾塘之上, 雜樹交蔭, 郭南結兩石橋, 橫水為 梁。又南逕藉田及藥圃西、明堂東。。。如渾水又南與武州川水會, 水出縣 西南山下。。 ${ }^{151}$

Ruhun River then heads south, dividing into two waterways. One branches off to the west and turns south. Having entered into the northern parkland, [the river] passes through several lakes and marshes. Again, it goes southbound and passes east of the Tiger's Ring, which was built in the fifth year of the Taiping Zhenjun reign for keeping tigers in captivity ... The river again bends south, passing through the Pingcheng county, south of the old city.

Another branch [of the Ruhun River] flows west of Baideng Mountain ... It then passes east of Ningxian Palace, the former residence of Emperor Xianwen when he became the retired emperor ... The river then goes southbound and passes through the Pingcheng county, east of the old city ... Having left the northern parkland from the south, as the river flows through the capital, on both sides of the waterway, rocks were laid on the riverbank in the tenth year of the Taihe reign, and an assortment of trees on the embankment cast overlapping shadows. Two stone bridges, laid south of the outer city, cross over the river as beams. Further south, [the river] flows west of the imperial fields and the herb garden, east of the Hall of

\footnotetext{
${ }^{150}$ Since its printing, this map has been associated with the city, and therefore must be considered in the discussion of Pingcheng. However, the near-perfect allocation of the palace-city at the center of the outer wall, and the unrealistic configuration of the arc-shaped northern and southern walls raises doubts about the accuracy of the plan, that it is, more than anything, an idealization inspired by the Kaogong ji description for the Chinese imperial city; see Steinhardt 1990, p. 79; also Murata 1981, pp. 71-76.

${ }^{151}$ Shuijing zhu, juan 13, pp. 205-207.
} 
Brightness ... The Ruhun River further heads south to merge with the Wuzhouchuan River that had originated from the mountain to the southwest of the county... ${ }^{152}$

From the way in which Li Daoyuan referred to Pingcheng as the "old city", we know that when he wrote this account, the capital of the Northern Wei had already been relocated south to Luoyang. The city, as he remembered it, was presented at its finest moment, after a century of refinement. However, Rome was not built in one day. The aforementioned palatial, ritual, and pastoral grounds of Pingcheng were added at various stages of the Tuoba's dynasty-building. If we are to look at the timing and condition in which these various imperial sites emerged as landmarks of the Northern Wei capital, we might be able to unlock the political messages behind the architectural façade.

\section{$\underline{\text { Kingship and Kinship }}$}

In the formative period of Northern Wei state-building, the Tuoba appeared to be actively engaged in carrying out rituals for purposes of ancestral veneration. These rituals were not intended as a deification of the Tuoba ancestors. Rather, they were for the "re-making" of the Tuoba ancestral lineage, since "the dead have no existence other than that which the living imagine for them." 153 As will be explored in this section, some of the intriguing ritual elements that appeared in this period were specifically incorporated to serve the Tuoba's own imperial interests, strengthening their dynastic claim as the ruling household of the Northern Wei.

\footnotetext{
152 Author's trans.

${ }^{153}$ Schmitt 1998, p. 1.
} 
In 398, after a thoughtful deliberation with his court, Emperor Daowu eventually adopted the dynastic title of "Wei” 魏 over the alternative suggestion of "Dai” 代. An imperial edict was issued by Emperor Daowu to explain his decision:

昔朕遠祖, 縂御幽都, 控制遐國, 雖踐王位, 未定九州。逮於朕躬, 處百代 之季, 天下分裂, 諸華乏主。民俗雖殊, 撫之在德, 故躬率六軍, 掃平中 土，凶逆蕩除，遐邇率服。宜仍先號，以爲魏焉。布告天下，咸知朕意。154

In the past, my distant ancestors ruled over Youdu ${ }^{155}$ and were in control of distant states. Although they had ascended upon the ruler's seat, the nine states had yet to be pacified. Up to my time, following behind hundreds of generations, all under Heaven have separated and parted, and the various states of the Central Plains were without a lord. Though the customs are disparate, the key to pacification is in the virtue [of the ruler]. For this reason, I personally led the six armies to sweep across the central lands, and to completely wipe out the fierce rebels, so that [all those] far and near would submit to my rule. I think it appropriate that we continue to use the former title, and to be [called] the "Wei". This is to be announced to all under Heaven, so that all would be made known of my intentions. ${ }^{156}$

In making the decision to go by the dynastic title of "Wei", Emperor Daowu's consideration was based on the notion that his accomplishment was the final piece in a grand scheme initiated by his ancestors. He emphasized the claim that the ruler's seat had been in the possession of the Tuoba household for hundreds of generations before he succeeded in bringing the various lands under one lord. Certainly, one might argue that if Emperor Daowu's intention was to maintain a continuity with the past, why not use the title of “Dai", which had been granted to Tuoba Yilu 拓跋猗盧 by Emperor Min of the Western Jin 晉㟲帝 (Sima Ye 司馬鄴, r. 313-317) early on in $315 .{ }^{157}$ The Tuoba ruling household had borne the title of the King of Dai 代王 up to 386 when Emperor Daowu

\footnotetext{
${ }^{154}$ Wei shu, juan 2, pp. 32-33.

155 Another name for Youzhou 幽州, consists of present-day northern Hebei province and parts of Liaoning province.

${ }^{156}$ Author's trans.

${ }^{157}$ Wei shu, juan 1, p. 9.
} 
first changed the title to the King of Wei 魏王. ${ }^{158}$ In light of this history, we see that in making the decision to go for the dynastic title of "Wei" over "Dai", the consideration was clearly something other than choosing the name that bore a longer history for the Tuoba.

My interpretation is that the final choice was made based on whichever title would give the newly founded state a stronger dynastic façade for the Tuoba. While the regime name "Dai" bears no historical significance in the Chinese tradition, the name "Wei" had long been in use, as early as the Western Zhou 西周 dynasty (1046-771 BCE) by one of its vassal states. The Wei territory included parts of present-day Henan, Hebei, Shanxi and Shandong provinces, which is exactly the area in which the Tuoba were active. As such, the Tuoba had subtly recreated their own history and turned themselves into heirs of a dynastic heritage that can be dated back as early as the Zhou. Having established this lineage with the rectification of dynastic titles, it is no surprise that the ritual practices undertaken by the Tuoba in the early phase of the Northern Wei would have been concerned, for the most part, with aligning the imperial ancestors for proper veneration.

In the twelfth month of the year 398, Emperor Daowu proclaimed himself emperor of the Wei at the Tianwen Hall 天文殿 (Hall of the Patterns of Heaven) in Pingcheng, completed just two months prior to the investiture ceremony. Immediately, in the following year (399), the emperor turned to carrying out sacrificial worship as his first order of business. As recorded in the Wei shu:

二年春正月甲子, 初祠上帝於南郊, 以始祖神元皇帝配, 降墰視燎, 成禮而 反。 159

\footnotetext{
${ }^{158}$ Wei shu, juan 2, p. 20.

${ }^{159}$ Wei shu, juan 2, p. 34.
} 
In spring of the second year [of the Tianxing reign], in the first month, on the day of jiazi, [the emperor] carried out sacrificial worship to Shangdi for the first time in the southern suburb, with Emperor Shenyuan [by the temple name] Shizu as a correlate. ${ }^{160}$ [The emperor] descended the altar to observe the burning fire, and returned [to the palace] when the ritual was completed. ${ }^{161}$

Several intriguing facts emerge from this simple entry. To start off with, the first imperial sacrificial worship of the newly proclaimed emperor of the Northern Wei was made to Shangdi 上帝 (or "Lord-on-High"), the supreme divine being that had emerged in the Shang 商 dynasty (c. 1700-1100 BCE). Though all ancestors of the Shang elite were known as $d i$ 帝 (or "Lord"), ${ }^{162}$ as the supreme $d i$, Shangdi was believed to be their first and primeval ancestor spirit, who was not to be directly consulted through divination or ritual. ${ }^{163}$ Since Shangdi was considered to be too distant to be worshipped directly by mortals, the souls of imperial ancestors ${ }^{164}$ were summoned by the Shang kings to act as intermediaries. This continued interaction between the living and the dead meant that the living remained protected by their ancestors, who continued to be cared for by the living through sacrificial offerings. ${ }^{165}$ It was this ancestral reverence that became, as Bodde

\footnotetext{
${ }^{160}$ Emperor Shenyuan, by the name Tuoba Liwei 拓跋力微, was recognized as the first leader of the Tuoba clan, from 219-277. He was posthumously honored as Emperor Shenyuan, with the temple name Shizu 始祖, which made him the ancestor of the Northern Wei dynasty.

${ }^{161}$ Author's trans.

${ }^{162}$ See Fowler and Fowler 2008, p. 21; also Keightley 2000, p. 123 for the notions of $d i$ and Shangdi. In the Shang dynasty, Shangdi was the overarching, all-powerful deity. As time went on, it was replaced by Tian 天 ("Heaven"), which demanded a moral righteousness in a ruler and good government, for the ruler would have been chosen and supported by it; Fowler and Fowler 2008, p. 30.

${ }^{163}$ Divination in the Shang was not just a matter of determining what the spirits wanted, but it was a way of telling the spirits what man wanted, and of seeking reassurance from the fact that the spirits had been informed; see Keightley 1984, p. 22.

${ }^{164}$ In the Shang hierarchy of the spirit world, below the Shangdi were the many ancestral spirits, in addition to natural deities, ghosts and even mythical monsters. Anything that went out of the ordinary in the natural order was seen as an omen that all was not well in the spirit world, and diviners could help to ascertain the wishes of the spirits and restore balance in daily events. However, only the ancestral spirits of the aristocracy could become divine or semi-divine beings worthy of worship; see Fowler and Fowler 2008, p. 21.

${ }^{165}$ Moreover, for the Shang people, ancestor worship was inextricably tied to the successful exercise of power, both spiritual and political. This undoubtedly was one of the reasons that participation in the worship was limited to members of the royal lineage, since it not only validated status, but also gave access to power; see Keightley 2004, p. 11.
} 
called it, "the most vital and sincere form of religious feeling" in early Chinese practice. ${ }^{166}$ By choosing the worship of Shangdi as the first sacrifice to be made on behalf of the Northern Wei dynasty, it is very likely that Emperor Daowu had intended to establish the Tuoba's ancestral landscape in the newly conquered realm. ${ }^{167}$

Since the spirit of ancestors served as intermediaries between the living and Shangdi, this particular sacrifice allowed the Tuoba to worship their own ancestors as correlates in the ritual for an efficacious outcome. In this manner, Emperor Daowu delicately, yet successfully, combined a dynastic ritual with ancestral worship. This urgency in rectifying the ancestral lineage is also reflected in the timely completion of the taimiao 太廟 (Grand Temple) later that year (399) in the tenth month, upon which, ancestral tablets of emperors Shenyuan 神元, Pingwen 平文, Zhaocheng 昭成, and Xianming 獻明 were moved into the temple. ${ }^{168}$ As new sovereigns in China proper, by placing their imperial ancestors as correlatives in the worship of Shangdi, the Tuoba ruling household could demonstrate itself as being in the position to communicate to Shangdi on behalf of its subjects. At the same time, the rituals reaffirm that these new sovereigns were descendants of a revered ancestral lineage, one worthy of being placed next to Shangdi in the sacrificial worship. As such, the immediate attention to ritual formalities clearly served the Tuoba's imperial interests, even if this urgency in establishing the taimiao and carrying out the worship of Shangdi appeared to place these new sovereigns in deference to Han Chinese dynastic rituals.

\footnotetext{
${ }^{166}$ Bodde 1942, p. 294.

${ }^{167}$ Here, I follow Schama's treatment of landscape as "constructs of the imagination projected onto wood and water and rock"; see Schama 1995, p. 61. In other words, landscape, as opposed to terrain or topography, is "a cultural and social construction, representing an artificial world as if it were simply given and inevitable"; see Mitchell 1994, p. 2.

168 These were the Tuoba rulers who came before Emperor Daowu, who were posthumously given the title of emperor upon the founding of the Northern Wei dynasty; see Wei shu, juan 2, p. 36.
} 
The location of the worship in the southern suburbs of Pingcheng is my second point of interest. Out of the four cardinal directions, based on existing archaeological findings, the sacrifice to Heaven in the southern suburbs can be considered as a core state ritual of native Chinese dynasties. ${ }^{169}$ This is what Kang Le referred to as the "Central Plains system" in his examination of the alternating orientation of Northern Wei state rituals. ${ }^{170}$ He advanced the notion that the southern suburbs of a dynastic capital, as a site of state ritual, had been practiced in the Central Plains for hundreds of years and was readily available to the Tuoba from the beginning of their state-building. However, a closer look at Emperor Daowu's accounts in the Wei shu reveals that after the initial sacrifice to Shangdi in 399, he never again returned to the southern suburbs of Pingcheng in the duration of his reign (398-409). In fact, he took turns rotating between the various other suburbs: to the north in the first month of the year 400 , to the east in the following month for the worship the sun, and finally in the western suburbs (fig. 11) in the fourth month of 405 .

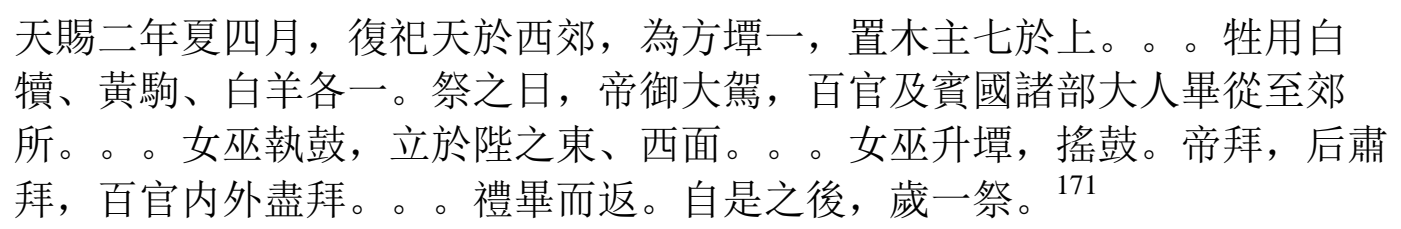
犢、黃駒、白羊各一。祭之日，帝御大駕，百官及賓國諸部大人畢從至郊 所。。。女巫執鼓, 立於陛之東、西面。。。女巫升墰, 搖鼓。帝拜, 后肅 拜, 百官内外盡拜。。。禮畢而返。自是之後，歲一祭。171

In summer of the second year of the Tianci reign (405), in the fourth month, [the emperor] again made sacrifice to Heaven in the western suburbs. A square altar was made, with seven wooden tablets bearing names of deities positioned on top of it ... One white calf, one yellow colt, ${ }^{172}$ and one white sheep were used as sacrificial animals. On the day of the sacrifice, the emperor commanded the imperial procession; the hundred ministers and chiefs of the various tribes and

\footnotetext{
${ }^{169}$ Based on archaeological records, the altar of the state of Lu in the Zhou dynasty was found to be situated south of the capital; see Shandong wenwu kaogu yanjiusuo 1982, pp. 15, 213. In the southern suburb of the Han Chang'an city, several large scale ritual sites have been found, which appear to have been where the Han emperors made their worship to Heaven; see Huang Zhanyue and Zhang Jianmin 1960; also Huang Zhanyue 1960.

${ }^{170}$ Kang Le 1995 , pp. 166-167.

${ }^{171}$ Wei shu, juan 2, pp. 36, 42.

${ }^{172}$ It is also important to note here that the use of horse as a sacrificial item never appeared in traditional Han Chinese rituals, and is a distinctive steppe feature that has been incorporated into the Northern Wei rituals.
} 
guest states all followed [him] to the suburbs ... Female shamans bearing drums stood by the steps, to the east and west [of the altar] ... The female shamans ascended the altar and rattled the drums. ${ }^{173}$ The emperor carried out his worship; the empress carried out the worship for women; the hundred ministers, inside and outside [of the gates], all carried out the worship ... They returned upon completing the ritual. From then on, this ritual [was carried out] once each year. ${ }^{174}$

This sacrificial ritual, facing west as the directionality for the worship of Heaven, is posited by Kang Le as one aspect of the opposing "north Asian steppe system" of state ritual. ${ }^{175}$ This system is said to have been made up of two alternating sacrifices, one in the spring and another in the autumn. ${ }^{176}$ These sacrifices have the following features: 1) a ritual site located west of the capital; 2) a square altar with seven wooden figures; 3) empress and consorts of the six palaces take part in the worship; 4) a female shaman plays the drum as part of the worship; 5) members of the imperial lineage serve as master of the ritual. ${ }^{177}$ If we are to accept the previously mentioned worship by Emperor Daowu in the western suburbs in the fourth month of 405 as the spring/summer sacrifice of the "north Asian steppe system”, then the “sacrifice at Baideng” by Emperor Mingyuan 明元帝 (Tuoba Si 拓跋嗣, r. 409-423), as referred to in the Wei shu, could be viewed as the autumn counterpart. This sacrifice was said to have been carried out west of the Baideng Mountain 白登山 (fig. 11), located in the northeastern suburbs, between the ninth and tenth months each year:

\footnotetext{
${ }^{173}$ Since the text determined that these drums were shaken, rather than beaten, by the shamans, they were most likely sistrums that could be held in one's hand.

${ }^{174}$ Author's trans.

${ }^{175}$ Kang Le 1995, pp. 167-169.

${ }^{176}$ The rituals of the north Asian steppes, particularly those of the Xiongnu, are examined by the Japanese scholar Egami Namio. He put forth the idea that it is usually made up of the spring and autumn sacrifices in an annual cycle; see Egami 1950, pp. 230-232.

177 The ritual sacrifices at the western suburbs, which Kang Le refers to as the "north Asia steppe system", is elaborated in the ritual treatise in the Wei shu; see Wei shu, juan 108, p. 2736. Although a Northern Wei ritual sacrifice, it had also been described in the dynastic history of the Southern Qi dynasty (479-502), in the section on the "Wei Captives"; see Nan Qi shu, juan 57, p. 985 on the Tuoba rituals to the west of the city.
} 
後二年, 於白登西, 太祖舊遊之處, 立昭成、獻明、太祖廟, 常以九月、十 月之交, 帝親祭, 牲用馬、牛、羊, 及親行貙劉之禮。別置天神等二十三於 廟左右，其神大者以馬，小者以羊。178

Two years later (414), west of Baideng [Mountain] where Taizu ${ }^{179}$ had previously visited, the temple for emperors Zhaocheng, Xianming, and Taizu was erected. Frequently between the ninth and tenth months, the emperor would personally attend the worship, using horse, cow and sheep as sacrifice, and would personally carryout the ritual of chuliu. ${ }^{180}$ Twenty-three other Heavenly deities were separately positioned to the left and right of the temple; the greater deities [to be worshipped] using horses as sacrifice, and the smaller deities with sheep. ${ }^{181}$

With the coexistence of these two systems of state rituals in the early Northern Wei, Kang Le advanced the notion that the Tuoba rulers adopted a practice of alternating between the two. That to an outsider it may appear to be an indiscriminate pastiche of dissonant practices, but in reality, only the "north Asian steppe system" was truly meaningful to the Tuoba. Whereas the Tuoba rulers personally attended most of the sacrifices made to Heaven conducted in the western suburbs and other rituals that derived from the "north Asian steppe system", they had a tendency to delegate proxies to carryout sacrificial rituals of the "Central Plains system". ${ }^{182}$ With this, Kang Le argued that deep down the Tuoba continued to value their own ritual practice, while using the "Central Plains system" as a symbolic marker for ruling over the Han Chinese subjects.

However, I would take a further step to suggest that the simultaneous existence of the two ritual systems in the Pingcheng period was a deliberate act by which the Tuoba again demonstrated their ability to maintain a "dual presence". In this case, it is manifested in the negotiation of ritual practices for the construction of an early Northern Wei notion of

\footnotetext{
${ }^{178}$ Wei shu, juan 108, pp. 2736-2737.

${ }^{179}$ Taizu 太祖 is the temple name of Emperor Daowu, as the founding emperor of the Northern Wei dynasty.

${ }^{180}$ The ritual of the chuliu is explained on the following page.

${ }^{181}$ Author's trans.

${ }^{182}$ Kang Le 1995, pp. 172-173.
} 
statehood. Most importantly, aspects of the "Central Plains system" should not be relegated as meaningless to the Tuoba. Taking Kang Le's argument one step further, I would even suggest that we should avoid treating the above mentioned ritual practices of the Pingcheng period as necessarily having belonged to two separate systems. What we see here is, in fact, a meshing together of different ritual traditions that appears to have been comfortably accepted in the Northern Wei society, and that the people living in Pingcheng, who participated in these state rituals, may not have necessarily felt the "discord" as we do today when we label these different rituals under separate categories.

If we look at the "sacrifice at Baideng", it mentions the ritual of chuliu which the emperor had personally attended. Chuliu is an ancient Chinese imperial practice during which the emperor would hunt on the day of liqiu 立秋 (the solar term marking the beginning of autumn) as part of the sacrificial ritual to the ancestral temple. In the Hou Han shu 後漢書 (Book of Later Han), it is said that:

立秋之日。。。使謁者以一特牲先祭先虞於壇, 有事, 天子入直射牲, 以祭 宗廟，名曰㽞劉。183

On the day of liqiu $^{184} \ldots$ the attendants [of the ritual] were made to use one type of animal as the initial sacrifice to [Emperor Shun of] Yu at the altar. When [it is indicated that the proper] condition has been attained, the emperor enters the enclosed grounds to hunt for sacrifices to worship the ancestral temple. This is called the ritual of chuliu. ${ }^{185}$

Here, in a ritual routine at the Baideng Mountain that had been determined by Kang Le as the autumn sacrifice of the "north Asian steppe system", ${ }^{186}$ we see the incorporation of an

\footnotetext{
${ }^{183}$ See Hou Han shu, zhi 8, p. 3182 for a description of the chuliu ritual.

${ }^{184}$ The first day of autumn marked in the ershisi jieqi 二十四節氣 (twenty four solar terms).

185 Author's trans.

${ }^{186}$ Kang Le 1995, p. 170.
} 
imperial ritual - the chuliu, which had long existed in China proper, as an essential element. At the same time, this "sacrifice at Baideng", although carried out in the northeastern suburbs of Pingcheng, remains faithful to the steppe directionality by erecting the ancestral temples to the west of the Baideng Mountain. Regardless of the terminology used to describe these events in our textual sources, my understanding is that, in practice, at the latest by the year 414 , there no longer existed separate systems of rituals. The Tuoba had managed to merge the various elements of their own interest together into a Northern Wei ritual system that furthered their own dynastic strategy. Incidentally, mountains also emerged from these sacrifices as an important site and the point of origin for carrying out imperial rituals in the Northern Wei. This point will be further demonstrated in the following chapter on the Yungang grottoes.

I believe that for the purpose of this thesis, the question of why the two ritual systems had been combined by the Tuoba in the "sacrifice at Baideng" is a moot point. Indeed, it could have simply been that both routines demanded the emperor's attention in the same season, and the reigning Northern Wei emperor, Emperor Mingyuan, conveniently combined the two so that he would be able to attend to both rituals in person. Also, the two sacrificial practices share an emphasis on ancestral veneration. The main event of the chuliu ritual required the emperor's sacrificial hunt to be made as worship at the ancestral temple. In conjunction, as accounted for in the Wei shu, the location for the "sacrifice at Baideng" was chosen based on Emperor Daowu's (father of Emperor Mingyuan) previous visit. Together, the two traditions embodied the Tuoba's dedication to constructing the ancestral landscape, both spiritually and geographically, as the emperors learned to use ritual practices as a bridge between kingship and kinship. 


\section{The Fiction of the mingtang}

If we now move from the more conceptual schemes of Northern Wei state rituals to the physical aspect of the Tuoba's interpretation of a ritual building, we are directed to a building complex that has been commonly referred to as the mingtang 明堂 (literally “Hall of Brightness") in the southern suburbs of Pingcheng. Descriptions of the mingtang are found in the Shuijing zhu:

明堂上圓下方, 四周十二堂九室, 而不為重隅也。室外柱内, 綺井之下, 施 機輪, 飾縹碧, 仰象天狀, 畫北道之宿焉, 蓋天也, 每月隨斗所建之辰, 轉 應天道, 此之異古也。加靈臺於其上, 下則引水為辟雍, 水側結石為塘, 事 准古制，是太和中之所經建也。187

The mingtang has a round top and a square bottom, with twelve halls on the four sides and nine chambers, and no overlapping corner [rooms]. Outside of the chambers but between the pillars, underneath the caisson ceiling, a rotating cogwheel mechanism is installed, decorated in [a shade of] light blue-turquoise. When looked up from below, it is as if the canopy of Heaven. Painted on it are the constellations of the north celestial pole, to represent the hemispherical dome. Each month, following the [twelve] chen, as determined by the handle of the Big Dipper, the [mechanism] moves in accordance to Heavenly ways. This deviates from the ancient [practice]. Fixing the lingtai above it, below [the mingtang] water is drawn to form the biyong. Next to the water, rocks are laid to form an embankment. The buildings are in accordance with ancient institutions, and had been built in the Taihe reign. ${ }^{188}$

The partial foundation of this building is one of the few remains of the Pingcheng city that has been discovered. ${ }^{189}$ (fig. 12) Based on the 2001 excavation report, the archaeological findings of a site, approximately two kilometers south of the city remains of the Ming 明 dynasty (1368-1644 CE) prefectural seat at Datong, Shanxi province, correspond to our existing knowledge of the Pingcheng mingtang, based on Li Daoyuan's descriptions. ${ }^{190}$

\footnotetext{
187 Shuijing zhu, juan 13, p. 207.

${ }^{188}$ Author's trans.

${ }^{189}$ For the archaeological report on the rammed earth foundation of the main building of the mingtang, the waterways and the stone-lined embankment, see Wang Yintian, Cao Chenming and Han Shengcun 2001.

${ }^{190}$ Wang Yintian, Cao Chenming and Han Shengcun 2001, pp. 26, 28-30.
} 
Located to the west of the Yu River, the rammed earth foundations revealed the entire site to be surrounded by a large circular waterway that ranged from 18 to 23 meters wide. (fig. 13) Being in such close proximity to the Yu River, water was undoubtedly drawn from the river into the waterway that encircled the site. Calculating from the inner embankment of the circular waterway, the diameter of the site is approximately 255 to 259 meters long. A rammed earth square platform is positioned at a 4-degree angle at the center of the site, of about 2 meters deep and a perimeter of 42 meters. At all four directions, a 凸 shaped rammed earth platform is positioned on the inner embankment, with the extra bit extended into the circular waterway, and all slanted at the same 4-degree angle. The report also reveals that on both sides of the waterway, sheets of regularly cut sandstone slabs were layered to create a three-leveled embankment, and fine stone pieces were wedged in between the crevices. ${ }^{191}$

This Pingcheng mingtang complex was ordered by Emperor Xiaowen 孝文帝 (Tuoba Hong 拓跋宏, later renamed Yuan Hong 元宏, r. 471-499) in the ninth month of the tenth year (486 CE) of the Taihe reign. ${ }^{192}$ The project lasted for five years, and it was not until the fifteenth year of the Taihe reign that the building complex was put into use. ${ }^{193}$ What confounds us most in Li Daoyuan's account is that, on one hand, he claimed that the mechanical wheel installation of the Pingcheng mingtang is different from the ancients, but then he concluded by reaffirming that the buildings were in accordance with ancient institutions. This phenomenon is much like many of the visual and material paradoxes characteristic of the early period of the Northern Wei that we will encounter in the following chapters, by which new meanings were endowed upon existing traditions and

\footnotetext{
${ }^{191}$ Wang Yintian, Cao Chenming and Han Shengcun 2001, p. 30.

${ }_{192}$ Wei shu, juan 7, p. 161.

${ }^{193}$ Wei shu, juan 7, p. 168.
} 
forms. Rather than critiquing the intriguing aspects of the Pingcheng mingtang as departures from ritual conventions, ${ }^{194}$ I prefer to read the paradox as simply another manifestation of the "dual presence" that featured in the Northern Wei Pingcheng period, and that the notion of a Pingcheng mingtang, as a marker of institutional continuity, was more of a fiction than a reality.

Owing to the widespread belief that the mingtang, as a ritual building, had been constructed by the legendary sovereigns of prehistoric times as well as by the Shang and Zhou emperors, its origin, architectural form, and functionality have been the subject of endless debates. ${ }^{195}$ This ambiguity is mostly the result of the survival of only very few existing records of pre-Qin 秦 mingtang structures. Moreover, the partial information on the mingtang in early classical literature, such as the Kaogong ji 考工記 (Records of the Examination of Craftsman) of the Zhouli 周禮 (Rites of Zhou) and juan 14 of the Li ji 禮記 (Record of Rituals), is at best sporadic and contradictory. ${ }^{196}$ However, what we do know is that as sites of imperial ceremony, the mingtang was usually accompanied by two other structural components, the biyong 辟雍 (literally “jade-disc pond”) and the lingtai 靈臺 (literally "platform for the observation of the Heavens"). Nancy Steinhardt suggested that initially the mingtang was the primary site of imperial sacrifices, but in time it came to share the space and functions of the other two structures. ${ }^{197}$ The biyong is referred to in most classical Chinese texts together with the mingtang as a building surrounded by a

\footnotetext{
${ }^{194}$ Xiong 2003, p. 72.

${ }^{195}$ For a more thorough and comprehensive study on the origins of mingtang in Chinese, see Wang Guowei 1940, juan 3, pp. 1-12. He explored the origins of the mingtang design from the three ancient prototypes, namely the palace structure (gongshi 宮室), ancestral temple (zongmiao 宗廟), and the court of repose (yanqin 燕寢). For studies in English, see Soothill 1951; Wu Hung 1996, pp. 176-187; also Wechsler 1985, pp. 195-211.

${ }^{196}$ See Kaogongji; also Legge 1967 for an English translation of the Li ji.

197 Steinhardt 1990, pp. 15-16.
} 
circular moat, ${ }^{198}$ where it was likely that the education of candidates for imperial services took place. ${ }^{199}$ Lastly, it was at the lingtai that the emperor would ascend for the ceremonial regulation of the calendar, synchronizing the events of Heaven and earth. ${ }^{200}$

In the context of a conquest dynasty like that of the Northern Wei, the existence of the mingtang complex has, for the most part, been treated as a marker of the linear progression of Chinese dynastic traditions, emphasizing the inheritance of a lineage, even in ritual practices. ${ }^{201}$ For this reason, the anomalies found in the Pingcheng mingtang complex have been explained away as unconventional and unprecedented by Victor Xiong, and that the intriguing three-in-one complex was, in fact, still in accordance with the reconstruction of Han Chang'an ritual spaces that housed the mingtang, biyong, and lingtai under one roof according to Steinhardt. ${ }^{202}$ However, I will argue that these rare features of the Pingcheng mingtang should never have been treated as anomalies in the first place. The name was only borrowed as a pretext for the Tuoba rulers to erect what really was intended to be a new type of ritual institution, particular to the Northern Wei, in the southern suburbs of Pingcheng. Rather than trying to fit this unusual structure into a linear progression of the mingtang as a ritual institution by reducing it to what Xiong had advanced as a "synthesist

\footnotetext{
${ }^{198}$ In Han times, two related but somewhat different views can be said to have existed on the biyong. The first view, recorded in the Baihu tong 白虎通 (The Comprehensive Discussions in the White Tiger Pavilion) by Ban Gu (32-92 CE), commissioned by Emperor Zhang as a compilation of court intellectual debates from the last century of the Eastern Han, maintains that it was a circular moat all by itself: "Biyong is like a bijade disk in order to bring order to the Heaven; it is filled up with water to symbolize the flow of civilization"; see Taiping yulan, juan 534, p. 2422b. The second view takes after the Hou Han shu 後漢書 compiled by Fan Ye in the mid-fifth century, in which the Eastern Han Emperor Mingdi was said to have "visited the biyong for a gathering and ordered for his ministers to compose poetry"; see Taiping yulan, juan 534, p. 2422a. In this case, biyong appears to have been understood as a building where the emperor could visit and gather with his ministers.

${ }^{199}$ In the $L i j i$, it is said that: "The Great Academy in the suburbs. For the Son of Heaven, it is called the biyong, and for the feudal lords it is called the pangong 泮宫.” See Taiping yulan, juan 534, p. 2422a.

${ }^{200}$ It is recorded in the Hou Han shu that when the Eastern Han Emperor Mingdi took the throne, he made suburban sacrifices to the five emperors at the mingtang and ascended the lingtai to "gaze (wang 望) at the cloud forms"; see Taiping yulan, juan 534, p. 2423a.

${ }^{201}$ Han Shengcun 2005, p. 34.

${ }^{202}$ Xiong 2003, p. 72; also Steinhardt 1990, pp. 15-16.
} 
model", ${ }^{203}$ I believe that we should interpret this architectural compound based on its actual functions rather than on its name.

A main feature of the Pingcheng mingtang was definitely the cogwheel mechanism that undoubtedly functioned as an astrological device. ${ }^{204}$ In fact, the entire architectural structure could be explained as based on contemporary astrological and geographical symbolism. To begin with, the building has a square foundation and a circular top. This specific shape certainly served the purpose of creating a hemispherical dome, colored in a shade of light blue-turquoise to represent the canopy of Heaven, and against which the constellations of the north celestial pole were painted. The cogwheel mechanism installed underneath the caisson ceiling was designed to rotate at a rate determined by the handle of the Big Dipper as it crossed between the twelve divisions designated by the twelve chen 辰 (celestial stations). ${ }^{205}$ The twelve divisions, in turn, correspond to the twelve halls of the main building, three on each of the four sides, with no overlapping corner rooms. (fig. 14) As such, the various architectural aspects of the building were transformed into a physical embodiment of the northern hemispherical dome.

One can of course use the traditional philosophical notion of “tian yuan di fang” 天圓地方 (round Heaven and square earth) to understand this design, as most Chinese scholars have

\footnotetext{
${ }^{203}$ Xiong 2003, p. 69.

${ }^{204}$ It is said that emperors of the Northern Wei had a keen interest in astrological studies, in their broad selection of officials in charge, the collection of data, as well as the invention and modification of observatory instruments. Some scholars have suggested that the study of the Pingcheng mingtang should be placed within the historical context of Northern Wei astrology, that the features of this particular mingtang had appeared against this background; see Li Hai, Hou Junmei and Zhang Lanying 1996, p. 35.

${ }^{205}$ In ancient Chinese astrology, the zhoutian 周天 is a great circle on the imaginary celestial sphere, in the same plan as the Earth's equator. The zhoutian is said to have been divided along the celestial equator into

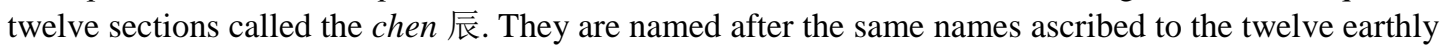
branches.
} 
gladly accepted as an indication of the mingtang's adherence to ancient institutions. ${ }^{206}$ However, I would like to direct our attention to the caisson ceiling under which the rotating cogwheel mechanism was installed. In his examination on the many forms and combinations associated with the "Dome of Heaven" $" 207$ concept in Western architecture that penetrated eastward beyond the limits of Roman authority, Alexander Soper saw the combination of beamed squares and diamond shapes - the Laternendecke, in China as the result of the Hellenistic conquests that had facilitated the process of its transmission into Asia. ${ }^{208}$ From northwestern India, particularly Gandhara and eastern Afghanistan, where a wealth of sculptural remains in stone and stucco bear close ties to the Greco-Roman traditions, it was in the decoration of ceilings in Buddhist cave temples (fig. 15a) that this particular architectural technique was introduced into northern China. ${ }^{209}$

This willingness, on the part of the Chinese, to take over entire ceiling compositions from a foreign source had reached its height around the end of the fifth century, gaining maturity in the cave temples of Dunhuang and Yungang, to the extent of being represented in painted imitations. (fig. 15b) Since the caisson ceiling of the Pingcheng mingtang emerged from this particular moment in history, I find it appropriate to bear in mind that these visual "oddities" could very well have been the Northern Wei appropriation of

\footnotetext{
${ }^{206}$ Li Hai, Hou Junmei and Zhang Lanying 1996, p. 36; also Xiong 2003, p. 71.

${ }^{207}$ The "Dome of Heaven" is one of the fundamental artistic expressions of Christian thought depicted in painting or mosaic on domes, apsidal half-domes, and other variants of vaulted forms; see Lehmann 1945, p. 1. By the time this ceiling decorative technique had reached northwestern India via the Hellenistic conquests, two standard practices had become the norm in Asia architecture, most likely originated with Gandharan predecessors. One was the stone dome with a lotus carved at its apex, and the other was the combination of beamed squares and diamond shapes, also known as the caisson or coffered ceiling; see Soper 1947, p. 228. ${ }^{208}$ Alexander Soper finds two fortunate circumstances in architecture that had encouraged the transmission and survival of Western forms in Asia. Cave worship that dominated sites from Afghanistan all the way through Turkestan into China, owing to Buddhist practice, made it possible to excavate dome and barrel vault forms out of stone. Secondly, in India, where the ancient building material was wood, possibly also due to practices of Buddhist worship, an honorific religious architecture of stone had also developed; see Soper 1947, p. 226.

${ }^{209}$ Soper 1947, pp. 233-237.
} 
material stimuli that came from outside of China proper. Moreover, this tangential discussion on the caisson ceiling serves as a reminder that cultural and material traditions should not be simply viewed in a linear progression. It was exactly the ability of the Tuoba to pull together concepts and forms from a variety of sources that made the Northern Wei such a culturally vibrant period.

In effect, this architectural scheme was intended to represent both the spatial and temporal dimensions of the realm ruled over by the Tuoba sovereigns, as they reconstructed the astrological and geographical world as they knew it in the Northern Wei. ${ }^{210}$ Spatially, it was believed that the ershiba xingxiu二十八星宿 (Twenty-eight Mansions) lodged in the twelve celestial stations governed their corresponding terrestrial divisions on earth that constituted the emperor's realm. Further still, the nine chambers at the center of the building can be said to have formed the notion of jiuzhou 九州 (Nine Provinces), an ancient territorial division referred to in the earlier dynasties as a symbolic representation of the Chinese realm, which was later applied concretely in the Warring States period as an administrative concept. Temporally, the twelve halls also represented the twelve months of a year, again marked by the twelve celestial stations. The sovereign was required, in fulfilling his administrative duties, to move from hall to hall as the year progressed from one month to the next. As the sovereign circumambulated around the structure, the temporal and geographical conceptual schemes combined to place him at the center of the Northern Wei state. In effect, the Tuoba used the caisson ceiling to apply a Western notion

${ }^{210}$ Xiong 2003, pp. 71, 73. 
of the dome of Heaven that worked together with the Chinese territorial concepts to create a representation of the Northern Wei realm that crossed between the two traditions. ${ }^{211}$

We are being told, at least through the eyes of Li Daoyuan, that this ritual complex in the southern suburbs of Pingcheng was built in accordance with ancient standards simply because the three major components were given the names of mingtang, lingtai, and biyong. Unfortunately, since we only have archaeological remains of the rammed earth foundations, the actual form and design of the lingtai cannot be determined, but the main building of the mingtang would have certainly been positioned above the central rammed earth platform, with the circular waterway serving as the biyong. However, upon his examination of the buildings in their entirety, even Li Daoyuan had to admit that the function of this structure "deviated from ancient practices". As such, we are clearly looking at a Northern Wei imperial site that attempted to maintain a sense of continuity with previous Chinese dynastic practices by perpetuating what I would call the fiction of the mingtang. The Tuoba sovereigns were well aware of the rules of the game involved in creating a façade of legitimate dynastic appearance. Ultimately, as demonstrated in our current studies of Pingcheng, how the Tuoba made use of the site, either for scholarly, ritual or astrological purposes, was never an issue in the view of the Northern Wei kingship, as long as the setup allowed for the fiction of the mingtang to be reinvigorated. In fact, this very ambiguity that confounded Li Daoyuan in understanding the form and design of the Pingcheng mingtang could be treated as another manifestation of the Tuoba's “dual presence".

\footnotetext{
${ }^{211}$ Soper also advanced the notion that although reconstructions of the mingtang claimed to have been based on descriptions from classical texts, they actually resulted in representations of the "Dome of Heaven", reminding one of the Buddhist Mandala scheme, reproduced in the even distributions of the halls and chambers in the design of the mingtang; see Soper 1947, pp. 238-241.
} 


\section{A MOBILE COURT}

Later in chapter four, using visual representations provided by tomb murals and clay figurines, I will be establishing that the Northern Wei elite in Pingcheng were familiar with a mobile lifestyle in which camp sites and tents were intrinsic to their everyday activities. However, an immediate question that comes to mind, and one that would be useful in setting up a context, is how we are to understand Pingcheng itself as a capital city? Further still, how are we to interpret the nature of the Northern Wei court in the Pingcheng period? The purpose of this inquiry is to move away from accepting, as a given fact, that the notion of a capital city suggested a sense of permanence and immutability of the imperial court. I will explore how a breakdown of the amounts of time the Northern Wei emperors spent in Pingcheng, as well as the different occasions that brought them away from the city, gives us an insight into the Tuoba's conceptions of a dynastic capital, one that would appear to be very different from our usual assumptions.

I have chosen to use the term "progress" to describe the movement of the Tuoba rulers. Such movement was dictated by specific circumstances, with an added element of imperial display. In practice, the Northern Wei emperors of the fourth and fifth centuries were very energetic, constantly roaming about the expanses of their realm, much like the Norman and Angevin kings of medieval England and parts of France who spent their lives incessantly travelling from one part of their dominions to another. ${ }^{212}$ As such, the Tuoba appear to prefer maintaining a mobile court, as they shuttled between Pingcheng and other outlying areas. Even after becoming imperial masters of China, we can say that the sedentary lifestyle was shunned as their nomadic way of life died hard, and one of its traditions survived in the way the Tuoba rulers chose to move with their courts to enjoy favorable

${ }^{212}$ Steane 1999, p. 71. 
climates and pleasant places. Incidentally, though no scholar has yet remarked on this particular feature of early Northern Wei rule, the progresses undertaken by the Tuoba contained the same agency as the more thoroughly studied European royal progresses epitomized by the Tudor monarchs (particularly Henry VIII and Elizabeth I) and the French Renaissance court in the sixteenth century. ${ }^{213}$ What these sovereigns shared with one another is the ability to create effective discourses through the ceremonial mobility that worked to advance their respective imperial goals.

In the case of the Tuoba, I will further look at how the displays of power through mobility were not limited to the ceremonial progresses of the emperor himself, but also demonstrated through the strategic centralization of their subjects around the capital. Certainly, the Tuoba's practice of mass population relocation upon their conquests of new territories can be said to reflect the "raid and take" practices of the nomadic lifestyle. However, my focus will be on those particular relocations that intentionally concentrated the conquered subjects in the proximity of the capital. As we shall see, these people contributed greatly to the notion of Pingcheng as the conceptual and physical seat of power in the Northern Wei. The picture that I hope to present is one that would allow us to recognize the mobile rhythms of an imperial court behind the façade of a permanent seat of power that appears to be an imitation of a Chinese-styled capital city. It was exactly the Tuoba's familiarity and comfort with this mobility, both of themselves and of their subjects, which allowed them to use the movement of people to create diverse expressions of imperial agencies that facilitated the strengthening of the Tuoba kingship.

\footnotetext{
${ }^{213}$ For more extensive studies on the progresses of the European monarchs, see Samman 1995 for the progresses of Henry VIII; Cole 1999 on the various aspects of the reign of Elizabeth I as a portable queen; also Knecht 2008, pp. 40-47 on the mobility of the French Renaissance court.
} 
Being the first of the conquest dynasties to emerge in the Chinese arena, the Northern Wei had setup an imperial lifestyle that would be adopted and repeated by the later emperors of the Khitan Liao 遼 (907-1125 CE), Jurchen Jin 金 (1115-1234 CE), Mongol Yuan 元 (1271-1368 CE), and Manchu Qing 清 (1644-1912 CE) dynasties. ${ }^{214}$ In fact, as will be explained in an examination of the movements of the first (Tuoba Gui 拓跋珪) and last (Tuoba Hong 拓跋宏) Northern Wei emperors of the Pingcheng period, these sovereigns retained an active rhythm of imperial life, though framed by different pretexts that suited the changing times. In the early days, many of the Tuoba's progresses were incorporated into hunting excursions and military expeditions. Whereas later on, as the Tuoba's rule of the Northern Wei grew more established and less volatile, these events came to include the management of state affairs along the way. The aim of this section is to look at how the progresses of the Tuoba could be treated as ways in which the emperors used their nomadic background to carry out a new method of rulership. In this manner, imperial power was asserted through the mobility of the emperor and his ability to strategically deploy his subjects in order to fulfill the interest of the state. ${ }^{215}$ This peripatetic feature of the Northern Wei court gave the emperor new channels to interact with his subjects that would not have been possible if he were to remain immobilized at Pingcheng.

\section{The Emperors' Peripatetic Agenda}

Upon proclaiming himself emperor of the Northern Wei in the twelfth month of 398, Emperor Daowu spent the years from 399 to his demise in 409 ruling the realm from

\footnotetext{
${ }^{214}$ Symons 2004, p. 56.

${ }^{215}$ In a way, this is not unlike the sixteenth century court of France, in which the court continued to function when "on progress", and was considered to be wherever the emperor happened to be. As the French kingdom grew larger and more peaceful, the court travelled more extensively, but its mobility varied, and each monarch had his own itinerary; see Knecht 2008, p. 40.
} 
Pingcheng as his seat of power. Although the previous discussions on ritual practices and institutions might have given the impression that the Tuoba were, in a sense, refurbishing their new home out of a growing fondness for their residence at Pingcheng, their actual movements in and out of the city in the turn of a year might just show another side of their relationship to this city.

The following chart is taken from accounts in the "Chronicles of Taizu" of the Wei shu $u^{216}$ that offer us the details of Emperor Daowu's whereabouts in the eleven years of his reign. In chronological order, I have gleaned information on every recorded instance in which the emperor travelled out of Pingcheng, as well as the purpose and destination of each trip. The right hand column contains substantiated or assumed reasons for which the emperor had stayed/returned to Pingcheng. Substantiated reasons are those directly provided within the context of the Wei shu, whereas those marked by [ ] are the events that I have determined, based on my own judgment, to be relevant to the emperor's movements in and out of the capital.

The emphasis here is on my choice of separating the two notions of "staying in" and "returning to" Pingcheng. Although the author of the Wei shu chose to use the phrase chejia huangong 車駕還宮 (“the emperor returns to the palace”) to indicate the emperor's return to Pingcheng after each trip, I find the term "return" to be rather subjective in presenting a preconceived mindset that the Tuoba considered Pingcheng as a "home" to return to. Rather, at certain points in Emperor Daowu's calendar, as in the year 406, it would appear that the emperor had only sojourned in Pingcheng to fulfill certain perfunctory duties before rushing back to the detached palace at the Chai Mountain 豹山

${ }^{216}$ Wei shu, juan 2, pp. 19-45. 
(Chaishan palace 㥪山宮 from hereon). In effect, the findings show us that the first Northern Wei emperor, in actuality, did not spend as much time in Pingcheng as we might have expected, especially when viewed in context of fervent construction of a capital city in 398 as we have discussed in the previous section. From the following chart, we can see that the northern and northwestern regions were most frequently visited by Emperor Daowu, which would serve as a good indication of the emperor's concerns in the context of contemporary political situation, in the formative period of Northern Wei state-building.

\begin{tabular}{|c|c|c|}
\hline Date & Travel Destination and Purpose & $\begin{array}{l}\text { Reasons for } \\
\text { Staying/Returning to } \\
\text { Pingcheng }\end{array}$ \\
\hline \multirow[t]{2}{*}{ First month, $399 \mathrm{CE}$} & & $\begin{array}{l}\text { [On the first day of the first } \\
\text { month, carried out the } \\
\text { Shangdi 上帝 ritual } \\
\text { sacrifice in the southern } \\
\text { suburbs] }\end{array}$ \\
\hline & $\begin{array}{l}\text { Traveled northwest to the Gobi } \\
\text { desert for an inspection tour of the } \\
\text { battle against the tribes of the } \\
\text { Gaoche 高車 }\end{array}$ & \\
\hline \multirow[t]{2}{*}{ Third month } & $\begin{array}{l}\text { Returned from the northern } \\
\text { frontline }\end{array}$ & \\
\hline & $\begin{array}{l}\text { Traveled northeast to the luyuan 鹿 } \\
\text { 苑 (Deer Park) to conduct a } \\
\text { military parade }\end{array}$ & \\
\hline Tenth month & & $\begin{array}{l}\text { [The taimiao 太廟 (Grand } \\
\text { Temple) was completed and } \\
\text { the ancestral tablets were in } \\
\text { place] }\end{array}$ \\
\hline \multirow[t]{2}{*}{ Fourth month, $400 \mathrm{CE}$} & $\begin{array}{l}\text { Inspection tour east to Zhuolu 溷鹿 } \\
\text { (present-day Hebei province), and } \\
\text { dispatched delegates to carry out } \\
\text { the tailao 太牢 }{ }^{217} \text { sacrifice to the } \\
\text { temples of Yao and Shun }\end{array}$ & \\
\hline & $\begin{array}{l}\text { Traveled west to Mayi 馬邑 } \\
\text { (present-day Shuozhou, Shanxi } \\
\text { province) to view the source of the }\end{array}$ & \\
\hline
\end{tabular}

${ }^{217}$ Sacrifices made to the Heaven and the Earth using cattle, sheep and swine. 


\begin{tabular}{|c|c|c|}
\hline & Lei River 灅水 & \\
\hline Seventh month & Returned to the palace & $\begin{array}{l}\text { [Began building and } \\
\text { refurbishing the Zhongtian } \\
\text { dian 中天殿 (Hall of the } \\
\text { Center of Heaven), Yunmu } \\
\text { tang 雲母堂 (Hall of the } \\
\text { Mother of Clouds) and } \\
\text { Jinhua shi 金華室 } \\
\text { (Chamber of the Golden } \\
\text { Flowers)] }\end{array}$ \\
\hline Third month, $401 \mathrm{CE}$ & $\begin{array}{l}\text { Went fishing, to present the fish as } \\
\text { sacrifice at the ancestral temple }\end{array}$ & \\
\hline $\begin{array}{l}\text { Seventh to eighth month, } \\
402 \mathrm{CE}\end{array}$ & $\begin{array}{l}\text { Traveled west to Chaibi 柴壁 } \\
\text { (present-day Xiangfen, Shanxi } \\
\text { province) to conquer the Later Qin }\end{array}$ & \\
\hline Tenth month & Returned victorious from battle & \\
\hline Eleventh month & $\begin{array}{l}\text { Stopped to rest en route at Jinyang } \\
\text { 晉陽 (present-day Taiyuan, Shanxi } \\
\text { province) }\end{array}$ & \\
\hline Twelfth month & Returned from the western frontline & \\
\hline Seventh month, $403 \mathrm{CE}$ & $\begin{array}{l}\text { Traveled north for an inspection } \\
\text { tour, to build a detached palace at } \\
\text { Chai Mountain 豹山, and sent } \\
\text { troops out on hunting expeditions }\end{array}$ & \\
\hline \multirow[t]{2}{*}{ Ninth month } & $\begin{array}{l}\text { Advanced to Nanping 南平 to plan } \\
\text { for a new city to be built south of } \\
\text { the Lei River }\end{array}$ & \\
\hline & Returned to the palace & \\
\hline Tenth month & & $\begin{array}{l}\text { [Began building the } \\
\text { Xizhaoyang dian 西昭陽殿 } \\
\text { (Western Hall of the Bright } \\
\text { Sun)] }\end{array}$ \\
\hline Eleventh month, $404 \mathrm{CE}$ & Traveled to the Chaishan palace & \\
\hline Second month, $405 \mathrm{CE}$ & Returned to the palace & \\
\hline Fourth month & & $\begin{array}{l}\text { [Sacrificial ritual in the } \\
\text { western suburbs] }\end{array}$ \\
\hline First month, $406 \mathrm{CE}$ & $\begin{array}{l}\text { Traveled north to the Chaishan } \\
\text { palace for an inspection tour }\end{array}$ & \\
\hline Second month & $\begin{array}{l}\text { Traveled to Daiyuan Mountain 代 } \\
\text { 園山 to build the Five Stone } \\
\text { Pavilion }\end{array}$ & \\
\hline Third month & Returned to the palace & \\
\hline \multirow[t]{2}{*}{ Fourth month } & $\begin{array}{l}\text { Again traveled to the Chaishan } \\
\text { palace }\end{array}$ & \\
\hline & Returned to the palace. & $\begin{array}{l}\text { Rouran incurrence on the } \\
\text { borders }\end{array}$ \\
\hline Eighth month & Back to the Chaishan palace & \\
\hline
\end{tabular}




\begin{tabular}{|c|c|c|}
\hline Ninth month & $\begin{array}{l}\text { Traveled to the south of the Gobi } \\
\text { desert to view the salt lakes }\end{array}$ & \\
\hline Tenth month & Returned to the palace & \\
\hline Fifth month, $407 \mathrm{CE}$ & $\begin{array}{l}\text { Traveled north for an inspection } \\
\text { tour, from Canhepo 參合陂 } \\
\text { (present-day Yanggao, Shanxi } \\
\text { province) via several stops to } \\
\text { Ruyuan 濡源 (source of the Luan } \\
\text { River 灤河, which used to be called } \\
\text { the Ru River 濡水, in present-day } \\
\text { Hebei province) }\end{array}$ & \\
\hline \multirow[t]{2}{*}{ Seventh month } & $\begin{array}{l}\text { Traveled from Ruyuan back west to } \\
\text { Canhepo to build the outer walls of } \\
\text { the North Palace }\end{array}$ & \\
\hline & Returned to the palace & \\
\hline Eighth month & Traveled to the Chaishan palace & \\
\hline Eleventh month & Returned to the palace & \\
\hline \multirow[t]{2}{*}{ First month, $408 \mathrm{CE}$} & Traveled to the Chaishan palace & \\
\hline & $\begin{array}{l}\text { Advanced to Canhepo to watch the } \\
\text { fishing activities at the Yuyan } \\
\text { River 于延水 }\end{array}$ & \\
\hline Tenth month, $409 \mathrm{CE}$ & & $\begin{array}{l}\text { Emperor Daowu died of } \\
\text { illness in the Tian'an dian } \\
\text { 天安殿 (Hall of Heavenly } \\
\text { Peace) }\end{array}$ \\
\hline
\end{tabular}

Several interesting phenomena appear from these accounts of Emperor Daowu's travels. First of all, the emperor remained very much involved in the military affairs of the Northern Wei troops. Whereas Elizabeth I crafted for herself the military role of protector of England, which her gender had deprived of her on the battlefield, through the military pageants that characterized the queen's progresses, ${ }^{218}$ the first emperor of the Northern Wei similarly asserted his military strength as well as his own responsibility for preserving the Tuoba kingship. On the northern and western frontlines, he had personally taken part in the conquests against the tribes of the Gaoche 高車 in 399 and the state of the Later Qin 後

\footnotetext{
${ }^{218}$ On her visits to fortified towns and harbors, Elizabeth would inspect the outposts of national defense. Her peacetime progresses included martial ceremonies with ritual displays of force, whereas in times of war, Elizabeth retreated to the greater security of the London area to oversee defenses and plot strategy; see Cole 1999, p. 155.
} 
秦 in 402. Even when not engaging in battle, Emperor Daowu seemed to have taken the training of his soldiers into his own hands, making sure that his troops were ready and alert. Upon returning from his inspection tour of the battle against the Gaoche in the third month of 399 , the emperor immediately traveled to the newly established Deer Park to the northeast of Pingcheng to further conduct an examination of his troops.

Following the conquest of the Later Qin at the end of the year in 402, after having spent half a year away on the western frontline, Emperor Daowu rested in Pingcheng for another half a year before taking off again up north to the Chai Mountain in the seventh month of 403. ${ }^{219}$ There, the construction of a detached palace was set in motion and the troops were kept in shape as the emperor dispatched them on hunting excursions. The Chaishan Palace is seen to have carried out multiple imperial functions. As a strategic outpost, it served as the military resting point for the Northern Wei emperors as they traveled to the frontline to oversee the battles against the Rouran 柔然 tribes, in their desire to maintain control of the steppe region north of the Gobi desert. ${ }^{220}$ Alternatively, it was also an establishment for

\footnotetext{
${ }^{219}$ The precise location of the Chaishan palace is yet undetermined, but based on tracing the routes of the Northern Wei emperors, scholars have come up with three locations. Maeda Masana, in his historicalgeographical study of Pingcheng, placed the Chaishan palace to the northwest of the capital city, in the Shanwu 善無 county; see Maeda 1994, pp. 136, 146. This view is further corroborated by Zhang Jihao who also put the detached palace to the northwest of Pingcheng, but in the mountainous region between the capital and Shanwu county; see Zhang Jihao 2003, pp. 41-66. The second hypothesis, advanced by Li Gaocai, Yin Xian and Gao Ping, placed the Chaishan palace to the northeast of Pingcheng, within the surrounding suburbs of the capital city, situated in the Langtou Mountain 狠頭山 in present-day Neimenggu province; see Li Gaocai, Yin Xian and Gao Ping 1990, p. 115. Finally, the third possibility was raised by Ma Changshou whose view was furthest from those of other scholars. He believed that the Chaishan Mountain of the Northern Wei was most likely what was later called the Zongcaishan Mountain 總材山 of the Tang dynasty, which is located in the western parts of present-day Neimenggu province, the furthest hypothetical location of the three suggestions; see Ma Changshou 1962, p. 253.

${ }^{220}$ It was in this region that includes present-day Mongolia and the Lake Baikal, stretching as far west as the Altai Mountains, that the Tuoba was in constant warfare against the Rouran, as well as trying to maintain a hold on the various tribes of the Xianbei confederation; see Lin Shiwei 2009, pp. 3-4, 13. The Rouran confederation became active at the turn of the fourth century, having remained on the Mongolian steppes after most other Xianbei groups migrated south to northern China to set up the various nomadic states such as the successive Yan states and the Northern Wei. Toward the end of the century, they were divided into eastern and western branches under the rule of two brothers, P'i-hou-pa and Yün-he-t'i respectively. In 391, it was the first time that they first fell victim to an attack by Emperor Daowu, in which half of the Rouran
} 
imperial leisure, especially when the emperors would stop over for hunting excursions as a part of their favorite past time. Here, at the Chaishan palace, the juxtaposition of imperial progresses, the hunts, and warfare reminds us of the not so dissimilar nature of these three types of imperial events. In fact, on the mobility of the French Renaissance court, Robert Knecht discusses the logistics involved in this process, claiming that moving the court was just like moving an army. ${ }^{221}$

These large scale royal hunts involving thousands, or even tens of thousands, of participants, invested this form of hunting with political meaning through sheer magnitude. ${ }^{222}$ As early as the third century CE, the Tuoba chieftain at the time was said to have "[led] several thousand horsemen out into the hills and marshes to hunt". ${ }^{223}$ In later centuries, the Khitan and the Jurchen all mobilized comparable numbers, but in the context of a respectable royal hunt in the Eurasian tradition, this figure is actually at the lower end. ${ }^{224}$ Hunting was viewed as the perfect antidote to idleness, since a person's senses were kept in tune by studying the ways of the animals and outwitting them. It enabled the soldiers to maintain the alertness and physical skills that would be required in battle, which was why Francis I was willing to subordinate politics to hunting and to allow it to dictate the movements of the French Renaissance court. ${ }^{225}$ Across the English Channel, his contemporary, Henry VIII organized his progresses around the hunt, and it was through this medium that the king was entertained by, and engaged with, prominent men in his

confederacy were reportedly captured by the Tuoba. What followed was a sequence of campaigns between the two groups, in 438, 439, 443 and 444, which ultimately ended in 449 when Emperor Taiwu personally mounted an invasion that severely defeated the Rouran and forced them to retreat from the frontier; see Barfield 1989, pp. 120-124.

${ }^{221}$ Knecht 2008, pp. 43-44.

222 The sheer magnitude of any organizational effort would convey additional political meaning through the original event itself, whether in building projects, or in the production of ceremonies, celebrations, or entertainments; see Allsen 2006, p. 8

${ }^{223}$ Wei shu, juan 1, p. 2. English translation is taken from Holmgren 1989, p. 53.

${ }^{224}$ Allsen 2006, p. 31; also Wittfogel and Feng 1949, p. 129.

${ }^{225}$ Knecht 2008, p. 80-81. 
realm. Although the actions of Henry VIII may be perceived as his preference of the pleasures of the chase, more importantly, the king's prowess actually fulfilled an important political role. Neil Samman refers to the "ritual of the hunt" as the sovereign's own way of communicating with his subjects as it allowed a wider group of people to take part in the imperial activities, and the distribution of the game from the hunts was an honorable reward that served an important role in the patronage system. ${ }^{226}$ In times of peace, the emperor and his court found plenty of time to exercise in the open air, as the progresses and hunting routines provided them with excitement akin to war.

Finally, there seems to be a pattern to the emperor's travels, starting with the year 403, one that correlates with the changing seasons throughout a year. With the completion of the Chaishan palace, the emperor began spending most of his summer months away from Pingcheng. Emperor Daowu would be seen returning to the capital just before the winter months, and to remain there until the state rituals had been carried out at the beginning of the following year. We might understand the Chaishan palace on the same terms as the Bishu shanzhuang 避暑山莊 (Mountain Villa for Avoiding the Heat) in Chengde 承德 was to the Manchus of the Qing dynasty, built between 1703 and 1792. Chengde's importance as a rural alternative from the Forbidden City in the Qing was derived from its favorable climatic conditions for the Manchus. The climate of Chengde was, and still is, slightly cooler in the summer than Beijing, ${ }^{227}$ and the man-made lakes and wooded hills of the villa would have generated a cooling effect as a summer residence, ${ }^{228}$ making the environs more comfortable than the constraints of the walls of the Forbidden City. The

\footnotetext{
${ }^{226}$ Samman 1995, pp. 64-65.

${ }^{227}$ It is said that the average temperature in Chengde in the month of July is 24.4 degrees Celsius, compared to 25.8 degrees Celsius for Beijing; see Dunnell and Millward 2004, p. 4.

${ }^{228}$ Forêt 2000, p. 42
} 
same can be said for the Tuoba's clear preference for the Chaishan palace, most noticeable between the years 403-408, as the emperor frequently shuttled between the detached palace and Pingcheng. The patterns of these imperial progresses were partly due to the reality of seasonal constraints. However, we should not overlook the obvious, that both Chengde and the Chai Mountain are located near the steppe zone. Apart from the climatic appeals of these detached imperial residences, it is very likely that both the Tuoba and the Manchus continued to maintain a strategic tie to the steppes for military expediency in their control of the borderlands.

At the same time, we cannot overlook the personalities and idiosyncrasies of the emperor himself. Contrary to what one might assume, in the span of ten years as emperor of the Northern Wei, Emperor Daowu's patterns of life did not become more settled in Pingcheng as time progressed. Aside from the previously mentioned military activities, the emperor also took delight in the small pleasures in life that brought him closer to nature. In the fourth month of the year 400, he traveled west to Mayi to look at the source of the Lei River. The third month of the following year, also in the spring time, Emperor Daowu went fishing and made a point of presenting the fish as sacrifice at the ancestral temple. Later, in the ninth month of the year 406, before returning to Pingcheng from the Chaishan palace, he decided to take a detour and entered into the Gobi desert to inspect the salt lakes. Finally in 408, again upon leaving the Chaishan palace, the emperor decided to advance to Canhepo to observe the fishing activities at the Yuyan River.

Although having taken place a thousand years after the demise of the Tuoba Northern Wei and in a completely different region of the world, the Italian envoy's descriptions of the 
French king's ceaseless journeying happens to be an apt portrayal of Emperor Daowu's diverse interests. In 1541, Gambara wrote of Francis I's restlessness:

His Majesty did not stay here longer than a day, but departed suddenly with his usual company and explores the strangest places in the country while chasing the poor deer. It is said that His Majesty will be here for the feast of All Saints. Opinions, however, differ: some say he will go directly to Fontainebleau; others that he will go to Picardy to inspect its frontiers; for my part, I believe that His said Majesty does not know which path to follow, as is his custom. ${ }^{229}$

Nothing better demonstrates the spontaneous nature of these imperial progresses than the above passage, highlighting the flexibility of the agenda, to the extent of being somewhat at the temperamental whim of the sovereign. In the case of the Tuoba, though it may have appeared that the emperor had gone fishing, hunting, and even sight-seeing, given the historical context of the formative period of the Northern Wei state, these visits to various types of geographical locations could have just as well been strategic inspections for resource and military purposes. At the same time, as we are aware of the costly expenses involved in the provisions, accommodations and transportation of each progress, ${ }^{230} \mathrm{I}$ would argue that these imperial progresses should not simply be treated as the emperor's pleasure trips, but had an impact on, and was a reflection of, the Tuoba's preferred method of rulership in the early Northern Wei.

\section{Affairs in the Capital}

While the emperor's time was split between overseeing military activities, cooling off at the Chaishan palace, and inspecting the landscape of his realm, Emperor Daowu remained

\footnotetext{
${ }^{229}$ The Italians were said to have been bewildered by the French king's restlessness since they were used to a more sedentary lifestyle within their relatively small city-states; see Knecht 2008, p. 42 for the quote.

${ }^{230}$ Cole uses the heavy costs of Elizabeth I's progresses, and her consistent commitment to travel, to emphasize the value the Queen had placed upon these trips, and their importance in advancing her personal and political goals; see Cole 1999, pp. 1-4.
} 
fully aware of the ritual and imperial duties that required him either to remain in or to return to Pingcheng. For the most part, the emperor was personally involved in several of the ritual sacrifices that were carried out, and it appears as if his travels were arranged to suit the timing of the rituals. In the first month of the year 399, he had waited until after the Shangdi sacrifice in the southern suburbs had been carried out before traveling to the Gobi desert to oversee the ongoing battle against the Gaoche tribes. Similarly in 405, the sacrificial ritual of the western suburbs took place after the emperor returned to Pingcheng from the Chaishan palace. Apart from fulfilling the ritual obligations, another pattern emerges tying the emperor's presence in the capital city to the architectural projects that were being undertaken. In the years 400 and 403, the various halls and chambers of the palatial complex in Pingcheng were added and refurbished only upon the return of the emperor. In fact, the accounts were recorded to the effect that Emperor Daowu's return to the capital allowed him to give his stamp of approval for the commencement of the imperial projects.

As such, we might suggest that the Tuoba held ambivalent feelings toward the notion of establishing a permanent seat of power at Pingcheng. According to the Wei shu, a series of construction projects in the Pingcheng vicinity had been actively carried out in this early period of the Northern Wei. The fact that the construction of these buildings had been so diligently recorded by court historians suggests that the intention was to depict the city as a permanent headquarter for the Tuoba, where they had begun to make themselves at home by surrounding themselves with sets of imperial, palatial and ritual complexes. The 
following table contains a series of palatial and ritual projects undertaken by Emperor

Daowu from 398 to 409 , covering the same period of time as that of the previous table. ${ }^{231}$

\begin{tabular}{|c|c|}
\hline Date & Buildings in and around Pingcheng \\
\hline Seventh month, $398 \mathrm{CE}$ & $\begin{array}{l}\text { Palace, zongmiao 宗廟 (ancestral temple), } \\
\text { and the sheji altar }\end{array}$ \\
\hline Tenth month & $\begin{array}{l}\text { Tianwen dian 天文殿 (Hall of the Patterns } \\
\text { of Heaven) }\end{array}$ \\
\hline Second month, $399 \mathrm{CE}$ & Luyuan 鹿苑 (Deer Park) \\
\hline Seventh month & $\begin{array}{l}\text { Tianhua dian 天華殿 (Hall of the Heavenly } \\
\text { Flowers) }\end{array}$ \\
\hline Tenth month & Taimiao 太廟 (Grand Temple) \\
\hline Second month, $400 \mathrm{CE}$ & $\begin{array}{l}\text { Began plowing and sowing the jitian 籍田 } \\
\text { (imperial fields) }\end{array}$ \\
\hline Seventh month & $\begin{array}{l}\text { Zhongtian dian 中天殿 (Hall of the Center } \\
\text { of Heaven), Yunmu tang 雲母堂 (Hall of } \\
\text { the Mother of Clouds) and Jinhua shi 金華 } \\
\text { 室 (Chamber of the Golden Flowers) }\end{array}$ \\
\hline Fifth month, $401 \mathrm{CE}$ & $\begin{array}{l}\text { Ziji dian 紫極殿 (Hall of the Purple Pole), } \\
\text { Xuanwu lou 玄武樓 (Pavilion of the Black } \\
\text { Warrior), Liangfeng guan 涼風觀 (Daoist } \\
\text { Temple of the Cool Winds), Shichi 石池 } \\
\text { (Rock Pond) and Luyuan tai 鹿苑臺 } \\
\text { (Pavilion of the Deer Park) }\end{array}$ \\
\hline Seventh month, $403 \mathrm{CE}$ & $\begin{array}{l}\text { Chaishan gong 豹山宮 (Detached palace at } \\
\text { Chai Mountain) }\end{array}$ \\
\hline Tenth month, $403 \mathrm{CE}$ & $\begin{array}{l}\text { Xizhaoyang dian 西昭陽殿 (Western Hall } \\
\text { of the Bright Sun) }\end{array}$ \\
\hline Tenth month, $404 \mathrm{CE}$ & Xigong 西宮 (West Palace) \\
\hline Sixth month, $406 \mathrm{CE}$ & $\begin{array}{l}\text { Leinan gong 灅南宮 (Detached Palace to } \\
\text { the South of Lei River) }\end{array}$ \\
\hline Seventh month, $407 \mathrm{CE}$ & $\begin{array}{l}\text { Outer walls of the Beigong 北宮 (North } \\
\text { Palace) }\end{array}$ \\
\hline
\end{tabular}

Here, we are confronted by two images of Pingcheng as the capital of the Northern Wei.

On one hand, the physical aspects of the city present an appearance as if the Tuoba had settled comfortably into an urban center, whereas the travel log of the emperor shows

${ }^{231}$ Wei shu, juan 2, pp. 19-45. 
otherwise. When considered together with Emperor Daowu's travels, it is clear to us that this extensive list of capital planning had not succeeded in tying down these new masters of northern China, nor was it carried out under such intentions. With the increasing number of buildings completed, the emperor had not put a halt on his "out-of-town" trips as we might have expected. Rather, with the establishment of the Chaishan palace, the frequency of his trips up north actually increased in the later years of his reign, particularly in the years 406-407. This demonstrates that there is no positive correlation between the sophistication of the physical aspects of Pingcheng as a full-fledged capital and the emperor's own disposition toward a settled lifestyle in the new capital. In fact, this mobile rulership was true not only of the first Northern Wei emperor, but remained a constant feature that was continued down to the last emperor of the Pingcheng period, Emperor Xiaowen.

Emperor Xiaowen spent the years 471-494 with his seat of power based in Pingcheng before he made the decision to relocate the capital to Luoyang. This move had been commonly treated as the ultimate marker of Emperor Xiaowen's push for a full-fledged Sinicization of the Northern Wei state. For this reason, he had been deemed by scholars who hold this view as the hand behind the Northern Wei Sinicization effort. ${ }^{232}$ However, I would like to propose the argument that by removing themselves further away from the steppe and establishing the capital in Luoyang, a city with a long history of serving as the capital of previous dynasties, the Tuoba were, in fact, exercising a more effective and centralized control of their realm, while at the same time, continuing their progresses. As we can tell from the nature of the inspection tours conducted by Emperor Xiaowen,

\footnotetext{
${ }^{232}$ This idea is most outwardly expressed in the works of Li Ping and Liu Jingcheng who attribute Emperor Xiaowen's successful and relatively stable ruler of the Northern Wei to his sinicization reforms, to the extent of suggesting that he was greatly influenced by the Dowager Empress Feng in this respect.
} 
although just as mobile and peripatetic as his forefathers, the emperor had developed a concern in the governance of the state and the wellbeing of his subjects. The following is a $\log$ of the trips taken by Emperor Xiaowen in the year 481. ${ }^{233}$

\begin{tabular}{|l|l|}
\hline Months in the year 481 & Travel Destination and Purpose \\
\hline First month & $\begin{array}{l}\text { Inspection tour down south, arriving in Zhongshan 中山 } \\
\text { (present-day Dingzhou, Hebei province). The emperor had } \\
\text { personally met with the elderly, inquired about the hardships } \\
\text { of the local population, and distributed relief funds to those } \\
\text { in need. }\end{array}$ \\
\hline Second month & $\begin{array}{l}\text { Advanced to Xindu 信都 (present-day Jizhou, Hebei } \\
\text { province) and conducted the same routine of inquiring about } \\
\text { and taking care of those in need as was done Zhongshan. } \\
\text { Upon returning to Zhongshan from Xindu, the emperor } \\
\text { conducted military exercises on the north bank of the } \\
\text { Tangshui 唐水 river. Later this month, the emperor returned } \\
\text { to the capital. }\end{array}$ \\
\hline Third month & $\begin{array}{l}\text { Traveled to Sizhou 肆州 (present-day Xinzhou, Shanxi } \\
\text { province) and conducted military exercise on the north bank } \\
\text { of the Yunshui 雲水 River. Wherever he passed through, the } \\
\text { emperor reviewed local commandery governors and district } \\
\text { magistrates for promotions and demotions. Later this month, } \\
\text { the emperor returned to the palace. }\end{array}$ \\
\hline Fourth month & $\begin{array}{l}\text { Traveled to Fang mountain 方山 (north of present-day } \\
\text { Datong, Shanxi province) to build the Yonggu stone } \\
\text { chamber 永固石室 on top of the mountain (fig. 4) for } \\
\text { Dowager Empress Feng. }\end{array}$ \\
\hline Ninth month & $\begin{array}{l}\text { Conducted a military parade in the southern suburbs, where } \\
\text { the emperor entertained his court to a banquet. }\end{array}$ \\
\hline
\end{tabular}

Although the events in the year 481 represent only a sample of Emperor Xiaowen's twenty-nine years of rulership, I have chosen this particular year for the wide range of activities in which the emperor personally took part. If we compare this chart against that of Emperor Daowu's travels, the attention given to the training of the troops remains a consistent element. This shows that after close to a century of Northern Wei rulership in

\footnotetext{
${ }^{233}$ Wei shu, juan 7, pp. 150-151.

${ }^{234}$ The Yonggu stone chamber later became the mausoleum of the Dowager Empress Feng upon her death in 490.
} 
northern China, the emperor continued to be very much involved in the military affairs, carrying out exercises with his troops wherever they camped. Nonetheless, a new aspect of the emperor's function as the sovereign of the Northern Wei state had been developed by this time. Emperor Xiaowen's trips have all been recorded as fulfilling particular duties in the management of state affairs, such as looking after the elderly, bringing relief funds to those in hardship, or reviewing the work of his local officials.

Of course, this can be interpreted in two ways. The first is that by his time, Emperor Xiaowen had learned the rules of statecraft, and was attentive to setting up a pretext to his frequent progresses out of Pingcheng. In contrast to the bluntness of the Wei shu in describing Emperor Daowu's progresses as leisure trips to fish, to hunt and to see the salt lakes, the rhetoric adopted for Emperor Xiaowen was much more serious and evoked the classical notion of an "inspection tour". ${ }^{235}$ This use of discourse as a means of recreating the imperial identity to suit contemporary needs was a method well practiced by the Manchus in their construct of the Qing dynasty. Emperor Qianlong (r. 1735-1796) framed his first four progresses to southern China in terms of carrying out his duties as a filial son, bringing his mother along to show her the sights of the Jiangnan 江南 region, south of the Yangtze River. ${ }^{236}$ Similarly, Emperor Xiaowen may not have wished to appear as the emperor who neglected his duties while being away from the capital. A second explanation might suggest a more practical purpose. Unlike Emperor Daowu, who was most likely still

\footnotetext{
${ }^{235}$ Howard Wechsler has shown that according to the Classic of History (Shu jing 書經), the hero Shun 舜 embarked on a year-long xun shou 巡守 to offer sacrifices at sacred sites, meet in audience with nobles, standardize weights and measures, and regulate ritual ceremonies. As he came to recognize the difficulties inherent in these tours, Shun decreed that these tours of inspection be carried out only once every five years. Wechsler suggests that when these tours were undertaken by subsequent rulers, they justified them by referring to the "tour of inspection" of Shun, claiming that sage kings took them to ascertain local conditions, as a means to reinvigorate loyalty among the people and to improve the government; see Wechsler 1985, pp. 161-169.

${ }^{236}$ Symons 2004, p. 61.
} 
in combat mode as the founding emperor of the Northern Wei, therefore the necessity for surveying geographical landscapes, Emperor Xiaowen had reached the stage of state building in which he was required to turn his attention inward toward civil governance. Regardless, both scenarios demonstrate that the Northern Wei emperors had mastered the ways in which imperial discourse could be manipulated to suit the times and circumstances.

As a peripatetic emperor and a sophisticated statesman, Emperor Xiaowen delicately combined the two identities as he continued to make his inspection rounds throughout the realm. Upon directing his attention inward, focusing on the governance of the Northern Wei state, the Northern Wei military's southward footsteps would have also undoubtedly brought Emperor Xiaowen geographically closer to the region of the Central Plains. In the year 469, when Emperor Xiaowen was still the crown prince, the Northern Wei had conquered the regions of Qingzhou 青州 (present-day central and eastern Shandong province) and Jizhou 冀州 (present-day northwestern Shandong province) by defeating the southern Liu Song 劉宋 state. ${ }^{237}$ This major advancement had expanded the territory of the Northern Wei to include the entire Yellow River basin, moving south all the way to the north bank of the Huai River 淮河. As such, the decision to relocate the capital from Pingcheng to Luoyang could, and should, be interpreted as a practical strategy for keeping a closer grip on the expanding territory and the growing subjects that were now all included under Northern Wei rule. Incidentally for the same purpose, apart from being in the habit of preserving their own mobile rhythms, the Tuoba were also keen on transferring their conquered subjects to the proximity of the capital, a common practice in the Pingcheng period that we will now examine.

${ }^{237}$ Wei shu, juan 6, pp. 127-129. 


\section{Centralizing the Conquered Subjects}

I would put forth the notion that in the early period of Northern Wei state building, the practice of centralizing their conquered subjects became another feature of imperial policy as the Tuoba learned to negotiate with the many identities that they now had to represent as the new masters of northern China. Globally, forced relocation as a form of population transfer has roots that stretch as far back as the Assyrian, Egyptian, Mesopotamian, and Anatolian empires who instituted this practice as a "tool to weaken, dismember, and eliminate the national dimensions of subject peoples." ${ }^{238}$ We can certainly assume that the Tuoba had practiced such policies as a method of collective punishment against those who resisted their conquest. At the same time, aside from adopting the more traditional imperial practice of the Qin and Han, relocating the population for the purposes of clearing land in opening up frontiers, I would argue that the Tuoba learned to strategically deploy different collectives as the "soft power" behind the different state projects. Furthermore, the Tuoba's ability to construct the first successful conquest dynasty in China proper was indebted to their capacity in maintaining cultural links with the various groups of people under their governance, thereby creating a shared Northern Wei identity.

In the second month of the year 399, the Deer Park (luyuan 鹿苑) was designed to be placed in the northern suburbs (fig. 16 ) of Pingcheng as, what I would call, a recreation of nature intended to make the Tuoba feel more at home in an "urban" surrounding.

以所獲高車衆起鹿苑, 南因臺陰, 北距長城, 東包白登, 屬之西山, 廣輪數 十里, 鳌渠引武州水注之苑中, 疏為三溝, 分流宮城内外。又穿鴻雁池。2 239

\footnotetext{
${ }^{238}$ Schechla 1993 , p. 240.

${ }^{239}$ Wei shu, juan 2, pp. 34-35.
} 
Using the captured people of the Gaoche to build the Deer Park; to the south it follows along the north side of the [Baideng] pavilion, to the north it arrives at the [northern] great wall [of the Tuoba], ${ }^{240}$ to the east it encloses the Baideng

[Mountain], and it is joined to the West Mountain, covering an area of tens of li. A channel was dug to direct the water of the Wuzhou River into the garden, divided into three trenches that separately flowed inside and outside of the palace grounds. [The waterways] again passed through the Great Goose Pond. ${ }^{241}$

My interest in this passage falls on the two insights that it provides. On a physical level, it clearly demonstrates that, apart from their frequent travels away from Pingcheng, the Tuoba made a point of bringing their familiar hunting grounds close to the capital, making sure that it would contain mountains, valleys and man-made waterways. In effect, the Deer Park represents the kind of open-air setting where the Northern Wei elite, such as the families of Poduoluo and Song Shaozu whom we will later discuss, might have enjoyed an outdoor banquet or an outing in full military regalia close to the capital. Here, we are reminded of the great gardens that encircled the city of Samarqand under the reign of Tamerlane, featuring palaces and pavilions where the ruler conducted receptions, banquets and weddings. ${ }^{242}$ Whereas scenes of Tamerlane's life in the open can be found represented in manuscripts, we have to rely on passages like the one above to give us a glimpse of the Tuoba's life in more colorful details.

As one of the main projections of imperial majesty, the royal hunts were finely balanced between the public and the private spheres. If the Northern Wei emperors' progresses to the Chaishan palace were intended as a more public spectacle, the Deer Park of Pingcheng

\footnotetext{
${ }^{240}$ The "great wall" being mentioned here is the northern great wall of the Tuoba, enclosing the pass between the Baideng Mountain to the northeast and the Leigong Mountain to the northwest. This wall had previously been located by the Japanese scholars Mizuno and Nagahiro as the north wall of the city, but this has recently been reevaluated by local scholars such as Cao Chenming, who believe that this northern wall formed a screen that protected Pingcheng from northern invasions; see Cao Chenming 2004, p. 10.

${ }^{241}$ Author's trans.

${ }^{242}$ Wilber 1979, p. 128.
} 
gave the imperial household, as well as the elite, a secure, artificial environment that reminds us of the "paradise [paradeisos]" of the Achaemenids in the ancient Near East. ${ }^{243}$ It is said that Cyrus the Great "had a palace and a large park [paradeisos] full of wild animals, which he used to hunt on horseback whenever he wished to give himself and his horses exercise. Through the middle of this park flows the Macander River; its sources are beneath the palace and it flows through the city of Celaenae also." ${ }^{244}$ The earliest Chinese equivalent of a paradeisos in text can be traced to Mencius's descriptions of the "hunting park seventy Chinese miles square” of King Wen 文王 of the Zhou 周 dynasty (ca. 1122 $\mathrm{BCE}),{ }^{245}$ and that "deer parks" in particular were common in the kingdoms of the Spring and Autumn period (722-481 BCE) as well as the subsequent era of the Warring States $(476-221 \mathrm{BCE}){ }^{246}$

The most well-known hunting park in Chinese history was, by far, the Shanglin yuan 上林 苑 (Supreme Forest) just outside of the capital Chang'an 長安, which was first laid out under the Qin 秦 $(221$ - 206 BCE) and then expanded during the Western Han 西漢 (206 BCE - 9 CE). ${ }^{247}$ This imperial park was exploited on a "multiple use" basis; put to economic use for agriculture and pasturage, as well as military use for the training of Emperor Wudi's 漢武帝 (Liu Che 劉徹, r. 141-87 BCE) imperial guards, mostly through large-scale hunting exercises. ${ }^{248}$ Incidentally, the fact that the Deer Park of the Tuoba was

\footnotetext{
${ }^{243}$ In the Greek texts they are called paradeisos, which goes back to the Old Persian paridaida, which has the basic meaning of "enclosure" or "domain". Such a hunting park was a key institution in Achaemenid Iran, though not an exclusively royal institution. While not necessarily an Achaemenid invention, it is possible that this institution had coalesced under the Persians who drew upon a number of Near Eastern antecedents in the elaboration of their hunting parks ; see Allsen 2006, pp. 34-36.

${ }^{244}$ Allsen 2006, p. 35.

${ }^{245}$ For the English translation of this quote from Mencius, see Dobson 1963, 1.3.

${ }^{246}$ Schafer 1968, pp. 320-325.

247 Allsen 2006, pp. 41-42.

${ }^{248}$ Schafer 1968, p. 333; Wu Suqin 1996, pp. 57-58; also Knechtges 1996, pp. 97-100 for an English translation of the Rhapsody on the Imperial Park originally written by Sima Xiangru in the Western Han.
} 
placed just within the northern great wall (fig. 6), which was intended to serve as a screen to shield Pingcheng from northern invasions, also made it a suitable location for the training of the Northern Wei troops. This was precisely what Emperor Daowu had carried out in the third month of 399 , immediately after the completion of the Deer Park.

Moving onto my second insight derived from the above passage, conceptually speaking, the process involved in the creation of the Deer Park reveals to us another major feature of the Tuoba's method of rulership in the Pingcheng period, carried over from their nomadic practices. That is to remove the conquered subjects from their native land, and to put them to work in the greater schemes of state building. Some of these population relocations were intended to clear lands in new territories as the Tuoba's realm expanded, such as the more than twenty-thousand households transferred to Daning 大寧 (present-day Zhangjiakou, Hebei province), who were given farming equipment and household plots per head to be put in charge of cultivating farmlands in $413 .{ }^{249}$ By encouraging farming on the frontiers, it helped the state to strengthen its control over newly conquered territories through establishing settled agricultural communities. Alternatively, others were brought to the capital, where they were put to various types of services, such as the households from Liangzhou 涼州, who brought with them the Buddhist “techno-complex" to Pingcheng in 439 that were essential to the creation of the Yungang grottoes as we will later explore. ${ }^{250}$

The Deer Park in the northern suburbs was built by the Gaoche who had been transferred to Pingcheng after their defeat by the Tuoba just earlier that year, when more than twentythousand people from seven tribes were captured and relocated. It brings to our attention

\footnotetext{
${ }^{249}$ Wei shu, juan 3, p. 53.

${ }^{250}$ Wei shu, juan 4, p. 90.
} 
the ways in which the Tuoba dealt with the populations of conquered states. First, they transferred peoples to the close surroundings of the capital. Second, they employed their relocated subjects in planning and building schemes in the process of creating their notions of the state. In the course of the Pingcheng period, the Tuoba carried out several major population transfers for the purpose of concentrating human resources at the center of imperial power. These separate strands of population inflow to the capital constituted a practical and deliberate tool of governance within the context of building and maintaining a growing state.

In the accounts of the Wei shu, based on the chronicles of the Northern Wei emperors, almost every conquest made by the Tuoba in the Pingcheng period was followed by some sort of forced movement of the defeated subjects. Interestingly, the majority of these people were transferred either back to Pingcheng or settled in the surrounding areas of the capital, and it is this phenomenon to which we should pay attention.

\section{Emperor Daowu 道武帝 (Tuoba Gui 拓跋珪) (r. 398-409)}

Approximately three hundred and sixty thousand people were transferred from the six regions to the east of the Taihangshan Mountain, including the general populace, local officials, and the Tuhe 徒何 and Gaoli 高麗 tribes, along with more than one hundred thousand artisans and craftsmen to fill the capital. ${ }^{251}$

(398)

Approximately two thousand households including commandery governors, district magistrates, local landowners and elite, local officials and the general populace of six regions and twenty-two commanderies were relocated to the capital. ${ }^{252}$ (398)

\footnotetext{
${ }^{251}$ Wei shu, juan 2, p. 32.

${ }^{252}$ Wei shu, juan 2, p. 34.
} 
More than twenty thousand people of seven Gaoche tribes were brought to work on the Deer Park at Pingcheng. ${ }^{253}$

(399)

The people of Gaoping 高平 (present-day Guyuan, Ningxia province) were relocated to the capital. ${ }^{254}$

(402)

\section{Emperor Mingyuan 明元帝 (Tuoba Si 拓跋嗣) \\ (r. 409-423)}

\section{Emperor Taiwu 太武帝 (Tuoba Tao 拓跋壽) \\ (r. 424-452)}

More than ten thousand households were transferred from the capital of Helian Chang 赫 連昌 (ruler of the $\mathrm{Hu}$ Xia 胡夏, a state that existed between 407-431) at Tongwan Cheng 統萬城 (present-day Jingbian, Sha'anxi province) back with the emperor. ${ }^{255}$ (426)

Six thousand men and women were transferred back from Helong 和龍 (present-day Helong, Jilin province, bordering between the PRC and DPRK) by general Yuan Pi 元不 upon the conquest of the Northern Yan 北燕 ruled by Feng Wentong 馮文通. ${ }^{256}$ (435)

With the emperor's personal conquest of the Northern Liang 北涼, ruled by Juqu Mujian 沮渠牧犍 (r. 433-439) ${ }^{257}$ more than thirty thousand households from the Liangzhou 涼州 region were transferred back to the capital as the emperor returned east. ${ }^{258}$ (439)

In the persecution of Buddhist monks, two thousand artisan households from Chang'an 長 安 (present-day Xi'an, Sha'anxi province) were transferred to the capital. ${ }^{259}$ (446)

Three thousand Dingling 丁零 (also known by several other names including the Gaoche 高車 and the Chile 敕勒) households were transferred from Dingzhou 定州 (present-day Baoding, Hebei province) to the capital. ${ }^{260}$ (447)

\footnotetext{
${ }^{253}$ Wei shu, juan 2, pp. 34-35.

${ }^{254}$ Wei shu, juan 2, p. 39.

${ }^{255}$ Wei shu, juan 4, p. 71.

${ }^{256}$ Wei shu, juan 4, p. 85. Incidentally, Feng Wentong was the grandfather of the later Dowager Empress Feng in the reign of Emperor Xiaowen.

${ }^{257}$ Juqu Mujian was the son of Juqu Mengxun, the Northern Liang ruler who was actively involved in Buddhist activities in the Liangzhou region in the late fourth and early fifth century. He and the state of Northern Liang will be discussed in more detail in chapter three.

${ }^{258}$ Wei shu, juan 4, p. 90.

${ }^{259}$ Wei shu, juan 4, p. 100.

${ }^{260}$ Wei shu, juan 4, pp. 101-102.
} 
More than five thousand households from the Lishi 離石 county (present-day Lüliang, Shanxi province) of the Xihe 西河 commandery (parts of present-day Shanxi and Neimenggu provinces) were transferred to the capital. ${ }^{261}$ (448)

When the emperor returned from the frontlines of his southern campaign across the Yellow River against the southern state of Song, he returned with more than fifty thousand surrendered households and separately settled them in the suburbs of the capital. ${ }^{262}$ $(451)$

\section{Emperor Wencheng 文成帝 (Tuoba Jun 拓跋鮥)}

(r. 452-465)

\section{Emperor Xianwen 獻文帝 (Tuoba Hong 拓跋弘)}

(r. 465-471)

The population of Qingzhou 青州 (present-day Shandong province) was transferred to the capital upon the Tuoba's defeat of the southern state of Song 宋. ${ }^{263}$

(469)

\section{Emperor Xiaowen 孝文帝 (Tuoba Hong 拓跋宏) \\ (r. 471-499)}

Upon defeating the troops of the southern state of Qi 齊 in the southern campaign, more than thirty thousand captives were sent to the capital. ${ }^{264}$

(481)

Altogether, in the span of a century, at least fifty-eight thousand people and one hundred thousand households, not to mention the other population transfers for which we do not have the numerical data, were relocated from all over northern China to the region of Pingcheng. This is a significant scale of orchestrated demographic movement that demonstrates a deliberate strategy on the part of the Tuoba. However, current studies on this subject have focused predominantly on the transfer of Han Chinese communities. For one, the studies appear to advance the view that these communities continued to separate themselves from the rest of the Northern Wei subjects for their assumed cultural

\footnotetext{
${ }^{261}$ Wei shu, juan 4, p. 102.

${ }^{262}$ Wei shu, juan 4, p. 105.

${ }^{263}$ Wei shu, juan 6, p. 129.

${ }^{264}$ Wei shu, juan 7, p. 150.
} 
superiority as Han Chinese, as in the case of the Liangzhou households. ${ }^{265}$ At the same time, scholars also treat the displacement of these Han Chinese captives as a punishment for their persistent resistance against the Tuoba, as with the elite households from Qizhou and Qingzhou who had been targeted. ${ }^{266}$ While these studies remain valuable as case studies on the experiences of the transferred communities, I think that it is also important for us to recognize these events as political and imperial strategic choices made by the Tuoba in their agenda for state-building, which is why it became the dominant post-war routine in the Pingcheng period. These relocations required just as much coordination and manpower as would be required in organizing troops for battle.

The few exceptions to this inward movement included the transfer of twenty-thousand people in 413 to Daning where land was distributed per head for agriculture, ${ }^{267}$ as well as the consecutive transfers of the conquered southern Song subjects in 446 (initially five thousand households, followed by another six thousand) to "populate" the area north of the Yellow River. ${ }^{268}$ This type of population relocation, as a method of expanding the frontiers of the realm through populating the area and the cultivation of land, had long been in practice from the earlier Qin and Han dynasties. The traditional practice of transferring people from the Central Plains to Lingnan 嶺南 (parts of present-day Guangdong, Guangxi, Hunan, Jiangxi provinces and northern Vietnam) in the southeast and to Yunnan 雲南 in the southwest are examples in which the Central Kingdom used its people as a means to

\footnotetext{
${ }^{265}$ See Bo Juncai 2010 for a study on the relocated Liangzhou households and their role in reviving Confucian studies in the Pingcheng period.

${ }^{266}$ See Xu Fuqian 1982 and Xing Bingyan 1983 for studies on the relocated households from Qingzhou and Qizhou, both situated in present-day Shandong province. The two papers look into how the transferred populations were separately relocated into different communities, most likely based on the extent to which they had resisted the Tuoba conquests. Thereby, the new communities of these forced migrants were also designated different roles in the services that they were required to provide to the Northern Wei state.

${ }^{267}$ Wei shu, juan 3, p. 53.

${ }^{268}$ Wei shu, juan 4, p. 100.
} 
advance into these new territories. ${ }^{269}$ Contrary to the southern frontier, the Han Emperor Wudi's establishment of the four northwestern commanderies in 111 BCE - Wuwei 武威, Zhangye 張掖, Jiuquan 酒泉, and Dunhuang 敦煌 in the Hexi 河西 corridor, was a direct response to the threat posed by the Xiongnu, and bore strategic, military, as well as economic (trade with the Western Regions) considerations. ${ }^{270}$

However, what we see happening in the Pingcheng period, from the above chart, is a much more unfamiliar pattern of state practice in the types of people involved as well as the directionality in which they were relocated across the realm. First of all, the people transferred by the Tuoba were generally captives of war or subjects of conquered regions, and the relocations all followed major battles with the detailed number of people and households accounted for in the Wei shu. ${ }^{271}$ Secondly, rather than moving these groups to the frontiers to create new communities, they were intentionally brought into the heartland of the Northern Wei. In the Han dynasty, we know that emperors had actively and compulsorily moved rich men, ranking officials and local elite from the provinces to the capital area as a means to uproot potential leaders of local communities. What was treated as a precautionary measure to weaken regional threats was transformed into a source of "soft power" in the Northern Wei, which was to be centralized around the capital as human resource for state projects or to be at the service of the court. In the following chapters, the

\footnotetext{
${ }^{269}$ See Zhang Longchun 2005 on the Qin and Han transfer of people to Lingnan; also Lin Chaomin 2005 on the transfer to Yunnan and its strategic importance.

${ }^{270}$ See Jia Wenli 2010; Wang Tingmei 2008; also Hui Fuping and Wang Siming 2005 on the establishment of the commanderies on the northwestern frontier.

${ }^{271}$ This was in contrast to the glaring absence in the Han annals that neglect to tell what happened to prisoners taken in wars against the Xiongnu, against the oasis states of the northwest, the Koreans, as well as the kingdoms of southern China. In a time of decades of warfare, what became of these hundreds of thousands of captives appear to remain a historical enigma; see Wilbur 1943, pp. 58-59.
} 
transfer of the Buddhist techno-complex from Liangzhou ${ }^{272}$ and the family origins of Song Shaozu in the northwestern region of Dunhuang are all examples that demonstrate how the concentration of the different groups of people in Pingcheng allowed for a negotiation of material and visual cultures against this background.

The concentration of the different groups of people at Pingcheng allowed the capital area to become an integrated unit that possessed a commanding position over the whole of the dynastic realm. In the Tuoba's construct of a multi-ethnic state, this was utmost important. In their deliberate attempts at relocating different groups of people from newly acquired territories to the close reaches of Pingcheng, the Tuoba were, in a way, constructing a Northern Wei identity that would provide them the grounds to govern over a growing empire. Much like the Manchus, who had the ability to bind warriors from a variety of cultural backgrounds to their cause as a multiethnic force, ${ }^{273}$ although the Tuoba's intentions cannot be directly linked to a military coalition by design, they had indeed served to strengthen contact and communication between the court and the rest of the Northern Wei state.

\section{CONCLUSION}

So goes the Moroccan proverb: "Roam and you will confound adversaries, sit and they will confound you." 274 The success of the Tuoba in the early Northern Wei Pingcheng period was precisely derived from their rituals of mobility. As we looked at the ways in which imperial life in Pingcheng was made up of a series of spectacles, some private and

\footnotetext{
${ }^{272} \mathrm{Su}$ Bai was one of the few scholars who linked the population transfers to the development of a Yungang model in the context of Buddhist stone sculptures, attributing its flourish in the Pingcheng period to the concentration of resources and skills in the capital; see Su Bai 1994, pp. 23-27.

${ }^{273}$ Rawski 1996, p. 834.

${ }^{274}$ Geertz 1983, p. 137.
} 
some public, I have followed several strands of discourses that present to us seemingly disparate notions of kingship practiced in juxtaposition by the Northern Wei emperors of this period. Court life, regardless of the culture it is in, necessitates that it is made up of a series of rituals that essentially strengthen and reaffirm the power and unchallenged authority of the ruling imperial household. Together with the royal progresses, they are the two pillars of the political theater in the ancient world. ${ }^{275}$

The rituals of the Tuoba, as symbols of power, were not mere incidental ephemera, but central to the eloquently crafted articulations of kingship through inspiring a sense of awe into the mind of the spectator. The ancestral worships and the outdoor progresses of the Tuoba were complementary in many respects, and identical in their function at the service of the emperor. Both provided the necessary pomp whereby hierarchies of dominance and deference are created. The notion of a ritual should not be limited to the traditional context of sacrificial worship, but the progresses and hunts of the emperors have also turned into another form of imperial ritual through the routine practices of spectacle. In this light, the study of power is not limited to asking questions about who governs and how they govern, but through the ways in which this power was demonstrated, or rather, flaunted. Access to this ritual determined the ownership of state discourse, and thereby the control over the agency of kingship. As such, I would argue against those who attempt to explain the Northern Wei experience by fitting it into what they presume to be an ultimately continuous Chinese experience. Rather, the historical process in the Pingcheng period was the result of a series of strategic choices made by the Tuoba throughout this formative period of Northern Wei state-building.

${ }^{275}$ Allsen2006, pp. 201-202. 


\section{Chapter 3: Yungang and the Tuoba Kingship}

鏊石開山，因岩結構，真容巨壯，世法所希。

山堂水殿，煙寺相望，林淵錦鏡，綴目新眺。

$$
\text { --- 《水經注》276 }
$$

Carving into rocks to open up mountains, conforming to the cliffs to build the structuring; the immortal features are grand and monumental, a rarity in this world. [Building] halls and palaces next to the mountain and water, smoke [from] temple [chimneys] gaze at one another; deep pools of water [reflect] in the woods like bright mirrors, filling one's eyes with new sights.

\section{--- Shuijing zhu (Commentary on the Waterways Classic) $)^{277}$}

\section{INTRODUCTION}

Situated 16 kilometers west of Pingcheng (fig. 4), these were the Yungang grottoes 雲岡石 窟 (literally translated as "cloud ridge grottoes") in the eyes of the aforementioned Northern Wei geographer Li Daoyuan. The Buddha of cave 20 (fig. 17) smiles benevolently and in peace upon those who dare to fix their eyes on such a demanding yet serene presence, as if peering from behind a veil of clouds that often shroud the local mountains. Revealed in full view in a shallow cave of which the overhead structures have weathered away, the Buddha sits cross-legged at a height of 13.7 meters. This sculpture is one of the largest to be preserved in the 45 major caves of the Yungang grottoes, all dated to the Northern Wei, that fill the southern cliff side of the Wuzhou Mountain 武州山 (fig. 18a).

The Yungang grottoes, excavated into a sandstone mountain range, extend to the east and west for approximately 1 kilometer with an additional 252 niches of all sizes, together

\footnotetext{
${ }^{276}$ Shuijing zhu, juan 13, p. 208.

277 Author's trans.
} 
sheltering more than 51,000 sculptures. These caves, all of which were opened and completed within this particular period when the Tuoba ruled over northern China, are, in themselves, a book of Northern Wei dynastic history. Apart from the Five Caves of Tan Yao (presently numbered as caves 20,19, 18, 17, and 16) (fig. 18b), which deviate from the norm in their spatial distribution, the grotto architectural style most commonly adopted at Yungang consists of one or two rectangular chambers, with or without a central pillar, and with the main Buddha image placed against the back wall. ${ }^{278}$ The caves are extraordinary for the architectural setting carved directly into a low range of mountainous cliffs, combining larger than life-sized stone Buddhas with rock-cut niches and columns, creating a monumental stone building of several storeys with a display of sculptured figures at the Wuzhou Mountain.

Contrary to China's long tradition in wooden architecture and timber works, large scale stone works have only recently started in the Han dynasty, mostly as statues of guardian beasts in a funerary setting. The practice of using stone as the preferred medium for figural sculptures and as an architectural framing device did not emerge until the introduction of Buddhist cave temples into third century northwestern China, eventually arriving at Pingcheng by the early fifth century. Yungang's application of western Classical systems of stone architectural image framing, as borrowed from Western Asia and India by way of Central Asia, were not accidental outcomes, but the result of an accumulation of a series of conscious choices made by successive Tuoba sovereigns, prompted by the geographical and cultural contexts in which they lived. Subsequently, new material culture practices were generated out of these specific historical moments that were particular to the Northern Wei. The main Buddha figures of the Five Caves of Tan Yao (figs. 19a, b, c, d, e)

\footnotetext{
${ }^{278}$ Su Bai 1994, pp. 35-36.
} 
share the same "fullness in the face, deep-set eyes that are thin and elongated, with a highridged nose and a strong body." 279 Their "foreign" looks were determined by the sculptural elements that had evolved from practices and aesthetic representations of Gandhara (fig. 20) and Mathura (fig. 21) in origin.

The visual outburst conveyed by monuments making use of images that implant powerful emotions in the viewer's mind did not, in my view, exist in the Chinese tradition until the dawn of the Northern Wei with the Tuoba's excavation of the Yungang grottoes. It should be emphasized that these specific choices made by the Tuoba distinguished them from rulers of the southern states, who would not necessarily have had embraced and deployed foreign material and cultural intrusions in the same manner. In the very act of designing and creating the Yungang grottoes, imperial involvement reveals major features of the Tuoba attitude and their newly formed power. This chapter will use aspects of the sculptures and caves to explore the different expressions and agencies of kingship in the Pingcheng period.

When we think of the Yungang grottoes in the Northern Wei, so much of what we now understand has been conceived in a teleological framework. We no longer think of asking why or how these larger than life-sized stone Buddha sculptures were created at this particular moment when northern China was unified under a nomadic rulership, one with strong ties to Central Asia via the steppe. As the first of its kind to appear in China, combining Buddhist art with notions of kingship, it is easy to take for granted the conscious and innovative designs at Yungang as simply an epiphenomenal cultural product that was tied to the spread of Buddhism being in some way natural or given.

\footnotetext{
${ }^{279}$ Su Bai 1986, pp. 435-446.
} 
The Yungang grottoes have been traditionally approached by previous scholarship as a distinctive aspect of Northern Wei Buddhism. ${ }^{280}$ Indeed, these caves were excavated against a particular cultural-historical background when Buddhism, as a new belief system, was seen by scholars such as Erik Zurcher, Tsukamoto Zenryū and Tang Yongtong to have been separately assimilated and domesticated in northern and southern China. ${ }^{281}$ In particular, Zurcher noted that northern Buddhism was strongly characterized by an influx of missionaries, scriptures and ideas from Central Asia, as well as large-scale translation projects backed by imperial patronage. Building upon this tradition, the Tuoba, as conquest rulers of nomadic origins, established the first ruling house in present-day northern China to have deployed Buddhism as state religion on such a widespread scale. ${ }^{282}$ The emergence

\footnotetext{
${ }^{280}$ Wright 1959; Li Hengcheng 2005; Sekino and Tokiwa 1926-1938; Soper 1966; Huntington 1986; also Mizuno and Nagahiro 1952-1956.

${ }^{281}$ Erik Zurcher suggested that in the south, Buddhism was amalgamated with domestic religions and local schools of thought, especially those of the elite; see Zurcher 2007, pp. 114-116. These local schools of thought included Confucianism, xиanxue 玄學 (Learning of the Abstruse, or Dark Learning), and an art of rhetoric known as qingtan 清談 (Pure Conversation), of which the latter two had enjoyed immense popularity in the Southern dynasties; see Qian 2001, p. 7. Most importantly, as much of the discussion of Buddhist ideas was carried out in the rhetoric of xuanxue and qingtan among the educated elite, this practice gave rise to what Tsukamoto Zenryū called Dōkyō-teki Bukkyō (Daoist Buddhism); see Tsukamoto 1942, p. 14. However, the more conservative treatment of Buddhist doctrines in the north, being embraced as a matter of personal conviction, often resulted in what Tang Yongtong saw as confrontations of mutual destruction between Buddhist followers and the non-believers, ultimately turning into wholesale suppressions of Buddhism at different points in Chinese history. In contrast to its volatile nature in the north, in the south, Buddhism was emphasized for its teachings of $y i$ 義 (doctrine) and $l i$ 理 (reasoning). Southern Buddhism was characterized by its interchangeability with хиапхие as a school of thought, drawing from commonalities with the philosophies of Zhuangzi and Confucius. In their attitude toward Buddhism, southerners tended to end up in a debate on the strengths and weaknesses of the three teachings of Confucianism, Daoism and Buddhism. Though sometimes carried on heatedly, such discourse nonetheless remained a debate on the level of reasoning, without becoming an interjection in one's personal conviction; see Tang Yongtong 2008, pp. 280, 332 .

${ }^{282}$ As eminent social figures, Buddhist monk scholars had a large religious following which they could call upon, most often consisting of both Han and non-Han peoples. By allying themselves with Buddhist religious figures, nomadic rulers of these fledging northern states found a convenient medium to appeal to their subjects on a common ground, one on which the former would not be an inferior participant for being a foreigner; see Li Qingling 2009, pp. 25-27. During the Sixteen Kingdoms period, several of the northern rulers were actively involved in promoting Buddhist teachings in their respective states. Shi Le 石勒 and Shi $\mathrm{Hu}$ 石虎 of the Later Zhao 後趙 (319-351 CE), Fu Jian 苻堅 of the Former Qin 前秦 (351-394 CE) and Yao Xing 姚興 of the Later Qin 後秦 (384-417 CE) had all been personally involved in sponsoring translation projects of Buddhist sutras or inviting eminent monk scholars to be at the service of their courts. On the other
} 
of these functional “cave temples" (shikusi 石窟寺) ${ }^{283}$ in the domestication of Buddhism in northern China undoubtedly testified to the fact that local communities worked together in building temples, making votive images and other pious works. In this context, the caves on the mountainsides were to be more than showcases of Buddhist images, but served as an important communal center for worship and offering.

In addition, the Five Caves of Tan Yao commissioned by Emperor Wencheng 文成帝 (Tuoba Jun 拓跋濬, r. 452-465) have been commonly recognized as carved to bear the likeness of five preceding Northern Wei emperors. They house the biggest stone sculptures of the Yungang grottoes and stand out as a reification of a distinctively new concept of venerating the Northern Wei emperor as "the coming Buddha Maitreya". ${ }^{284}$ This notion was devised by the first Daoren tong 道人統 (Controller of Clergy, also Controller of Religion), ${ }^{285}$ Fa Guo 法果 (birth and decease dates unknown), who was active between

hand, Juqu Mengxun 沮渠蒙遜 of the Northern Liang 北涼 (397-439 CE) was said to have dedicated a stone sculpture at the Tiantishan grottoes in honor of his mother.

${ }^{283} \mathrm{Su}$ Bai had coined the term shikusi, emphasizing on their function as the place where monks resided, meditated, copied out scripture manuscripts, and where lay communities gathered for religious activities. Therefore, he refers to these grottoes as "cave temples" to better define their social and practical function; see Su Bai 1986.

${ }^{284}$ Wright attributed the Northern Wei's success in resolving the conflict of loyalties between state and religious powers, ever so intensely played out in contemporary southern courts, to Fa Guo's ingenious devise of regarding the reigning Northern Wei emperor as a Buddha incarnate; see Wright 1959, p. 61. Apart from resolving the conflict of loyalties, Wolfram Eberhard sees Fa Guo's veneration of the Northern Wei emperor as "the coming Buddha Maitreya" to be a delicate means of legitimizing the Tuoba kingship. In his view, the Tuoba sovereign knew very well that his people would be regarded as "barbarians" by the Han Chinese gentry of the old system, regardless of whether or not they conformed to the patterns of Confucian behavior. The Tuoba's traditional practice of Shamanism might very well be regarded by the Han Chinese as similar to that of the "superstitions" held by the ordinary uneducated. Faced with such a dilemma, upholding Buddhism to receive Fa Guo's veneration in return was an appropriate alternative to bolster the Tuoba's superiority as rulers; see Eberhard 1952, pp. 80-81.

${ }^{285}$ The selected Daoren tong was to be the most pre-eminent position in the Buddhist clergy, at least as recognized by the state. He was to lead the entire Northern Wei Buddhist community by personal authority and charisma, and to coordinate state-wide religious affairs on a macro level, leaving the affairs of each monastic temple to the resident abbot. However, during the initial period of appointment, the Daoren tong remained a nominal figure without concrete responsibilities. It was not until the later restoration of Buddhism in Emperor Wencheng's reign ( 452-465) that the Daoren tong would take on new responsibilities in carrying out aspects of state rulership; see Liu Kangle and Han Lin 2008, p. 198. 
386-409 in the reign of the founding emperor, Emperor Daowu 道武帝 (Tuoba Gui 拓跋

珪, r. 386-409).

初, 法果每言太祖命睿好道, 既是當今如來, 沙門宜應盡禮, 遂常致拜。謂 人曰: 能鴻道者人主也，我非拜天子，乃是禮佛耳。286

At the time, Fa Guo often spoke of Taizu's ${ }^{287}$ wisdom and his love for the Buddha's teachings, which makes him a present-day Buddha. It is entirely proper that Sramana should do reverence, and so they frequently bow [to the emperor]. [Fa Guo] says to other, "One who can promote the teachings of Buddha is the sovereign of the people. I do not bow to the Son of Heaven; it is the Buddha whom I am worshipping." 288

Scholars of art history, focused on Yungang's contributions for its rich source of Buddhist imagery, held an immense interest in decoding the main Buddha sculptures in the Five Caves of Tan Yao as representing a particular iconographic scheme. Proponents for this approach include Sekino Tadashi and Tokiwa Daijo in the 1930s, Alexander Soper in the 1960s, and John Huntington in the 1980s. ${ }^{289}$ In their view, the Yungang grottoes embodied the concept of a family cult in its design, from serving as an ancestral temple for the imperial household to holding a talismanic function for the Northern Wei state with the sovereign acting as the patriarch figure, as prescribed by Confucian teachings. These interpretations suggest that by dedicating the earliest caves to ancestors of the imperial family the Tuoba initiated the practice of adopting images of deities as a part of imperial iconography. However, what is lacking here is a sense of imperial agency and a focus on the material and technological particularities that conceived of the excavation of the Yungang grottoes in early fifth century northern China.

\footnotetext{
${ }^{286}$ Wei shu, juan 114, p. 3030-3031.

${ }^{287}$ Taizu 太祖 is the temple name of Emperor Daowu, founding emperor of Northern Wei dynasty.

${ }^{288}$ For English translation, see Soper 1959, p. 95.

${ }^{289}$ Sekino and Tokiwa 1926-1938, pt ii, pg. 16; Soper 1966, p. 242; also Huntington 1986, pp. 142-160.
} 
Moving forward from previous scholarship, this thesis will focus on the imperial agency of the Yungang grottoes outside of a traditional Buddhist context, as a direct medium for public imperial expression. This chapter intends to temporarily remove the Yungang grottoes from this already much studied Buddhist narrative and turn to examine the Tuoba's conceptions of these larger than life-sized stone sculptures carved into a low mountain range, not as religious icons, but as imperial monuments on behalf of the Northern Wei sovereigns. The Tuoba's innovation lies in their ability to adopt Buddhist material and imagery as convenient visual agents for a new imperial expression that diverged completely from previous Chinese practices, one which was in line with the Hellenistic and Western Asian visual commemorations of victory and conquest.

In pursuit of their new claim to dynastic power, the Tuoba continued to seek out means through which they could maintain, what I would like to call a "dual presence" 290 in their self-expression as sovereigns of northern China. The Northern Wei, at its apex, ruled over an expanse of land that stretch from the eastern end of the Eurasian steppe to the Central Plains in the Chinese heartland (figs. 1a, b). On one hand, the Chinese had a tradition of dynastic commemoration using words that usually took the form of a stone stele (fig. 26), as opposed to visually representing the sovereign's image for public display. It was important for the Tuoba to maintain this tradition, so as not to appear as ostentatious and crude conquerors in the face of their Han Chinese subjects. Nonetheless, their culturalgeographical proximity to the steppe-land predicated that the Tuoba were exposed to, and more ready to adapt, the monument traditions of their contemporaneous Sassanid (224-651 CE) sovereigns, most notably seen in the mountain range rock reliefs at Naqsh-e Rostam

${ }^{290}$ See a discussion of this term in chapter one, pp. 2-3. 
(fig. 22) and Taq-e Bostan (fig. 23) in present-day Iran. ${ }^{291}$ The Sassanids were actively involved in a competitive exchange of visual and ritual manifestations of kingship with Byzantium through the construction of monuments from third to seven century CE. Whereas the Byzantines cultivated spaces and activities of urban environments (fig. 24) to celebrate the emperor, the Sassanids inherited and engaged a tradition of Western Asian memorial intervention in natural environments. ${ }^{292}$ In this discussion, I have benefitted from Matthew Canepa's explanation of this competition and the ways in which different approaches to the manifestation of kingship were derived as a result.

As neither the long-standing Chinese tradition, nor their own nomadic practices included representations of rulers, the Tuoba had to experiment with creating their own stone monument tradition. They benefitted from the ways in which Buddhism was exported into northern China, relying heavily on the use of sculptures and cave temples. This chapter will deconstruct the ways in which the Tuoba took advantage of the new material forms and practices transferred into northern China as introduced by Buddhism. Using Stuart Piggott's idea of a techno-complex, ${ }^{293}$ we can enumerate a whole range of activities that were essential to the realization of this complex in the Northern Wei, namely monk scholars, texts and translators, images, architecture, as well as ways of working in stone. Though originally a set of practices and visual imagery that accompanied the spread of Buddhist teachings, the particular cultural-historical background of the Tuoba allowed them to reconfigure this Buddhist complex to suit the needs of the Northern Wei state.

\footnotetext{
${ }^{291}$ Naqsh-e Rostam is located about 3 kilometers northwest of Persepolis, in Pars province Iran. The name in Persian means "Picture of Rostam" because of the seven gigantic Sassanid rock carvings (226-309 CE) below the tombs of the Achaemenian kings (522-404 BCE). Taq-e Bostan is located 5 kilometers from the city center of Kermanshah in western Iran in the heart of the Zagros mountains. It contains some of the finest and best-preserved examples of Persian sculpture under the Sassanids.

${ }^{292}$ Canepa 2009, p. 99.

${ }^{293}$ See a discussion of this idea in chapter one; see pp. 32-38.
} 
Moreover, it was through the tradition of Buddhist sculptures developed at Yungang that the Tuoba attempted to claim divine protection over an inspired rulership, which was unprecedented in the Chinese tradition of kingship.

The Yungang grottoes can be treated as metaphorically embodying the two sides of a Hellenistic coin. (fig. 25) In effect, the Buddhist iconography and images applied within the caves can be seen as a new vocabulary that combined the sovereign's own image with symbols of power and victory. The stone Buddha sculptures were created with the intention of representing the likeness of Northern Wei emperors, while the use of stone and the impressive size of these sculptures also served as a symbol of imperial might and permanence. We can perhaps understand that the Tuoba, as victorious conquerors, were eager to manifest themselves and their power in a manner parallel with that of contemporary Hellenistic and Sassanian imperial practices, such as in the construction of monuments and the minting of coinage. On the other hand, the practice of previous Chinese emperors, whose very claim to supremacy and the Mandate of Heaven was derived from the mysteriousness and transcendence that surrounded them, required the emperors to remain shrouded, away from their subjects. Here, the Tuoba's "dual presence" is beautifully merged at Yungang. The sculptures fulfilled the Tuoba's desires of selfproclamation as Northern Wei emperors, while taking care not to reveal their true features to those who should regard them in awe, ultimately merging the two identities by representing the Northern Wei emperor as a present-day Buddha.

\section{A NEW IMPERIAL MONUMENT: THE FIVE CAVES OF TAN YAO}

Our understanding of the Tuoba's revolutionary approach to establishing a new monument tradition starts with the imperial project commissioned by Emperor Wencheng in the 
Heping reign (460-465). The then Shamen tong 沙門統 (Controller of Sramanas, a changed title from the previous Daoren tong), ${ }^{294}$ Tan Yao 曇曜 (dates of his birth and decease are unknown), ${ }^{295}$ proposed the excavation of the initial five caves at the Wuzhou Mountain. As recorded in the Wei shu:

\section{曇曜白帝，於京城西武州塞，鏊山石壁，開窟五所，鏶建佛像各一。高者七 十尺，次六十尺，彫飾奇偉，冠於一世。296}

Tan Yao submitted to the Emperor [a proposal] to dig out the mountain wall of Wuzhou Pass, west of the capital, open up five caves, and carve Buddha images in them, the tallest to be seventy feet high, the next tallest sixty feet high, with carvings and decorations superb, a crowning glory to the world. ${ }^{297}$

One might question how a project apparently instigated by the Shamen tong, Tan Yao, could reflect an imperial agency? The intertwined relationship between religion and politics is an age-old phenomenon. According to Pierre Bourdieu, religion's two fundamental social functions are: 1) to consecrate the social order as legitimate; 2) to provide people with a means to make sense of their positions in the social order. ${ }^{298} \mathrm{He}$ further claimed that, "religion conserves the social order by contributing ... to the 'legitimation' of the power of 'the dominant' and to the 'domestication of the dominated"". ${ }^{299}$ Much like the Christian missionaries sent from Rome to Anglo-Saxon England who realized the importance of first converting the kings and their immediate

\footnotetext{
${ }^{294}$ Tan Yao had first assumed the position of Daoren tong after the death of Shi Xian in the early Heping era (460-465), when the title was changed to Shamen tong; see Wei shu, juan 114, p. 3037. The change of a single term from the previous Daoren tong to Shamen tong, though passing in the accounts of the Wei shu, is evident of a shift of imperial focus. While the term Daoren referred to members of the religious community, treating both Buddhism and Daoism as equals in the Northern Wei religious life, Shamen indicates an emphasis on the former's importance in state rulership.

${ }^{295}$ See Gaoseng zhuan, juan 11, p. 413 for a very brief mention of Tan Yao in the biography of a contemporary monk by the name Xuan Gao 玄高. Tsukamoto Zenryū's work in Japanese contains a detailed discussion of Tan Yao's birth and decease dates. He noted that Gaoseng zhuan was completed by Hui Jiao in 519, close to around fifty years after Tan Yao's death, according to his activities in Northern Wei history, but surprisingly there was no dedicated biography of him; see Tsukamoto 1942, pp.145-152.

${ }^{296}$ Wei shu, juan 114, p. 3037.

${ }^{297}$ English translation consulted Hurvitz 1956, p. 72, with modifications.

${ }^{298}$ Bourdieu 1991, pp. 39-41.

${ }^{299}$ Bourdieu 1991, p. 4.
} 
followers before converting the rest of the people, ${ }^{300}$ the Northern Wei emperor was the most desired patron of the Buddhist clergy. The merging of this mutual interest between Buddhism and the Tuoba sovereigns was materialized by the conception of the Yungang grottoes. Tan Yao's biddings simply served as a convenient driving force that motivated Emperor Wencheng to explore his own ambitions in exploring new expressions of the Tuoba kingship.

We can suppose from their sheer size that these stone Buddha sculptures were to be more than just votive offerings on behalf of the reigning emperor. The materiality of these sculptures was meant to convey a sense of imperial agency, awing the viewers into submission to the imperial might. At the same time, the caves of Yungang not only functioned as a religious space for worship, but embodied immense ancestral significance, especially if we take into consideration the Tuoba's own tradition of excavating caves out of mountainsides to create a functional space for the purpose of an ancestral temple. In the "Treatise on Rites" of the Wei shu:

\section{魏先之居幽都也，鋥石為祖宗之廟於烏洛侯國西北。自後南遷，其地隔遠。 真君中, 烏洛侯國遷使朝獻, 云石廟如故, 民常祈請, 有神驗焉。其歲, 遣 中書侍郎李敞詣石室, 告祭天地, 以皇祖先妣配。。。石室南距代京可四千 餘里。 301}

The forefathers of the state of Wei had resided in Youdu; ${ }^{302}$ they excavated into the mountain rocks to build an ancestral temple located northwest of the state of Wuluohou. ${ }^{303}$ Later, after [they] relocated to the south, [they] were distanced from this place. During the years of the Taiping Zhenjun reign, emissaries from the state of Wuluohou who came to pay tribute spoke of the stone temple that was preserved

\footnotetext{
${ }^{300}$ In the case of these Christian missionaries, they had encountered more hindrance in this process of conversion most probably due to the decentralized power held in the hands of the bretwaldas, the rulers of Britain, in contrast with the Northern Wei autocracy; see Mayr-Harting 1972, pp. 18-21.

${ }^{301}$ Wei shu, juan 108, pp. 2738-2739.

302 The region consisting of present-day northern Hebei province and parts of Liaoning province.

303 The state of Wuluohou 烏洛侯国 has existed only in the historical records of the Wei shu, in which a section is dedicated to this nomadic group that had most likely been close to where the Tuoba clan had originated, which is around present-day Daxing'an mountain range in northwestern China.
} 
in perfect condition. Local people frequently worshipped [there], and [the place] was proven efficacious. That year, [Emperor Taiwu] sent the Deputy Minister of the Secretariat, Li Chang, to the stone temple to make sacrifices to Heaven and Earth, with the imperial father and mother as correlatives ... The Dai capital ${ }^{304}$ is approximately more than four thousand $l i$ south of the stone temple. ${ }^{305}$

Against this background, the excavation of the caves was as much an act of display by the Tuoba sovereigns in manifesting their devotion to the Buddha, as it was an assertion of the Tuoba's kingship through a public worship of their lineage. Bearing this in mind, I will argue that the caves at Yungang were conceived with the intention of functioning both as a "cave temple" for the worship of Buddha, as well as for paying reverence to the Tuoba ancestral lineage in the capacity of an ancestral hall. The sculptures at Yungang, despite using Buddhist imagery as iconography, were very much designed as monuments of the Tuoba's kingship. Either through a direct visual appeal of the sovereign's magnificence and power, as will be discussed when we look at the Five Caves of Tan Yao, or by adopting Buddhist imagery as an indirect allusion to contemporary political phenomena, as revealed in the conception of paired Buddhas and paired caves.

As early as the 1980's, John Huntington had already raised the idea that the Tuoba sovereigns achieved the deification of their imperial ancestors through the main Buddha figures in the Five Caves of Tan Yao. He "decoded" the five main Buddha sculptures in the Five Caves of Tan Yao as a complete iconography that was to serve an auspicious function. ${ }^{306}$ According to his interpretation, the five main Buddha images formed a coherent iconographic scheme:

\footnotetext{
${ }^{304}$ Another name for the Northern Wei capital at Pingcheng, since the name of the Tuoba's regime had first been that of Dai before changing to Wei.

305 Author's trans.

${ }^{306}$ He claimed that this viewpoint is situated within the greater world of Buddhist iconography, that given the highly complex iconographic programs being developed contemporaneously in other parts of Asia, it would
} 
Cave XX: $\quad$ Sukhavati Amitabha (Buddha of the past)

Cave XIX: Ketumati Maitreya (Buddha of the future)

Cave XVIII: Sakyamuni/Vairocana(Buddha of the present)

Cave XVII Tusita Maitreya (Buddha of the future)

Cave XVI Laiying Amitabha (Buddha of the past)

This particular scheme of pairing each sculpture to a particular Buddha has been questioned by some recent scholars of Buddhist art history as somewhat problematic. Dorothy Wong and Pokan Chou both pointed out to $\mathrm{me}^{307}$ that the Buddha Vairocana features most prominently in the Flower Garland Sutra (also known as Avatamsaka sutra and Huayan Jing 華嚴經), which was a popular teaching of the later dynasties, particularly of the Khitan Liao (907-1125 CE), but not of the Northern Wei, during which the Lotus Sutra (also known as Miaofa Lianhua Jing 妙法蓮華經) was the most influential and widely circulated Buddhist scripture. ${ }^{308}$ For this reason, the idea that Buddha Vairocana would be featured in the Five Caves of Tan Yao as the central figure is questionable.

While the iconographic scheme of the Five Caves of Tan Yao is a subject of debate that requires further study by Buddhist art historians, the intent of this chapter is to draw our attention away from the need to identify the power of Yungang as having derived entirely from its religious aspects. For now, disregarding pairing the iconographic imagery to specific Buddhas will allow us to focus on the power of Yungang as a monument of kingship, derived from the sensory appeal of the sculptures themselves, in which the agency of the Tuoba sovereign could be conveyed through a direct visual appeal of the immense figures. These figures were imbued with the sovereign's power in two respects.

\footnotetext{
be inconceivable that Tan Yao would have designed the cluster of five caves without an inherent iconographic theme; see Huntington 1986, pp. 142-160.

${ }^{307}$ I would like to thank Professor Dorothy Wong and Professor Pokan Chou for going over this issue regarding Buddhist iconography of the Five Caves of Tan Yao with me at the 2011 AAS conference in Hawai'i.

${ }^{308}$ Miaofa lianhua jing (T.9, no. 262).
} 
First of all, only a major authority could have commissioned these images, staggering in their size. Secondly, the implied likeness between the sculpture figures and the Northern Wei emperors also indicated this authority as being equal to that of a Buddhist deity. Moreover, we will also begin to recognize that much like the Hellenistic and Sassanian monuments, with their visual repertoires of conquest and submission, the Tuoba managed to achieve the same statements at Yungang through a combination of literary and statuary expression.

The impetus behind this unprecedented monumental project, in the form of the Yungang grottoes, required a major change from previous monument practice and a change in conceptual framework. The notion of imperial monuments in the Western view presupposes a tangible image or statue that embodies a sense of immanence and permanence, one that endures the test of time with the application of specific imagery that evoke emotions such as that of triumph and conquest. However, in the early Chinese memorial culture, the notion of imperial commemoration took the form of the ancestral cult, which was achieved through a ritualized ${ }^{309}$ remembrance based on practices of recitation, contemplation and reflection. ${ }^{310}$ It is the importance accorded to the materiality of language and remembrance that consisted of the remarkable feature of "memorialization" in an early Chinese context, giving rise to the tradition of inscribing words on stone steles in the previous Qin and Han dynasties. The agency of stone steles on

\footnotetext{
${ }^{309}$ Ritual offerings and performances were simply systematic ways of reinforcing the structured mental effort on the part of the living which reached out to the ancestors; see Brashier 2011, p. 2-3.

${ }^{310} \mathrm{~K}$. E. Brashier also highlights the "fixed and repeatable" nature of the hymns inscribed on Eastern Han steles to point out the "memorative" nature of these texts; see Brashier 2005, p. 260.
} 
its beholders is that of memorization and recitation, through which a tangible material demanded a preservation of the inscribed knowledge within the memories of the living. ${ }^{311}$

The Tuoba's adoption of Buddhist iconography, which embodied a repertoire of shared imagery and teachings, turned the sculptures at Yungang from a tangible memorial in the Western tradition into an inherent practice of rhetorical remembrance that fulfilled the traditional Chinese understanding of a memorial culture. This not only required a familiarity with new materials as medium, but also suggests that the Tuoba were experimenting with new ways of conceiving the agency of kingship. As I shall explore in the following section, the Yungang grottoes not only represented the Tuoba's choice of using images over the use of words in their construction of a distinctly Northern Wei practice of memorialization, the stone sculptures also changed the ways in which the Tuoba sovereigns wished to be viewed by their subjects.

\section{From Words to Images}

Chinese society was, and still is, one in which writing served as the essential tool of the ruling elite and a source of a shared view of the world. The written word was a tool that established and expressed social bonds between social groups and different generations, making explicit their allegiances to one another, ultimately maintaining order in society. In addition to writing with a brush, texts were often cut into stone in the form of steles (bei 碑)

\footnotetext{
${ }^{311}$ In Brashier's study of the Eastern Han stele, he sees it as part of a memorial culture in two senses. First, the nature of the hymn set it against a background culture of memorized knowledge. Second, the stele was a memorial in the tangible present of its stone, which was intended to preserve the dedicatee for future generations; see Brashier 2005, p. 268.
} 
(fig. 26), which meant that they could be put on "public display"312 and that they would endure. However, in referring to such writing as "public display", we also need to keep in mind the limited public sphere in which these texts played their role. ${ }^{313}$ In traditional Chinese antiquarian classification, devised by the Qing 清 (1636-1912 CE) scholar Ye Changzhi, there were four basic rules for erecting steles according to the Confucian tradition. They are for the purposes of extolling virtues (shude 述德), commemorating achievements and military campaigns (minggong 銘功), recording events (jishi 記事), and compiling words of wisdom (zuanyan 纂言). ${ }^{314}$ As such, the combination of words and stone created a perfect medium for emperors of the Chinese tradition to celebrate their own achievements as virtuous sovereigns, especially after a successful military campaign or the enthronement of a new emperor.

The act of erecting steles for imperial commemoration was further incorporated into the Chinese fengshan 封禪 rituals, as a crucial component in the emperor's sacrifice to Heaven and Earth respectively. ${ }^{315}$ The most famous stele inscriptions of this nature were erected in the Qin dynasty as a part of the fengshan ceremonies carried out by the First

\footnotetext{
${ }^{312}$ Michael Nylan uses the term "public display" in reference to one of two senses: either the ritual spectacle took place outside the palace complexes or, if taken place inside the palace, word of the display was meant to be relayed to the outside; see Nylan 2008, p.60.

${ }^{313}$ Kern 2008, p. 224.

${ }^{314}$ Yushi jiaozhu, juan 3, p. 315.

${ }^{315}$ The earliest existing textual appearance of the fengshan rituals was in the Writings of Master Guan (Guanzi 管子), a compilation of Chinese philosophical materials named after the philosopher Guan Zhong 管仲 who was active in the seventh century BCE, Prime Minister to the Duke Huan of Qi, and was later edited by Liu Xiang 劉向 in the Western Han. In the section on fengshan, Master Guan attempts to dissuade the Duke Huan from carrying out the fengshan ceremony, as the latter compared himself to the Three King Ancestors of the ancient time who had taken order from Heaven to unify the world. Master Guan gave the example that in the ancient times when such grand ceremonies were held, the most precious types of food were available to be offered, finely thatched grass made into mats, and rare fish as ambrosia. These are indications that the reigning ruler has attained order under heaven in unifying the world. Master Guan pointed out to Duke Huan that as none of these auspicious signs in nature has occurred, he should not insist on holding the fengshan ceremony in worship of Heaven and Earth. Duke Huan then gave up the idea; see Guanzi, juan 50, pp. 1006-1011.
} 
Emperor Qin Shihuang 秦始皇 (Ying Zheng 贏政, r. 221-210 BCE) upon the unification of China in $221 \mathrm{BCE}$, as he toured the newly conquered eastern regions with the Classicists. It was there that he erected a series of stele inscriptions on the top of venerated mountains, and commissioned his Prime Minister Li Si 李斯 to draft the texts, extolling the emperor's virtues in bringing order to the realm and to commemorate his successful campaigns in unifying the other six states of the Warring States period. The Shiji preserves six of the altogether seven inscriptions, of which the inscription on the Zhifu Mountain 之 眾山 (present-day Yantai, Shandong province) dated to 218 BCE illustrates the general prose of the entire series. ${ }^{316}$ The inscription is presented here in its entirety for those unfamiliar with Chinese imperial inscriptions to get a better sense of the kind of rhetoric and language being used:

Now, in His twenty-ninth year,

維廿九年

According to the season of mid-spring, 時在中春

The mildness of yang has just arisen.

陽和方起

The August Emperor travels to the east,

皇帝東游

On His tour He ascends [Mt.] Zhifu,

巡登之罧

Looks down on and illuminates [the lands by] the sea.

臨照于海

The attending officials gaze in admiration,

從臣嘉觀

Trace back and contemplate [His] excellence and

brilliant accomplishments,

原念休烈

Recall and recite the fundamental beginning:

追誦本始

The Great Sage creates His order,

大聖作治

Establishes and fixes the rules and measures,

建定法度

Makes manifest and visible the line and net [of order]. 顯箸綱紀

Abroad He instructs the feudal lords;

外教諸侯

Brilliantly He spreads culture and grace,

光施文惠

Enlightening them through rightness and principle.

明以義理

The six kingdoms had been restive and perverse,

六國回辟

Greedy and criminal, insatiable -

貪戻無厭

Atrociously slaughtering endlessly.

虐殺不已

\footnotetext{
${ }^{316}$ The six inscriptions are included in chapter six, “Qin Shihuang benji” 秦始皇本紀, the Basic Annals of Qin Shihuang in Shi ji 史記 (Records of the Grand Historian) by Sima Qian; see Shi ji, juan 6, p. 249.
} 
The August Emperor felt pity for the multitudes, And consequently sent out His punitive troops, Vehemently displaying His martial power.

Just was He in punishment, trustworthy was He in acting, His awesome influence radiated to all directions, And there was none who was not respectful and submissive. He boiled alive and exterminated the violent and cruel, Succored and saved the black-haired people, And all around consolidated the four extremities. He universally promulgates the shining laws, Gives warp and woof to all under heaven Forever to serve as ritual norm and guideline.

Great, indeed, is [...]!

Within the universe and realm

One follows receptively His sage intent.

The multitude of officials recite His merits, Ask to carve [this text] into stone, To express and transmit the constant model. ${ }^{317}$

皇帝哀眾
遂發討師
奮揚武德
義誅信行
威燀旁達
莫不賓服
烹滅鲥暴
振救黔首
周定四極
普施明法
經緯天下
永為儀則
大矣口哉
宇縣之中
承順聖意
群臣誦功
請刻于石
表垂常式

皇帝哀眾 遂弡討師 奞揚武德 義誅信行 威燀旁達 莫不传服 烹滅彊暴 振救黔首 周定四極 普施明法 經緯天下 永為儀則 大矣口哉 宇縣之中 承順聖意 群臣誦功 表垂常式

As the First Emperor to reign over China in a unified entirety, Qin Shihuang's routine practice of carrying out the fengshan ceremonies at venerated mountains in all directions of his realm turned the word-stone-mountain complex into an imperial monument tradition that served as a marker of dynastic legitimacy. This was the ritual of kingship practiced by Chinese emperors from Qin and onward, one constructed with words and based on a shared knowledge of literary motifs rather than the use of visual themes or patterns. Chinese commemorative practice relied on a sense of an aligned world order as a result of the virtues and achievements of the reigning emperor, thus pleasing Heaven and Earth. The "shining laws" and "ritual norms" had an impact, not only on the human subjects of the Qin empire, but was followed "within the universe and realm", crossing between the human and natural worlds. As Martin Kern pointed out, the expression of kingship, having derived agency from the stone inscriptions in which the calligraphy was an important

\footnotetext{
${ }^{317}$ Translation after Kern 2000, pp. 35-37.
} 
aspect of culture and sovereignty, "extended from the human sphere into the cosmic realm, transforming a natural site into a site of civilization and human history." ${ }^{318}$ In this memorialization tradition, the viewers of the stele inscriptions became recipients and, in turn, carriers of this public memory.

In this manner, Chinese dynastic commemorative tradition was distinct from the Hellenistic and Persian portrayals of triumph that instilled different visual sensations in their viewers, such as the Arch of Constantine (dedicated in $315 \mathrm{CE}$ ) in Rome, Italy and the rock-face relief at Naqsh-e Rustam (present-day Fars, Iran) of Shapur I (r. 240/42270/72 CE). The Arch consists of relief scenes from the Italian campaign of Constantine against Maxentius, depicting Constantine's army victorious at the Battle of Milvian Bridge while the enemy drowned in the river Tiber (fig. 27). Similarly, the rock relief of Shapur I dated to the third century depicts Shapur's triumph over the Roman emperor Philip (fig. 28), who is on his knees begging for peace. What these reliefs accomplish through direct visual impact, the stele inscriptions convey in a didactic manner. The inscription on the Zhifu Mountain does contain narratives of how the emperor sent out "punitive troops", who "boiled alive and exterminated the violent and cruel". Nonetheless, the viewers are being told what had happened and how they should remember the events, as dictated by the rhetoric. It is only with the Tuoba's excavation of the Yungang grottoes that the notion of producing a direct visual impact onto an audience was incorporated into the Chinese monument tradition, through which a new agency of kingship was deployed.

${ }^{318}$ Kern 2008, p. 225. 


\section{Changing Agencies of Kingship}

The transition from using words to images in the Northern Wei monument tradition involved more than just a change in the method of communication. In fact, the agency of kingship as derived from the Mandate of Heaven, which is the reason why Chinese emperors made regular sacrifices to Heaven and Earth in times of blessing and hardship, was transferred into the emperor's own hands. The inscriptions and reliefs on Mount Behistun $^{319}$ (fig. 29a) near the city of Kermanshah in western Iran provide good examples of how Darius I (r. 522-486 BCE) adopted the use of words to reaffirm the legitimacy of his rule as derived from divine will, but turned to the application of images to illustrate his power and authority which had earned him the empire.

In the introduction of the Behistun inscriptions, Darius says, "By the will of Auramazda 320 these lands walked according to my law, as it was to them by me commanded, so they did." ${ }^{321}$ The notion that the sovereign had succeeded in ending warfare and in establishing an ordered and unified realm, either by the will of Auramazda or by the Mandate of Heaven, as the recipient of divine favor to command the lands, suggest a similar view of kingship in both Achaemenid Persia and Qin China. However, a look at the rock reliefs that accompany the inscriptions shows a different side of how Darius the Great wielded his

\footnotetext{
${ }^{319}$ The Behistun inscriptions and reliefs were authored by Darius I sometime between his coronation as king of the Achaemenid Empire in $522 \mathrm{BCE}$ and his death in 486 BCE. The inscription was written in three different cuneiform script languages: Old Persian, Elamite, and Babylonian (a later form of Akkadian). This piece of inscription is to cuneiform what the Rosetta Stone is to Egyptian hieroglyphs, as the document most crucial in deciphering the cuneiform script. The inscription is approximately 15 meters high by 25 meters wide and 100 meters up a limestone cliff. It is illustrated by a life-sized bas-relief of Darius I, attended by other figures.

${ }^{320}$ Also known as Ahura Mazda, Ohrmazd, Hourmazd, Hormazd, Aramazd and Azzandara. This is the Avestan name for a divinity who was proclaimed the uncreated God by Zoroaster, the founder of Zoroastrianism. Auramazda is described as the highest deity of worship in Zoroastrianism.

${ }^{321}$ The inscription begins with a brief autobiography of Darius, followed by a lengthy sequence of events in which he fought nineteen battles in a period of one year to put down multiple rebellions throughout the Achaemenid empire. Darius proclaimed himself victorious in all battles during the period of upheaval and attributed his success to the grace of Auramazda; see Olmstead 1935, p. 247.
} 
power so that the lands succumbed to his law. The life-sized bas-relief of Darius I (fig. 29b) depicts him holding a bow as a sign of kingship, with his left foot on the chest of a figure, ${ }^{322}$ lying on his back before the victorious sovereign. On his left are two servants; ten figures of a smaller scale stand to the right with hands tied and roped around their necks, representing the conquered subjects. In the fight to protect the throne, Darius had to rely on more than just divine will of Auramazda to ensure his success. The harsh measures of taking his opponents into captivity and subjecting them to public humiliation were emphasized to set an example for those who might be tempted to defy him, as the images serve to reenact Darius's triumph. As will be discussed in the following sections, by venerating the emperor as "the coming Buddha Maitreya", the Tuoba ingeniously combined the two sources of kingship at Yungang, blending the division between divine will and the emperor's own human agency.

Indeed, if we are to compare the sculptures at Yungang with the Sassanian monuments, the immediate impression is that the Buddhist imagery of the former appears too calm and peaceful to be an assertion of power and triumph on behalf of the Tuoba sovereigns. The rock reliefs of Naqsh-e Rostam and Taq-e Bostan convey power and triumph of the Sassanian kingship through images of the Sassanian sovereign in motion, whether it is that of Shapur I granting mercy to a kneeling figure of the Roman emperor Philip (fig. 28) or the investiture and triumph of Ardashir III over the Roman emperor Julian II (fig. 30). In both scenes, the sovereign is portrayed in the position of power and victory, and he is further distinguished from the rest of the people who are depicted in acts of obeisance and deference. However, while these images certainly struck fear and force into their viewer's

\footnotetext{
${ }^{322}$ The supine figure is reputed to be the usurper Gaumata, against whom Darius I had fought against in 522 BCE before he ascended the throne.
} 
heart, the Tuoba's adoption of Buddhist iconography, while subtle, exerted an additional sense of power through size, magnificence and peacefulness.

One must remember that different from life-like images of human that simply evoke secular feelings and emotions, the very nature of Buddhist iconography is to emphasize the universality of the Buddha's blessings, and to evoke the spiritual. Alongside this intensely spiritual message, the presence of the Buddha's image also brought secular issues to mind. The images would reveal to the faithful and knowledgable laymen the Five Precepts, which constitute the basic Buddhist code of ethics, undertaken by lay followers of both the Theravada and Mahayana traditions. In concise terms, these are:

1. Do not kill

2. Do not steal.

3. Do not engage in improper sexual conduct.

4. Do not make false statements.

5. Do not drink alcohol.

These precepts serve the same function as the laws for every society, and lay down the terms in which members of the society are to engage with one another. Though they were not inscribed on the rock surface next to the sculptures as were the Behistun inscriptions, or erected as stone steles in the Chinese monument tradition, they are implied within the very image of Buddha.

Whether this was an intentional design on behalf of the Tuoba sovereigns upon the commission of Yungang is not to be known, but the sculptures at Yungang had indeed combined the essence of both the Western (visual) and Chinese (rhetorical) monument traditions in the legitimization of kingship. The visually engaging qualities of the Sassanian rock reliefs that exert power and force on the viewers are preserved in the images of the Buddha, while the more didactic features of the Qin stone steles in glorifying 
the sovereign's achievements of bringing order to this world are also encapsulated in the presence of Buddha. Furthermore, through a reinvention of nature, the Tuoba sovereigns attempted to create new rhetorical narratives in order to establish the legitimacy of their rule. The claim for legitimacy, as pointed out by Max Weber, is "the need of any power ... to justify itself." 323 Justification for legitimacy in any form of domination stems from the need of privileged groups or individuals to look upon their acquired position and advantages as well deserved. This validity of a power may be expressed through a system of consciously made rational rules, rested upon personal charisma, or founded upon tradition. ${ }^{324}$ The deified kingship expressed at Yungang visually presents a strong case for an imperial strategy of legitimation through the spread and reception of imperial virtues. Not only did the Tuoba sovereign possess kingly virtues through his own accomplishments, he also embodied and received the duty of promoting the moral virtues of Buddhism.

By expanding the imperial commemorative tradition from a literary system to a set of visual and ritual languages derived from a Buddhist cave temple complex, the Tuoba constructed a rhetorical and sensational space in which they could renegotiate the terms of what defines a legitimate kingship. Moreover, it was through the material and visual expression at Yungang that the Tuoba demonstrated their ability to maintain a "dual presence" in their self-expression as emperors of the Northern Wei. In fact, the "Yungang Model", ${ }^{325}$ as coined by Su Bai in reference to the new grotto tradition that was seen to have developed, was an organic composite of artistic elements from China, India and a version of the transmitted Hellenistic stone architectural practice. Together, these various

\footnotetext{
${ }^{323}$ Weber 1978, p. 953.

${ }^{324}$ For Weber, the "pure" types of domination correspond to these three possible types of legitimation. The forms of domination occurring in historical reality constitute combinations, mixtures, adaptations, and modifications of these "pure" types; see Weber 1978, p. 954.

${ }^{325}$ Su Bai 1994, pp. 23-47
} 
strands of influence created a new form of representation for the imperial monument tradition in the Northern Wei to engage a wider audience.

\section{A NEW IMPERIAL APPROACH: THE CAVES AS ENGAGING SPACES}

With the excavation of the Yungang grottoes, the Tuoba sovereigns were not only experimenting with a different medium in the expression of kingship, but were attempting to reach out to a new social stratum in the Northern Wei society as the intended audience for their imperial legitimation. The previous Chinese imperial monument tradition based on the use of words and rhetoric was limited to the literate and elite audience only. The choices of stone as material, human figure as form, and the Buddha as iconography, would have all appeared rather new and unfamiliar to the scholar officials and elite who were raised in the literary tradition. Nonetheless, the universal applicability of Buddhism, at least as this faith had been promoted by the monastic communities in northern China by including the illiterate, ${ }^{326}$ commended itself for having already developed a set of technoand material-complexes that would facilitate the sovereign in developing new methods of engagement and with a whole new audience.

One of the underlying assumptions in the Weberian theory of legitimate rulership is that regimes have an absolutely, or nearly absolute, ability to possess over the minds of their subjects. However, J. E. Lendon argued that in an age without mass media and when the

\footnotetext{
${ }^{326}$ The appeal of Buddhism stemmed from its availability and applicability to all people regardless of background; it did not require literacy, and most importantly, it presented a promise of personal salvation to its believers. A cross cultural parallel can be made using the example of the acceptance of Christianity into Anglo-Saxon Britain. Charles Thomas held the view that the appeal of Christianity stemmed from its universal availability to all people; see Thomas 1981, pp. 33-34. In medieval China, Buddhist temple grounds provided an educational site for the lay public, mostly through public lectures and mural paintings that made the teachings of Buddha easy to understand, even for the illiterate; see Xie Chongguang 1990, pp. $58-60$.
} 
majority of a regime's subjects were illiterate, it is problematic for us to attribute strateties of legitimation to the Roman emperor. This would require that "the emperor believed that he could not only communicate effectively with his subjects, but also that he thought he could persuade great numbers of subjects by the means of communication available to him, and that he thought that this persuasion would contribute materially to his power." 327 While this thesis does not propose to examine the Tuoba kingship through the Weberian lens of legitimation, the act of switching from using words to images as the medium for imperial commemoration suggests that the Tuoba made an attempt to try out new approaches of effective communication with their subjects. It is precisely for the fact that the majority of the Northern Wei subjects would have been illiterate that Buddhism, also known as the "teaching by images" (xiangjiao 象教), proved to be a more accessible platform.

\section{Emperor in the Face of Buddha}

The caves of Yungang were, at the same time, iconographic settings and functional spaces that provide a particular set of relations for their onlookers. "What do pictures really want?" asked W.J.T. Mitchell, for whom vision is as important as language in mediating social relations, which are not reducible to language, to the sign, or to discourse. ${ }^{328}$ Whereas previous scholars argued that the foreign origins of the Buddhist faith granted the Tuoba a claim to legitimacy in a new belief system, where the new sovereigns were no longer considered as outsiders in the eyes of their Han Chinese subjects, ${ }^{329}$ I will argue that

\footnotetext{
${ }^{327}$ Lendon 2006, p. 60.

${ }^{328}$ Mitchell 1996, p. 82.

${ }^{329}$ Zurcher and Wright pointed out that the foreign origins and the universal applicability of the Buddhist faith were the very reasons for Buddhism to win over the support and protection of northern nomadic sovereigns. Once it became a competitive strand of popular teachings, Buddhism had another function across the Yellow River region in northern China. It provided non-Han sovereigns an attractive alternative to the
} 
it is the visual and tangible appeal of the sculptures and caves at Yungang which provided new modes of engagements that allowed the Tuoba to redefine expressions of kingship.

Visitors to Yungang become participants in a range of bodily perceptions, triggered by sight (upon seeing the stone sculptures from a distance), followed by the sense of touch (the tactile sensation of feeling the stone surfaces), and wrapped up with a feeling of somatic awareness (the physical sensation of lowering one's body in obeisance). The emotions evoked at Yungang include personal responses, public memories, as well as religious convictions, depending on the onlooker and the capacity of the visit. Here, it is the imperial intent behind the construct of these public memories at Yungang that will be examined with regard to the expression of the Tuoba kingship through a new monument tradition. The Five Caves each feature an oversized Buddha sculpture excavated out of the Wuzhou Mountain, which takes over most of the space within a single cave, leaving meager room to the left and right for sculptures of attending Buddhas and bodhisattvas, and decorated with scrolls of lotus, acanthus and linking roundels that fill up the rest of the cave. ${ }^{330}$ This composition forces the viewer to focus on the main image, while relegating all other elements into the background. Clearly, this particular spatial arrangement was intended to highlight the agency of the main Buddha figures within each cave.

\footnotetext{
Confucian principles for their control of the central plains, as the latter would have deprived them of an independent cultural and political identity. Moreover, Buddhist monks, who were often foreigners, depended on the sovereigns' favors, and without native family networks, proved to be useful and trustworthy subjects; see Zurcher 2007, p. 116; Wright 1959, p. 57. Many Chinese scholars, such as Zhang Jinlong and Luan Guichuan, view the Tuoba's affinity for Buddhism as having provided an alternative group of people for the sovereign to rely on apart from the Han Chinese officials who were educated in and practiced the Confucian tradition. At the Northern court, many Han Chinese officials continued to provide service to the Tuoba rulers, engaging in military and political state affairs. Many were local land owners and gentry through which the Tuoba could efficiently control the regional populations. Yet the political core remained closed off to the Han Chinese, consisting mostly of Tuoba families; see Zhang Jinlong 2002, p. 114; also Luan Guichuan 1995, p. 61.

${ }^{330}$ Su Bai 1994, p. 29.
} 
On the notion of the sort of power exerted by images and figures bearing a sense of realism, aesthetically pleasing or fearful images have been found to have the ability to exert power over a living audience, impressing them with the values of their subject matter or of their owners. ${ }^{331}$ This social agency ${ }^{332}$ of an inanimate image was achieved through engaging the viewer's attention to evoke certain responses. Caves 19, 18, 17, 16 (fig. 19b, c, d, e) are all enclosed by rock façades, as the caves were literally hollowed out of the mountainside. In particular, the façades of caves 19 and 18 (fig. 19b, c) consist of two vertically aligned openings that form an entrance and a framed window that reveal the main Buddha's face and upper body. The immediate visual impression of the sculpture is intentionally distorted so that when seen from the outside, one's gaze is directed at the face of the Buddha and nothing else. As a result of this partial view, the exact size of the sculpture cannot be gauged until the visitor steps into the cave. It is then that one is struck by the coolness of the cave and the magnificent figure that looms out of the shadows. The viewer is forced to tilt his/her head as much as possible in order to take in the full height of the sculpture; the face of the Buddha now seems to be much more distant than it was from the window view, putting the viewer into submission in its other-worldly gaze.

Cave 20 is the only cave at Yungang that is exposed in open air, but not as a result of the designer's original intention. It appears that cave 20 should also have had some sort of façade, though not necessarily the same as the other four, which were hollowed out of the mountainside and hidden behind a rock façade that was in one piece with the cave. The back wall of cave 20 shows square holes (fig. 19a), which were dug out to hold wooden rafters for the pavilion structure that served as a façade like that currently on the outside of

\footnotetext{
${ }^{331}$ Freedberg 1989, pp. 199, 201; also Rawson 2002a, p. 124.

332 Gell 1998, pp. 7-9.
} 
caves 5 and 6 (fig. 31). Regardless of the type of façade, it has eroded away and collapsed to reveal the entire cave in clear view. ${ }^{333}$ This was a rather serendipitous outcome as the main Buddha figure of cave 20, with its flamboyant display of marvelous sculpturing details to be seen from far away, provided a whole new sensory experience for the presentday visitor, who could for the first time take in the entire presence of the Buddha in one view. For once, Yungang could discard the modesty that the Tuoba inherited from previous Chinese imperial practices and appear as a dazzling jewel encased in the Wuzhou Mountain, asserting its presence, hard to be missed by a passing traveler.

Although without textual evidence to substantiate the assertion that the five main sculptures designed by Tan Yao were indeed created in the image of Northern Wei emperors, both Western and Chinese scholars accept the view that the Five Caves of Tan Yao were an integral element of the Tuoba's portrayal of the imperial lineage. ${ }^{334}$ In this case, the sight of these five caves would have evoked a sense of ancestral remembrance for the ruling household. The deification of Northern Wei sovereigns in the form of colossal sculptures, encased in the Tan Yao caves, is founded on the same concept as imperial deifications at the fringes of the Classical world. Hellenistic dynasties of Western Asia, such as Antiochus I of Commagene (present-day south-central Turkey) in the 1st century BCE (fig. 32), created gigantic statues to manifest his own representation alongside that of

\footnotetext{
${ }^{333}$ Li Hengcheng 2005, p. 46. Local Datong scholars, Yin Xian and Liu Junxi, raise a new possibility that the façade of cave 20 had most likely collapsed along with the west wall at the time of the Northern Wei excavation. This is because the platform, steps, and the stone walls of cave 20 have now been dated, according to the masonry style, which is similar to that of the mingtang (Hall of Brightness) in present-day Datong, Shanxi province, dated to the Taihe reign of Emperor Xiaowen. For this reason, the two scholars suggest that the collapse had most likely taken place during the excavation of the Heping reign under Emperor Wencheng, which allowed cave 20 to be re-designed into an exposed sculpture, rather than being hidden inside a cave; see Yin Xian and Liu Junxi 2006, pp. 339-343.

${ }^{334}$ Soper 1959, p. 96-97; Rowland 1937, pp. 101-102; also Du Doucheng 2009, p. 226.
} 
other gods. ${ }^{335}$ As put forth by Knauer, nomadic empires situated on the crossroads between the Hellenistic world and the eastern nomadic realms, such as the Kushans (second century BCE - third century CE), were most likely inspired by these statues of Western Asia, thereby producing larger than life-sized ancestral portraits in self-characteristic features (fig. 33). ${ }^{336}$

Scholars generally turn to two slightly earlier Buddhist dedications by Emperor Wencheng for further evidence to suggest that the Five Caves of Tan Yao were commissioned to fashion five Northern Wei emperors in the image of Buddha. ${ }^{337}$ In both scenarios, the statues were created with the specific intention of manifesting kingship through the representation of the reigning sovereign and the imperial ancestors. Bearing the face of the Buddha, these statues drew strength from a non-worldly spiritual source and were designed to impress upon the viewers. ${ }^{338}$ Referring to the year 452 before the project at Yungang had taken shape, the Wei shu states:

詔有司為石像, 令如帝身。既成, 顏上足下, 各有黑石, 冥同帝體上下黑
子。339

The authorities were commanded to fashion a stone image that would be in the likeness of the emperor's person. When this was completed [there were found to be] black stones on the face and under the feet that were mysteriously identical with the upper and lower moles on the emperor's body. ${ }^{340}$

\footnotetext{
${ }^{335}$ Knauer suggests that the statues of Antiochus I were most likely the source of this sudden urge to "go big" in stone sculpturing shared by both the Yungang and the Buddhas in rock niches in Bamiyan. Though the Bamiyan were intended to be seen from afar as there was never a wall of remaining rock in the front, Yungang took on the tradition of being half hidden within the cave sanctuaries; see Knauer 1983, p. 35.

336 These kingdoms were formed between the 3rd century BC and the 2nd century AD on territory Hellenized by the campaigns of Alexander and his successors; see Knauer 1983, p. 38.

${ }^{337}$ Scholars who interpreted these five caves as bearing imperial manifestations from a socio-political perspective include Soper 1966, p. 242; Sekino and Tokiwa 1926-1938, pt ii, pg. 16.

${ }^{338}$ While southerners continued to carry on the tradition of producing some of the largest and most dramatic spirit road sculptures, northerners proclaimed their power with larger than life-sized cliff carvings of the Buddha. It has been argued by Ann Paludan that in the north, care for the ancestors was largely transferred to Buddhist sites as tomb statuary took a second place; see Paludan 2006, p. 100-106.

${ }^{339}$ Wei shu, juan 114, p. 3036.

${ }^{340}$ English translation after Soper 1959, p. 96.
} 
Subsequently in 454:

敕有司於五級大寺内, 為太祖已下五帝, 鑄釋迦立像五, 各長一丈六尺, 都 用赤金二十五萬金。341

The authorities concerned [were] to have five standing images of Sakyamuni cast in the 'grand temple of the five-storeyed [pagoda]' on behalf of the five emperors from Taizu on; each to be sixteen feet high, with a total use of 25,000 jin of copper. $^{342}$

In the first account, the stone image was deliberately fashioned to be in the likeness of Emperor Wencheng himself. The supernatural appearance of the emperor's moles is described as evidence of resemblance between the person and his sculptural representation. This suggests that in the Northern Wei, at least by the time of Emperor Wencheng's reign, there was already a practice of replicating human images in a sculptural setting by drawing upon the notion of verisimilitude. ${ }^{343}$ On the other hand, the concept of the number "five" was coded with imperial significance, as five copper statues of the Buddha Sakyamuni were cast and dedicated on behalf of the five emperors who preceded Emperor Wencheng. The design behind the Five Caves of Tan Yao combined the practice of sculptural representation by verisimilitude with the coded significance of the number "five" in the imperial lineage. By correlative implication, the caves evoked the viewer's imagination into believing in the identity of the image and that of the depicted. As argued by Kris and Kurz, the actual nature of the image is less important, as the belief in the "magical function" of the image grows stronger. ${ }^{344}$

\footnotetext{
${ }^{341}$ Wei shu, juan 114 , p. 3036.

${ }^{342}$ Sekino and Tokiwa 1926-1938, pt ii, pg. 16; English translation after Soper 1966, p. 242.

${ }^{343}$ This required the viewer of the sculpture to believe that it is real, however much one may wonder at the kind of craftsmanship that makes the figure appear like the actual person. Also, the issue here is the striving for resemblance, not the actual attainment of it, or whether the sculpture can objectively be said to have achieved verisimilitude; see Freedberg 1989, pp. 199, 201.

${ }^{344}$ Kris and Kurz 1979, p. 77.
} 


\section{An Imperial Platform}

The excavation of the Yungang grottoes can also be understood as the product of intense political struggle in the formative period of the Northern Wei, during which the sovereign learned to manage the growing influence of popular religions, turning them into an extension of imperial power and the manifestation of kingship. As the imperial motivations behind the excavation of Yungang turned what was originally intended as a religious sanctuary into a space that conveyed a sense of imperial agency, the target audience of these sculptures was no longer limited to simply those who followed in Buddhism. When a Northern Wei subject viewed the Five Caves of Tan Yao, we cannot know whether it was the Buddha or the Tuoba sovereign which occupied the person's mind. However, the blurring line between the Buddha and the emperor worked in the Tuoba's imperial interest, particularly as a method of appealing to a wider audience.

A brief review of how Buddhism coexisted with Daoism, its long-time opponent rooted in indigenous beliefs and practices, will demonstrate the former's strength in merging with another entity as a way of building itself into a new environment. Through the heated debates between followers of Buddhism and Daoism, the teachings of the former, derived from a foreign tradition, had to come to terms with the ways and world-view of the local Chinese elite. ${ }^{345}$ Buddhist teachings combined two main threads of contemporary popular thought in China - the longing for immortality and the Confucian belief in man's duty and the moral basis of society. Moreover, with Buddhism's strong reliance on the use of images, the Buddha came to be associated with indigenous Chinese figures with

\footnotetext{
${ }^{345}$ The struggle between Buddhism and Daoism was an ongoing process of debate between believers on both sides beginning in the fourth century and continued into the early Tang dynasty. Livia Kohn looks at these debates as an integral part of the adaptation of Buddhism into Chinese culture, particularly in the south where debates on this new religion followed in continuation of the gentry's qingtan tradition and allowed the ruling aristocracy to come to terms with a foreign religion in its midst; see Kohn 1995, p. 1, 21.
} 
supernatural and auspicious powers, thus gaining acceptance by native viewers. ${ }^{346}$ Referring to the iconographic fluidity of Buddhist representations, Jean James even goes on to say that the Buddha, Laojun 老君 and/or Taishang Laojun 太上老君 were all one in the popular mind in the early phases, as Buddhist iconography was first introduced to China. ${ }^{347}$ The representation of Xiwangmu 西王母 (Queen Mother of the West) on the money tree base from Mianyang (fig. 34a) and that of the Buddha in a similar position on the base of another money tree from Pengshan (fig. 34b), both dated to the third century from Sichuan province, demonstrate the ways in which the Buddha was incorporated into indigenous cults. ${ }^{348}$ The conflation of iconography allowed certain themes in Buddhist imagery to be absorbed into popular Chinese representations and to obtain a foothold in everyday life and thought. ${ }^{349}$

Monasteries, with their particular ways of life, structures and rules, conveniently displaced other existing social institutions as they were fitted into lay societies. According to Jacques Gernet's figures, at the time of the Northern Wei, there were 47 great state monasteries, 839 monasteries patronized by princes, dukes, eminent families, nobles of the Five Degrees, and marquises, as well as up to 30,000 or more monasteries sponsored by commoners. ${ }^{350}$ Even if a number of the monasteries patronized by the aristocratic families

\footnotetext{
${ }^{346}$ Ann Paludan claims that earlier examples of Buddhist images from the second to early third centuries are convincing proof of a widespread familiarity with certain aspects of Buddhism, but strictly speaking they cannot be regarded as Buddhist sculpture. She argues that Buddhist art is that which is created to serve the Buddhist faith, and that its role is to spread and strengthen Buddhism. Since these earlier examples were borrowed images, used by the Chinese in the context of their own, they do not serve the Buddhist beliefs and should not be considered Buddhist art; see Paludan 2006, pp. 108-110.

${ }^{347}$ James 1989, p. 72.

${ }^{348}$ Wu Hung suggests that the Han dynasty Chinese perceived the Buddha as a deity similar to Xiwangmu and Donggong, as they shared a commonality in immortality. Wu further proposes that images of the Buddha could simply be another type of xiangrui; see Wu Hung 1986, p. 273.

${ }^{349}$ When conditions were ripe at a later point in time for genuine conversion to Buddhism, people were already familiar with its images and stories, and were used to seeing them in everyday contexts; see Paludan 2006, p. 112.

${ }^{350}$ Gernet 1995, p. 4.
} 
were inaccessible to the general population, those sponsored by commoners were still the most numerous, which suggests that Buddhism was as much a faith among commoners as it was among the elite. Buddhist teachings, in the form of story-telling and characterized as the "teaching by images", was most suitable for communicating with the illiterate. As such, Buddhist monasteries became the primary point of education at the grass-root level, and gradually gained the reputation as center and hub of medieval Chinese social activities. ${ }^{351}$

If Buddhist monasteries reached out to illiterate commoners using images and sculptures as a method of conveying Buddhist teachings and thoughts, the Yungang grottoes adopted the same repertoire to convey imperial agency to an audience for whom the sovereign would have normally been remote and elusive. This is not to say that, as imperial cave temples, the Yungang grottoes were indeed available at all times to the common people and that they were allowed access into the caves. Although the smaller caves numbered 4, $14,15,21-45$ were sponsored by non-imperial households, they are dated to post-494 CE, after the relocation of the Northern Wei court from Pingcheng to Luoyang, when imperial projects at Yungang have long ceased. ${ }^{352}$ During the Pingcheng period, the prominent caves discussed in this chapter may have been inaccessible to the common people as an imperial site, but since the caves also functioned as a religious ground, we can argue that the caves of Yungang may have been open to the greater monastic community on certain days of Buddhist festivals. Moreover, owing to the esteemed position held by the Yungang grottoes in the Northern Wei, the Buddhist iconography and imagery applied there were

\footnotetext{
${ }^{351}$ Xie Chongguang looks at monasteries as cultural and educational centers, where thoughts and ideas from the West were first introduced into China by visiting monks, and further promoted among a wider population through lectures and debates that bear a Buddhist tradition of giving public teachings; see Xie Chongguang 1990, pp. 56-65.

${ }^{352}$ Li Zhiguo 1999, p. 17.
} 
most likely much sought after and circulated among members of the Buddhist community and copied by local monasteries.

Apart from the Five Caves of Tan Yao, the paired-caves at Yungang are another Northern Wei grotto conception that embodied new ways of representing contemporary imperial authority during the Pingcheng period in a manner that can be easily understood through indirect allusions to popular Buddhist stories. Presently numbered as 9-10 (fig. 35) and 7-8 in their respective order, these paired-caves presumably followed the Five Caves of Tan Yao in the sequence of excavations. They are all dated to the reign of Emperor Xiaowen (r. 471-499 CE), before he relocated the Northern Wei capital to Luoyang in 494 . The pairedcaves are defined as a set of two side-by-side caves excavated at the same time, sharing a common design concept, with an interrelated management of space, and mutually complementary in the imagery chosen for the sculpturing formula. ${ }^{353}$

Chinese scholars mostly agree that these paired chambers were opened around the time when the Dowager Empress Feng acted as supervising regent to the young Emperor Xiaowen, between the years 471-490, when the latter was nominally the emperor but actual decision-making rested in the hands of the dowager empress. ${ }^{354}$ During this period,

\footnotetext{
${ }^{353}$ The paired-caves were designed to be symmetric when combined together, and would share one comprehensive concept. When taken apart, each cave contains its own independent iconographic significance; see Wang Jianshun 2006, p. 722.

${ }^{354}$ Li Hengcheng 2005, pp. 78-79; Wang Jianshun 2006, pp. 726-727. However, Alexander Soper raised an entirely different reading of the paired caves of 7-8 and 9-10. He suggested that these were dedicated to the imperial parents, to mothers as well as fathers. Soper took a retrospective approach of using evidence provided by the imperial work at the Longmen grottoes of a later date, in present-day Luoyang, Henan province, to corroborate his interpretation. In the "Treatise on Buddhism and Daoism", it is said that in the early Jingming reign (500-503 CE), Emperor Xuanwu 宣武帝 (Yuan Ke 元恪, r. 500-515 CE) “ordered that two caves should be made in memory of his parents, Gaozu and the Dowager Empress Wenzhao, at Yique Mountain [i.e. Longmen Mountain] south of Luoyang, taking as a model the rock-cut caves of Lingyansi [i.e. Yungang] at the former capital.” See Wei shu, juan 114, p. 3043. Original text reads “於洛南伊關山, 為 高祖、文昭皇太后營石窟二所。” English translation is based on Soper's work. By the same logic, except in reverse chronology, Soper believed it to be most natural to assume that the nearly identical Yungang
} 
the term er sheng (二聖, literally meaning “the two revered ones") frequently appears in the Wei shu. In the fifth year of the Taihe reign (481):

沙門法秀謀反伏誅。駿表曰: 忽有狂豎, 謀逆聖都。明靈幽告, 發覺伏 誅。。于穆二聖，仁等春生。355

The Sramana Fa Xiu who planned a rebellion was captured and killed. Cheng Jun submitted a memorial saying, "Unexpectedly, there was a violent and petty person who planned to rebel in the imperial capital. The bright spirits secretly convey, [the rebels were] made known, captured and killed ... The dignified two revered ones, [bring] benevolence to all [as if] the birth of spring. ${ }^{356}$

In the tenth year of the Taihe reign (486):

\section{今二聖躬行儉素，詔令殷勤。357}

Presently, the two revered ones are humble and simple in their personal behavior and are deeply affectionate in their decrees. ${ }^{358}$

From these accounts, the term er sheng clearly refers to an idea of "paired-monarchs" in describing the joint rulership of Dowager Empress Feng and Emperor Xiaowen. The recurrence of this term in textual records is a strong indication of its prevalent use in the Northern Wei, and that it was a characteristic feature of Emperor Xiaowen's rulership at Pingcheng.

\footnotetext{
paired-caves 7-8 and 9-10 were dedicated by Emperor Xiaowen to his grandfather and father; the former pair to Emperor Wencheng and his consort, the latter pair to Emperor Xianwen and his consort. Though this line of reasoning appears rather thin, neglecting possible iconographic formulae in the grotto designs, it nevertheless attributes a great degree of imperial patronage to these paired-caves. Furthermore, it reaffirms the argument of this thesis that in the process of designing and creating the Yungang grottoes, imperial involvement manifested major features of the Tuoba's rule during the Pingcheng era; see Soper 1960, pp. 6465.

${ }^{355}$ Wei shu, juan 60, p. 1348.

${ }^{356}$ Author's trans.

${ }_{357}^{357}$ Wei shu, juan 62, p. 1383.

${ }^{358}$ Author's trans.
} 
This idea of "paired-monarchs" had perhaps derived from the Lotus Sutra, for which the Tuoba possessed an immense preference, and was the most widely circulated scripture during the Northern Wei. In the "Emergence of the Treasure Tower" of the Lotus Sutra, the Buddha of Abundant Treasures, in practicing the path of bodhisattva, made a vow:

若我成佛、滅度之後, 於十方國土有說法華經處, 我之塔廟, 為㯖是經故, 踊現其前，為作證明，讚言善哉。359

If, after I have become a Buddha and entered extinction, in the lands in the ten directions there is any place where the Lotus Sutra is preached, then my funerary tower, in order that I may listen to the sutra, will come forth and appear in that spot to testify to the sutra and praise its excellence. ${ }^{360}$

Later, when the Buddha Sakyamuni preached the Lotus Sutra at Mount Gridhrakuta in front of the Buddhas that were emanations of his body, the assembly wished to participate in the opening of the tower of seven treasures that had risen up out of the earth and stood suspended in the air. According to the Lotus Sutra:

於是釋迦牟尼佛, 以右指開七寶塔戶, 出大音聲, 如卻關錀開大城門。即時 一切眾會, 皆見多寶如來於寶塔中坐師子座, 全身不散, 如入禪定。又聞其 言： “善哉, 善哉! 釋迦牟尼佛! 快說是法華經, 我為㯖是經故而來至 此。” 爾時四眾等、見過去無量千萬億劫滅度佛說如是言, 歎未曾有, 以天 寶華聚, 散多寶佛及釋迦牟尼佛上。爾時多寶佛, 於寶塔中分半座與釋迦牟 尼佛, 而作是言： “釋迦牟尼佛！可就此座。” 即時釋迦牟尼佛入其塔中, 坐其半座, 結加跌坐。361

The Buddha Sakyamuni, with the fingers of his right hand, then opened the door of the tower of seven treasures. A loud sound issued from it, like the sound of a lock and crossbar being removed from a great city gate, and at once all the members of the assembly caught sight of the Abundant Treasures Thus Come One seated on a lion seat inside the treasure tower, his body whole and unimpaired, sitting as though engaged in meditation. And they heard him say, "Excellent, excellent, Buddha Sakyamuni! You have preached this Lotus Sutra in a spirited manner. I have come here in order that I may hear this sutra."

\footnotetext{
${ }^{359}$ Miaofa liaohua jing 妙法蓮華經 (The Lotus Sutra) in T.9, no.262, pp. 32c11-32c13.

${ }^{360}$ English translation after Watson 1993, p. 171.

${ }^{361}$ Miaofa lianhua jing in T.9, no.262, pp. 33b23-33c8.
} 
At that time the four kinds of believers, observing this Buddha who had passed into extinction immeasurable thousands, ten thousands, millions of kalpas in the past speaking in this way, marveled at what they had never known before and took the masses of heavenly jeweled flowers and scattered them over the Buddha of Abundant Treasures and the Buddha Sakyamuni.

At that time, the Buddha of Abundant Treasures offered half of his seat in the treasure tower to the Buddha Sakyamuni, saying, "Buddha Sakyamuni, sit here!" The Buddha Sakyamuni at once entered the tower and took half of the seat, seating himself in cross-legged position. ${ }^{362}$

Thereafter, whenever the Lotus Sutra was involved, the term "paired Buddhas" refers to that of the Buddha of Abundant Treasures and the Buddha Sakyamuni. The former was so impressed by the latter's preaching of the sutra that he shared half his seat, allowing for the Buddha Sakyamuni to enter into the stupa and to share a space on the throne. The Tuoba's attention to the Lotus Sutra was most probably due to the concept presented in its teachings of having paired Buddhas in the presence of a congregation, which could be used to justify the unusual state of affairs of having joint monarchs at court. ${ }^{363}$ The Dowager Empress Feng, in her cultivation of the young Emperor Xiaowen, was much like Buddha Abundant Treasures, whose appearance would indicate a formal recognition of the successor's accomplishments. ${ }^{364}$ Thereby, it was also within this peculiar imperial environment that a new type of iconography developed at Yungang, representing pairedBuddhas within one niche, also known as erfo bingzuo (二佛并坐, literally meaning “two Buddhas seated side-by-side"). In a Buddhist context, whenever this image appears at Yungang, the two Buddhas are undoubtedly that of Sakyamuni and of the Abundant Treasures.

\footnotetext{
${ }^{362}$ English translation after Watson 1993, pp. 175-176.

${ }^{363}$ Zhang Yan 2005, pp. 16-18; Li Zhiguo 1999, p. 14; also Li Xueqin and Li Lifen 2006, p. 28.

${ }^{364}$ Yin Xian 2006, p. 417
} 
Within the paired-caves 9 and 10, these paired-Buddha sculptures are positioned on the north wall of the front chambers, at exactly the same location in both caves. (figs. 36a, b) However, the correlation between paired caves and Buddhas do not necessarily have to be a static program. ${ }^{365}$ In caves 7 and 8 , a paired-Buddha niche is positioned on the lower north wall of the former, while the latter has a single Buddha seated in a round niche at the same location. With the passing of the Dowager Empress Feng in 490, Northern Wei rulership changed from a state of joint sovereignty to that of sole authority of Emperor Xiaowen. Since caves 7-8 are the latter of the two sets of paired-caves, their iconography probably reflected the new political development under Emperor Xiaowen, as he gained full ownership of Northern Wei kingship. Previously, such developments in the intricate political environment at court would have been knowledge restricted to the officials and the aristocratic families close to the seat of power. The Yungang grottoes presented itself as a direct channel through which the emperor or, in the case of the paired-caves and paired-Buddhas, the Dowager Empress asserted an imperial presence and authority using Buddhist iconography to communicate the political subtleties to a greater audience.

\section{A NEW IMPERIAL MATERIAL: STONE}

Jessica Rawson sees the repertoire of works involved in the project of Yungang as the most important channel in bringing in Western stone architectural styles and designs to northern China. ${ }^{366}$ Indeed, the cave temple tradition that defined Buddhism in northern China was the outcome of a choice of a foreign tradition to produce new expressions of kingship, which in turn allowed the Tuoba to create a completely new narrative for Buddhism and its role in the Northern Wei state. Most importantly, the Tuoba's monument

\footnotetext{
${ }^{365}$ Wang Jianshun 2006, pp. 725-727.

${ }^{366}$ Rawson 1984, pp. 36-39.
} 
tradition was underpinned by their use of stone, borrowed from Western Asia; carving out of a low mountain range a site of imperial commemoration.

It should be emphasized here that in central China since the Shang 商 (1600-1046 BCE) and Zhou 周 (1046-256 BCE) dynasties, the tradition of using stone was little employed. Secondly, major deities of the early dynasties and those of the Confucian ritual were never depicted. Thus, the representation of gods in human form was of little importance in Chinese religious life, and possibly for the same reason the depiction of kings failed to develop. ${ }^{367}$ As such, carving sculptures out of stone, a material much less socially and ritually valued than that of jade or bronze, was further relegated to obscurity.

It was not until the Han dynasty that stone carving gained an increased popularity and that it was generally applied in a funerary context and involved two basic methods. ${ }^{368}$ The first is the earlier line representation that has its origins in traditional jade and bronze carving, and the second is the bas-relief method (fig. 37). Alongside this tradition of stone reliefs that began in the later Western Han (206 BCE-24 CE) and into the Eastern Han (25-220 $\mathrm{CE}$ ), the practice of carving stone sculptures was also first deployed as an aspect of the tomb complex in the Han. One of the most famous examples surviving today is from the tomb of the military general Huo Qubing 霍去病 (140-117 BCE), containing the most

\footnotetext{
${ }^{367}$ Traditional Chinese aesthetic approach in the Shang and Zhou represented an abstract concept of the scene, rather than its reality. It was only by the Han dynasty when Chinese artistic practices took a turn and human figures gradually came to be a subject on pictorial stones, but only in a funerary context; see Lim 1987, p. 51.

${ }^{368}$ The increased popularity of stone carving under the Han can be attributed to several factors. The first was purely practical. As developments in agriculture and industry had led to a great increase in the production of iron, and metal tools of high quality were now freely available, stone work became easier and quicker than before. Secondly, political conditions in the early Han forced the rulers to reestablish unity of empire under a centralized administration based from their new capital city. Like the Qin emperors, those of the Western Han used large scale architectural projects to reinforce unity, and stone was the perfect medium for largescale manifestations. Finally, stone was popularly associated with the search for immortality. As a type of material, stone endured, and endurance or long life was a way of avoiding death; see Paludan 2006, pp. 5960.
} 
well-known sculptural depiction of the theme "horse trampling a barbarian" (fig. 38), dated to 117 BCE. $^{369}$ In this case, while the carving method remains similar to the traditional line representations applied on jade carvings, both the subject matter of conquest and the image of a horse were foreign concepts. The very exotic nature of this stone sculpture was possibly intended to reinforce Huo Qubing's importance as the general who conducted a series of campaigns against the Xiongnu on the western frontiers of the Han state and opened up China's route to the west.

However, despite the appearance of new representational subjects, we should note the deliberate absence of a portrayal of the general himself in this particular piece of sculpture. Rather than a statue honoring Huo Qubing in a Western commemorative tradition, it appears to be more of a guardian sculpture, by which the master of the tomb was implied. This was true for most of the Han stone statues at this time, which continued to be applied in a funerary context throughout the Eastern Han, and eventually inherited by the southern dynasties in the establishment of the spirit road (shendao 神道) (fig. 39) - namely, permanent attendants made of stone in the form of auspicious beasts that line the path leading up to the tomb. By contrast in the north, the Tuoba's proclamation of kingship using larger than life-sized cliff carvings of the Buddha gave stone representations in human form a social agency outside of the funerary context, making use of a composite of foreign concepts.

\footnotetext{
${ }^{369}$ It is said that Emperor Wudi ordered the tumulus to be made like Qilian Mountain, site of one of Huo Qubing's famous victories in present-day Gansu province against the Xiongnu, and it is recorded that this artificial mountain was covered with large boulders brought from afar and with strange stone animals and monsters; see Paludan 1991, p. 18.
} 
We can better understand the Yungang grottoes as a monument complex if we treat it as the eastern end of a continuum of stone architectural tradition that stretched from Western Asia and the Hellenistic sphere into northern China, embracing regional variations via the Parthians (present-day northeastern Iran) and the Kushans (present-day northern Afghanistan, northern Pakistan, and southern Tajikistan and Uzbekistan) along the way. This is not to say that China never had a tradition of sculptures in human form before the introduction of Buddhism and the techno-complex that came with it. But the early examples generally existed in a functional setting, such as that of the bronze figurines holding up the stand for the set-bells of the Marquis Yi of Zeng (fig. 40). ${ }^{370}$ For the Tuoba to turn to a new medium (stone) and a new concept of sculpture (mountainside sculptures for a religious purpose), both unprecedented in the Chinese material tradition, the various choices that converged to produce what we now find at Yungang responded to particular historical conditions faced by the Northern Wei state. The Tuoba's unification of the northern kingdoms with the final conquest of Northern Liang (fig. 41) in 439 and the persecution of Buddhism under Emperor Taiwu 太武帝 (Tuoba Tao 拓跋壽, r. 424-452 CE) contributed essentially to this choice.

\section{Borrowing from the West}

During the Sixteen Kingdoms (304-439 CE), before the Tuoba's conquest of northern China, it was through the patronage of the nomadic rulers that monk scholars, sutra texts, images and even temple designs were bought in from monasteries of distant Buddhist centers in India and Central Asia. ${ }^{371}$ By the time of the excavation of Yungang, the sources

\footnotetext{
${ }^{370}$ Hubei sheng bowuguan 2007, pp. 62-63.

${ }^{371}$ Among the nomadic ruling households of the Sixteen Kingdoms period (304-439 CE), those of the Later Zhao (319-351 CE, Shi 石 family of the Jie), Former Qin (351-394 CE, Fu 苻 family of the Di), Later Qin
} 
from which the Northern Wei received this architectural package were still the kingdoms of Central Asia, which in turn were in contact with the famous Indian Buddhist centers Gandhara (present-day northern Pakistan and eastern Afghanistan), Mathura (present-day north India) and Amaravati (present-day central western India). ${ }^{372}$ It was in these areas that Alexander the Great established his most eastern kingdoms in the fourth century BCE, and as a result, provincial forms of Classical architecture and imagery were introduced to these regions. Through local adaptation, these Central Asian variations of Classical representation picked up new elements en route into northern China with the introduction of Buddhism.

It is in India where we find a particular architectural style of the "chaitya halls" to be the origins of what was later developed into one of the most prominent architectural features at Yungang - a square central shaft with two or even three tiers of arched niches, also known as the central stupa pillar (fig. 48). In Sanskrit, the term "chaitya hall" refers to "halls containing that which is worthy to be gazed upon", ${ }^{373}$ designed with a stupa in the back of the chamber, for worshippers to circumambulate around it to pay homage. A good example is the great chaitya hall at the Karla caves (Maharashtra, India) dated to around $120 \mathrm{CE}$

(384-417 CE, Yao 姚 family of the Qiang) and Northern Liang (397-439 CE, Juqu 沮渠 family of the Xiongnu) were the most active in sponsoring Buddhist activities and in allowing Buddhist monks to gain prominent positions in their courts. This relationship is exemplified in the accounts of Buddhist monk scholars retained at various northern courts, such as those of Fotu Deng 佛圖澄, Shi Dao'an 释道安, Kumarajiva 鳩摩羅什, and Tan Wu Chen 昙無識 from Gaoseng zhuan 高僧傳, Biographies of Eminent Monks, compiled in around 519 by the monk scholar Hui Jiao 慧晈 (497-554 CE). For references to the Gaoseng zhuan, this thesis uses the Zhonghua shuju edition of 1992, edited by Tang Yongtong. For a study of Gaoseng zhuan and the tradition of Chinese monastic biography, see Kieschnick 1997, in which he sees Hui Jiao, the compiler of Gaoseng zhuan, as being both a historian and a student of Buddhist teachings, with allegiances to both literary traditions.

${ }^{372}$ Elfriede Regina Knauer's paper on the western connections of the Yungang caves provides very telling examples from Western and Central Asia which could have stimulated the stone sculpture forms at Yungang, see Knauer 1983, pp. 35-37; see also Wu Hung 1986, pp. 266-267.

${ }^{373}$ Based on the definition provided by the Encyclopaedia Britannica. 
(fig. 49). ${ }^{374}$ Transferred to Central Asia, from where this architectural design was introduced into China, cave 38 at Kizil, Kucha (present-day Xinjiang province) presents a slight variation dated to around late fourth century. A similar architectural framework was in place, consisting of a central pillar that was created by excavating passageways dug into the back wall of the main chamber (fig. 50). ${ }^{375}$ Eventually, it was in the caves of Liangzhou as we see at Tiantishan and Matisi, ${ }^{376}$ which sit on the western edge of presentday Gansu province, where the Yungang grotto style found its prototypes. Cave 1 of Matisi contains one of the few examples of a central pillar of Kuchan style that currently exists in the Hexi Corridor, with a large Buddha image on the front and two low passageways to the left and right, connect by a back passage parallel to the wall (fig. 51ai). It is representative of the more "primal" grotto architectural style as it was first introduced into China, by comparison with those of Matisi Cave 2 (fig. 51aii) and Tiantishan Cave 1 (fig. 51b), which had already developed into stupa pillar forms, divided into several tiers with arched niches. ${ }^{377}$

As Buddhist teachings and paraphernalia travelled into northwestern China, the region of Liangzhou became the primary recipient and the point of origin for the development of new variations. The Wei shu describes Liangzhou as such:

\footnotetext{
${ }^{374}$ The area around a chaitya hall was a particularly auspicious location for votive offerings. Originally, chaityas were said to be the natural homes of earth spirits and were most often recognized in small clusters of trees or even in a single tree. According to Buddhist texts from about $200 \mathrm{BC}$, wandering Indian ascetics often gathered near chaityas to beg alms from local religious pilgrims and to pay homage to the deities residing therein. Later, the term chaitya assumed the distinctive meaning of a meeting place or meditation grove; thus the practice of circumambulation around a central pillar within a grotto was developed as an act of paying homage; see Spink 2007, p. 134; also Zhao Shengliang 2006, p. 6.

${ }^{375}$ Ma Shichang 2003; Zhao Shengliang 2006, p. 7.

${ }^{376}$ For a complete debate on the dating of the Liang caves with a central stupa pillar, see Zhao Shengliang 2006, pp. 6-7. Liangzhou grottoes that contain central stupa pillars of which the dating has been contended include caves 1, 4, 8 of Tiantishan, the eastern and western caves of Jintasi, the Thousand Buddha Cave of Wenshushan and Ten-Thousand Buddha Cave, caves 2 and 8 of Matisi, and caves 2 and 4 of Changma.

${ }^{377}$ Using the form of the central pillar as one of the criteria for his typology, Su Bai assigned the Tiantishan caves to the first phase of Liangzhou grottoes; see Su Bai 1986.
} 
涼州自張軌後, 世信佛教。敦煌地接西域, 道俗交得其舊式, 村塢相属, 多 有塔寺。378

Liangzhou had, from Zhang Gui ${ }^{379}$ onward, for generations believed in Buddhism. Dunhuang touches upon the Western Regions, and the clergy and laity both acquired the old fashions. The villages, one after the other, had many reliquaries and temples. ${ }^{380}$

Owing to its geographical position of straddling the corridor that led to the Western Regions, Liangzhou in the fourth and fifth centuries was a trading hub that linked northern China with Persia and India, where Sogdian merchants visited in great numbers. ${ }^{381}$ With the continuous inflow of Buddhist monks and teachings into China through the northwestern silk roads, it was also where various strands of sculptural techniques and representative styles were gathered and redistributed as local artisans acted as agents in this process. ${ }^{382}$

In northern China during the Sixteen Kingdoms, rulers of the states of the Former Qin (351-394 CE), the Later Qin (384-417 CE), the Western Qin (385-400; 409-431 CE) and the Northern Liang (397/401-439 CE) were all actively involved in the excavation of cave temples, clustered within present-day Gansu province. The most famous of these include the caves of Mogaoku 莫高窟 (Dunhuang, Gansu province), Maijishan 麥積山 (Tianshui, Gansu province), Binglingsi 炳靈寺 (Linxia, Gansu province), Tiantishan 天梯山 (also known as the Liangzhou 涼州 caves in Wuwei, Gansu province), Matisi 馬蹄寺 and Wenshushan 文殊山 (both in Sunan, Gansu province). The Tuoba were to have based their

\footnotetext{
${ }^{378}$ Wei shu, juan 114 , p. 3032.

${ }^{379}$ Zhang Gui 張軌 (255-314) was the provincial governor of Liangzhou during the Western Jin, and father of Zhang Shi 張定 (r. 317-320) who established the Former Liang (317-376).

${ }^{380}$ English translation is based on Leon Hurvitz's translation of the "Treatise on Buddhism and Taoism" in Mizuno and Nagahiro 1952-1956, vol. 16, p. 61.

${ }^{381}$ Soper 1958, p. 134.

${ }^{382}$ Su Bai 1986, p. 435.
} 
designs on these existing examples as they prepared for the excavation of the Five Caves of Tan Yao. So much so, that Su Bai named the earliest dated grottoes and statuette styles found in the Hexi Corridor, Dunhuang and Turfan as the "Liangzhou Model". The major features of this model consist of a rectangular main cave with a central pillar, a Sakyamuni or Maitreya Buddha as the central image, walls covered in the thousand-buddha motif, with flower and leaf scrolls as decorative pattern. ${ }^{383}$ Two sculpture methods existed at this time. The most common were the stucco sculptures applied over wooden, stone, or woodand-straw cores, which was the method prominently adopted at Dunhuang. Stone sculptures directly carved out of the mountainside in rock-cut sanctuaries were much less common in Liangzhou, but became the norm in the "Yungang Model". 384

However, of all these precedents, it was the Northern Liang 北涼 (397-439 CE) ruling household of a Xiongnu group that the Northern Wei held in highest regard, and recognized as the source of their own Buddhist techno-complex. ${ }^{385}$ With Emperor Taiwu's conquest of Northern Liang in 439, the Northern Wei succeeded in unifying all of northern China for the first time since the fall of Western Jin in 316. It is recorded in the Wei shu that in the fifth year of the Taiyan reign:

\footnotetext{
383 Su Bai 1986, pp. 438-442.

${ }^{384}$ The most striking difference between the Yungang grottoes and those of the Liangzhou tradition is that the former contained images of the Buddha carved directly into stone cliffs and sheltered by rock-cut sanctuaries. The stone Buddha sculptures of Yungang are encased in rock-cut sanctuaries, an architectural style that dates back at least to the 3rd century India and Central Asia. The cells that honeycomb the mountain-sides at Kyzil and other Central Asian sites are the precedents of the earliest cave temples of China. Alternatively, the earlier stucco sculpturing of the Liangzhou grottoes, most representative being that of the Mogao grottoes at Dunhuang, was applied over a wooden, stone, or wood and straw core for its statues, a technique most probably developed in the region that included modern Persia, Afghanistan and northern India; see Rowland 1935, pp. 23-24. However, this innovation at Yungang was more likely the result of the geological particularities in the different regions. Workers from Dunhuang would have had no opportunity to carve in stone as the rock at Dunhuang is sedimentary and would crumble or split when being cut into. The decision to use relief sculpture on the interior walls of the Yungang caves rather than fresco paintings would have been a local one, benefitting from the sandstone cliffs of the Wuzhou Mountain. For a geological study of the Yungang vicinity, see Yungang shiku wenwu yanjiusuo 2005, p. 8.

385 Tang Yongtong 2008, pp. 333-334; Gao Ping 1999, pp. 65, 79; Sekino and Tokiwa 1926-1938, pt.ii, pp. 34-35.
} 
冬十月辛西，車駕東還，徙涼州民三萬餘家于京師。386

In the tenth month that winter, on the day of xinyou, the emperor returned east, relocating more than thirty-thousand households to the capital from Liangzhou. ${ }^{387}$

The "Treatise on Buddhism and Daoism", the final chapter of the Wei shu, further elaborates on the significance of this population transfer in the Northern Wei's borrowing of the Northern Liang model of Buddhism:

太延中，涼州平，徙其國人于京邑，沙門佛事皆俱東，象教彌增矣。388

In the middle of the Taiyan reign, Liangzhou was conquered and its population was transferred to the [Wei] capital, the monks came eastward with their Buddhist paraphernalia, and 'teaching by images' spread far and wide.",389

The monk scholars, sculptors and artisans who later worked on designing and excavating the first Buddhist caves at Yungang were more than likely to have been among the households relocated from Liangzhou. ${ }^{390}$ Through them, the architectural package of stone figures, arcaded niches and pillars as framing devices and decorative patterns of halfpalmette scrolls ${ }^{391}$ (fig. 44) were placed into the hands of the Tuoba and prominently applied at Yungang. This was not achieved without having been first worked out in variations that emerged in India and Central Asia. On his expedition into desert Cathay, as Sir Aurel Stein travelled along the ancient Silk Road, his findings bear distinct traces of

\footnotetext{
${ }^{386}$ Wei shu, juan 4, p. 90.

${ }^{387}$ Author's trans.

${ }^{388}$ Wei shu, juan 114 , p. 3032

${ }^{389}$ English translation after Soper 1958, p. 141.

${ }^{390}$ Especially since the regions east of the Hexi corridor had previously undergone major persecutions against Buddhism between 446 and 452, upon the revival of Buddhism, the former Buddhist center of Liangzhou again provided the cultural stock on which Northern Wei Buddhism could rely, this time, in the form of grotto sculptures; see Qin Dashu 2005, pp. 247.

${ }^{391}$ The flower and leaf scrolls at Yungang were widely applied in India and Central Asia, and it was in Gandhara where the scrolls took on new decorative forms and were transported into the hands of the Tuoba. At Yungang, the half-palmette motif was applied prominently in an alternative Buddhist architectural context, and as a response to the demand of religious needs, these decorative borders were adapted to represent a lotus, as a flower associated with Buddhism; see Rawson 1984, p. 66.
} 
the ways in which Classical and Greco-Buddhist elements were picked up and passed on in local architectural traditions. At the ruins of a temple at Miran (ancient oasis town on the southern rim of the Taklamakan desert), where the Lop Nur (also known as the Lop Desert, a huge marsh in the past, in present-day eastern Xinjiang province) meets the Altun mountains, Stein uncovered fragments of stucco sculptures including a colossal Buddha head, closely resembling in style the reliefs of Greco-Buddhist work. ${ }^{392}$ Later at the Lop Nur, while clearing a heap of timber debris that belonged to the decoration of a wooden structure, Stein again discovered carved wooden panels and posts that retained beautifully designed floral decoration in relief (fig. 45). He was reminded of the flower ornaments from the sculptures of Gandhara, and a piece of what would have been the top part of a door frame showed intertwined garlands of acanthus leaves and clematis, which was even more Classical in design. ${ }^{393}$

The flower and leaf scrolls that decorate the caves of Yungang in an all-pervading fashion are an excellent example of the tenacity of inherited motifs from Central Asia, worked into simplified acanthus or half-palmette leaves in the hands of local artisans. Chinese decorative patterns had a long tradition of using geometric or animal imagery that began with the bronze vessels of the Shang and Zhou dynasties. The half-palmette motif from both Western Asian and Greco-Roman traditions (fig. 46a) were widely applied in India and Central Asia, and it was also in Gandhara (fig. 46b) where the scrolls took on new decorative forms and were taken east into the Northern Wei as a part of the Buddhist techno-complex. In the embellishment of Buddhist sculptures and architecture, the halfpalmette scrolls were frequently adapted to represent a lotus in response to the demand of

\footnotetext{
392 Stein 1912, p. 353.

${ }^{393}$ Stein 1912, p. 405.
} 
religious needs (fig. 46c). ${ }^{394}$ However, these scrolls also assumed an important position in Northern Wei decorative patterns on furnishings in an everyday setting (figs. 47a, b, c).

Apart from the central stupa pillar and the half-palmette scroll that reveal adaptations of architectural practice undertaken at Yungang, a number of small stone sutra pillars found in shrines at the Wenshushan grottoes in Liangzhou, dated to as early as the 420s and 430s during the reign of the Northern Liang kings, bear stylistic similarities in the sculptural representations executed in the earlier caves at Yungang. ${ }^{395}$ In cave 7 of the Yungang grottoes (dated to the late 460s), the west wall of the antechamber is covered by superimposed tiers of small arcaded niches (fig. 44) that remind us of the Linghu Sa pillar at Wenshushan (fig. 52a), though slightly less classical in the proportions and details. ${ }^{396}$ Two major bodhisattvas in cave 13 (dated somewhat later than cave 7, but presumably initiated the excavation at the same time), which stand in the left and right reveals of the window (fig. 52b), retain the billowing scarf with the forked and pleated ends that are worn by the bodhisattvas on the Tian Hong sutra pillar from Wenshushan (fig. 52c). ${ }^{397}$

This attachment to the Northern Liang Buddhist visual representations was more than just a matter of paraphernalia and stylistic transfer. In fact, King Juqu Mengxun 沮渠蒙逊 (r. 401-433 CE) of the Northern Liang ${ }^{398}$ had set an example for the Tuoba rulers of being

\footnotetext{
${ }^{394}$ For a detailed discussion of the development of these flower and plant scrolls, as well as their function on Buddhist architecture and the adaptations of motif that took place, see Rawson 1984, p.66. For a typology of the various acanthus designs, see Wang Yanqing 2008, pp. 43-48.

${ }^{395}$ Yang Yimin and Tang Xiaojun 1998, p. 49; also Soper 1958, p. 131.

${ }^{396}$ Soper 1958, p. 148.

${ }^{397}$ Soper 1958, p. 149.

${ }^{398}$ Of the five Liang states (Former, Later, Northern, Western and Southern), all of which were devout Buddhist regimes established within the Liangzhou region (consisting of present-day Gansu province, bordering the Western Regions to the west, including parts of present-day Ningxia province to the north, also parts of present-day Qinghai province along the Qilian Mountain), the Northern Liang was most famous of them all, especially in the reign of Juqu Mengxun (401-433 CE). The Liang states were thriving Buddhist centers of the Sixteen Kingdoms due to their geographical location on a major pass of the Silk Road. Monk
} 
personally involved in the commission and excavation of the cave temples. In this manner, the sculptures were elevated from serving as communal religious spaces sponsored by local families to holding imperial agency as an icon of the ruling household. ${ }^{399}$ In the Guang hongming ji 廣弘明集 (Extended Collection of Expanding Illumination) by Shi Daoxuan 释道宣 of the Tang dynasty (618-907 CE):

\begin{abstract}
涼州南百里崖中泥塑行像者。昔沮渠蒙逊王有涼土專弘佛事。於此崖中大造 形像。千變萬化驚人眩目。有土聖僧。可如人等。常自經行。無時暫舍。遥 見便行。人至便止。觀其面貌。如行之状。有羅土于地者。後看足跡納納。 今見如此。400
\end{abstract}

In the cliffs one hundred $l i$ south of Liangzhou are clay sculptures in the form of moving figures. Formerly, King Juqu Mengxun ruled over the region of Liang and was dedicated to promoting and providing service to the Buddha. Images were created on these cliffs, of a thousand changes and ten-thousand mutations that surprised the people and dazzled the eyes. There are holy monks made of earth that, just like humans, frequently walk past by themselves, and at times [they] temporarily come to rest. [The earth-made monks] walk when they are seen from a distance, and they stop when people come close. Looking at their appearance, it is as if they are in motion. There are those who scattered earth on the ground, and later saw the damp footprints. It is the same as seen today. ${ }^{401}$

These cave temples, as referenced in the above text, are now widely accepted by Chinese scholars to be the Tiantishan caves (fig. 42). ${ }^{402}$ Apart from having a keen interest in opening up cave temples out of mountain cliffs, King Juqu Mengxun also experimented

\footnotetext{
scholars and merchants from the Western Regions all had to make their way through the Liang states before reaching the Chinese heartland; thus a religious center was established on this commercial route; see $\mathrm{Lu}$ Qingfu 1994, p. 9. Lu provides a chart of all the monk scholars who traveled through the Liang states during this time, where they came from, when they came to China, and the Buddhist activities in which they were involved. A second chart lists monk scholars native to Liangzhou, as well as the activities that they were involved in; see Lu Qingfu 1994, pp. 10-12, 13-15.

${ }^{399}$ Unlike the Former and Later Qin, in which Buddhist activities in Chang'an consisted mainly of public lectures and scripture translations sponsored by the rulers, the Liang states of the Hexi corridor explored Buddhist teachings and practices via tangible forms, most notably embodied in what we now refer to as Buddhist cave temples; see Sullivan 1969; Zhang Xuerong and He Jingzhen 1994, p. 104.

${ }^{400}$ Guang hongming ji, juan 15 in T.52, no. 2103, pp. 202b21-202b26.

${ }^{401}$ Author's trans.

402 On a full report of what remains of the Tiantishan/Liangzhou caves, see Zhang Xuerong 1993, pp. 50-54; Zhang Xuerong and He Jingzhen 1994, p. 104; Du Doucheng 2009, pp. 166-167.
} 
with the idea of drawing strength from a non-worldly spiritual source to be embodied by stone statues. It is said that,

\section{北涼河西王蒙逊為母造丈六石像，在於山寺，素所敬重。403}

The Hexi King [Juqu] Mengxu of the Northern Liang dedicated to his mother a stone sculpture of six zhang within the mountain temple, which has long been revered. ${ }^{404}$

This stone sculpture is now generally believed to be a poorly preserved Buddha sculpture of 3.6 meters in cave 16 at Tiantishan (fig. 43). ${ }^{405}$ Thereby, paying homage to the Buddha for one's personal blessings coincided with paying reverence to whomever the statue was intended to represent, which turned it into the form of ancestral deification that the Tuoba adopted with the excavation of the Five Caves of Tan Yao.

From this chain of contact and transmission, Liangzhou clearly held a prominent role in the flow of people and ideas from Central Asia and India, reaching as far east as Pingcheng. As the "Liangzhou Model" was further readapted by the Tuoba into the "Yungang Model", a new sculptural tradition developed under the Northern Wei. ${ }^{406}$ The Tuoba adopted such aspects of the Buddhist sculptural framework that suited their objectives, as framed by the Liangzhou tradition, to create a new repertoire at Yungang. In this process, architectural and decorative features were hybridized as they came in contact with traditional Chinese elements. Pilasters carved out of the south wall in cave 6 at Yungang (fig. 53a) were sometimes replaced by pagoda-like structures. Similarly, on the west wall of cave 9 , found below Chinese-styled roofs with its projecting rafters, we see imitations of the wooden

\footnotetext{
${ }^{403}$ Fayuan zhulin, juan 13, p. 467.

${ }^{404}$ Author's trans.

405 Zhang Xuerong and He Jingzhen 1994, pp. 104, 106; Lu Qingfu 1994, p. 17.

${ }^{406} \mathrm{Su}$ Bai was the first person too point out that the concentration of skilled craftsmen, local elite and resources from conquered territories at Pingcheng provided the conditions for the development of a Yungang Model; see Su Bai 1994, pp. 23-47.
} 
dougong carved into the walls with inverted V-shaped timbers that supported the eaves (fig. 53b). The fluidity in the application of visual elements at Yungang, and the ease in which imagery of different cultural spheres could be combined in an organic manner, allowed the Tuoba sovereigns to create their own monumental tradition out of what was originally introduced as a Buddhist techno-complex. Indeed, this Northern Wei innovation was shaped by variations that developed out of Western Asian and Hellenistic stone architectural traditions.

Despite the acquisition of new skills in working with sculpture in human form and a range of visual repertoires for the representation of people and events, the switch to using mountain-side stone chambers as the imperial medium required a "motive power", the essential variable in creating a necessary condition for the rest of the events to play out. The persecution of Buddhism that took place under his grandfather Emperor Taiwu was most likely the event that prompted Emperor Wencheng to devise a means of materializing a renewed presence of Buddhism in the Northern Wei society, one that would also bolster the Tuoba kingship through a reinvigorated imperial patronage. The permanence and solidity of the nature of stone made it a perfect choice for his purpose.

\section{Materializing Kingship through the Restoration of Buddhism}

In the year 446, a state-directed persecution of Buddhism was ordered by Emperor Taiwu, the same emperor who, in the first year of his reign, had scattered flower petals on the day celebrating the birth of Buddha out of reverence, and the same person who had brought the Buddhist paraphernalia eastward from Liangzhou with the conquest in 439. Scholars have suggested various reasons for Emperor Taiwu's sudden reversal of attitude toward Buddhism. Some say that the Buddhist clergy was targeted as a part of the ripple effect 
triggered by the political challenge against the emperor, imposed by the crown prince, also supervising regent, Tuoba Huang 拓跋晃 (428-451 CE), who associated much with the Buddhist community. ${ }^{407}$ Others have pointed to the grand councilor Cui Hao 崔浩 $(?-450$ $\mathrm{CE}$ ), a devout Daoist, as the instigator behind the persecution of the Buddhist clergy, making this a religious struggle that turned political. ${ }^{408}$

Pin-pointing an individual or event as the cause of the first major suppression of Buddhism in Chinese history is not the issue at question here. The importance lies in recognizing that the persecution of Buddhism by Emperor Taiwu, who was previously a devoted patron, had to do with the socio-political ramifications of the increasingly growing Buddhist community that threatened to undermine the power of the state over its subjects. The exemptions enjoyed by Buddhist monasteries from taxation, corvée labor, and military conscription were originally privileges granted on the premise that theoretically producing and owning nothing, members of the monastic community could not be taxed. Rather, they should devote themselves to understanding the Buddha, oversee the precepts, and to pray for the well-being of the state. ${ }^{409}$ However, the abuse of this immunity produced great Buddhist establishments with abundant wealth and labor at their disposal. ${ }^{410}$ These

\footnotetext{
${ }^{407}$ Han Fu 2004, pp. 78-79.

${ }^{408}$ Cui Hao had introduced the Daoist monk Kou Qianzhi 寇謙之 (365-448 CE) to serve as the emperor's religious advisor. In the year 440, Emperor Taiwu officially changed his reign name to that of Taiping Zhenjun 太平真君 (True Lord of the Great Peace) by the Daoist tradition, officially adopting Daoism as the new state religion; see Wei shu, juan 4, p. 93. There are other scholars who do not necessarily agree that the subtle balance of power between the state and the Buddhist monastic order was the reason for Emperor Taiwu's suppression of Buddhism. Luan Guichuan, for one, sees this issue from an ethnographic point of view, which I do not agree with. He believes that the Tuoba rulers' innate feeling of insecurity as outside rulers, who have come face to face with a sophisticated Chinese civilization, the choice of either Buddhism or Daoism as state sponsored religion was inevitably ambivalent and opportunistic; see Luan Guichuan 1995, pp. 57-61.

${ }_{409}$ Gernet 1995, pp. 30-31.

${ }^{410}$ This inherent contradiction in the Buddhist view of materialism is investigated by John Kieschnick. Looking at the impact of Buddhism on the evolution of Chinese material culture, Kieschnick focuses on the ideas, behaviors and relationships that coalesce in the manufacturing and handling of certain objects. The juxtaposition between material comfort and spiritual advancement is a constant theme in Buddhist teachings,
} 
religious grounds turned into competitors of the state in managing local land settlements, as well as a safe haven for military conscript evasions by encouraging men of age to take the tonsure. ${ }^{411}$ In this manner, the relationship between the state and Buddhist monastic communities grew tense, where any transgression of the latter would be taken as a direct offense against the sovereign, who had granted these privileges in the first place as a sign of a magnanimous kingship.

In the year 438, the first social ramification of a rapidly growing Buddhist clergy in the Northern Wei was exposed. The battle against the Rouran tribes to the north (fig. 54) in that year required a large reserve of human and fiscal resource, which was undermined by the exemptions enjoyed by the growing Buddhist monastic communities. ${ }^{412}$ In preparation for this particular battle, Emperor Taiwu had to decree for the first time for "those of age under fifty to be unfrocked." ${ }^{413}$ The situation was further exacerbated when a private armory was discovered by the emperor as he passed through a monastery in Chang'an en route to suppress Gai Wu's rebellion in the Guanzhong region of 445. The discovery of an armory, a distillery, a private storage of valuables owned by local wealthy families, as well as a hidden room for conducting illicit affairs with the women of local gentry, all in the hands of a local monastery triggered the emperor's rage and the situation reached a point

\footnotetext{
beginning with the story of Śākyamuni when he gave up his princely lifestyle and rejected material pleasures in the act of renunciation. It is believed that when we attach ourselves to the material world, moral duties are neglected for the most fleeing forms of pleasure, since the material world is simply a dream from which we must awaken sooner or later. Nonetheless, certain objects could be harnessed for the greater cause of the rejection of the material world, but to do so requires meticulous attention to detail and adherence to Buddhist codes of behavior in their manufacture and use. Moreover, material goods are used as a lure, a reward for the pious and those who give, in assurance that in keeping in line with these practices, their wealth will increase and never decrease; see Kieschnick 2003, pp. 9-16.

${ }^{411}$ Gernet 1995, pp. 94-141; Lu Qingfu 1994, p. 17.

${ }^{412}$ Li Xueqin and Li Lifen 2006, p. 12.

${ }^{413}$ Original text reads “罷沙門年五十已下.” See Wei shu, juan 4, p. 88. Author’s trans.
} 
of no return. ${ }^{414}$ An imperial edict was issued ordering the execution of the monastic clergy in Chang'an and for Buddhist scriptures, statues and temples to be destroyed. Ministers who stayed behind in the capital were to issue the imperial command in the four quarters for the example set in Chang'an to be similarly applied. ${ }^{415}$ Emperor Taiwu further decreed, stating:

彼沙門者, 假西戎虛誕, 妄生妖擘, 非所以一齊政化, 布淳德於天下也。自 王公已下, 有私養沙門者, 皆送官曹, 不得隱匿。限今年二月十五日, 過期 不出, 沙門身死, 容止者誅一門。416

Those Sramanas borrow the vain falsehoods of the Western barbarians and recklessly create disaster and calamity. Theirs is not the way to make uniform the effects of government or to spread earnest virtue through the world. From princes and dukes on down, if there be persons who are privately supporting Sramanas, they shall all send them to the officials; they may not conceal them. The limit is the fifteenth day of the second month of this year. Anyone who exceeds the limit without surrendering the Sramanas shall himself die. If anyone harbors them, the whole family shall be executed. ${ }^{417}$

When Emperor Wencheng succeeded to the throne in 452, the nationwide persecution of Buddhism was still a fresh memory. As the son of the deceased crown prince Tuoba Huang, who had tried to protect members of the Buddhist monastic community up to his death in 451, it is not hard for us to argue that Emperor Wencheng would have had a great affinity for Buddhism. On Tuoba Huang's actions during the persecution, it is said that:

恭宗言雖不用, 然猶緩宣詔書, 遠近皆豫聞知, 得各為計。四方沙門, 多亡 匿獲免, 在京邑者, 亦蒙全濟。金銀寶像及諸經論, 大得秘藏。而土木宮 塔，聲教所及，莫不畢毀矣。 418

\footnotetext{
${ }^{414}$ See Wei shu, juan 114, pp. 3033-3034; for an account of the emperor's discovery at the Buddhist temple in Chang'an. For a discussion on the suppression of Buddhism by Emperor Taiwu, see Wei shu, juan 114, pp. 3032-3034; Han Fu 2004, pp. 77-87; Luan Guichuan 1995, pp. 57-61.

${ }^{415}$ Han Fu 2004, pp. 77-78. Also see Wei shu, juan 114, p. 3032-3034.

${ }^{416}$ Wei shu, juan 114 , p. 3034.

${ }^{417}$ English translation is after the work of Leon Hurvitz in Mizuno and Nagahiro 1952-1956, pp. 65-66.

${ }^{418}$ Wei shu, juan 114, p. 3035.
} 


\begin{abstract}
Although his words were not heeded, Gongzong ${ }^{419}$ [tactfully] delayed the issuing of [his father's] decrees. [Members of the Buddhist clergy], near and far, were all pre-cautioned to separately take measures [of self-preservation]. Sramanas of the four quarters were mostly able to go into hiding and saved their lives; those in the capital received full assistance. Statues of the Buddha made of gold and silver along with various scriptures were preserved for the most part. Nonetheless, where the imperial decree had reached, temples and stupas made of earth and wood were completely destroyed. ${ }^{420}$
\end{abstract}

These protective measures allowed for Emperor Wencheng's restoration efforts to be carried out at a rapid pace, as members of the Buddhist monastic communities resurfaced from hiding. The Shamen tong Tan Yao was one of these Liangzhou monks who had relocated to Pingcheng under Emperor Taiwu's reign, and had successfully survived the following persecution. He remained socially and politically involved in Northern Wei state affairs, and was integral in the excavation of the Yungang grottoes.

In 452, Emperor Wencheng issued an imperial edict for the revival of Buddhism:

今制諸州郡縣, 於眾居之所, 各㯖建佛圖一區, 任其財用, 不制會限。其好 樂道法, 欲為沙門, 不問長幼, 出於良家, 性行素篤, 無諸嫌穢, 鄉里所明 者, 㯖其出家。率大州五十, 小州四十人, 其郡遙遠臺者十人, 各當局分。 421

[For] the various provinces, prefectures, and sub-prefectures, wherever multitudes dwell, to permit the building of one reliquary in each place and to tolerate the expense, setting no limit. Those who love the Way and the Law and wish to become Sramanas, be they old or young, if they come from a good family, if their nature and conduct have always been sincere, if they are not suspected of indecency, and if they are vouched for by their native villages, shall be permitted to leave the household life, as a rule fifty in the large provinces, forty in the small provinces, and ten in prefectures far from the Capital. ${ }^{422}$

\footnotetext{
${ }^{419}$ Even though Tuoba Huang did not live to be an emperor, he was honored posthumously as Emperor Jingmu 景穆帝 with the temple name Gongzong 恭宗 by his son Emperor Wencheng.

420 Author's trans.

${ }^{421}$ Wei shu, juan 114, p. 3036.

${ }^{422}$ English translation is after the work of Leon Hurvitz in Mizuno and Nagahiro 1952-1956, pp. 69-70.
} 
Expedited by a renewed imperial support and sponsorship, Buddhist activities once again picked up throughout the Northern Wei state. In a short time, temples were repaired and statues and scriptures were restored to their original appearance. ${ }^{423}$ Nonetheless, recent experience in the persecution of Buddhism may have prompted both the Shamen tong Tan Yao and Emperor Wencheng to seek out a less destructible material medium than that of earth and wood for a monument that would bear distinct significance for each party. For Tan Yao and the rest of the Buddhist community, this new monument would signify a renaissance of Buddhism and its renewed presence in the Northern Wei. By analogy, we might argue that Emperor Wencheng had a clear picture in mind as to whom he was dedicating the sculptures, and whom his subjects should revere upon. That is, the Tuoba imperial lineage and the Northern Wei kingship which rested upon it.

Having recognized the power of images in Chinese society, Tan Yao, who originally hailed from Liangzhou, would have been quick at realizing that stone sculptures and cave temples provided a perfect tool for reinforcing the faith. The philosophical aspects of the Buddhist doctrine are not always easy to explain, but even the most illiterate could appreciate a simple visual representation of a powerful being. Mere physical presence of the Buddha carries with it the basic idea of Buddhism, and that the escape from suffering in this world applied to all. Out of mutual interest, the Tuoba acted on harnessing this power of Buddhist images to serve their kingship. Through the imperial project of the Yungang grottoes, the symbolic associations of stone sculpture turned into material manifestations of the Tuoba imperial power. It was within this historical context that the larger than life-sized stone sculptures of Buddha, the first of its kind to appear in China, were designed and excavated at Yungang. Acting on the Western Asian idea that central

${ }^{423}$ Wei shu, juan 114, p. 3036. 
authority is strengthened by visible proof of imperial might, the Tuoba designed the Yungang grottoes as a deliberate imperial act, to impress and to pacify their subjects with the power and magnificence of a dynasty that has the Buddha's blessings.

\section{CONCLUSION}

The sculptures of the heads of former United States presidents - George Washington, Thomas Jefferson, Theodore Roosevelt and Abraham Lincoln - carved into the granite face of Mount Rushmore near Keystone, South Dakota in 1941, derive their aura of sacredness from condensing the temporal process of American history into a single image. ${ }^{424}$ The initiator and original sculptor of Mount Rushmore, Gutzon Borglum, had hoped that the presidential faces would "endure until the wind and rain alone shall wear them away," and that the permanence which they embody would imply that the values enshrined there would provoke a consensus of interpretation that extends to far future generations. ${ }^{425}$ The Yungang grottoes that took form on the landscape of northern China close to one and a half millennium before Mount Rushmore bore the exact same hopes and dreams of the Tuoba ruling household. Indeed, regardless of the ultimate destiny of the Northern Wei state, the sculptures at Yungang would show succeeding generations that the Tuoba kingship had reached an apex of material greatness. No one could doubt that a ruling house, which carved a mountain into the magnificent likeness of the Buddha, was one of power and audacity.

A look at the sculptures at Yungang reveals that as these originally foreign looking figures and architectural sets gradually eased into the Northern Wei material culture, the imperial

\footnotetext{
${ }^{424}$ Glass 1994, p. 267.

${ }^{425}$ Borglum 1930.
} 
patrons behind this project were seeking out new narratives for the expression of the Tuoba kingship. Having already established themselves in northern China through military conquest, in the formative years of the Northern Wei Pingcheng period, the Tuoba aimed at gaining symbolic ownership, as in ways in which this new kingship was to be defined, through developing new approaches to appeal to their subjects. In the case of the Yungang grottoes, the Buddhist techno-complex provided the necessary vocabulary for the Tuoba to reconstruct the agency of kingship, combining the use of images and didactic teachings into one imperial discourse that continued to remain visible on the Chinese landscape. In the following chapter, we will turn to look at other forms of self-expression in the Pingcheng period, as the Northern Wei elite incorporated their self-image and aspects of their everyday practices in the use of murals, figurines and other tomb furnishings. Incidentally, life as they had enjoyed was represented for our interpretation in the eternal residence for the afterlife. 


\title{
Chapter 4: Life and Death of the Northern Wei Elite
}

\author{
風俗仍舊，婚娶喪葬，不依古式。
}

---《魏書》 《高允傳》

The customs and practices remain the same for marriage and funeral, not to follow the ancient ways. $^{426}$

--- Wei shu, "Biography of Gao Yun",427

稍僭華典，胡風國俗，雜相揉亂。

\section{---《南齊書》《魏虜傳》}

Little by little, having transgressed the Chinese codes, the customs of the $h u$ and the practices of the realm were mixed together. ${ }^{428}$

$$
\text { --- Nan Qi shu, "Biography of the Wei Captives",429 }
$$

\section{INTRODUCTION}

Several Northern Wei tombs of the fifth century Pingcheng period have been excavated in the past decade at Datong, Shanxi province. They reveal to us an extraordinary range of figurines, furnishings and murals, combining traditional Chinese elements with Central Asian practices that featured in the lives of Northern Wei elite. What can we say about the tomb occupants in these mural paintings (Shaling 沙嶺 M7; ${ }^{430}$ Yunbolilu 雲波里路 M1; $;^{431}$ Zhijiabao 智家堡 $\mathrm{M} 1^{432}$ ) (figs. 55a, 56a, 57a) who have been portrayed prominently across

\footnotetext{
${ }^{426}$ Here, in the Wei shu, the dynastic history of the Northern Wei, customs and practices refer to the Tuoba's own nomadic traditions on the steppes, whereas the ancient ways are the traditions in the Central Plains by the Han Chinese.

${ }^{427}$ See Wei shu, juan 48, p. 1073. Author's trans.

${ }^{428}$ Since Nan Qi shu was written as the dynastic history of the southern state of Qi, contemporaneous to the Northern Wei, the terminology represents a southern Han Chinese point of view. Here, the use of $h u$ refers to the non-Han Chinese whose practices would be viewed as a transgression upon the traditional Han codes, and the "realm" refers to Northern Wei practices.

${ }^{429}$ The "Wei captives" refers to the Northern Wei Tuoba from a southerner's point of view; see Nan Qi shu, juan 57, p. 990. Author's trans.

${ }^{430}$ See Datong shi kaogu yanjiusuo 2006a for the excavation report and images of the mural paintings.

${ }^{431}$ See Datong shi kaogu yanjiusuo $2011 \mathrm{~b}$ for the excavation report and images of the mural paintings.

${ }^{432}$ See Wang Yintian and Liu Junxi 2001 for the report on the stone sarcophagus.
} 
an entire wall with the spouse as a couple? Seated side by side underneath some type of structural setting, they overlook an open air feast in the outdoors, quartered off with cloth screens and mobile tents, as depicted in murals that span across the adjacent walls. Why do we find in the tombs of fifth century Pingcheng elite (Yanbei Shiyuan 雁北師院 M5; ${ }^{433}$ Sima Jinlong 司馬金龍 $\mathrm{M}^{434}$ ) (figs. 58, 8) sets of clay figurines arranged in military formation that were only found in Han dynasty tombs of the emperor, princes, and the highest ranking generals? How are we to determine the agency of these flamboyantly decorated stone sarcophagi (Yanbei Shiyuan M5; Zhijiabao M1; Yuchi Dingzhou 尉遲定 州 $\mathrm{M}^{435}$ ) (figs. 59, 60,61) that represented the household of the deceased both physically and conceptually? Though stone coffins and sarcophagi had already been deployed in Han tombs, the notion of shaping the sarcophagi into an actual building structure, using intricate sets of architectural elements, was an undeniably new practice. These intriguing visual and material paradoxes force us to reconsider the adaptability in the cultural affiliations of Northern Wei elite, in which these tomb occupants of fifth century northern China manifested the world they lived in as the eastern end of a continuum across the Eurasian steppe.

In an early Chinese context, a tomb provided an eternal residence for the afterlife of its occupants, as life and death were parts of a single continuum. Moreover, from at least the third century BCE, the Chinese demonstrated keenness in combining images, models and

\footnotetext{
${ }^{433}$ See Liu Junxi and Zhang Zhizhong 2001 for the brief excavation report of Yanbei Shiyuan M5. For the full report on the entire Yanbei Shiyuan cluster, see Datong shi kaogu yanjiusuo 2008. A large section is dedicated to the stone sarcophagus in M2 with detailed drawings.

${ }^{434}$ See Shanxi sheng Datong shi bowuguan and Shanxi sheng wenwu gongzuo weiyuanhui 1972 for the excavation report of the Sima Jinlong tomb.

${ }^{435}$ See Datong shi kaogu yanjiusuo 2011a for the excavation report of Yuchi Dingzhou M1, with drawings of the stone sarcophagus.
} 
objects from life in tombs, with the intention of duplicating life above ground. ${ }^{436}$ Therefore, a tomb presents not just a view of the afterlife, but also a reflection on actual practices of daily life. As will be explored below, Northern Wei burial practices took over aspects of Han Chinese and Central Asian steppe traditions while incorporating their own self-image in the use of murals, figurines and furnishings that displayed strong characteristics of elite life in the Pingcheng cultural environment.

With its steppe origins, the Northern Wei presided over a culturally vibrant region, and members of the elite households shared in maintaining the "dual presence" by juggling between identifying themselves with certain cultural practices of the Eurasian steppe and at the same time adjusting to particular traditions of the Chinese arena. Their new collective identity was often expressed through a hybrid application of imagery and material form, through which new notions of Northern Wei material culture were to be derived. A close reading of some of these tombs will reveal to us a diverse range of discourses born out of cultural expressions that bind together in the (re)creation of the tomb occupant's identity.

If we are to unpack the particular cultural environment at Pingcheng that allowed for such a "dual presence" in the Northern Wei society, we can exploit Pierre Bourdieu's concept of a habitus: the set of socially learned dispositions and practices that are acquired through the activities and the experiences of everyday life. ${ }^{437}$ If we view practical dispositions as embodied habit, we can explore the social environment in which this habitus was shaped at different points in time. Moreover, to understand fully the various constructions of such a

\footnotetext{
${ }^{436}$ Jessica Rawson applies this notion to her examination of the model universe of the First Emperor; see Rawson 2002a, p. 132.

${ }^{437}$ Bourdieu 1977, pp. 78-85.
} 
habitus, we need to examine the different sources of these activities, which shaped and reshaped daily practice through lived experiences. As Bourdieu might have argued, the particular repertoires in each tomb should be viewed as part of a symbolic system in which minute distinctions of taste were the basis for social judgment. ${ }^{438}$ I shall illustrate the reconfiguration of material culture in the capital of Northern Wei using two case studies, complemented by several tombs that fulfill the following criteria: 1) date to the Pingcheng period, between the years 398-494 CE; 2) located in or on the outskirts of Datong, Shanxi province; 3) contain representational schemes of the tomb occupants' habitual social context, either with the use of mural paintings, clay figurines, or stone sarcophagi.

The distinctive cultural variables that appear in these different repertoires provide a glimpse of the ways in which members of the Northern Wei capital elite saw themselves through a conscious negotiation of material cultures available to them, thereby redefining their new social identity. As "oddities" appear in the form of variations in a standard funerary discourse, we are motivated to explore the different vocabularies used by people of diverse backgrounds in their expressions of social relations. Moreover, the agency conveyed through these individual discourses not only impacts on how the tomb occupants wished to represent their own identities, but at the same time, on how we are to interpret a particular funerary space.

In the following case studies, the different cultural affiliations of the tomb occupants and their families dictated that their respective encounters with the "other" would result in different responses to the application of visual elements. For members of the nomadic elite who had had just started settling into Pingcheng, like Lady Poduoluo of Shaling M7 whose

${ }^{438}$ Bourdieu 2010, pp. 49-55. 
tomb is dated to $435 \mathrm{CE}$, mother of a Xianbei general of the Poduoluo 破多羅 clan, the Han Chinese burial traditions of depicting banquet and procession scenes as preexisting figurative repertoires were convenient frameworks that they could adopt and adapt. Whereas for members of the Han Chinese households, who continued to hold prominent positions in the Northern Wei court, in the case of Song Shaozu buried in Yanbei Shiyuan M5 dated to $477 \mathrm{CE}$, their cultural encounters with the "other" at Pingcheng created a new distinctive taste reflected in the changing forms of stone sarcophagi. The house-shaped sarcophagi with Classical architectural elements of the fifth century northern China (figs. $59,61)$ were of a completely different representational tradition from the earlier Han stone coffins in the Central Plains that were actually imitations of wooden boxes (fig. 97). ${ }^{439}$ As these novelties became a new fashion to be sought after, they reveal to us that material culture not only contains human agency, they are the very objects that constructed the identities of their creators and consumers.

This chapter will build on the notion advanced by Albert Dien, who proposed that a study of material culture will demonstrate that the non-Han control in northern China of this period played an active role in the formulation of what we now consider to be Chinese conventions. ${ }^{440}$ I will further break away from the traditional view of relegating specific visual or material elements as indications of either a Sinicization process with regard to the nomadic incomers, or the preservation of one's roots in the case of a Han Chinese family,

\footnotetext{
${ }^{439}$ These Han stone sarcophagi intended to bear the shape and designs of wooden boxes were mostly found in the Shandong region, including parts of present-day northern Jiangsu and eastern Henan province. They date to the Western Han and early Eastern Han. Even when buildings are depicted on these sarcophagi, they are carved into the sides as an image, rather than using stone parts that represent architectural sets like the ones we begin to see in the Northern Wei; see Xin Lixiang 2000, pp. 198-220; also Wang Jianzhong 2001 , pp. 5, 72-77. They are also found on stone coffins from the Sichuan region that bear imitations of wooden features, especially in the representation of gateways (que 閶); see Xin Lixiang 2000, pp. 271-288.

${ }^{440}$ Albert Dien argued that although this period was undeniably one of instability and warfare, it would be a mistake to assume that it was a time of little significance culturally. In fact, in terms of material culture, the Northern and Southern dynasties period filled in a continuity of development that built upon the Han foundations and led into the accomplishments of the Sui and Tang; see Dien 2007, pp. 13-14.
} 
such as Lucy Lim's treatment of the lacquer painted wooden screen in the tomb of Sima Jinlong. ${ }^{441}$ Instead of an examination of single artifacts or of categorical types, which has been the common approach adopted by most scholars in dealing with Northern Wei tomb materials, the entire tomb space will be treated as a functional set, providing a setting and context to which the performances and narratives were played out. ${ }^{442}$ The negotiation of material culture was carried out through a changing pattern of the consumption of material goods with attached cultural values. These, in turn, produced new notions of interaction and encounter between the incoming nomadic groups and the local Han Chinese.

The Tuoba's transition into China proper was exercised through the use of material culture, and in many ways, they acted as patrons and facilitators in the negotiation that contributed to creating what we now know of as Chinese culture. It is worth bringing our attention to the idea that the "form/design" and "meaning" of any given object or visual representation can take on different cultural affiliations, since the former may be borrowed or adopted, but the latter would always be endowed with new notions by the current users or patrons. Whereas the timber imitation of the house-shaped stone sarcophagus or the systematic layout of a tomb mural may have been borrowed from earlier Han forms, they were given new meanings by people who now embraced a new set of practices. The ability to examine new meanings to which traditional forms and repertoires were endowed allows us to further deconstruct the "dual presence" of the Northern Wei elite in Pingcheng. The following sections will demonstrate ways in which Northern Wei families of nomadic and

\footnotetext{
${ }^{441}$ Lim sees the existence of this lacquer screen with figure scenes in Chinese style as an indication of a substratum of Han Chinese tradition that was preserved in north China during the nomadic occupation; see Lim 1989, p. 26.

${ }^{442}$ For the approach used to treat objects in functional sets as opposed to linear typology, see Rawson 1998, pp. 113-119. Jessica Rawson looks at how Chinese burials do not simply "store" artifacts, but that these material objects are integral to constructing patterns of beliefs and thoughts of their makers and users. In this view, all aspects of a tomb burial should be considered as a "set" of materials or as interrelated "packages".
} 
Han Chinese origins used different combinations of material culture to indicate their respective transitions into the new habitus that they all shared and took part in reshaping, as well as how a person's private and public identities could be separately expressed.

Moreover, I will demonstrate that various regional strands had merged in Pingcheng, as funerary traditions of the Central Plains and the Hexi corridor 河西走廊 (present-day Gansu province) blended in with a mixture of additional Central Asian and steppe elements. In his studies of the mural tombs that date to the Wei-Jin, Southern and Northern Dynasties period (c. 220-589 CE), Zheng Yan examined the cultural ties between the Hexi corridor and the Central Plains, using comparisons in the images depicted in tomb murals and aspects of the tomb structure as identifying markers. ${ }^{443}$ The structural set of sloping passageway, domed ceiling in the antechamber and a vaulted ceiling in the back chamber originally formed in Eastern Han (25-220 CE) brick-chamber and stone-chamber tombs of the Guanzhong region, as well as the deployment of brick facades in the form of a multistoreyed pavilion above the tomb entrance, all find a continuation in the later Hexi tombs of the Wei-Jin period. The tomb murals, on the other hand, reveal an even stronger consistency in practice between the two regions, in the application of pictorial schemes centered on two thematic subjects, which Zheng Yan had labeled to be those of production/consumption and immortality.

Zheng Yan's work was inspired by, and grounded in, a much earlier historio-geographical hypothesis advanced by Chen Yinque in the 1950s. Chen Yinque proposed that, with the Yongjia Rebellion of 311, when the Xiongnu invaded the Western Jin 西晉 (265-316 CE) capital at Luoyang, and the ensuing warfare that eventually resulted in the southward flight ${ }^{443}$ Zheng Yan 2002, pp. 145-180. 
of the Jin ruling house, the Hexi corridor presented itself as a corner in the northwest removed from the ongoing warfare. ${ }^{444}$ As such, with the migration of elite families who were fleeing the Central Plains, ideas and practices were transferred to the Liangzhou region at the eastern end of the Hexi corridor, where they merged with local traditions to create new cultural expressions. Chen Yinque further suggested that by 439, when Northern Wei conquered the state of Northern Liang founded by a Xiongnu ruling group, regional characteristics of Liangzhou became an influential cultural strand that defined the Pingcheng period, and even throughout the Northern Dynasties up to the late sixth century.

Against this background, focusing only on mural tombs, Zheng Yan's work intended to bring forth the notion that this northwestern strand of funerary practice of Liangzhou could have stimulated the hybrid nature of negotiating material culture throughout the Northern Dynasties period. Unfortunately, at the time of the publication of his book in 2002, no mural tombs dated to the Northern Wei Pingcheng period had yet been excavated, and Zheng Yan could not make further comparisons with the Wei-Jin murals to confirm Chen Yinque's hypothesis. ${ }^{445}$ Archaeological findings at Datong in the past decade have recently provided us with a much richer set to work with, from which murals paintings, clay figurines and stone sarcophagi have emerged. By incorporating the sets of clay figurines into this discussion, I believe that apart from receiving impact from the Hexi region in the northwest, the tomb repertoire in Pingcheng also directly absorbed aspects of former Han princely burial practices from the Central Plains, particularly in the display of clay figurines in military and ceremonial formations. Moreover, I will also argue that Liangzhou was more than simply a repository of Han culture and tradition when the

\footnotetext{
${ }^{444}$ Chen Yinque 1954, p. 2.

${ }^{445}$ Zheng Yan 2002, p. 175.
} 
Central Plains was caught in a time of warfare. As previously established in the discussion of the Yungang grottoes, Liangzhou was China's gateway to Central Asia and further west. When we talk of the transfer of practices and cultural expressions from Liangzhou to Pingcheng, we should think of this process as an eastward extension of the cultural continuum across the Eurasian steppe, one which included a variety of peoples active in northern China. It was through this process that the various practices and traditions of a region originally controlled by a mixture of ruling households, including the Han Chinese (Former Liang 前涼 and Western Liang 西涼), Di 氏 (Later Liang 後涼), Xiongnu (Northern Liang 北涼), and Xianbei (Southern Liang 南涼), all came to merge under the Northern Wei.

As the various funerary traditions eventually merged in Pingcheng, the use of mural paintings and clay figurines became the two dominant forms of discursive expressions in the recreation of the life of the deceased. While it might appear that their only difference lies in the use of different material forms in representing a standard funerary repertoire, I shall argue that figurines and murals actually produced two distinct points of view in the Northern Wei tomb narrative; the former as seen through the eyes of the tomb occupant, whereas the latter provides us an account of the tomb occupant's life from the viewer's perspective. Moreover, benefitting from Erwin Panofsky's dualistic perception of funerary art as reflecting prospective and retrospective concerns, ${ }^{446}$ as well as Maurice Halbwachs's notion that one cannot think about the events of one's past without placing it within a social environment, ${ }^{447}$ I will demonstrate that these two distinct narratives reflect different

\footnotetext{
${ }^{446}$ Panofsky 1964, p. 10.

${ }^{447}$ In looking at the social frameworks of memory, Halbwachs argues that it is in society that people normally acquire their memories, and that it is also in society that they recall, recognize, and localize their
} 
attitudes toward the function of the burial space: as a cross between localizing the "perpetuated" past and tending to the immediate concerns of the afterlife.

The visual and historical specificities of these selected tombs make them useful starting points for understanding the ways in which members of the society at Pingcheng expressed their identities and cultural values through an innovative application of material culture in a burial context. An examination of the Northern Wei expression of a "dual presence" in the respective applications of "form" and "meaning" may reveal discrepancies in the ways in which the tomb occupants, or their families, chose to display their public affiliations and private allegiances. The mural images of Lady Poduoluo and the set of clay figurines that belonged to Song Shaozu may appear to have followed the forms of Han funerary pictorial schemes as precedents. However, in the representation of the building structures, in which the tomb occupants are seated, and the dressing style of the figurines' robes and hats, a lot more can be said of how a new Pingcheng identity was achieved through these expressions. Further, house-shaped stone sarcophagi (fig. 59), found in a number of tombs by this time, bear a strong resemblance to the Christian Roman reliquary boxes decorated with sets of architectural elements. But it was the Chinese ideological framework of viewing the tomb space as an eternal residence for the afterlife of the deceased that turned the sarcophagi into actual households that fitted the Chinese preoccupation of conceiving life and death as a single continuum.

The viewer of these images, figurines, and tomb furnishings is encountered, at one and the same time, by what Roland Barthes would call the perceptual message and the cultural

memories. Individuals always use social frameworks when they remember, and it is thereby necessary to place oneself in the perspective of the collective group; see Halbwachs 1992, pp. 37-40. 
message. ${ }^{448}$ At the cultural crossroads of Pingcheng, the contextual display of certain visual/material pairings should not be taken simply as incidental "happenings", but deserve to be recognized as intentional "constructs". As such, the following sections will explore the ways in which specific visual and material repertoires were deployed to transform the burial space into a setting that conveyed the discursive agency of the tomb chamber as a spatial and cognitive extension of the life of the dead.

\section{CASE STUDY I: SHALING M7 OF LADY PODUOLUO}

In 2005, a cluster of tombs dated to the Northern Wei Pingcheng period (398-494 CE) was excavated east of the Yu River 御河 in the southeastern suburbs of Datong, Shanxi province. The cluster is situated on high ground approximately 1 kilometer northeast of Shaling 沙嶺 village, giving the tomb cluster its name. Of the 18 discovered burials, the single-chambered brick tomb M7, located furthest north and oriented facing the west, has been attributed to the mother of a Xianbei general by the clan name of Poduoluo 破多羅, buried in 435 CE. ${ }^{449}$ It is one of the very few Pingcheng period tombs to be discovered that contains well preserved full-length murals painted onto the brick walls. Moreover, inscriptions were found on a piece of lacquer fragment that identified the tomb occupant and date of burial, making M7 the most extraordinary finding of the entire tomb cluster and one of the most important Pingcheng period tombs currently excavated.

\footnotetext{
${ }^{448}$ The perceptual message of an image is not drawn from an institutional stock, and is not coded. In order to understand it, all that is required is the knowledge bound with our perceptions. On the other hand, the cultural message is derived from a symbolic image that is connoted rather than denoted, and requires s shared system of values and practices between the maker of the image and the recipient; see Barthes 1977, pp. 32-51. ${ }^{449}$ Since the Shaling tomb cluster was excavated quite recently in 2005 , and a brief report on M7 was only published in 2006, it remains rather understudied in both Chinese and English scholarship; see Datong shi kaogu yanjiusuo 2006a for the excavation report.
} 
As a single-chambered brick tomb, Shaling M7 consists of three structural components: the burial chamber, a corridor, and a long sloping passageway (fig. 62). The 10-meter long passageway, with pounded-earth walls varying from 1.2 meters at its narrowest point to 1.4 meters at its widest point, is lined with bricks of up to 1.4 meters long and 0.28 meters thick along the eastern end. The passageway then leads into a slightly narrower corridor, which is 1.6 meters long and 1.14 meters wide, with brick-lined walls and a cloister vault ceiling. Beyond the corridor is a rectangular burial chamber of 4.2 meters in length and 3.4 meters in width, capped by a vaulted ceiling with a curved pyramidal profile. Inside the main chamber, the tomb occupant was buried accompanied by objects of everyday work that range from lacquer vessels to pottery and iron wares. Depicted on the four walls and along the corridor (fig. 63) are murals that consist of an image of the tomb occupant, a banquet scene, an outdoor procession, pairs of guardian warriors, and the traditional Han tomb motif of Fuxi 伏羲 and Nüwa 女嗗, a pair of deities in ancient Chinese mythology, who are reputed to have created mankind. Though rather small in size and meager in its funerary paraphernalia when compared against other Northern Wei Pingcheng tombs, Shaling M7 proves to be a useful case study for its rich range of visual representations, and for containing a crucial piece of textual record that places the tomb occupant in historical context.

It is within the main chamber where a piece of lacquer fragment, from a vessel that can no longer be recognized, was found bearing an inscription that allowed the Chinese archaeologists to date this specific tomb to $435 \mathrm{CE}$, and determined the tomb occupant to be the mother of a Xianbei general of the Poduoluo clan. ${ }^{450}$

\footnotetext{
${ }^{450}$ While the original archaeologists on the site had determined in the report that the tomb occupant is the mother of the general who goes by the clan name Poduoluo, the characters Poduoluo tai furen 破多羅太夫
} 
...元年歲次豕韋月建中吕廿一日丁未侍中主客尚書領太子少保平西大將軍 ... 破多羅太夫人 ... 殯於第宅迄於仲秋八月將祔葬 水住 $\ldots$. 無期欲 $\square$ 之德昊天国极 $\ldots$. 莫 ...歲月云 451

... the first year, when the year falls in line with the shiwei constellation [of the Twenty-Eight Mansions], in the fourth month, on the twenty-first day of dingwei, the Palace Attendant, Minister of the Ministry of Receptions, Concurrent Junior Preceptor of the Heir Apparent, Grand General to Pacify the West ... Senior Lady Poduoluo ... [her coffin is to be] temporarily kept at home until the second month of autumn, which is the eighth month of the year, when she will be jointly buried [with her husband] $\square \square \square \square$ at the tomb chamber, to be replaced with ... kind faces [of a person's parents] ... an indefinable period of time, the $\square$ virtues [to be requited] are boundless as heaven ... not to ... the years and months. ${ }^{452}$

Despite several missing characters, from what can be deciphered, this fragment of an inscription provides an insight into several details regarding the tomb occupant and her family. As determined in the excavators' report, time of death was on the twenty-first day of the fourth month of the first year of the Taiyan reign (435 CE); time of burial was the

\footnotetext{
人 can produce two separate readings. In the archaeological report, scholars have treated the character tai 太 as a marker of seniority, that the deceased was the mother of general Poduoluo. However, Zhang Qingjie raised a second reading. He gave three reasons as to why the deceased should be identified as the wife of general Poduoluo, and not the mother. First of all, Zhang Qingjie explained that Poduoluo is only a clan name. While it is possible for a commoner to be referred to by his clan/family name, for such a high ranking general, he found it hard to believe that the general would be mentioned without his given name. For this reason, Zhang Qingjie suggested that the general's full name should be Poduoluo Tai. As such, the deceased would be his wife instead of his mother. Secondly, Zhang Qingjie questioned the likelihood of having murals depicting the grand military procession if the deceased wasn't, in fact, the wife of the general, especially since the general's father did not seem to have held any official capacity worth being mentioned in the inscriptions. Finally, Zhang Qingjie used the depiction of the couple in the mural as an indication that the people interred in Shaling M7 must have been a couple of high social status, and that it would only be fitting if they were the general and his wife; see Zhang Qingjie 2010, pp. 133-138. Despite this alternative reading of the tomb occupant's identity, I still wish to adopt the original reading as provided by the archaeological report, that the deceased was the general's mother, the Senior Lady Poduoluo. I think that it seems too convenient and coincidental for the general's given name (Tai 太) to be the exact word used to indicate a senior lady, as in tai furen 太夫人. Also, it does not seem to be that unlikely for the given name of the general to be omitted when referring to his mother simply by the clan name, and even if it appears to be against the epitaph conventions, I do not think that it is sufficient reason to completely alter the identity of the deceased. Moreover, just because the deceased and her husband did not hold any official capacities in the Northern Wei court or a high social status, this does not mean that murals of the grand parade and luxurious banquet were unsuitable. I believe that we should consider the multifarious ways in which a person is positioned within society and his or her social network. Apart from being the wife of her husband, Senior Lady Poduoluo was also the mother of her son, and I believe that was reason enough for her to enjoy the lifestyle that her son could afford, even in her afterlife. The couple depicted in high social status could simply be a son's wishes for the kind of life that he wanted for his parents, which also, in return, reflect his own social standing.

${ }^{451}$ The ...represents an unknown number of missing characters, and each $\square$ stands in for one missing character; see Datong shi kaogu yanjiusuo 2006a, pp. 8-12 for a discussion of the lacquer peeling inscription. ${ }^{452}$ Author's trans.
} 
eighth month of that year; the title and rank of her son was the Junior Preceptor of the Heir Apparent (Taizi shaobao 太子少保) in the Northern Wei court, and he was also appointed the Grand General to Pacify the West (Pingxi da jiangjun 平西大將軍) in the army. The term fuzang 祔葬 ${ }^{453}$ is used here for the burial of Lady Poduoluo in the eighth month, and the archaeologists of this report refer to it as a joint burial, without further explanation, simply that she will join her husband who had passed away earlier on. However, if we look at the examples of fuzang given by the Hanyu dacidian 漢語大詞典 (Comprehensive Chinese Word Dictionary), we will see that the notion of a fuzang did not refer to being interred within the same space, but that the second burial was to be located next to the predecessor, most often one's ancestor or husband. ${ }^{454}$ Unfortunately, we do not have any skeletal remains to corroborate the number of tomb occupants interred in Shaling M7, and as other nearby burials were all damaged to different degrees, this one remains the only well preserved tomb in the area. ${ }^{455}$ One may turn to the image of the tomb occupant for additional clue, but as we shall later discuss, the portrayal of the deceased as a seated couple appears to be a Northern Wei Pingcheng practice that would not necessarily indicate the actual number of tomb occupants.

For the purpose of this thesis, the tomb occupant will from hereon be referred to as Lady Poduoluo. This piece of personal information sets the context for the following discussion, as we are able to attribute the objects and visual representations contained within Shaling M7 to a family of a particular socio-cultural background in the Northern Wei, as an expression of their identity and cultural allegiance. However, if the inscription provides us

\footnotetext{
${ }^{453}$ See Datong shi kaogu yanjiusuo 2006a, p. 12 for the term fuzang.

${ }^{454}$ See Hanyu dacidian for the term fuzang 祔葬: “Joint burial. Also refers to being buried next to a previously existing tomb mound.” Author's trans. The original text of the definition states: 合葬。亦谓葬于 先莹之旁。

${ }^{455}$ Datong shi kaogu yanjiusuo 2006a, pp.4- 5.
} 
with a textual clue to the public identity of the Poduoluo clan, an official recognition by the Northern Wei state, the murals in Shaling M7 reveal a more private view of the tomb occupant in her social environment. It is in the desire to understand how members of the Pingcheng society placed themselves between their public and private lives, in terms of how they recognized their own identities, that the following discussion will develop around the pictorial repertoires that constructed the story of Lady Poduoluo. Moreover, it will be argued as we look at specific examples, that it is through the hybrid pairing of "form" and "meaning", in the application of mural images within the systematic constraints of traditional themes and motifs, that the tomb occupant's past was localized and remembered.

\section{A New Pictorial System}

The pictorial portrayal of a tomb occupant's life through a collage of scenes represented on pictorial stones constituted an important type of decorative set in a Chinese burial tradition from the Han dynasty and onwards. In fact, it was in the Eastern Han, particularly from about $84 \mathrm{CE}$ to $184 \mathrm{CE}$, when stone reached its pinnacle as a popular medium in areas of northeast China, particularly the Shandong peninsula, ${ }^{456}$ and the Chengdu plains to the

\footnotetext{
${ }^{456}$ Barbieri-Low found that the concentrated cluster of dated monuments in the Shandong peninsula as having begun at around 83-87 CE and disappeared soon after the area was ravaged by the Yellow Turban Rebellion in 184 CE. There is evidence for a continued stone monument tradition after this date, but much of it exists in the way of reused materials from earlier monuments. Why this one area developed such a market for stone funerary monuments has much to do with an intertwining of geography and cultural history, as suggest by Barbieri-Low. The low hills of the Shandong region are filled with easily quarried limestone, which were transportable on a network of waterways. Stone monuments also have a deep history in this area of northeast Asia, with the stones, as a material, treated as objects of worship. Finally, in the Han dynasty, Shandong was a zone of concentrated population population and wealth from agriculture and manufacturing, with few equals in the empire; see Barbieri-Low 2007, pp. 84, 278 notes. For a comprehensive list of dated monuments, see Jiang Yingju and Yang Aiguo 2001, pp. 36-42. Based on a regional stylistic analysis, Xin Lixiang lays out five stone-carving traditions: 1) Shandong peninsula and northern Jiangsu and Anhui, 2) the area around Han period Nanyang commandery in present-day Henan province, 3) western Shanxi province and northern Shaanxi province, 4) Sichuan and northern Yunnan province, 5) the immediate area around the Eastern Han capital at Luoyang. This study claims that sixty percent of all existing decorated stones from the Han period came from the Shandong peninsula region; see Xin Lixiang 2000, pp. 13-14.
} 
southwest, ${ }^{457}$ for lining tombs and for constructing funerary monuments above ground. ${ }^{458}$

Traditional pictorial stones of the Han dynasty consisted of images carved in relief ${ }^{459}$ or

painted as murals, ${ }^{460}$ such as those that we see in the Dahuting tombs in Mixian, Henan

province (figs. 64a, b) and the Yinan stone chamber tomb in Shandong province (fig.

65). ${ }^{461}$ The subjects of representation generally consisted of the following subjects: 1)

mythological scenes; 2) daily life scenes; 3) official scenes; 4) filial piety scenes, virtuous

rulers, or classical scenes of "Confucian” values; 5) auspicious omens; 6) Daoist scenes. ${ }^{462}$

\begin{abstract}
${ }^{457}$ In the Eastern Han, there were two prominent types of burials, rock-cut tombs and underground brick tombs. Both had appeared earlier in north China. Pictorial decorations were carved on stone coffins, on the walls of cliff tombs, and on stone slabs set in brick tombs. Alternatively, they were also molded on bricks. With its local regional variations of representative style, the same themes and designs in this funerary art recur in the tombs in Sichuan all the way to Shandong; see Rawson 2001, pp. 253-308.

${ }^{458}$ Barbieri-Low attributed this growing popularity of using stone as the material for monumental sculptures and buildings to the arrival of Buddhism; see Barbieri-Low 2007, p. 84. The funerary monuments above ground consisted of, for the most part, the small three-walled structures built as family offering shrines during the Eastern Han period. The first few examples of these were discovered in Shandong province, one at Xiao Tang Shan and the other three reconstructed shrines of the Wu family, of which the Wu Liang Shrine is most well known and received extensive scholarly attention. In particular, Wu Hung has suggest that the iconography of the Wu Liang Shrine stone carvings would be best understood only in their original architectural setting, before trying to discover a "universal" pattern that could be applied to all Eastern Han monuments; see Wu Hung 1989. Later excavations in Henan, Shandong, Anhui and Jiangsu provinces uncovered the stone wall slabs of several more shrines. Much like the pictorial stones that lined the inside wall of the Eastern Han tombs, these family shrines above ground also contained pictorial schemes on the inside surfaces of their walls. Jean James's paper examines these newly discovered shrines with particular attention to the relationship between the functions of the architecture and the agency of the images, which would hopefully reveal some indications of the meaning of these images within the context of Han society;
\end{abstract} see James 1998/1999.

${ }^{459}$ Han stone pictorial representations commonly found in tomb burials involved two basic methods. The first is the earlier line representation that has its origins in traditional jade and bronze incision. The second is the bas-relief method as we see more widely applied in the Sichuan and Shandong regions of the Eastern Han; see Gao 1987, pp. 46-47.

${ }^{460}$ As early as the Western Han, pictorial images began entering into tomb decorations, and these mural paintings had the advantage of representing dynamic activities, narrative cycles and landscape scenes. Wu Hung saw the growing prevalence of the chamber tombs after the first century BCE stimulated the creation of tomb murals, as well as relief carvings; see Wu Hung 2010, pp. 101-102.

${ }^{461}$ See Henan sheng wenwu yanjiusuo 1993 for the report on the Dahuting tombs at Mixian, Henan province, and Zeng Zhaoyu, Jiang Baogeng and Li Zhongyi 1956 for the report on the Yinan stone chamber tomb in Shandong province.

${ }^{462}$ This very generalized breakdown is taken from Martin Powers's work on the art and political expression in early China. He looks at the growing ranks of Confucian scholars of the latter Han dynasty as having prompted a new style of art that rejected the previous styles that were synonymous with wealth and power of the old nobility, but one which allowed for these ambitious Confucian scholars to create new modes of "political" expressions, and created a dialectics of rhetoric through visual representations. See Powers 1991, pp. 31-72 for his examination of the subject matters in Han art forms. However, these pictorial expressions and stock motifs were not applied universally throughout Han China. Michael Nylan looked at the distinctive characteristics of the Han tombs in the Sichuan region through an examination of some of the pictorial and figural representations found in these tombs. She suggested that some of the scenes depicted, which would have been identified as motifs relating to historical stories or morals in the Han tombs of other regions, may 
They are represented through the application of transmitted designs and stock motifs that reflect a convention of customizable modularity, ${ }^{463}$ based on the depiction of figures and scenes taken out of historical stories, celestial realms and the immortal worlds.

The depiction of past exemplars of excellent conduct (fig. 65) is also most pronounced in Han pictorial schemes, and it is through the repetitive act of carving particular motifs onto stone that what is proper or vital in the past was thought to be preserved for the present, and revitalized for the future. ${ }^{464}$ From this practice developed a growing tendency to encode messages of "political" arguments that appealed to publicly recognized values in classical Han engravings by the Eastern Han. These political justifications were derived from facts of recent history, historical precedents recorded in the classics, and appeals to natural events that were interpreted as omens for values such as "legitimacy", "filial piety", or "benevolent governance". ${ }^{465}$ The stories of King Cheng 成王 and the Duke of Zhou 周 公, or that of the baby Zhao $\mathrm{Wu}$ 趙武 and his rescuer Cheng Ying 程嬰, were some of subjects most commonly included in the repertoire of political persuasion. This pursuit of a didactic voice in the funerary narrative relied on the use of recognizable motifs that could be pieced together and broken down, depending on the penchant of the patrons, which could be best described as being characterized by Lothar Ledderose's notion of "module not carry their expected cultural meaning in Sichuan. A distinct example is the historical scene of the
assassination attempt of the First Emperor of Qin. Outside of Sichuan, there is no doubt that this scene
celebrates the utility to the continued security of the family and state of a fierce ethical commitment to one's
patron, even unto death. By contrast, the figures appear without a related association or a visual context in
the tombs of Sichuan, such as at the entrance to the tomb at Leshan Mahao. As a result, this positioning gave
the figures a completely new function. They serve as an explicit and unambiguous warning to grave-robbers,
using the stock composition of a man pursued by another dagger-throwing man. Nylan attributed this
difference in the application of images to the strong sense of alienation from both the political center and
from the mainstream ways felt by the Sichuan patrons of the Chengdu plains; see Nylan 2003, pp. 384-391.
463 Barbieri-Low 2007 , p. 93 .
${ }^{464}$ Liu 2005, p. 23 .
${ }^{465}$ See the chapter on Powers's book that deals with classical themes as political arguments; Powers 1991 , pp.
$188-223$. Also see the extensive studies on the Wu Liang Shrine, focusing on how the images reflect the
ideologies embraced by the patrons in Wu Hung 1989; also Liu, Nylan and Barbieri-Low 2005. 
systems". ${ }^{466}$ In contrast, throughout the later Wei-Jin period, and especially by the Northern Wei, a growing sense of individuality emerged from the pictorial depictions. Rather than using the past as a reaffirmation of one's present or future, it was a concern for the expression of a person's experiences in life and the relational contexts within which a person was defined by society that became the focus of the Pingcheng mural repertoire.

The Hexi region played a crucial role in the development of the tomb mural tradition in northern China between the late third to early fifth century, at the time of the Wei-Jin period. Population transfers from the Central Plains to the Hexi corridor began in the Western Han with the stationing of troops on the borderlands as measures to open up as yet unexplored land. Later, with the fall of Luoyang to the nomadic ruling households, which forced the Jin court to flee south, the Hexi corridor in the northwest was one of the few places relatively untouched by warfare. Refugees who headed there included influential families from the capital in Luoyang, who brought with them pictorial traditions of the Chinese heartland that merged with local practices, in a region governed by a mixture of Han and steppe ruling groups. As previously discussed, Zheng Yan noted continuity between the Hexi tombs and the Eastern Han tombs of the Central Plains region in structural setting and in the application of pictorial schemes as broken down into thematic subjects. However, as the traditional Han stone reliefs required an investment in labor and expenditure ${ }^{467}$ that could not be continued as these families took on a more rustic

\footnotetext{
${ }^{466}$ As put forward by Ledderose, module systems do not occur in China alone, but the Chinese started working with module systems early in their history and developed them to a remarkably advanced level in all fields. So much so that modularity seemed to have conformed to a distinctly Chinese pattern of thought; see Ledderose 2000, p. 2.

${ }^{467}$ The huge cost of these pictorial stones was raised by Barbieri-Low as he explored the customizable prefabrication characteristic of these Han stone reliefs. Even in the Han dynasty, while imperial and royal tombs were unique, custom-designed creations, built for patrons of immense wealth, moderately wealthy families in the provinces endeavored to convey the same appearance of lavish tomb decorations without having to spend an unattainable level of expenditure. For this reason, stone carvers in northeastern China accommodated these needs with the system of customizable prefabrication that allowed most elements of a
} 
lifestyle on the northwestern frontiers, ${ }^{468}$ the practice of relief carvings ceased and gave rise to the prevailing mural tradition. Moreover, what was originally painted onto the polished surfaces of stone slabs or across a section of a brick wall surface in the Han tradition was replaced by the more common use of mural paintings on individual bricks that were distributed across the brick walls of the Hexi tombs (fig. 66).

Furthermore, these changes in the application of physical material did not happen without a growing predilection for the depiction of scenes taken straight out of everyday activities in a Hexi elite household. This new local pictorial tradition can be broken down into three major categories: 1) farm production; detailed scenes at every stage from sowing to harvesting, as well as peripheral activities that included nomadic practices of hunting and herding, together with mulberry picking; 2) preparations of banquets; the emphasis at Hexi is on the word "preparations" and not the actual banquet scene, and it is through depicting the laborious work involving hunting, butchering, herding and cooking that the bountiful banquet was reflected; 3) feasting and entertainment; this is the one category most similar to that which were commonly found on the Han pictorial stones. ${ }^{469}$ The brick mural tombs of the Hexi corridor, in Jiuquan, Jiayuguan and Dunhuang carried on the Han practice of portraying the tomb occupant as part of a banquet scene. Rather than being at the head of the banquet or in the act of receiving guests, the tomb occupants of the Hexi brick murals

stone monument to be constructed and decorated off-site using standardized modules. For a detailed account of the production involved in making these customizable stone reliefs, see Barbieri-Low 2007, pp. 93-96. The same is true for their Roman counterparts, as we can see in the production of the sarcophagi. For most of the individuals who commissioned a sarcophagus, it would have been a massive, once in a lifetime, investment by which posterity would judge them. The labor required in its production was of a different order of magnitude than that for other commodities. For this reason, it was in the interest of the producer to reduce unnecessary costs and waste, and to organize work that featured "mass production" so as to make it profitable; see Russell 2011.

${ }^{468}$ Farming and herding in the Hexi region during the Wei-Jin period can be explored based on the images depicted on the mural bricks that line the walls of the Hexi tombs; see Zhao Xueye 2007.

${ }^{469}$ See Wang Lei 2004 for a further discussion on how this new focus on the everyday life on the farm reflected a shift from the previous moralistic and didactic emphasis of the Han pictorial schemes to the WeiJin interest in the representation of reality. 
are depicted as taking part in daily activities, in a series of brick murals that piece together the routines of daily life, not unlike a comic strip, as featured in Jiayuguan M6 (fig. 67). Moreover, whereas in the Han repertoire, the lady of the household and other women of the household could only enjoy the gaieties of the banquet as onlookers from the second floor (fig. 68), the Hexi depictions started a tradition of involving the role of the lady and her female guests as having their own separate banquet next to that of the men, such as that in Jiayuguan M5 (fig. 69).

Up to this point, the pictorial representations of the Han tradition, either on stone or brick, represented snapshots of moments in the tomb occupant's life, rearranged into a pastiche on the inside surface of the tomb walls to construct a functional space for the afterlife of the deceased. At this time, the images were either represented in their entirety on individual pieces of stone slabs that were divided into several vertical registers, or a larger image was depicted across several adjoining pieces of stone slabs (figs. 70a, b). Although this pictorial scheme continued into the Hexi mural brick tradition, most notably in the Wei-Jin period tombs of the Jiayuguan region, it is in Dingjiazha M5 in the Jiuquan region that a transition appeared, as the murals expanded to cover the entire wall surface of the tomb chamber (fig. 71). ${ }^{470}$ For the first time, various motifs developed in the previous centuries were synthesized into a single pictorial program. However, the practice of using registers was retained to divide the wall generally into three tiers, like those at Dingjiazha M5, which I believe demonstrates the tenacity of habitual practices in such transitions, and not necessarily a partition of the universe as suggested by Wu Hung. ${ }^{471}$

\footnotetext{
${ }^{470}$ For a conservation report on the current state of Dingjiazha M5, see Chen Gengling and Ma Qinglin 2002. See also Zhang Pengchuan 1979 for a discussion of the images applied in the Dingjiazha M5 murals, focusing on the thematic subjects being represented and the artistic treatment of the pictorial representations. ${ }^{471}$ It is this concern with the idea of dividing the burial space into three tiers that Wu Hung came up with the notion of a tripartite universe that reflect the contemporary belief about the afterlife, consisting of the cosmic
} 
By the fifth century, a further change took place in the application of murals in the Northern Wei tombs at Pingcheng, turning individual scenes into a panoramic view that spans across the entire wall as one big scenario, without the use of registers. So far, this is true for all the mural brick tombs that have been uncovered in the Pingcheng area, as indicated by the reports for Shaling M7, Yunbolilu M1, a news release of Fadianchang M1, and from what remains of the murals in Wenyinglu M1. ${ }^{472}$ As such, a more or less standardized pictorial scheme emerged, positioning the image of the tomb occupant prominently against the back wall, flanked on both sides by scenes of the activities that the deceased had previously enjoyed, and will be expected to continue to engage in the afterlife. This new framework suggests a shift in the perspective of the tomb space, and I will argue that this layout enhances the social and functional roles performed by the tomb occupant. Moreover, by replacing the use of motifs of the previous pictorial tradition with a comprehensive and descriptive scene, the entire tomb chamber is integrated into a cohesive narrative, with the image of the tomb occupant at its center. As a result, these later tomb murals allowed for a more creative expression of individuality as the murals were no longer limited by the boundaries of the bricks or stone slabs.

Finally, it was also in the Pingcheng murals where we notice a relocation of the setting of the tomb occupants from a traditional Han styled indoor banquet scene to that of an open

realm, the immortal paradise and the earthly abode. However, if we take a look at the actual images depicted in each register, we will see that Wu Hung's argument of the tripartite universe was rather arbitrary. While the top register does depict heavenly phenomena, auspicious omens and immortals, the middle and bottom registers both represent scenes, figures and activities of the earthly environment. Even Wu Hung acknowledged that the relationship between the three different realms is unclear, and that it is difficult to determine the position of the deceased; see Wu Hung 2010, pp. 34-35.

${ }^{472}$ See Datongshi kaogu yanjiusuo 2006a for Shaling M7; Datongshi kaogu yanjiusuo $2011 \mathrm{~b}$ for Yunbolilu M1; Zhang Qingjie 2008 for the news release on Fadianchang M1 as no report has been published yet, and see Zhang Qingjie and Liu Junxi 2011, p. 53 for an image of the mural; also Datongshi kaogu yanjiusuo 2011c for Wenyinglu M1. 
air camp site. On Han pictorial stones, while the representation of the tomb occupant as the master of the household varies from one tomb to another, the setting remains consistent, that the activities were conducted in an indoor environment. This is indicated often by some inconspicuous yet important markers. In Dahuting M2 of Mixian (fig. 64a), it is the hanging curtains and tassels that not only frame the scene but also suggest the event is taking place within the household. The pictorial stone slab from Jiaxiang has two registers (fig. 68). The bottom register shows men in carriages accompanied by attendants on horses and on feet. This complements the top register which depicts the household of tomb occupants. It is said that an unharnessed horse resting beneath a tree next to the house, as a motif in the Han pictorial scheme, signifies that the deceased had retired from public life. ${ }^{473}$ While this image certainly could have taken on symbolic meanings through time, I would point out that its original meaning may have been as simple as it appears to our eyes: that the guest has entered the household and is now paying homage to the host who sits prominently in the center of the scene, with the women of the household seated on the second floor. ${ }^{474}$ We see a similar use of registers in the stone carving from Xuzhou (fig. 70b). Again, in the bottom register, guests arrive by carriage and horse; they enter into the household to be greeted by the host, and entertained by dancers and musicians who are presented in the top register. Later as we examine the Pingcheng murals, we will find subtle markers that indicate a distinct relocation of the setting in which the tomb occupants were represented.

\footnotetext{
${ }^{473}$ Jean James suggests that this particular motif of an unharnessed horse made its earliest appearance known to date on the stone coffin in Shizhuan tomb 10, excavated at Jining, Shandong province in 1988; see James 1998/1999, p.19. For the excavation report, see Zhao Chunsheng and Wu Jian 1992.

${ }^{474}$ Barbieri-Low attributes the varying number of women depicted on the second floor to the practice of Han workshops of prefabricating these standardized stone images, while anticipating patrons who would be survived by different number of widows; see Barbieri-Low 2007, pp. 94-96.
} 


\section{East Wall: Positioning Lady Poduoluo in Her Household}

The murals of Shaling M7 take up approximately 24 square meters of wall space in total, painted in red, black and blue, and are distributed across the four walls of the main chamber as well as on the ceiling and the sides of the corridor that leads into the chamber

(fig. 63). Upon entering into the main chamber, our eyes are immediately drawn to the back wall (east wall), where the image of Lady Poduoluo is presented together with her husband as a seated couple facing forward, and enlarged out of proportion (fig. 55a), with respect to images on other walls. The seated couple is flanked by the north and south walls that are filled with images and decorations that create a rich depiction of a military procession and outdoor feasting scenes (figs. 55b, c). As these two walls appear almost chaotic, with the multitude of people and events depicted, they further serve as a foil to make the tomb occupants stand out as the central figure of this burial space.

Lady Poduoluo and her husband take up a good part of the entire east wall, approximately 3.82 square meters of wall space. The two are seated underneath a Han styled pavilion, one with a hipped roof and clearly delineated tiles and eaves. Underneath the eaves are redcolored dougong structures from which curtains are hung in a U-shape. Seated inside the pavilion, the man on the right wears a loose robe with crossed-over collars that form a Vshape, placing his left hand on a black wooden support, a household furnishing used for leaning against when one is seated in an upright position, and holding a fly-whisk in his right hand. The woman seated to the left wears the same type of garment; her face accentuated with a dab of rouge on her cheeks and colored lips. She also holds something in her right hand, which cannot be made out properly but is most likely to be a round fan. The background of the couple's seat is decorated with fish scale patterns, and the seat is divided in the middle with a red line. In front of the couple stands a crooked-legged table 
with food vessels placed upon it, provided by male and female attendants who flank the pavilion in a much diminished size.

The positioning of Lady Poduoluo, enlarged and depicted in a frontal view, manifests a new development in the representation of the tomb occupant at the head of the entire pictorial framework that had emerged in fifth century northern China. In the Han pictorial stone tradition, either as reliefs or murals, the images of the tomb occupant appeared as a part of a greater scene, engaged in the activities of feasting and banqueting. Most importantly, the tomb occupant depicted as the host in these activities is portrayed in side or three-quarter view, either at the head of the banquet or seated in the midst of guests, as demonstrated in the Dahuting M2 mural (fig. 64a) and the pictorial stone slab from Jiaxiang (fig. 68). In Wu Hung's view, this more traditional and unbalanced pictorial scheme of the tomb occupant presents an "episodic" narrative. It is an enclosed scene in which the ideas to be expressed are contained within the internal structure of the image, and the viewer becomes an observer or onlooker of an event. ${ }^{475}$ By contrast, the frontal and balanced portrayal of Shaling M7 reveals an "iconic" attitude toward the image, putting the viewer in deference to the portrayed figure while forcing an inevitable eye-contact.

Building on this point, Zheng Yan raised the idea that this changing perspective was partly due to the widening impact of religious images. As the depictions of Xiwangmu 西王母 (Queen Mother of the West) (figs. 34a, b) and Dongwanggong 東王公 (King Father of the East) became more popularized in the Han, their representations were hugely influenced

${ }^{475}$ Wu Hung 1989, pp. 132- 134. 
by Buddhist iconographic schemes deployed in monasteries and cave temples. ${ }^{476} \mathrm{He}$ believes that the "iconic" attitude demanded by the frontal view of the tomb occupant befitted the Chinese funerary practices of ancestral veneration. In fact, even in a religious pictorial scheme, such as the stone carvings at Yungang, frontal and side-view portrayals appear to differentiate between a static image and one that suggests a scene in action. The image set of Vimalakirti and Manjusri on the south wall of Yungang cave 6 clearly uses the side-view portrayal, one which is rarely used for the depiction of the Buddha, to convey the episodic setting of a lively debate between the two characters (fig. 72). ${ }^{477}$ Thereby, the viewer becomes an onlooker, a member of the expected gathering crowd, as Vimalakirti and Manjusri expounded on the Dharma and competed in demonstrations of their supernatural powers.

By the Pingcheng period, this growing focus on the image of the tomb occupant turned it into the most important and prominent element in the entire pictorial set, positioned against the back wall in a frontal view. Though at first glance, the viewer might assume that this choice was to place the tomb occupant apart from the rest of the repertoire, the side-view portrayal of the tomb occupant underneath a rectangular building on the eastern end of the south wall suggests otherwise. The choice of the different angles of portrayal applied on the two walls confirms the notion that they were specifically adopted to elicit

\footnotetext{
${ }^{476}$ Zheng Yan tackled this idea in several of his papers; see Zheng Yan 1998, pp. 57-61; Zheng Yan 2003, pp. 59-61; also Zheng Yan 2011, pp. 223. As for the representation of Xiwangmu most often in a full frontal position and attended by servants to each side, see Erickson 1994, p. 16. Wu Hung suggested that Han dynasty Chinese perceived the Buddha as a deity similar to Xiwangmu and Dongwanggong, and that images of the Buddha, which were introduced into China at the time, enriched the representations of Chinese indigenous cults, and reflect a random borrowing of Buddhist elements by Han popular art; see Wu Hung 1986, p. 273. This conflation of iconography, which allowed certain themes in Buddhist imagery to be absorbed into popular Chinese representations, had been discussed in chapter three; see pp. 123-125.

${ }^{477}$ This is a scene from the Vimalakirtinirdesha Sutra, teaching the meaning of non-duality. For an English translation of the sutra, see Watson 1997. This image frequently appears in the cave sculptures at Yungang and Longmen in the Northern Wei. It first appeared as a mural painting at Dunhuang in the Sui, in cave 276; see Zou Qingquan 2010.
} 
separate responses from the viewer, in order to construct an engaging representative scheme. While one is expected to gaze upon the east wall in deference to the master of the household, the banquet on the south wall invites the viewer to step inside the scene as a guest of the household. This new development not only represents a shift in the physical layout, but also a change in the function of the pictorial scheme carried out within a tomb space.

The image of the seated couple becomes the first thing that one sees when emerging from the corridor. This dominance not only makes us consider what function was intended by placing the portrait of the tomb occupants on this very wall, but also suggests the possibility that these images contained other levels of agencies within this particular space. Here, we might consider Jessica Rawson's treatment of the Ming Emperor Wanli's (r. 1572-1620 CE) portrait as a starting point to elucidate our understanding of the sources that gave agency to the tomb occupants' image in Shaling M7. Rawson proposes the concept of dividing the world into three levels: the everyday world, the institutional world, and the conceptual world, as a method of considering a more complex model of the world in which we live. ${ }^{478}$

If we are to adopt the same world model, the image of the tomb occupant, which sits prominently on the east wall in Shaling M7, has agency for the viewer at three different

\footnotetext{
${ }^{478}$ Rawson 2007a, pp. 95-113. Using the portrait of the Wanli emperor as an example to examine the sources of belief that gave the portrait agency, Rawson looks at the everyday world in level one as being composed of the things that maintain the emperor's day-to-day existence, such as foods and clothing. The institutional world in level two reminds us that the emperor fulfilled a major institutional role in court, and that in life, he was seen in court audiences wearing the ceremonial robes depicted in the portrait, embodying the beliefs shared by many in the Ming society about the central relationship of the emperor to the universe as a whole. Finally in the third level is the conceptual world, which contains notions of rituals, efficacy of offerings to the ancestors, and the possibility that a tomb will provide an afterlife for the emperor. The ideas explored in Rawson's paper on the agency of, and the agency for, the Wanli emperor, centered on a ritual portrait of the Emperor and other artifacts discovered in his tomb, are based on aspects of the concept of agency as explored and developed by Alfred Gell; see Gell 1998, pp. 68-72.
} 
levels. At an everyday level of physical embodiment, it places Lady Poduoluo in a central position in relation to the events that are being carried out and the objects of consumption as depicted. As in any society made up of people, the world in which the tomb occupant had lived was made up of institutions. That is, Lady Poduoluo was wife to her husband, mother to her son, and also the female head of the household. ${ }^{479}$ Her place in this familial social structure is conveyed through the depiction of a couple rather than an individual. Finally, and the most important agency to concern us in this burial chamber, is the conceptual world invoked by the tomb occupant's image and the rest of the mural repertoire, underpinned by the belief that a tomb provides an afterlife for the deceased in terms of space and sustenance. As such, the main chamber of Shaling M7 was transformed into what the tomb occupant's family intended to portray as a physical and cognitive embodiment of the life she previously led, and expected to enjoy in her afterlife. As a physical surrounding, the burial chamber was conceptualized as the household of Lady Poduoluo; on a cognitive level, the wall murals and the everyday objects that accompanied her interment provided a reenactment of her everyday experience and sustained the belief that these would continue into the future.

In unpacking the visual and material elements that pieced together the life and physical world of Lady Poduoluo, we should keep in mind that cultural items as reflected in the mural images may express an identity, but they do not define it, especially when it comes to an individual's dynamics within a collective. As Edmund Leach found in the 1950s in the hills of northern Burma, an individual's clan identity does not necessarily vary with

\footnotetext{
479 This notion of how a person's identity could be constructed based on his or her social relations had been inspired by Neil Coomber's thesis on the performative construction of gender in Bronze Age China. He looked at how gender was (re)created and (re)produced through performances which incorporated a structured material repertoire. Ultimately, identity was materialized and reified through performance, and in effect, an ontological process of "boying the boy and girling the girl"; see Coomber 2011, pp. 1-2.
} 
measurable cultural traits, whether material or non-material. ${ }^{480}$ Rather, it is a person's perception of themselves, conditioned by how others react to that person, which determines the social identity of an individual, even if the person no longer speaks a certain dialect or wears a particular type of clothing. The symbolic significance of a cultural trait is in fact a statement about the status of the person involved. As such, a person can have multiple expressions of his or her identity, and these markers of cultural traits only reveal an aspect of this individual placed in a particular social system. As I have previously argued, the image of Lady Poduoluo on the east wall of Shaling M7, in its specific position in the entire setting of the tomb chamber, invoked a sense of physical and cognitive presence of her former life and the world in which she lived. Thereby, it provides a suitable starting point for our discussion, as we take apart some of her everyday practices, which may or may not be representative of the elite life in fifth century Pingcheng.

A look at several other Pingcheng tombs that contain images of the tomb occupant shows us that what we have in Shaling M7 exemplifies a new formulaic repertoire for the portrayal of tomb occupants in the Northern Wei. On the east wall of Yunbolilu M1 (fig. 56a) and on the inside surface of the north wall of the stone sarcophagus in Zhijiabao M1 (fig. 57a), we see almost an exact replica of the seated tomb occupant, facing forward as a couple, in an enlarged and prominent position. Although formulaic, these examples nonetheless represent a distinct starting point for us to understand the Northern Wei view on the agency of a tomb chamber. The portrayal of a couple seated side by side no longer merely functions as a representation of the tomb occupant. Rather, it has a more symbolic meaning. It serves to place the tomb occupant in his or her familial context, and as a

\footnotetext{
${ }^{480}$ Leach 1970 , pp. 11-17, 52-55. Leach refers to material cultural traits as types of houses or pottery, and non-material traits as shared social values and belief systems.
} 
reminder to the viewer that the burial space is not just the physical embodiment of the afterlife. Rather, it is also a functional space in which a myriad of performances intersected to define the deceased by his or her role in society.

In these Pingcheng murals, apart from changes in the pictorial format and the intention behind having the image of the deceased, a relocation of the preferred setting for the tomb occupants also appeared. A predilection for the outdoors is accomplished through the use of differentiating markers that serve to remind the viewer of the "dual presence" of the Northern Wei life at Pingcheng; adhering to the systematic continuities of the Chinese burial tradition while holding onto aspects of lifestyle on the steppe. Even after having settled into Pingcheng, much like the royal households of the Il-khans and the Timurids in thirteenth to sixteenth century Central Asia who adopted a semi-nomadic lifestyle that coexisted with the erection of palaces in new capitals, ${ }^{481}$ the rhythms of pastoral nomadism continued to dominate court life in the Northern Wei.

The first differentiating markers in the Shaling murals lie within details such as the halfdrawn curtains hung from the beams and the trees on each side of the pavilion, both approximately the same height as the building itself. Authors of the excavation report refer to this architectural structure as the tomb occupants' residence, obviously focusing on a selective reading of seeing it as an acculturation to a Han lifestyle, which the authors have accepted as preconceived notions that passed on from the Han tombs. ${ }^{482}$ However, the architectural style of this Shaling tent-pavilion appears to be a variant of a Central Asian

\footnotetext{
${ }^{481}$ In his study of the Ilkhanate and the Timurid court life, O'Kane pointed out that even with a shift into sedentary practices, seasonal migrations were often preferred, apart from providing grazing lands essential to livestock, as they provided a means to escape the extremes of heat and cold which characterize the Central Asian plateau; see O'Kane 1993, p. 249.

${ }^{482}$ Datong shi kaogu yanjiusuo 2006a, p. 23.
} 
tent, similar to a court tent of the fifteenth century Timurids (fig. 73). Of all the records that describe court tents of the great Islamic dynasties, those from the Mughal emperors, who were Turko-Mongol descendants of the Timurids based on the Indian subcontinent, are the most extensive. Provisions were made for court tents to be established at the Mughal palaces, as the arrangement of tents allowed for greater freedom for the flow of air so badly needed in the Indian climate, a better view of the sovereign for his subjects, but also an enclosed imperial space when such privacy was needed (fig. 74). ${ }^{483}$ A juxtaposition of the Shaling tent-pavilion with the Timurid and Mughal examples transforms what would have been noted as an oddity in the Shaling pictorial representation into an architectural tradition that prevailed among the nomadic peoples.

Though in Shaling M7, what would have been the canopy of a tent was replaced by a Chinese styled wooden roof. From the roof hangs the curtains to be drawn up or let down for the flow of air, and the entire structure stands on an elevated dais on which the tomb occupants are seated. Whereas the Han practice was to sit on a cushion placed on the floor, elevating the hosts' seat on a dais in this case might suggest that it is exactly because the banquet was intended to be conducted in the rough outdoor environment, the hosts needed to be raised above the mud and dirt of the ground into a more comfortable sheltered arrangement. This point is further advanced on the inside of the north wall of the Zhijiabao M1 sarcophagus, where the tomb occupant is portrayed as a couple seated on a raised dais or a couch bed, underneath a simple canopy raised on poles (fig. 57a). Curtains that would have draped from the canopy are rolled up, while two tassels that hang on both sides dance in the wind.

${ }^{483}$ Andrews 1987, p. 150. 
Furthermore, when looking at the murals of Shaling M7 and Zhijiabao M1, it is hard to miss the conspicuously positioned trees right next to where the tomb occupants are seated. In fact, the mountains, trees and grass that mark the landscape serve as a second type of differentiating marker in these mural settings. In Shaling M7, the two trees on each side are both approximately the same height as the pavilion, with sprawling branches and shoots of leaves, give off the sense that the hosts of the banquet are seated in a shaded area, in the shadows cast by the surrounding trees. Even in the case of Yunbolilu M1, where a hall is clearly depicted as an embellished setting for the tomb occupant, it is worth noting that, unlike the traditional Han repertoire, the façade that we see does not suggest an overall indoor setting for the scene (fig. 56a). Only the tomb occupant couple and their attendants in close quarters are framed underneath the facade, whereas the rest of the gathering is placed outdoors. Furthermore, the archaeologists of Yunbolilu M1 made a point of noting in the report that "tufts of grass are drawn next to all the human figures." 484 However, these distinguishing markers are only meaningful in the eyes of those who know what to look for in a seemingly paradoxical scene. Indeed, we might even interpret Yunbolilu M1 as representative of a transitional phase in which the original Han pictorial setting of indoor banquets continued to linger on as a stock motif, even when the tomb occupant's leisure enjoyments had already relocated into a natural environment. From these aspects, we are introduced to Pingcheng elite families who were comfortable with combining their own everyday activities that originated from the steppe world with existing funerary traditions of the Chinese sphere.

\footnotetext{
${ }^{484}$ In the excavation report, the archaeologists specifically pointed out that there are tufts of grass drawn next to all the human figurines on the east wall of Yunbolilu M1; see Datong shi kaogu yanjiusuo 2011b, p. 19. The original text reads 所有人物的身體旁均繪有小草。
} 


\section{North and South walls: Remembering Lady Poduoluo in Leisure and Ranks}

With the image of Lady Poduoluo on the east wall, to her left and right are the banquet and military procession scenes depicted on the south and north walls respectively. The setting in an open air environment, as previously established by Lady Poduoluo's tent-pavilion, is further expanded when we look at the banquet and feasting scene on the south wall (fig. 55b). The mural on the south wall, taking up approximately 5.4 square meters, depicts a "zoomed out", or even panoramic, view of what appears to be a camp site in the most luxurious style. Framing the entire scene are rows of rolling hills, mountains, and trees that border along the top and bottom of the wall. The miniature scale of the mountains and trees gives the viewer a sense of distance, and suggests that the human activities depicted in this scene were conducted in a natural environment, where the mountains and hills could be seen at a distance; the trees serve as an intermediary zone between the human realm and the unpredictable wilderness.

As such, the use of screens became an important aspect in understanding this mural, one that bears dual functions. It not only serves as a physical attribute of the outdoor campsite environment, but the screens were applied as a part of the pictorial framework, as a replacement of the former use of registers. Running down in a zigzag pattern through the center of the south wall, the screen divides the mural into two functional spaces. The eastern end (left side of the mural) is where the tomb occupant hosts the feast from a threewalled structure at the head of the banquet, facing a gathering that has been arranged into three horizontal rows. On the western end (right side of the mural) is a campsite where the preparation of the food is being undertaken. We see female attendants bustling in and out of the tents, and the butchering of animals is depicted in great detail in the open air (fig. 75). A break in the setup of the winding screen is purposely located for the attendants to 
cross between the two sections, a function that other types of division would not be able to fulfill. The same kind of application is found on one of the wooden coffin boards scattered in Zhijiabao M2, excavated nearby Zhijiabao M1; two screens serve to quarter off the area where food is being prepared in a large cauldron (fig. 76). ${ }^{485}$ As such, the screens performed a visual function for the viewer to differentiate the two different scenes, and also a practical function within the mural for the separation of space. And most important of all, this was precisely how actual camp sites were organized in life in the open.

The tents, dividing screen, and camp fire are all temporary arrangements that contribute to the mobile and open-air nature of these banquets. Indeed, the co-existence of tents and pavilions in these images does not present a discord in the presentation of life in Pingcheng, and there is no need to single out either practice as having been replaced by the other. In the late fourteenth century, Tamerlane's life in Samarkand was described by his contemporary as being very much in the open air, including accounts of receptions, banquets and weddings. ${ }^{486}$ Great gardens encircled the city, and when they were occupied by the court, the garden grounds were enclosed by walls of cloth. In fact, tents and awnings were everywhere in these gardens, regardless of whether they also displayed permanent structures. This is a sight that we now begin to see as having existed in the Tuoba's court at Pingcheng centuries before Tamerlane's time.

\footnotetext{
${ }^{485}$ Several earth chambered and brick chambered tombs have been discovered by archaeologists north of the Zhijiabao village, which is south of Datong city. Unfortunately, the site had been greatly disturbed as a result of previous looting activities, and apart from the previously mentioned house-shaped stone sarcophagus of Zhijiabao M1, only three wooden panels of the coffin were found scattered around this tomb, which will be referred to as Zhijiabao M2 in the order of the excavations. For the report on the painted coffins, see Liu Junxi and Gao Feng 2004.

${ }^{486}$ Wilber 1979, p. 128.
} 
To make such a way of life functional, ox-drawn carts and carriages, like that which we see under one of the trees next to the tomb-occupant's pavilion on the east wall, as well as those resting on the outskirts of the banquet on the south wall, served as the main mode of transportation for the transfer of these tents. Similarly, the clay figurine set in Yanbei Shiyuan M5 (dated to $477 \mathrm{CE}$ ), Datong, Shanxi province, contains a clay cart figure, which consists of a base board on which a yurt is being carried and held in place by another end board (fig. 77). Archaeologists of the excavation report described it as a carriage with a tortoise-shelled cover, ${ }^{487}$ but it could very likely be a yurt-cart of the nomadic migratory tradition, that can be drawn either by ox or horse, as the Greek geographer Strabo described the Scythians in 7 BC, that: "As for the Nomads, their tents, made of felt, are fastened on the wagons in which they spend their lives... ${ }^{488}$ In his study of prehistoric central Eurasia, David Anthony argues, using archaeological findings from the steppe graves of the Yamna culture (3500-2500 BC) in the southern Ural region, that solid-wheeled wagons and carts, probably pulled by oxen, have existed as early as around 3100-3000 BC on the Pontic-Caspian steppe. ${ }^{489}$ Together, all of these distinct elements put together a clear picture of the ways in which life in Pingcheng can best be treated as a manifestation of the eastern end of the Eurasian steppe cultural continuum.

For the Tuoba who had just settled into northern China from a life on the steppe, it would be no surprise if camp sites were mobile cities, and the tents which the rulers and the elite

\footnotetext{
${ }^{487}$ For a discussion of the different models of the clay ox-carts, see Zhang Zhizhong 2008, pp. 81-84.

${ }^{488}$ Jones 1917, p. 223; also Bunker 2002, p. 12.

${ }^{489}$ Anthony argues that steppe pastoralism was dependent on the triad of grazing animals (sheep or cattle), horseback riding and ox-wagon transport. See Anthony 1986, p. 310. The Yamna culture was the first steppe culture of Eurasia to possess riding horses and wagons, and seems to have been the first archaeological culture strongly oriented towards stock-breeding deep in the steppe. Anthony points out that while horses improved long-distance scouting, trade and warfare, wagons which were most probably drawn by oxen provided the long bulk transport for tents, food and supplies that freed herders from logistical dependence on the river valleys and permitted them to move deep into the steppes with their herds for an entire season; see Anthony 1995, p. 561.
} 
occupied could be considered as mobile estates and palaces. The north wall of Shaling M7, which takes up approximately 6.43 square meters, further advances and manifests this portrayal of the mobile environment at Pingcheng (fig. 55c). The mural merged what would have been either hunting or military combat scene in a Han stone relief or a Wei-Jin brick mural into a military procession, although the excavation report continues to refer to it as a carriage and horse procession scene. ${ }^{490}$ Indeed, a large carriage with a canopied top, curtains covering the front, and flags hoisted on its rear take the central position of the wall. The head of a male figure appears above the carriage under the canopy, suggesting the master of the household who was also the commander of this military procession. ${ }^{491}$ In the case of Lady Poduoluo, this person would most likely be her son, a Northern Wei high ranking general. Here again, it is suggested that the mural representations were designed to embody the life of the deceased as defined by the status and actions of those with whom they shared a system of social relations. In Shaling M7, even if Lady Poduoluo had never taken part in one of these military processions, she is who she is for being the mother of the man who commanded this troop.

The carriage is led at the front by scouts on horseback, soldiers playing the bugle, foot soldiers in red cape and hat with spears, bows and arrows, flag bearers, as well as musicians, drummers and acrobatic entertainers (fig. 78). This group of people appears to be nothing out of the ordinary for a grand and flamboyant procession. However, what follows behind the carriage is an entirely different entourage, as ranks of light cavalry and

\footnotetext{
${ }^{490}$ Datong shi kaogu yanjiusuo 2006a, pp. 15-16. The archaeological report for the Shaling tomb describes the north wall using the same terminology as would be used in describing a Han period tomb, namely, the carriage and horse outing scene.

${ }^{491}$ In this period, there was a growing phenomenon of the overlapping of militarists and great families with landed estates. Mark Lewis argued that the distinction was between those who merely wielded local influence and those who, by accumulating military forces, were able to act at the regional or imperial level. It was this divergence of military power from social authority that became a defining feature of the political history of the Northern and Southern dynasties; see Lewis 2009, p. 33.
} 
heavy-armored cavalry file in military formation (fig. 79). Although the cavalry and foot soldiers are in complete combat garb, they are not engaging in a battle, as they would an actual combat scene of the Han repertoire (fig. 80). The drummers, bugle players and acrobats are depicted in the middle of a performance, but unlike the entertainers who accompany a banquet, they are lined up in ranks and perform while advancing in motion like a modern military parade. It is very important to note that this is a completely new perspective on the representation of power and might. Much like the effect of the stone Buddha sculptures at Yungang, in this particular scene, power is wielded and a sense of awe struck into the viewer's mind, all accomplished without the need or desire to depict an actual combat. The flamboyantly dressed soldiers and the well-disciplined behavior of even the marching musicians and entertainers suggests the effectiveness of this troop and that one would not wish to end up on its opposing side.

Nonetheless, these pictorial characteristics of Shaling M7 do not, in any way, represent the development of a standard mural trope of the Pingcheng tombs. In fact, I would argue that the scenes present themselves as a channel for the tomb occupant's individual expressions, or even their outlook on life. Unlike the application of stock motifs and modular patterns of the Han pictorial stones, as a complete pictorial set, ${ }^{492}$ the Pingcheng murals serve more like a pictorial biography of the deceased. Unfortunately, the mural on the north wall of Yunbolilu M1 had been completely damaged, and we have no way to identify what would have been depicted as the rest of the Yunbolilu repertoire or to examine it as we did with Shaling M7. However, the entire south wall is covered by a representation of what appears

\footnotetext{
492 While a single object is compared with other objects, a set presents within itself similarities or differences between the individual parts. Treating the murals within a particular tomb space as a pictorial set with constituent elements allows me to breakdown the different components of the scene and to examine the individual variations as a change in the set's functional characteristics that could reflect upon the identity of the tomb occupants as recognizable references; see Rawson 1998, pp. 107-133.
} 
to be a hilly terrain covered with thick woods (fig. 56b). The only figures depicted in this scene are members of a very small hunting party, as referred to by the tomb report, ${ }^{493}$ resting underneath a tree with three unharnessed horses. Here, it is rather significant that, in the representation of what would easily be called a hunting scene, the patrons of these murals decided to depict both the men and the horses at rest. Moreover, three small deer stand unthreatened next to the men, giving off a general sense of serenity and ease. All in all, this scene suggests that the tomb occupant who enjoyed this lifestyle was a person removed from the hustle and bustle that radiated from the walls of Shaling M7. The luxury and glory so well displayed with regard to Lady Poduoluo are replaced by a peaceful retreat into nature as desired by the tomb occupant of Yunbolilu M1. As such, these murals prove to be expressive means for the viewer to grasp the most important aspects of life in the eyes of the various tomb occupants.

All of these pictorial representations were expected to transform into a functional embodiment of the afterlife for the deceased. In this context, the notion of the cosmic realm in Han and Wei-Jin murals was not lost in the Pingcheng tombs, but took on new significance. The image of the cosmic sages of Fuxi and Nüwa in Shaling M7, painted onto the underside of the arch above the tomb corridor, is a traditional Han auspicious image (fig. 81). ${ }^{494}$ The two figures are depicted wearing flower garlands on their heads, arms folded in front of their chests, with their lower bodies in the form of dragon's tail entwined together, and a muni treasure pearl decorated with flame designs suspended in

\footnotetext{
${ }^{493}$ The archaeologists labeled the south wall of Yunbolilu M1 as a hunting scene; see Datong shi kaogu yanjiusuo 2011b, p. 24.

${ }_{494}$ As a sage king, Fu Xi represents the Yang cosmic force and is regarded as a cultural hero who invented aspects of civilization, whereas Nüwa is a female cosmic deity of the Yin force and thought to have saved mankind from extermination. Together, the two are believed to have given rise to the human race through their union. In the Han stone engravings, Fuxi and Nüwa usually are shown together holding a square and a compass, respectively, as metaphors for just and even rule; see Powers 1991, pp. 113-114; also Zhao Wucheng 2005, p. 67. However, Mark Lewis interprets the two objects as suggesting the linking of the square earth to the round heaven; see Lewis 1999, p. 204.
} 
the air between Fuxi and Nüwa. These muni treasure pearls are most commonly found on the lintel of the cave entrances or at the top of the entrance arch at Yungang, and in a Buddhist context, they suggest a boundary between the secular world and the Buddhist world. ${ }^{495}$ By placing this specific image on the underside of the arched ceiling of the corridor, it is not visible to either a visitor approaching the tomb chamber from the passageway, nor from the position of the tomb occupant inside the chamber. Only when one raises one's head upon crossing through the narrow corridor will the two figures become visible. This particular location of the motif at the entrance of Shaling M7 turned the image of Fuxi and Nüwa into a marker of separation between the world of the living, to which the funerary procession must return, and the realm of the afterlife, in which the deceased will embark on a new journey. ${ }^{496}$

\section{CASE STUDY II: YANBEI SHIYUAN M5 OF SONG SHAOZU}

In 2000, during the renovation project of the Yanbei Shiyuan 雁北師院 (Yanbei Normal Institute) compound, for which the building complex was to be expanded, archaeologists of the Datong Archaeological Institute discovered a cluster of over one hundred tombs, dated to the Northern Wei, Ming 明 (1368-1644 CE) and Qing 清 (1644-1912 CE) dynasties, as well as some present-day burial sites. The eleven tombs dated to the Northern Wei are situated as a smaller cluster to the northwest, all oriented facing south. Out of the eleven Northern Wei burials, six are earth pit tombs and five are brick chamber tombs,

\footnotetext{
${ }^{495}$ The appearance of the muni treasure pearl suggests a growing Buddhist influence in the Northern Wei. At Yungang, the muni treasure pearls appear on the lintel of the cave entrance or at the top of the entrance arch. $\mathrm{Xu}$ Runqing raises the notion that the positioning of these treasure pearls suggests crossing over a boundary from the secular world into the Buddhist world. By the same understanding, by placing the muni treasure pearl in between Fuxi and Nüwa underneath the arch of the corridor that leads into the tomb chamber, it also turns the chamber into a Buddhist world; see Xu Runqing 2011, p. 174.

${ }^{496}$ In the Wei Jin tombs, the imagery of Fuxi and Nüwa was commonly applied onto the inside of coffin lids as well as in the form of wall murals in the tomb chamber. It was generally believed that this image would help the deceased achieve ascendance in the afterlife; see Zhao Wucheng 2005, pp. 66-68.
} 
including single and double-chambered layouts. My focus is on the brick singlechambered tomb M5, attributed to Song Shaozu 宋紹祖 and his wife, dated to 477, the first year of the Taihe reign under Emperor Xiaowen. ${ }^{497}$

Yanbei Shiyuan M5 consists of a sloping passageway, two arched tunnels, two air shafts, an arched corridor and a rectangular chamber with a curved pyramidal profile (fig. 82). The passageway is 31 meters long in total and 1.14 meters wide, much longer than that of Shaling M7. Upon reaching the 2.85 meter-long corridor that leads into the tomb chamber, the width narrows down to 0.96 meters and further tapers down to 0.90 meters at the northern end where it leads into the chamber with a cloister vault ceiling. The tomb chamber itself is similar in structure to Shaling M7, but slightly bigger in size. Since the walls have a concave curvature, the widest point in the east-west direction is 4.24 meters, and 4.13 in the north-south direction. A house-shaped stone sarcophagus with mural paintings on the inside of the stone panels takes up much of the space within the tomb chamber; 2.52 meters wide and 2.65 meters deep, with a height of 2.28 meters. A set of clay figurines is laid out throughout tomb chamber (fig. 83), radiating outwards from underneath the covered façade of the stone sarcophagus to the walls, and as far as the tomb entrance, where tomb guardians stand guard at the southern end of the corridor. To the east and south of the chamber are clusters of figurines, including armored cavalry, foot soldiers, household objects, livestock, and several westerners amidst them. To the west are more armored cavalry along with some harnessed horses. To the north are the tomb occupants' finely decorated ox-carts, as well as ranks of flag-bearers. In front of the façade of the stone sarcophagus, light armored cavalry, pilot carriages, heavy armored cavalry and

\footnotetext{
${ }^{497}$ An extensive report has been published on the Yanbei Shiyuan tomb cluster, with a focus on the brick chamber tomb M5 attributed to Song Shaozu and his wife. Most of the factual details in this thesis regarding Yanbei Shiyuan M5 were taken from this publication; see Datong shi kaogu yanjiusuo 2008.
} 
harnessed horses are arranged in a processional formation. Finally, five female attendant figurines are placed inside the sarcophagus, along with lacquer plates, an iron mirror and other small objects.

Two sets of human bones, one male and one female, were discovered in the excavation of the tomb, but as the tomb had previously been looted and greatly disturbed, the bones were found scattered on top of the stone sarcophagus, along with a silver bracelet and a piece of amber jewelry, on the ground of the chamber against the north wall, as well as against the west wall of the corridor. These skeletal remains and accessories had most likely been scattered and discarded by the looters as they refilled the tomb. An epitaph brick found in the earth refilling in the northern section of the tomb passageway contains twenty-five characters in three columns (fig. 84):

\section{大代太和元年歲次丁 / 巳幽州刺史敦煌公敦 / 煌郡宋紹祖之殹}

In the Great $\mathrm{Dai}^{498}$ in the first year of the Taihe reign, the year of dingsi, [here lies] the coffin of Song Shaozu from the Dunhuang commandery, who was the Regional Inspector of Youzhou and [also held the title of] the Duke of Dunhuang. ${ }^{499}$

This textual evidence reveals to us that the tomb occupant by the name Song Shaozu 宋紹 祖 was originally from the Dunhuang commandary, and that he was buried in the first year of the Taihe reign (477 CE). In his lifetime, he had held the position of the cishi 刺史 (Regional Inspector) of Youzhou 幽州, ${ }^{500}$ and was given the title of Dunhuang gong 敦煌

\footnotetext{
${ }^{498}$ Before Tuoba Gui renamed the territory ruled over by the Tuoba as the state of Wei in 386, it had been known as the state of Dai since 315, and the name Dai became interchangeable with the use of Wei during the earlier period of the Northern Wei.

${ }^{499}$ For more details on the brick epitaph, see Datong shi kaogu yanjiusuo 2008, pp. 161, 200-204. Author's trans.

${ }^{500}$ The region of Youzhou under the Northern Wei spanned parts of present-day Hebei province, Beijing city and Tianjin city.
} 
公 (Duke of Dunhuang). Since female skeletal remains were also found, it is assumed that Song Shaozu was jointly buried with his wife in Yanbei Shiyuan M5. ${ }^{501}$

\section{The New Outsider}

In Richard Jenkins's discussion of the collective identity and the different ways of "symbolizing belonging", the sense of homogeneity within a community can, first and foremost, be expressed in language, but also further symbolized in heraldry, dress, ritual or other material and practical forms. ${ }^{502}$ When groups of people derive their collective identity by drawing boundaries between themselves and other groups, such boundaries are usually fluid and changeable, and individuals can make independent choices in aligning themselves with certain collectives. It is through the reconfiguration of his own tomb assemblage that Song Shaozu explored new notions by which he expressed a conscious sense of belonging as a fifth century northerner. In this process, the family background of Song Shaozu, a Han Chinese elite clan on the northwestern frontiers in Dunhuang at the cultural crossroads where north China was linked to Central Asia, indicates that the meaning of an "outsider" in the Pingcheng context might be reconsidered. Whereas most scholarship on this period continues to treat the nomadic ruling households in northern China as the outsiders, whose acquisition of Central Plains practices or material culture was an attempt to "fit in"; Yanbei Shiyuan M5 demonstrates how the Han Chinese elite,

\footnotetext{
${ }^{501}$ Osteological studies have been done on the two sets of skeletal remains in Yanbei Shiyuan M5, which has revealed one male to be between the years 50-60 and one female to be between 45-50. From the way the male occupant's femur was bent, the archaeological report suggests that this was someone who had spent long periods on horseback, which fits the narrative as displayed by the military figurines in the tomb chamber. For the osteological report on the two tomb occupants in M5 along with other skeletal remains from the Yanbei Shiyuan cluster, see Datong shi kaogu yanjiusuo 2008, pp. 205-223.

502 Jenkins emphasizes that the sense of homogeneity or uniformity in a local community is derived from a group of people seeing themselves as minimally similar through a symbolic construct, a mask of similarity which all can wear in order to ascribe to being members of a collective. As such, communal membership can be said to be imagined, but as a potent symbolic presence in people's lives, it sets the terms by which people construct a sense of themselves and their relationships with one another; see Jenkins 2008, pp. 132-147.
} 
such as Song Shaozu, living in fifth century northern China should be viewed as the "new outsiders".

Although having been the Regional Inspector of Youzhou and having held the title of the Duke of Dunhuang, Song Shaozu is not to be found in any of the dynastic histories, nor is he mentioned in other textual sources. With the osteological studies done on the bones of the male tomb occupant, archaeologists have determined Song Shaozu to be of at least 50 years of age when he died. ${ }^{503}$ Since the epitaph says that Song Shaozu was originally from Dunhuang, this puts him in his teens when Emperor Daowu conquered the state of Northern Liang in 439 and relocated more than thirty-thousand households east to Pingcheng. ${ }^{504}$ Among these households was the Song family of Dunhuang, of which Song Yao 宋繇 had been mentioned at length in the Wei shu. ${ }^{505}$ Although we have no substantial evidence to place Song Shaozu in the same family as Song Yao, the report for Yanbei Shiyuan M5 suggests that, since he had been given the prestigious title of the Duke of Dunhuang, he must have come from a local elite family. ${ }^{506}$ Even if Song Shaozu was not directly related to Song Yao, it is very likely that they were of the same family clan. As such, the study of Song Shaozu and Yanbei Shiyuan M5 will not only be an isolated case, but can be used to understand how members of regional Han Chinese elite families identified with their new social environment in Pingcheng.

While Shaling M7 contains pictorial depictions which allow the viewer to see into the life of Lady Poduoluo and the social relations which defined her in the Pingcheng society,

\footnotetext{
${ }^{503}$ Datong shi kaogu yanjiusuo 2008, pp. 203, 206.

${ }^{504}$ Wei shu, juan 4, p. 90.

${ }^{505}$ Wei shu, juan 52, pp. 1152-1153.

${ }^{506}$ Datong shi kaogu yanjiusuo 2008, p. 204.
} 
Yanbei Shiyuan M5 offers an intriguing range of funerary objects that reflect a difference in the distinctive taste of the tomb occupant. As elaborated by Pierre Bourdieu on the judgment of taste through the notion of distinctions, lifestyles are the systematic products of habitus. He has argued that the personality, the quality of the person, is affirmed in their capacity to appropriate an object of quality, or one endowed with the greatest power of distinction. ${ }^{507}$ In the following sections, we might be able to examine the "personality" of Song Shaozu through the lens of his "distinctions in taste" in the construction of his afterlife.

The house-shaped stone sarcophagus in Yanbei Shiyuan M5 is a prominent example of how the form or design of an object could be borrowed, but that the symbolic meaning behind it is most definitely derived from the local habitus. Moreover, the clay figurines representing a full military assemblage in Yanbei Shiyuan M5, which only existed in the tombs of the kings or grand generals in the Han dynasty, are a particular feature of the Pingcheng tomb repertoire through which the tomb occupants appropriated a "taste" of the past perhaps, to take on a higher social status in their afterlife than that which they had held in life.

\section{Clay Figurines: Buried like a Prince}

Altogether with 113 clay figurines, the figurine assemblage of Yanbei Shiyuan M5 is surprisingly confined to the categories of tomb guardians, warriors, domestic attendants and the $H u$ foreigners. This is extraordinary since the figurine sets uncovered from other

${ }^{507}$ Bourdieu 2010, pp. 168, 278. 
Pingcheng period tombs featured prominently the musicians and dancers, ${ }^{508}$ which are missing from this assemblage. Rather, it is the large military assemblage that makes up a great majority of the entire figurine set in Yanbei Shiyuan M5, and seizes our attention as something out of the ordinary. Consisting of light armored and heavy armored cavalry as well as foot soldiers and flag bearers, these warriors appear to have stepped out of the mural painting on the north wall of Shaling M7. A common feature shared by the mural and the clay figurines is the attention to detail in the representation of the people, especially when it comes to the variety of headgears and clothing worn by each person, one type or another, depending on the role they performed in the figurine assemblage. Dorothy Wong has used the visual representations of nomadic patrons of Buddhist art to demonstrate how the donors constructed and advertised their identity through a selfrepresentation using a number of elements, including that of costume. ${ }^{509}$ Here, the apparel of these clay figurines can tell us much about the environment and lifestyle with which Song Shaozu was willing to be identified, one which corresponded to the cultural geographical position of the Northern Wei on the eastern end of the Eurasian steppe.

First and foremost, an attention to headgear in the production and representation of these figurines may be attributed to the climatically more severe lifestyle on the northern steppe, where life on horseback made it a habitual practice for hats to be worn at all times, often

\footnotetext{
${ }^{508}$ These other contemporary tombs include those of Sima Jinlong and Yanbei Shiyuan M2, an unidentified tomb of the same cluster as Yanbei Shiyuan M5. For the archaeological reports and discussions of their figurines, see Shanxi sheng Datong shi bowuguan and Shanxi sheng wenwu gongzuo weiyuanhui 1972; Wang Heng 2000; also Datong shi kaogu yanjiusuo 2008, color plates 18-20.

${ }^{509}$ Dorothy Wong uses these visual representations to demonstrate the fluidity of the boundaries in defining a person's identity, constructed and advertised through a number of elements: costume, name, rank, social status, geographical locality, and the social and religious groupings to which they belonged. They provide the most concrete evidence of how donors saw themselves and how they wanted to be seen. On one level, they reflect a degree of social and historical reality. At another level, they carry an implicit message that reveals the deep-seated attitudes of the social order of which the donors were a part; see Wong 2003, pp. 84-107.
} 
with neck-flaps. ${ }^{510}$ The most commonly seen headdress in Song Shaozu's figurine assemblage is what Albert Dien calls "the distinctive Xianbei headgear" (fig. 85), one that covers the head with a soft tall dome-like hat, with a drape that covers the wearer's ears and neck. ${ }^{511}$ This is found on all the domestic attendants, both female and male, as well as on the processional flag bearers. Most intriguingly, the flag bearers in this figurine set appear to have their headgears fastened with a girdled chin-strap (fig. 86). Incidentally, the appearance of chin-straps in the Northern Wei was raised by Shing Müller as evidence of the transcontinental cultural transfer between the Mediterranean and East Asia in ancient and medieval times with regard to the diffusion of funerary practices. According to Müller, the custom of using a metal device or a girdle to hold the jaw of the deceased had first appeared on the Asian part of the Eurasian continent probably in the eighth century BCE in the Tarim Basin, and was brought east to Pingcheng no later than the fifth century CE. ${ }^{512}$

In line with the tradition of the horsemen on the steppe in Central Asia, helmets were also widely used in the Northern Wei, with stylistic features that suited the tastes of the new nomadic owners, and much evidence suggests that some of the helmets were not

\footnotetext{
${ }^{510}$ In the Turkic and Mongolian traditions, these neckflaps were made out of leather and often attached to metal helmets; see Karasulas 2004, p. 30.

${ }^{511}$ Dien 1992, p. 46.

${ }^{512}$ Golden lip-bands and mouth-pieces have been used for the deceased in the Near East as early as 2000 BCE, and they had spread throughout Western Asia and along the north coast of the Black Sea during the Hellenistic period. Metal chin-straps dating from earlier than the Northern Wei period have only been discovered outside of the modern borders of China, with the most famous examples coming from the royal tombs at Tillya-tepe in Shibarghan, northern Afghanistan. The tombs were built between the first century $\mathrm{BCE}$ and the first century $\mathrm{CE}$. These chin-straps are simple, long, golden strips widened in the middle and tapered towards the ends. They were found in situ under the jaw, with both ends extending to the temples, and the perforations at the ends of the golden chin-straps indicate that they were sewn onto fabrics that were most likely fastened on the skull. However, Müller sees the metal chin-straps of the Northern Wei Pingcheng tombs as indebted to the fabric chin-straps traditions of the Tarim Basin. The use of headbands and the presence of jaw-guards hark back to the Yingpan and Sampula finds in Xinjiang. However, no metal chinstraps were used in any of these examples, in contrast to the chin-fastening devices made of gold foil as used in the Hellenistic world, represented in the Tillya-tepe finds. Overall, Müller believes that the Northern Wei chin-straps continued certain traditions from the Tarim Basin, but were also inspired by new ideas from beyond East Turkestan that introduced the jewellery techniques used (such as the hinges) and the choice of metals; see Müller 2003, pp. 45-52.
} 
necessarily made out of metal, but were soft and padded helmet-like hats. At least three main types of warrior helmets are represented on the Song Shaozu figurines: 1) the rounded metal helmet with a short piece of neckflap that curves outward on the heavyarmored cavalry (fig. 87a); 2) the same rounded metal helmet and short neckflap with an additional padded rooster's comb attached to the top on the light cavalry (fig. 87b); 3) a non-metallic padded helmet-like hat with a long neckflap on the armored foot soldiers, something similar to the Alannic padded helmet made of silk and linen from KarachaevoCherkessk, Russia, dated to the eighth to ninth century CE (figs. 87c, d). If we understand identity as constructed through interaction between people, and that the process by which identity is acquired and maintained requires choice and agency of the people claiming this identity, a person's clothing, as a direct visual experience, becomes the most clear cut marker of their cultural association. ${ }^{513}$ Dien attributes these outfits to the Xianbei, for the very reason that these markers of apparel do not occur associated with other groups, such as that of the $H u$ foreigners, and certainly not with the Han Chinese. ${ }^{514}$

These distinct headgears came with matching robes and armor on the clay figurines. The foot soldiers are fitted with a knee-length lamellar armor worn over the inner robe, covering the front and back of the soldier's body but not the shoulders nor the arms (fig. 87c). Red and black lines are drawn horizontally and vertically, respectively, to clearly mark the lamellar construction. On the domestic attendants, processional flag bearers, and the light cavalry, we see the combination of loose-fitted trousers (female attendants have lengthier robes that cover their feet) and a kaftan-like coat with one breast crossed over the other, either tied or buttoned to one side (figs. $85,86,87 \mathrm{~b}$ ). However, the coat of the light

\footnotetext{
${ }_{514}^{513}$ Sorensen 1997, pp. 93-114.

${ }^{514}$ Dien 1992, p. 44.
} 
cavalry seems to contain a further variation, in that the robe was much closer-fitting and buttoned up at the center in a Turkic fashion. ${ }^{515}$ This would have facilitated the rider's position on horseback, and reducing the friction of the robe against the wind for the rider. Very different from the light cavalry, both the rider and the horses of the heavy-armored cavalry are covered in armor plates made of iron. In particular, the horses are represented in one-piece bardings, ${ }^{516}$ referred to as "iron horses" in fifth and sixth century poetry. ${ }^{517}$ Unfortunately, the details of construction are not clearly indicated on the figurines, except that the horses are covered entirely, revealing only the four hooves.

Although, in Dien's study of the stirrup's appearance in China in the fourth century, he discusses how it made possible for the use of heavier armor on both the rider and the horse, changing the trajectory of Chinese military history, none of the figurines in this set shows any indications of the existence of the stirrup. ${ }^{518}$ It seems likely that even by the year 477 at the time of the interment of Song Shaozu, the stirrup had yet to become a widely used object, at least as part of the standard equipment set for a horseman, together with the saddle and the saddle flaps. However, we might also entertain the notion that the figurine assemblage was not meant to represent the troops commanded by Song Shaozu in his lifetime by accurate realism. ${ }^{519}$ This is, of course, if he even was a military man. Rather

\footnotetext{
${ }^{515}$ In Antony Karasulas's survey of the nomadic clothing, these kaftan-like coats were often held in place with the belt, but none of the figurines in the Song Shaozu assemblage shows an indication of the existence of a belt; see Karasulas 2004, p.30.

${ }^{516}$ Dien 1981, pp. 37-38.

${ }^{517}$ See Yu Xin 庙信's poem in Yu Zishan ji 13.29b; also Lu Chui 陸倕's poem in Wen xuan, juan 56, p. $772 b$.

${ }^{518}$ For a discussion of the development of horse armor and how it might have been facilitated by the appearance of the stirrup, probably in the fourth century; see Dien 1981, p. 36. Dien further elaborates on the effect of the stirrup on Chinese military history, and how the adoption of stirrup changed the trajectory of some of the battles from the fourth century onwards; see Dien 1986.

${ }^{519}$ This involves the concept of reality by verisimilitude and resemblance, that when a figure is created with intricate craftsmanship that makes the figure appear vivid, the viewer cannot but believe that the figures are real, despite the fact that the viewer might wonder at the kind of skills involved in the craftsmanship; see Freedberg 1989, pp. 197-199.
} 
than serving as the fighting force for the protection of the tomb occupant, or as a marker of his supposed military background, it is possible that these figurines fulfilled the secret aspirations of Song Shaozu as he appropriated a "taste" of the past to attain a higher social status in the afterlife than that he had actually held in life.

The above discussion of the figurines' apparel reveals to us several distinctive features by which the tomb occupant openly identified himself as a member of the greater collective who shared in the Pingcheng habitus, demonstrating a continuation of Eurasian steppe characteristics. A second issue to be considered is what do the clay figurines, as a complete military assemblage, tell us about the tomb occupant's private aspirations? Or even, how would the tomb occupant wish for others to remember him? Whereas collective identity evokes powerful imagery of people who are in some respects similar enough to one another, an individual's identity emphasizes on uniquely embodied differentiation. ${ }^{520}$ If the figurines' characteristic steppe apparel provide an insight into the state of "being" of Song Shaozu at the moment of his interment, the following discussion on the figurine set as a whole will bring us closer to finding out the trajectory of his "becoming", in his afterlife, with the adoption of new identity markers through the reconfiguration of material culture.

Clay figurines and models, just like the pictorial stones, were commonly used in Han burials as an aspect of the funerary repertoire that accompanied the tomb occupants. In fact, figurine attendants, models of granaries, as well as everyday objects, all made out of clay, were to be found in tombs as early as the Warring States period (476-221 BCE) of the Eastern Zhou. ${ }^{521}$ By the Eastern Han, with the development of the multi-chambered tombs,

\footnotetext{
${ }^{520}$ Jenkins 2008, p. 102.

${ }^{521}$ Huang Xiaofen 2003, p. 217. The Eastern Zhou burial of Changtaiguan Tomb 1 at Xinyang, Henan province offers a good example of these tomb figurines. The rectangular tomb chamber was built as a large
} 
a reconfiguration of tombs allowed for more space for different categories of funerary goods, to the extent of having separate chambers for horses and carriages, for grain storage, as well as for armory. These functional props reinforced the symbolic function of the clay figurines, using furniture, instruments and other paraphernalia to assist the figurine assemblage to fulfill their assigned roles. These objects, either real or surrogate, were all deployed to enhance the various "roles" "522 that were essential to the construction of an ideal afterlife for the tomb occupant. The majority of Han tomb figurines assumed domestic roles such as attendants, servants, guards, and performers. For example, the rockcut tomb at Beidongshan near Xuzhou, Jiangsu province contains a set of 422 painted clay figurines placed in different sections of the tomb; guards stationed in shallow niches along the tomb passage way, male and female attendants in various tomb chambers, as well as dancers and musicians in a suggested music and dance hall. ${ }^{523}$ It is the representation of this kind of "indoor" roles that dominated most of the Han figurine assemblages.

By the Northern Wei period, while the notion of clay figurines is nothing out of the ordinary as a category of funerary goods, it is the prominence given to the military roles in the Yanbei Shiyuan M5 assemblage that is significant. Represented either on horseback or on foot, these warrior figurines in full-fledged armor remind us of the terracotta warriors of the First Emperor Qin Shihuang at Lishan, and those of the Han Emperor Jingdi at Yangling. Whereas the Qin warrior figurines are life-sized, made entirely out of clay and then painted in color, the Han figurines of Jingdi are miniature in size and many were

\footnotetext{
wooden box and divided into seven compartments. The figurines were found in the six outlying compartments that surround the central one. The excavators have dated this tomb to the early Warring States period, around the middle and late fifth century BCE; see Henan sheng wenwu yanjiusuo 1986, pp. 18-20.

${ }_{522}$ In an ancient Chinese tomb context, tomb figurines rarely, if at all, represented named individuals. Instead, they were made to signify certain general roles that were essential to providing a setting and an environment for an ideal afterlife; see Wu Hung 2010, p. 102.

${ }^{523}$ For the brief excavation report of the Beidongshan Han tomb, see Qiu Yongsheng, Wei Ming, Li Xiaohui and Li Yingde 1988; also see Li 1990 for an examination of the Beidongshan tomb.
} 
discovered "naked" and armless as they were originally dressed in clothes made out of fabric and fitted with wooden arms (figs. 88, 9). ${ }^{524}$ As such, the Song Shaozu figurines acquired the miniaturized stature from the Han tradition, whereas the intricacy in which the minute details of the soldiers' robes and armor shaped out of clay echoed the troops of the First Emperor.

Here, however, I would like to point out that standard Han funerary repertoire, in the representation of the army, appears to focus on the production of objects, through which the "human environment" of the tomb occupant was implied. In the Shuangrushan M1 tomb burial in Jinan, Shandong province, attributed to Liu Kuan 劉寬, King of Jibei in the Western Han, remains of horses, functional chariots, groups of metal chariot fittings, along with iron swords and crossbows were uncovered. ${ }^{525}$ This particular collection symbolizes the King's troops by metonymy, in which the substitution of weapons, horses and chariots for a troop of soldiers is based on an understood association. In fact, the figurine representation of actual soldiers in formation was a rare occurrence in the Han and only existed for the imperial and princely tombs. In addition to the army of Emperor Jingdi, other Han terracotta warrior sets include those from the Shizishan tomb attributed to Liu $\mathrm{Wu}$ 刘戊, third King of Chu in the Western Han, as well as those that belong to the tombs

\footnotetext{
${ }^{524}$ For a basic understanding of the terracotta warriors of Qin Shihuang and those of the Han Emperor Jingdi, see Michaelson 2010 and Si 2010a.

${ }^{525}$ For the excavation report of the Han tomb at Shuangrushan, see Shandong daxue kaoguxi, Shandong sheng wenwuju and Changqing xian wenhuaju 1997. Since no epitaphs, seals or inscriptions have been found in this tomb, the identity of the tomb occupant had to be determined based on the funerary goods and how they corresponded to some of the textual sources. Chinese archaeologists and scholars have determined Shuangrushan M1 to be the tomb of Liu Kuan, King of Jibei in the Western Han, excavated sometime between 98-87 BCE in the reign of Emperor Wudi, and interred either in 87 BCE or somewhat later; see Ren Xianghong 1997. For a discussion of the chariot fittings see Cui Dayong 1997; also see Shandong daxue kaoguxi, Shandong sheng wenwuju and Changqing xian wenhuaju 1997, p. 199 for a list of the burial goods that included weapons, horses, chariots, and chariot fittings.
} 
at Yangjiawan in Xianyang, Shaanxi province, attributed to two high ranking generals under Emperors Wendi and Jingdi. ${ }^{526}$

This knowledge presents us with an oddity, where Yanbei Shiyuan M5 obviously deviates from the Qin and Han precedents in which terracotta warriors were deployed as a marker of the highest burial status, indicative of power and authority. In the Han dynasty, when only a handful of tombs have been discovered to contain terracotta warrior, Song Shaozu's warrior figurines might even be viewed as a transgression upon sumptuary protocol, as they certainly did not correspond to the tomb occupant's social status, a member of the Northern Wei court, who was not even mentioned in the Wei shu. However, Yanbei Shiyuan M5 is not an independent occurrence in the Pingcheng period. The tomb of Sima Jinlong 司馬金龍 dated to 484, a sideline descendant of the royal Sima clan of the Eastern Jin, who remained in the north and served in the Northern Wei court, also contains a similar set of warrior figurines (122 on foot and 88 mounted) (fig. 8). ${ }^{527}$ To have what only appeared in the highest ranking tombs of the Han dynasty found in two Pingcheng tombs leaves us to consider whether these warrior figurines embodied the private ambitions of the deceased in an unconventional manner. It is possible that the Northern Wei tomb occupants hoped that these warrior figurines would assist them in constructing a new identity in the afterlife, one which they had secretly sought after but could not attain in their lifetime, elevating their status to that of Han princelings.

\footnotetext{
${ }^{526}$ For the excavation report of the Yangjiawan tombs, see Shaanxi sheng wenguanhui, Shaanxi sheng bowuguan and Xianyang shi bowuguan Yangjiawan Han mu fajue xiaozu 1977. See Si 2010b for a discussion of the terracotta soldier figurines; also see Zhan Li and Zhou Shiqu 1977 for a discussion of the Western Han cavalry based on an examination of the Yangjiawan clay figurines. The two large tombs at Yangjiawan found next to the group of Han figurine soldiers have been attributed by some scholars to Zhou Bo and his son Zhou Yafu. The two were famous generals in early Han history, and the dating of the two tombs to early Western Han make them the most probable tomb occupants of Yangjiawan, which could explain the exclusively military content of their tomb figurines.

${ }_{527}$ The tomb of Sima Jinlong contains a set of 367 clay figurines, with the same type of functional breakdown as that of Song Shaozu; see Shanxi sheng Datong shi bowuguan and Shanxi sheng wenwu gongzuo weiyuanhui 1972, pp. 20-33, 64.
} 
Although the data is yet too restricted to draw any conclusions, it is rather interesting that these warrior figurines appeared in the tombs of two Han Chinese elite officials who had served in the Northern Wei court. Though the biography of Song Shaozu is not to be found in the dynastic histories, we might be able to use Sima Jinlong's record in the Wei shu as a parallel. According to his biography, Sima Jinlong was the son of Sima Chuzhi 司馬楚之 and Princess Henei 河内公主, and was the ninth generation descendent of Sima Kui 司馬 馗, younger brother of Emperor Xuandi 晉宣帝 (Sima Yi 司馬懿, d. 179-251 CE) ${ }^{528}$ of the Western Jin. His father began serving in the Northern Wei court under the Tuoba emperors in 419 and was ultimately given the nobility title of Prince Langya 琅躯王. Later, this title was inherited by Sima Jinlong, who also successively held the official ranks of shizhong 侍中 (Palace Attendant), zhenxi dajiangjun 鎮西大將軍 (Grand General to Guard the West), kaifu 開府 (Area Commander), Yunzhong zhen dajiang 雲中鎮大將 (Grand General of the Yunzhong Commandary), Shuozhou cishi 朔州刺史 (Regional Inspector of the Shuozhou region), ${ }^{529}$ and libu shangshu 吏部尚書 (Imperial Secretary of the Ministry of Personnel). Upon his death in 484, Sima Jinlong was granted the titles of dajiangjun 大將軍 (Grand General), sikong gong 司空公 (Grand Minister of Works), Jizhou cishi 冀州刺史 (Regional Inspector of the Jizhou region), ${ }^{530}$ and was posthumously made Prince Kang 康王. ${ }^{531}$

\footnotetext{
${ }^{528}$ Sima Yi was an influential statesman of the state of Wei during the Three Kingdoms period, and when his grandson, Sima Yan 司馬炎 established the Jin dynasty and made himself emperor, Sima Yi was posthumously made Emperor Xuandi.

${ }^{529}$ The region of Shuozhou is in present-day Shanxi province.

${ }^{530}$ The region of Jizhou is in present-day Hebei province.

${ }^{531}$ Wei shu, juan 37, p. 857.
} 
No one can know for certain if Sima Jinlong had harbored private ambitions, nurturing the possibility of one day bringing the Sima clan back to the throne. Although we will never be able to establish his secret aspirations from the textual records, the appearance of the large warrior figurine set in Sima Jinlong's tomb may indicate how the tomb space served to retain the collective memory of the Sima clan. The same might be true for Song Shaozu, who, though not of imperial descent, was of an elite family from the northwestern peripheries of the Chinese heartland, where his forefathers can be assumed to have regarded themselves as the proxy ruler of the Dunhuang region, far from the reaches of the central government. Moreover, although on his epitaph it is said that Song Shaozu held the nobility title of the Duke of Dunhuang in his lifetime, interestingly, this was not recorded in the dynastic histories, unlike the three other Dukes of Dunhuang of the later period. ${ }^{532}$ Thus it seems possible that Song Shaozu was not given the title by the Northern Wei emperor, but may have assumed this honorary title to accompany him in the afterlife. The purpose of this discussion is not to question whether Song Shaozu had indeed been granted the title of the Duke of Dunhuang. Rather, I make this point to suggest the possibility that particular deviances in the use of material culture in the Pingcheng tombs may have been deployed and viewed as intentional "transgressions" of the tomb occupants, challenging the present with the power to construct their afterlife in order to rectify that which was not realized in their lifetime.

What the two tomb occupants shared in common was a lifelong desire to make claims to a more glamorous identity, one which could be finally attained in the afterlife through the acquisition of a set of military figurines. As members of their respective clans, Song Shaozu and Sima Jinlong each inherited the memories of the families, consisting not only

\footnotetext{
${ }^{532}$ Datong shi kaogu yanjiusuo 2008, p. 204.
} 
of a series of individual images of the past, but expressions of the general attitude of the collective. ${ }^{533}$ These memories do not only reproduce the family's history, but as they have been passed down through the generations, they also come to define the family itself. Both of these individuals carried the historical burden of living up to the memories of either being a royal descendant or a regional lord who was second to none in a corner of the empire. In this manner, the figurines should not be treated simply as the embodiment of a continuation of the life of the deceased, but as mechanisms through which identities were (re)produced and (re)created. ${ }^{534}$ In effect, the figurine assemblage in Yanbei Shiyuan M5 helped in redefining the tomb occupant's identity by which he wished to be remembered.

\section{Stone Sarcophagus: Appeals of a New Fashion}

The house-shaped stone sarcophagus in Yanbei Shiyuan M5 is an imitation of a timber hall that is three bays in width, with an over-hanging single-eave and gable-end roof at the top (fig. 59). The corridor in front of the building is supported by four octagonal columns that are 1.03 meters in height, carved with patterns of coiled dragons and inverted lotus flowers on the plinths. This flamboyantly ornamented building consists of over one hundred pieces of meticulously carved stone architectural parts, including sandstone panels, columns, beam frames, and the mortise and tenon joints. The front corridor underneath the overhanging eave expands across all three bays of the sarcophagus width and occupies a bay in depth. Behind the corridor, the central bay is opened up by a two-leaved stone slab door, carved with beast-faced door knockers, decorative door nails in the shape of bulging

\footnotetext{
${ }^{533}$ Halbwachs 1992, p. 59.

${ }^{534}$ This notion of using material culture in a funerary context as mechanisms behind the (re)production and (re)creation of identities is based on Coomber's thesis that looks at Bronze Age China. Moving away from a processual archaeological framework, he looked at how we might investigate, not what the objects signified or correlated, but rather how identities were created through the negotiation of material culture; see Coomber 2011, p. 7.
} 
buttons, and lotus flowers. However, these ornaments are not limited to just the decoration of the door. In fact, the entire outer wall of the building is covered with a total of 26 door knockers and 239 door nails that vary in size and form.

In spatial distribution, the stone sarcophagus takes up almost the entire chamber, leaving only meager space on the four sides for the tomb figurines to be placed around it (fig. 83). In fact, the sarcophagus appears to be rather cramped inside the tomb chamber, and it raises the question of why the tomb occupant chose this particular arrangement. In the Chinese concept of the burial space, the tomb chamber already functions as the household of the afterlife, why was there a need to construct a house out of stone that fitted perfectly within a house out of earth and bricks?

To begin with, it is important for us to remember that the Chinese had just began using stone as a new artistic and architectural material between the second and first centuries BCE, most often posited as opposed to wood. This opposition may have been understood in symbolic terms based on the natural characteristics of the two types of materials. Wood, being relatively more fragile and vulnerable to the natural elements, was commonly associated with the temporal mortal existence. Stone, with the physical characteristics of strength, plainness and endurance, was equated to notions of eternity and immortality that were much sought after by the Han elite. ${ }^{535}$ It was from this dichotomy that two kinds of architectural structures emerged. Structures made of wood were used by the living, and those made of stone were dedicated to the dead, the gods and the immortals. The double association of stone with death, on the one hand, and immortality, on the other,

\footnotetext{
${ }^{535}$ Wu Hung 1997, pp. 153-155; also Paludan 2006, pp. 103-104. Moreover, since in the Chinese concept the creation of an image brought into existence the qualities of the subject depicted, stone carving and stone sculptures can influence its surroundings in both the visible and invisible worlds in perpetuity; see Paludan 2006, pp. 115-116.
} 
strengthened the link between death and immortality with the application of stone architectural structures in a funerary context. ${ }^{536}$

As such, both Zheng Yan and Wu Hung turned to several aspects of the funerary architectural traditions of the Han dynasty as possible sources that gave rise to the houseshaped stone sarcophagi that began to appear in the Northern Wei as a choice of tomb furnishing. ${ }^{537}$ Zheng Yan looked to two funerary practices of the Han dynasty as having provided the material tradition for the house-shaped stone sarcophagi, like that of Yanbei Shiyuan M5, to have been conceived: 1) the stone coffins decorated with architectural elements in the Eastern Han Sichuan region; $\left.{ }^{538} 2\right)$ the stone ancestral halls erected above ground in the funerary yards that would have remained intact and visible above ground in the Northern Dynasties. ${ }^{539}$ Based on his observations, Wu Hung further advanced this line argument with two more sources: 3) the cliff tombs of Han princes such as that of Liu Sheng, King of Zhongshan of the Western Han; 4) the coffin pavilions of the Northern Dynasties assumed to have been made out of timber and intended as a resting spot for the coffins before they were interred. ${ }^{540}$ With the above examples, Wu Hung suggested that these house-shaped stone sarcophagi of the Northern Dynasties inherited a Chinese tradition of combining architectural structures and ritual functions.

\footnotetext{
${ }^{536}$ As this link was established during the second and first centuries BCE, it prepared a new ground for imagining and constructing the afterlife, and was responsible for many changes in funerary art and architecture, including the use of stone; see Wu Hung 1996, p. 122.

${ }^{537}$ In their studies, both Wu Hung and Zheng Yan were intent on tracing a continuous development from the Eastern Han period and onward, for explaining the appearance of house-shaped stone sarcophagi in the Northern Dynasties. See Zheng Yan 2001, pp. 81-83; also Wu Hung 2002.

${ }_{538}^{538}$ For a detailed examination of Han house-shaped stone coffins in the Sichuan region, see Luo Erhu 2000.

${ }^{539}$ Some well-known examples of the stone mortuary shrines above ground in the Eastern Han include those at Baiji 白集, Jiangsu province, Xiaotangshan 孝堂山, Shandong province, the Zhu Wei 朱鰖 shrine in Shandong province and the $\mathrm{Wu}$ Liang Shrine 武梁祠 in Shandong province. The latter had been well studied by scholars in the past decades; see Wu Hung 1989; also Liu, Nylan and Barbieri-Low 2005 for a collection of works in the book published on the occasion of the exhibition of the Wu Family Shrines organized by the Princeton University Art Museum in 2005.

${ }^{540}$ Wu Hung 2002, pp. 34-41.
} 
However, in so far as the physical form of the stone sarcophagus of Yanbei Shiyuan M5 is concerned, it reveals itself to be a novelty of the Pingcheng period. As insightfully argued by Chen Xin, the stone sarcophagi that we now find in the Han and Northern Dynasties tombs should not be considered to be of the same tradition, simply for the apparent resemblance to the shape of a house that all of them share in common. ${ }^{541}$ The Han stone sarcophagi that we now mostly find in the Sichuan region were carved out of a solid block of stone, much like the Roman burial chests, but with their lids in the shape of a gable roof (figs. 89a, b) ${ }^{542}$ Pillars and doorways were indicated by engraving on the stone walls, with no openings or removable panels in the place of a door. Further, Roman and Han sarcophagi even appear to share a common motif of partially opened doors, as put forth by Deng Fei (figs. 90a, b). ${ }^{543}$ The original Roman myths enacted around Hade's gate that gave rise to this image on the Roman sarcophagi may have been readapted by the Han Chinese. In line with traditional Chinese funerary beliefs, this notion of a door that represented the transition between life and death was incorporated into a gateway to the spirit worlds in the West, in the hopes of providing a benign outcome for the deceased. ${ }^{544}$

\footnotetext{
${ }^{541}$ This idea is fully elaborated in Chen Xin's dissertation submitted to the University of Oxford; see Chen Xin 2011, pp. 59-60.

${ }^{542}$ See Liu Zhiyuan 1958 and Leshan shi yamu bowuguan 1993 for the reports of two Sichuan tombs with house-shaped stone sarcophagi.

${ }^{543}$ Based on Jessica Rawson's work on the Han tombs, in her dissertation submitted to the University of Oxford, Deng Fei put forth the notion that like many other elements in Han burials, the half opened door found on Han sarcophagi may have also been derived from the Western world and adapted by the Chinese, giving new meanings to the image. Though there is not much information on the routes by which this motif had likely been introduced into China; see Rawson 1999 also Deng Fei 2010, pp. 181-182.

${ }^{544}$ As explained by Britt Haarlov, in the Roman context, the door has been characterized as the door of Hades, the grave door as well as the door of death. In either case, the symbols that surround the motif express the idea of a door which can open onto new life; see Haarlov 1977, pp. 42-56. However, Fei Deng noted that this open door motif rarely occurred in the later burials of Northern and Southern dynasties period, as well as that of the Tang; see Deng Fei 2010, p. 182-183.
} 
By the Northern Dynasties period however, Chen Xin pointed out that a new form of the stone sarcophagus as found in Zhijiabao M1 prevailed, made up of large stone panels, with the pillars and doorway illustrated on the same panel as the walls (fig. 60). ${ }^{545}$ This type of stone sarcophagus looks like a rudimentary prototype of what we have in Yanbei Shiyuan M5. At the time when she wrote her dissertation, the sarcophagus of Yanbei Shiyuan M5 was singled out for its intricate stone imitation of the entire timber architectural framework, separately put together piece by piece. ${ }^{546}$ Fortunately in 2011 , with the new findings from Yuchi Dingzhou M1 dated to the year 457, we see a similar stone sarcophagus with individual pieces that imitated the timber pillars and rafters (fig. 61). The only difference between the two is that the patrons of Yuchi Dingzhou M1 decided to go for an easier reproduction of the dougong structure by carving it into the capitals of the columns. In effect, the two examples appear to embody a similar concept, but just a difference in the degree of meticulous execution on behalf of the patrons.

Rather than exploring these extraordinary Pingcheng sarcophagi solely within a funerary tradition, I will argue that they were produced out of a negotiation of new material concepts. I would like to advance the notion that we might consider the development of these Pingcheng sarcophagi as a collateral outcome of what was going on at the Yungang grottoes with the introduction of Buddhism. The appearance of the new features on the stone sarcophagi of Yuchi Dingzhou M1 (457) and Yanbei Shiyuan M5 (477) coincided with the first sounds of the rock-cut activities at Yungang that created architectural structures out of the mountainside. In fact, the façade of these two examples, with their

\footnotetext{
${ }^{545}$ Other sarcophagi of the same form and design as that of Zhijiabao M1 includes those of Yu Hong and Ning Mao; see Shanxi sheng kaogu yanjiusuo, Taiyuan shi wenwu kaogu yanjiusuo, and Taiyuan shi Jinyuan qu wenwu lüyouju 2005; also Tomita 1942.

${ }^{546}$ A similar example in wood was discovered in the tomb of Kudi Huiluo in Shouyang, Shanxi province, dated to 562 in the Northern Qi period; see Wang Kelin 1979.
} 
over-hanging rafters supported on pillars, demonstrate a striking resemblance to the façade of the paired caves 9 and 10 at Yungang (fig. 35). Since no Buddhist temple of the fifth century survived, we do not know for certain if this was meant to imitate the halls of a Buddhist monastery. However, we do know that architectural sets and ways of working with stone that originated in the Classical world were transferred and adopted into northern China, with the transfer of the Buddhist techno-package, to suit new material needs. ${ }^{547}$ As such, the use of columns as a set of ornamented façade that most distinguish the sarcophagi of Yanbei Shiyuan M5 and Yuchi Dingzhou M1, might be understood as a Northern Wei rendition of a rock-cut façade such as those that decorate the Al Khazneh temple and tomb complex ruins at Petra, Jordan, dated to around the first century CE (fig. 91). While Al Khazneh combined Hellenistic architectural decorations with Western Asian rock-cut practices on the side of a mountain cliff, ${ }^{548}$ it was at Pingcheng where this façade was further advanced to incorporate local elements of timber construction that were imitated out of stone.

Moreover, there is also the Western tradition of decorating reliquary boxes in architectural elements that presents itself as another possible source of material and visual stimulus. ${ }^{549}$ In a paper illustrating the ways in which Graeco-Buddhist or Gandharan art of the Late Antiquity in northwestern India and Afghanistan manifested as the easternmost extension

\footnotetext{
${ }^{547}$ As examined by Rawson, the practice of combining a religious temple with a dynastic shrine, as embodied in the concept behind the Yungang project, paralleled a Kushan practice most prominently demonstrated at Surkh Kotal, and that all the caves at Yungang show traces of architectural and decorative influence from Central Asia or Afghanistan; Rawson 1984, pp. 35-62.

${ }^{548}$ While the ornamental detail of the Khazna has Greek sources, the practice of decorating rock-cut tombs as though they were buildings was a Western Asia tradition; see Rawson 1984, pp. 42-44.

${ }_{549}$ Jessica Rawson looks at the Eurasian mass as home to two of the most enduring complexes of ornament traditions, the Classical European and the Chinese. The Western tradition was founded upon the structural vocabulary of Greek and Roman architecture, while the Chinese tradition was based on a pictorial scheme consisting of images of birds, plants and animals. Although both traditions employ the use of visual motifs, the Chinese use of bird and flower designs make use of allusions through literary and historical traditions, whereas in the West, the ordered architectural system provide a capacity to convey social, political and religious hierarchies; see Rawson 2006c.
} 
of the Roman Imperial style and the forms of techniques of Early Christian art, Benjamin Rowland looks at the Bimaran gold reliquary ${ }^{550}$ as exemplifying resemblances between particular aspects on the reliefs of Gandhara and the sarcophagi of Christian Rome (fig. 92). ${ }^{551}$ The Buddha figures that decorate the sides of the reliquary, which suggests a pyxis in form, are each framed within an arch of the arcade that girdles the casket. This application of architectural elements on the reliquary relief echoes the arcade design prevalently found on early Christian sarcophagi, which was then adapted to suit the decorative needs of Buddhist stone stupas in Gandhara (figs. 93a, b). The notion of decorating boxes with architectural elements that started off in the form of early Christian sarcophagi would have also transferred with the Buddhist techno-complex into the earlier period of the Northern Wei. In effect, these new historical developments in fifth century northern China could have very well combined to give impetus to the creation of the trendsetting house-shaped stone sarcophagus of Song Shaozu in Yangbei Shiyuan M5.

This particular sarcophagus represented the tomb occupants' distinctive taste, not only in the seemingly faithful representation of a Chinese timber hall with all its architectural features, but also for the profuse decorative motifs and images depicted all around. Although the external appearance of the sarcophagus seems to have adopted an imitation of the Chinese timber design, the excessive application of the door knockers and the door nails beyond their functional use, makes us wonder if these architectural elements had been transformed into simply ornamental sets. In effect, they were applied in the same manner as the half-palmette scrolls that prominently decorate the stone coffin bed inside

\footnotetext{
${ }^{550}$ The Bimaran reliquary is a golden cylindrical relic container found in Bimaran, Afghanistan. The frieze on the reliquary bears one of the earliest depictions of the Buddha from the northwestern region of Gandhara. The arcading around the side consists of eight pointed arches, each with a figure represented at the center; see Zwalf 1985. Reginald Le May has demonstrated that the Bimaran reliquary should be dated to no later than the late first or early second century CE; see Le May 1943, pp. 122-123.

${ }^{551}$ Rowland 1946, pp. 44-47.
} 
the sarcophagus, having only been recently introduced to China in the late fourth and early fifth century as a variant of the Western acanthus and vine ornament design (figs. 94a, b). ${ }^{552}$

The most striking image depicted on the set of coffin bed leg panels inside the sarcophagus is that of two animals carved in low relief on the north end of the southwestern platform (fig. 94a). The archaeological report describes this image as what appears to be a monkey with a sharp face perching on the back of a tiger kneeling on its hind legs. ${ }^{553}$ However, this bears a strong resemblance to the motif of animal combat, between two creatures, one preying on the back of another, which was derived from the Eurasian steppe. This type of motif is commonly found on metal belt-buckles, which represented a type of regalia for the pastoral peoples of northern Eurasia and was an important prestige item (fig. 95). ${ }^{554} \mathrm{I}$ believe that what we have on the Yanbei Shiyuan M5 coffin bed leg panel is a Northern Wei response and adaptation of this visual encounter. As this motif of animal combat usually occurred in pairs on metal belt-buckles, I would further argue that the original design was to have another pair of animals depicted on the other end of the panel, with both pairs facing each other. However, it is very likely that the artisans working on the coffin bed were not familiar with this motif, thereby turning it into simply another decorative pattern, along with a beast's face and a palmette (fig. 94b). Clearly, this sarcophagus should no longer be viewed within the limitations of any particular material

\footnotetext{
${ }^{552}$ Rawson delineates some of the Western forms of this foliage pattern before arriving in China in Rawson 1984, pp. 35-36. See chapter three for more discussions on the half-palmette scroll applied in the Buddhist context and in the everyday life as a decorative pattern; see pp. 139-140.

${ }_{553}^{55}$ For a description in the excavation report, see Datong shi kaogu yanjiusuo 2008, p. 96.

${ }^{554}$ To the pastoral peoples of northern Eurasia, belts were not just a practical means of holding up and fastening items of clothing. They were adorned with visual symbols that identified the owner's clan, rank, and prestige. By contrast, the belt hooks worn by the Chinese indicated power and wealth, but never clan and rank. Belts ornamented with a series of metal plaques first occurred in the Caucasus early in the first millennium BCE; see Bunker 2002, p. 94.
} 
tradition, but that it represents the richness of the motifs and ornament sets available to someone working with stone in fifth century Pingcheng.

To further explore the sarcophagus of Yanbei Shiyuan M5 as the embodiment of the tomb occupant's habitus that structured his social practices in lifetime, we should also turn to examine the repertoire of mural paintings on the inside of the wall panels. While most of the murals have peeled off, three partial sections are preserved on the north and west walls (figs. 59b, 96). Together, these images present the viewer with a lively entertainment scene consisting of musicians and dancers. They have appearances very different from the figures portrayed in the figurine assemblage in facial features, body stature, and apparels in clothing. Indeed, so strong is the contrast, the murals and the figurines might as well have come from two separate tombs from completely different regions or time periods. If we look at the two musicians who are seated on the ground, each with a musical instrument in his hands, the two men are dressed in the traditional Han Chinese robes, characterized by the wide and flowing gowns with wide sleeve openings, and a tall cap that sits on the heads. The two types of musical instruments are even more removed from those found on the Shaling M7 murals or the musician figurines of Sima Jinlong, consisting of wind and percussion instruments. The appearance of qin 琴 (seven-stringed Chinese zither) and ruan 阮 (a four-stringed Chinese lute), objects closely linked to the lifestyle of Han Chinese scholar officials, remind us immediately of an Eastern Jin molded tomb brick relief depicting the Seven Sages of the Bamboo Grove and Rong Qiqi.

These images present us with two points of interest. First of all, the musicians and dancers all suggest a scene out of domestic life that would have been elusive to others outside of the Song household. Not only were these representations physically painted on the inside 
of the sarcophagus, they were also intended for the tomb occupants' eyes only. Secondly, the contrast between the apparel and the facial features depicted on the clay figurines and the sarcophagus murals manifest a coexistence of two cultural spheres at work. This sheds a new light on our understanding of Song Shaozu as a person, who was caught in a time and place when an individual could carry multiple identities and share various cultural affiliations in different aspects of their life. As such, I would like to suggest that the space inside of the stone sarcophagus was intended to construct what we might assume to be the tomb occupant's preferred habitus of leisure in his private domestic life. This interpretation further helps us to answer the initial question of why Song Shaozu saw the need to build a stone house that assumed much of the space inside a house of brick and earth. We could take a look at the separate functions of the figurines and the sarcophagus paintings within this particular tomb space, producing two discourses on the cultural point of view of the tomb occupant, both in private and in public.

However, as I have repeatedly stressed, while the form of an object can be directly transferred, the meaning embodied within the design will more than likely to have been redefined by the individual patrons and makers. Even stone sarcophagi from the same time period and region could convey different agencies within a tomb space depending on the specific choices in the application of visual images. The sarcophagus that we see in Zhijiabao M1, estimated to be of the late Taihe reign (sometime between 484-489), ${ }^{55}$ is minimalistic in ornamental architectural details, much like a house that could not be completed due to budgetary issues, if we compare it against the splendid and flamboyant house of Song Shaozu (figs. 59, 60). Nonetheless, it preserves the entire set of murals

\footnotetext{
${ }^{555}$ This dating was determined by archaeologists who looked at the palmette scroll painted on the triangular stone beam of the sarcophagus and compared it against the other palmette examples that we see in the Yungang grottoes, particularly caves 9 and 10 that contain scrolls of a similar style and structure, completed between the years 484-489; see Wang Yintian and Liu Junxi 2001, pp. 50-51.
} 
painted on the inside of the sarcophagus panels, producing a complete yet condensed repertoire of what we saw on the walls of Shaling M7. In the simplified images, the central positioning of the tomb occupant couple on the north wall, seated on an elevated dais under a tent canopy, signifies the head of a banquet. The tree continues to be an outdoor marker, positioned on one side and of the same height as the canopy. Finally, on the south wall, directly opposite the tomb occupants who are flanked by attendants bearing food and drinks, we have two female attendants who stand more prominently in size, and one male attendant holding onto a horse while the other takes control of an ox-drawn carriage.

Clearly, this pictorial set represents the bare minimum of what constitutes an outdoor feasting scene in the Pingcheng period, and it simplified what was elaborately portrayed in Shaling M7. Furthermore, unlike Song Shaozu, who truly intended for his house-shaped stone sarcophagus to contain the function of an actual household, in which everything found inside the sarcophagus were to represent the domestic life most intimate to the deceased, the tomb occupant of Zhijiabao M1 transformed the sarcophagus into the embodiment of his living world. In effect, by the Pingcheng period, the sarcophagus functions not only as a funerary furnishing, but it could also be transformed into an aspect of the life of the deceased, working together with the spatial and pictorial schemes of the tomb chamber with individual variations.

On a conceptual level, the clay figurines symbolize Song Shaozu's public identity, how he defined himself as a member of the greater collective at Pingcheng, whose life was colored by strong colors of the steppe. So much so, that even his private aspirations of obtaining a higher social status in the afterlife could be turned into a public declaration through the deployment of the figurine assemblage. On the other hand, the painted images on the 
inside of the sarcophagus express the tomb occupant's most intimate comfort zone, possibly a private side of the tomb occupant obscured from the rest of his social network. As a physical embodiment, this distinction of the tomb space and the sarcophagus space marked the separation of the tomb occupant's social sphere and domestic sphere. The entertainers and musicians depicted on the inside of the sarcophagus are the very people who usually accompanied the master of the household in mural paintings. What is even more striking in this case is that, as a common figurine category, entertainers and musicians are missing from the Yanbei Shiyuan M5 assemblage. In other words, the sarcophagus murals, positioned on the inside of the tomb occupant's "house", and for his eyes only, conveyed the agency of transforming that smaller space into his domestic life, one that was surrounded by a greater social life.

As such, the paradox of cultural markers demonstrated in the clay figurines, murals, and the form of the stone sarcophagus in Yanbei Shiyuan M5 should no longer be a problematic visual scheme. I argue instead that the intriguing elements in Yanbei Shiyuan M5 should be treated as a microcosm of the Pingcheng society, where the new lifestyle and practices from the steppe land merged with aspects of existing traditions in the Chinese sphere. Members who shared in this new habitus were comfortable in interchanging these cultural markers as an expression of how they saw themselves in private and public social contexts.

\section{CONCLUSION: READING THE TOMBS}

From the above case studies, two distinct funerary narratives emerged in the Northern Wei Pingcheng period with the separate applications of mural paintings and clay figurines. Though, an immediate reaction to the two types of repertoires is to assume that they 
simply provided different types of materials for the tomb occupants to construct a continuation of their previous lives in the afterworld. Shaling M7 and Yanbei Shiyuan M5 are two well preserved tombs with identified tomb occupants, and displayed with complete sets of funerary goods and furnishings. As such, I wish to turn to Erwin Panofsky's dualistic perception of funerary art, reflecting both prospective and retrospective concerns, as a basis for understanding how mural paintings and figurine assemblages constructed coexisting attitudes toward death in the Northern Wei Pingcheng period. ${ }^{556}$ Most strikingly, the prominent portrayal of tomb occupants as the focus point of Shaling M7 makes the lack of any representation of the tomb occupant in Yanbei Shiyuan M5 a design by intent. In effect, I would like to raise the possibility that the application of mural images and clay figurines created two different points of view in how the tomb occupants intended to tell the story of their lives.

In Shaling M7, an outsider, upon stepping into the tomb chamber, is immediately aware that the mural paintings were created based on a scheme of depicting the life of the deceased through the viewer's point of view. On the main wall (east wall), the viewer is introduced to the protagonist of the story, Lady Poduoluo, and through the dress as well as the type of building against which she and her husband are being placed, the habitus of the protagonist is also being setup. However, a careful observer will notice that on the two side walls, Lady Poduoluo no longer appears with her husband. At the head of the congregation enjoying the banquet, and within the carriage in the middle of the military procession, it is the master of the household who is depicted as carrying out the activities. We do not even

\footnotetext{
${ }^{556}$ In his study of the use of tomb sculptures in burials of Ancient Egypt, Panofsky looks at how tomb paintings contained a retrospective attitude limited to the survivors and not extended to the departed, and embodied an imaginative commemoration of the past. Alternatively, tomb sculptures were the magical provisions for the future, taking care of the prospective needs of the deceased by providing them with the necessities of the afterlife; see Panofsky 1964, p. 10, 16, 35.
} 
know if, in her case, the master of the household was intended to be Lady Poduoluo's husband or son. Either way, the appearance of a man as the central figure in the mural depictions suggests that Lady Poduoluo's position in society was defined by her relationship to these pivotal male family members. Since we have been told by the epitaph that at least one of the tomb occupants of Shaling M7 is indeed the mother of a Northern Wei Xianbei general, the mural paintings clearly were not intended as a faithful portrayal of Lady Poduoluo's everyday life. Rather, I would like to suggest that the murals were a visual construct of the social relationships through with Lady Poduoluo and her family were defined in the Northern Wei Pingcheng society. Though not necessarily derived from her own experience, it is in society that people normally acquire and localize their memories, ${ }^{557}$ and the murals present a social context in which Lady Poduoluo's memories would be preserved.

By contrast, the tomb occupants in Yanbei Shiyuan M5 are introduced to us through an intentional neglect in providing the image of the deceased, namely Song Shaozu and his wife. This may be attributed to the nature of using clay figurines as the choice of funerary assemblage. As previously established in the discussion of the Yungang sculptures, the Chinese did not have a tradition of creating non-functional sculptures in human form, and it was with the introduction of Buddhism that sculptures of deities began to appear in stone. In fact, the first image of a tomb occupant to exist in the form of a sculpture only appeared later on in the tenth century tomb of Wang Jian 王建 (r. 907-918 CE), founding emperor of the Former Shu dynasty(907-925 CE) in Chengdu, Sichuan province. ${ }^{558}$ Without using a central image of the tomb occupant, the funerary assemblage of Yanbei Shiyuan M5

\footnotetext{
${ }^{557}$ Halbwachs 1992, pp. 38, 53.

${ }^{558}$ For the excavation report, see Feng Hanji and Zhongguo kexueyuan kaogu yanjiusuo 2002.
} 
presupposed the notion that the funerary assemblage should be organized from the point of view of Song Shaozu. The fact that the murals were painted on the inside of the houseshaped stone sarcophagus, and that the repertoire consisted of musicians and dancers, clearly suggest that they were meant for the enjoyment of the tomb occupants, and were not intended to be viewed by an outsider. Moreover, as we have already suggested that the warrior figurines may have begun as part of the tomb occupant's intention to construct a new identity in his afterlife, in order to compensate that which was not realized in his lifetime, the entire repertoire of Yanbei Shiyuan M5 presents a prospective and anticipatory attitude toward what was to come in the future.

On one hand, the mural paintings posited Lady Poduoluo in a network of social relations that defined her as an individual - wife to her husband, lady of the household, and mother to a Northern Wei general, revealing the tomb occupant's concern with how she would be remembered through intersecting familial ties. On the other hand, Yanbei Shiyuan M5 reveals to us that Song Shaozu was more concerned with the (re)construction of identity by which he would be commemorated. As the master of his household, his extravagant domestic life presented a stark contrast against the stoic figurine army that was clearly deployed to represent a degree of power and authority that was not endowed upon the tomb occupant in his lifetime. As such, we see that funerary repertoires and furnishings enjoyed a state of fluidity in the Northern Wei Pingcheng period, as individuals of different social and cultural backgrounds were comfortable in choosing particular elements to suit their own needs in the expression of one's attitude toward death and what the afterlife was supposed to achieve. It was in these brick chamber tombs where the life and death of the Northern Wei elite had intersected. 


\section{Chapter 5: The Many Faces of the Tuoba}

唧唧復唧唧，木蘭當戶織。

不聞機杼聲，唯聞女嘆息。 問女何所思, 問女何所憶, 女亦無所思，女亦無所憶。 昨夜見軍帖, 可汗大點兵。 軍書十二卷, 卷卷有爺名。 阿爺無大兒，木蘭無長兄。 願為市鞍馬, 從此替爺征。 東市買駿馬, 西市買鞍谑, 南市買緷頭，北市買長鞭。

朝辭爺孃去, 暮宿黃河邊。 不聞爺孃喚女聲, 但聞黃河流水鳴戝淺。

旦辭黃河去，暮至黑山頭。 不聞爺孃喚女聲, 但聞燕山胡騎聲啾啾。

萬里赴戎機，關山渡若飛。 朔氣傳金㭛, 寒光照鐵衣。 將軍百戰死, 壯士十年歸。

歸來見天子, 天子坐明堂。 策勳十二轉, 賞賜百千強。 可汗問所欲，木蘭不用尚書郎， 願借明駝千里足，送兒還故鄉。

爺孃聞女來, 出郭相扶將。

阿姐聞妹來, 當戶理紅妝。

阿弟聞姐來, 磨刀霍霍向豬羊。

開我東閣門，坐我西間床。

脫我戰時袍, 著我舊時裳。

當窗理雲䰅，對鏡貼花黃。

出門見伙伴，伙伴皆驚惶。

同行十二年，不知木蘭是女郎。

雄兔腳撲朔, 雌兔眼迷離。

兩兔傍地走, 安能辨我是雄雌。

\footnotetext{
${ }^{559}$ Chinese text taken from the Yuefu shiji 樂府詩集 compiled by Guo Maoqian in the Song dynasty, which remains as the earliest existing text on the "Ballad of Mulan"; see Yuefu shiji, juan 25, pp. 373-374.
} 
Tsiek tsiek and again tsiek tsiek;

Mulan weaves, facing the door.

You don't hear the shuttle's sound,

You only hear Daughter's sighs.

They ask Daughter who's in her heart,

They ask Daughter who's on her mind.

"No one is on Daughter's heart,

No one is on Daughter's mind.

Last night I saw the draft posters,

The Khan is calling many troops.

The army list is in twelve scrolls,

On every scroll there's Father's name.

Father has no grown-up son,

Mulan has no elder brother.

I want to buy a saddle and horse,

And serve in the army in Father's place."

In the East Market she buys a spirited horse,

In the West Market she buys a saddle,

In the South Market she buys a bridle,

In the North Market she buys a long whip.

At dawn she takes leave of Father and Mother,

In the evening she camps on the Yellow River's bank.

She doesn't hear the sound of Father and Mother calling,

She only hears the Yellow River's flowing water cry tsien tsien.

At dawn she takes leave of the Yellow River,

In the evening she arrives at Black Mountain.

She doesn't hear the sound of Father and Mother calling,

She only hears Mount Yen's nomad horses cry tsiu tsiu.

She goes ten thousand miles on the business of war,

She crosses passes and mountains like flying.

Northern gusts carry the rattle of army pots, ${ }^{560}$

Chilly light shines on iron armor.

Generals die in a hundred battles,

Stout soldiers return after ten years.

On her return she sees the Son of Heaven,

The Son of Heaven sits in the Splendid Hall.

He gives out promotions in twelve ranks

And prizes of a hundred thousand and more.

The Khan asks her what she desires.

"Mulan has no use for a minister's post,

I wish to ride a swift mount

To take me back to my home."

\footnotetext{
${ }^{560}$ Army pots were used for cooking food at daytime and for beating out the watches during nighttime, thus the rattling sound that accompanied the northern gusts.
} 
When Father and Mother hear Daughter is coming,

They go outside the wall to meet her, leaning on each other.

When Elder Sister hears Younger Sister is coming,

She fixes her rouge, facing the door.

When Little Brother hears Elder Sister is coming,

He whets the knife, quick quick, for pig and sheep.

"I open the door to my east chamber,

I sit on my couch in the west room,

I take off my wartime gown

And put on my old-time clothes."

Facing the window she fixes her cloudlike hair,

Hanging up a mirror she dabs on yellow flower powder.

She goes out the door and sees her comrades,

Her comrades are all amazed and perplexed.

Traveling together for twelve years,

They didn't know Mulan was a girl.

"The he-hare's feet go hop and skip,

The she-hare's eyes are muddled and fuddled.

Two hares running side by side close to the ground

How can they tell if I am he or she?"

--- Anonymous, “Ballad of Mulan”,561

\section{MULAN AND THE KHAN}

The girl named Mulan 木蘭, who joined the army in her father's stead by dressing as a man, has both inspired and bewildered centuries of imagination. Having been derived almost entirely from a folk ballad, this story had turned into a timeless subject of literary repertoire with legacies up to the present-day. ${ }^{562}$ The popularity of Mulan is derived from the fact that her influence, and the qualities that she embodies, surpassed the realms of a literary character, as her spirit of filiality, patriotism and courage transformed this fictional

\footnotetext{
${ }^{561}$ English translation is after the work of Hans H. Frankel; see Frankel 1976, pp. 68-72. For a different translation, see Arthur Waley's work in Mair 1994, pp. 474-476.

${ }^{562}$ The versatility of Mulan as a literary character allowed the story to take on various forms and meanings at different points in Chinese history. After her debut more than a millennium ago with the Poem of Mulan, some of the more famous adaptations of the story of Mulan include a sixteenth century play, a milieu of drama and prose productions in the Qing dynasty, a Peking opera in the early twentieth century, and a film in 1939 during the Sino-Japanese war; see Kwa and Idema 2010, pp. xi-xxxii.
} 
heroine into a cultural symbol, particularly in times of the Chinese national resistance in the twentieth century. ${ }^{563}$ With the release of the Disney movie Mulan in 1998, our woman warrior received international recognition and was further equated as an icon for "Chineseness". The irony in all of this is that the dominating "Chinese" represented in the story of Mulan were, most likely, none other than the subject of this thesis - the Tuoba of the Northern Wei. Even the name "Mulan", which means "magnolia" in standard Chinese, has been suggested by Chen Sanping to be a variant derived from a foreign word meaning "bull" or "stag", a courtesy name adopted by military men in the fifth and sixth centuries, and commonly used as a surname by non-Han Chinese families at the time. ${ }^{564}$

The Mulan shi 木蘭詩 (the “Ballad of Mulan” or the "Poem of Mulan”) is of unknown origin and date, but it is generally believed to have been created in the Northern Wei, with aspects of its literary refinements accumulated in later periods. Its earliest known record was in the Gujin yuelu 古今樂錄 (Musical Record Old and New), written by the monk scholar Zhi Jiang 智匠 of the southern Chen 陳 dynasty (557-589 CE) in approximately $568 \mathrm{CE}^{565}$ Zhi Jiang's work is unfortunately no longer extant, but its contents were most frequently cited and referenced in the anthology Yuefu shiji 樂府詩集 (Collection of Music-Bureau Poems), compiled by Guo Maoqian 郭茂倩 during the twelfth century,

\footnotetext{
${ }^{563}$ Of all female warriors and heroines in Chinese history and literature, the first to come to mind is always the legendary Mulan, whose name has become synonymous to a jinguo yingxiong 巾幗英雄 (a head-dressed hero). During the Sino-Japanese war from 1937-1945, Mulan further became a symbol of the resistance movement against the Japanese occupation, represented in film and huaju 話剧 (spoken drama); see Hung 1989, pp. 164-168.

${ }_{564}^{564}$ Chen Sanping 2012, pp. 43-54.

${ }^{565}$ From our current knowledge of the Gujin yuelu as found cited in other sources, Zhi Jiang appears to be very familiar with the court music of the southern Liang (502-557) and Chen (557-589) dynasties, most likely having served in the court himself or had access to the inner court life. Based on the content included in Gujin yuelu, it has been determined by literary historians to have been completed at around 568. Zhi Jiang's records go as far back as the Han dynasty, and he made comparisons between the ballads of the past and present. The earliest mention of the Gujin yuelu is found in the dynastic history of the Sui (589-618 CE), in which it is noted that "there were 12 juan to the Gujin yuelu, written by the Sramana of the Chen dynasty, Zhi Jiang"; see Yu Yizhi 2008, p. 81; also Sui shu, juan 32, p. 926.
} 
under the Song 宋 dynasty (960-1276 CE). The earliest text of the "Ballad of Mulan” available to readers in the present-day also comes from this anthology. Attributing the Gujin yuelu as his source for this ballad, Guo continues to classify it in the group of northern ballads called gujiao hengchuiqu 鼓角横吹曲 (songs accompanied by drums and horizontal flutes). ${ }^{566}$ These were songs that were originally performed on horseback as a form of military performance on the go, as we had seen being vividly acted out in the murals of Shaling M7. (fig. 55c)

Recent scholars mostly agree that the poem originated in the Northern Wei, some time during the fifth and sixth century, when the Tuoba were engaged in a series of wars in unifying northern China. ${ }^{567}$ Some even go to the extent of identifying the military event described in the poem with a famous battle in the early Northern Wei, when Emperor Taiwu 太武帝 (Tuoba Tao 拓跋壽, r. 424-452 CE) defeated the invading Rouran 柔然 army in $429 \mathrm{CE}^{568}$ Scholars who arrived at this dating primarily relied on the usage of the term Kehan 可汗 (Khan/Khagan) in the "Ballad of Mulan", especially its co-existence with the term Tianzi 天子 (Son of Heaven) in the same context. Given that this ballad had already been textually recorded in the south by Zhi Jiang into the Gujin yuelu by the late sixth century, we can ascertain that it had been in wide circulation at the time, and would have been alluding to events that happened in an early period. As such, the above

\footnotetext{
${ }^{566}$ Guo mentions Gujin yuelu as his source for the poem, and his version has been accepted by virtually all scholars as the most authentic, since it appears to preserve more of the basic features of a folk ballad than do the other versions; see Yang Shengzhi 1985, p. 399. Two other Song dynasty anthologies, Wenyuan yinghua 文苑英華 (Gems of Literary Writings) and Gu wenyuan 古文苑 (Collection of Ancient Writings), contain slightly different versions of this poem. Wenyuan yinghua was compiled in $982 \mathrm{CE}$ by a team headed by $\mathrm{Li}$ Fang under an imperial order. Little is known about the original compiler of $G u$ wenyuan. Although it was likely compiled in the Tang dynasty, this anthology was not discovered until the Northern Song period and became known especially through Han Yuanji's re-editing in the late twelfth century.

${ }^{567}$ Yang Shengzhi 1985, p. 401; Chen Youbing 1996, p. 428; Lu Kanru and Feng Yuanjun 1968, pp. 246-

247; also Wang Yunxi 1962, pp. 119-120.

${ }^{568}$ Wang Rubi 1984, pp. 38-40.
} 
mentioned scholars turn to the Northern Wei as the most probable historical context, when northern China was first unified for the sovereign to be designated as the Son of Heaven, yet the Tuoba were still fresh enough as a bourgeoning ruling household in the Chinese tradition to have retained the designation of a Khagan in the Turko-Mongol tradition. ${ }^{569}$

Since the "Ballad of Mulan" was originally a folk ballad, the appearance of this particular designation suggests that, at the time of its creation, addressing the emperor as the Khagan was not an uncommon practice for the ordinary people in northern China. This is an interesting practice barely noticeable from reading the official historiography. Secondly, the interchangeability of the two terms within one literary work suggests that the people of this period, in northern China, were comfortable in regarding their sovereign, both as the Khagan in the Central Asian tradition, and as the now quintessential Chinese notion of the "Son of Heaven". 570

Since Gujin yuelu is no longer extant, the only textual basis for establishing the "Ballad of Mulan" as having originated in the Northern Wei is founded upon Guo Maoqian's passing annotations written in the Song dynasty, classifying the ballad as a gujiao hengchuiqu

\footnotetext{
${ }^{569}$ The word Khan was originally an Altaic term used by the Tunguses, and subsequently adopted by the Rouran and the Turks into Central Asia as a title for a sovereign, widely used by medieval nomadic TurkoMongol tribes living to the north of China, where the term developed into the double word Khagan/Qagan by the early fifth century. However, in Chinese, both terms appear to be interchangeable; see Parker 1986, pp. 436-437. The Rouran's activities in Central Asia have been credited for giving the title the wide currency it enjoyed for many centuries; see Henning 1952, pp. 501-502. However, some scholars advance the notion that the title of Khagan had unquestionably been in use even before the rise of the Rouran, among the Xianbei as early as the middle of the third century CE; see Parker 1896, pp. 436-437; also Yao Dali 2005, pp. 25-26.

${ }^{570}$ The notion of Tianzi, "Son of Heaven", though a very old Chinese royal title, is a theophoric construct that contrasts the absence of any other theophoric names in archaic East Asia. Scholars have attempted to answer the question as to where this notion had originated. Their findings based on oracle bones and bronze inscriptions now present to us a new realization that Tian, or "Heaven" started as a "barbarian" deity, imposed by the victorious Zhou tribes who conquered the Shang, the first veritable Chinese dynasty; see Chen Sanping 2012, pp. 119-121; Guo Moruo 1936; also Creel 1970, pp. 493-506. Furthermore, the political notion that a sovereign's right to rule came from a "mandate of heaven" was undoubtedly part of the Zhou propaganda in legitimizing their conquest of the Shang civilization as fledging statesmen. See Rawson 1989 and Creel 1970, p. 44 on the transition of the Zhou from "barbarians" into "statesmen".
} 
characteristic of the Northern and Southern dynasties period. For this reason, some scholars argue that the ballad could have more likely been a literary creation of the Tang 唐 dynasty (618-907 CE), featuring the reign of Li Shimin 李世民 (Emperor Taizong 唐太 宗, r. 626-649 CE), who had assumed the title of Tian Kehan 天可汗 (Heavenly Khagan) upon his defeat of the Eastern Turks (also known as the Tujue 突厥) ${ }^{571}$ and made the Tang the dominant power in Eastern Asia and parts of Central Asia. ${ }^{572}$ Regardless, the exact dating of the ballad is not only a moot issue but also, for the most part, a sino-centric idiosyncrasy if we consider it from a "nomadic perspective". As pointed out by Chen Sanping, both the Sui 隋 and Tang ruling houses were the Tuoba's political and genealogical heirs and were called Tuoba/Tabyach by contemporary nomadic people. ${ }^{573}$ Since the joint designations of "Son of Heaven" and "Khagan" had lingered into the seventh century, it was most certainly, among other traditions, a legacy of the Tuoba. Therefore, the "problem" of dating should not prevent us from acknowledging the bigger picture that there was a time in Chinese history when the Son of Heaven was also regarded as a Khagan by his people.

Victor Mair and Mark Bender advance the hypothesis that the original "Ballad of Mulan" was introduced from the oral tradition of the Xianbei people when the Tuoba clan established the Northern Wei dynasty and unified northern China. ${ }^{574}$ Along with other anonymous ballads written down in the Chinese language during this period, it reflects

\footnotetext{
${ }^{571}$ During the Sui and early Tang dynasties, China's major external rival was the Eastern Turk tribal confederation that had united the pastoral nomadic tribes living on the steppe and deserts of Inner Asia to the north of China proper. In the Sui-Tang transitional period, the Chinese-Inner Asian frontier was a middle ground with opportunities for political, cultural, and material interaction; see Skaff 2004, pp. 120, 122.

${ }_{572}^{57}$ Hu Zhuoxue and Hu Hailong 2011, pp. 10-11.

${ }^{573}$ Chen Sanping 2012, pp. 4-38, 42.

${ }^{574}$ Mair and Bender 2011, p. 326. He Yuping also suggests the possibility that the story behind the "Ballad of Mulan" had been circulating as a folk song for some time before the Northern Wei, receiving literary stimulants from different regions, before arriving at the version that we now see before us; see He Yuping 2004, p. 20.
} 
features of a northern steppe culture over a far-flung, multi-ethnic empire, through the heroine's uncharacteristic flouting of her gender roles, and her outright expressions of courage and military prowess. The image of Mulan is unprecedented in Chinese classical poetry. Her major characteristics - valor, fighting skills, and resourcefulness in military affairs - align her with the images of northern horsewomen in other yuefu 樂府 (MusicBureau) poems. ${ }^{575}$ These poeticized images of horsewomen reflect the cultural values shared by all the ethnic groups that were then living in an embattled northern China. In this social system of shared values, accomplishments in military disciplines were seen as an important part of an individual's life, whether that individual was a man or a woman, which is a feature that would only have been found in a steppe cultural sphere. ${ }^{576}$

However, if this was all there is to the significance of Mulan, the story would not have been nearly as versatile or powerful. The original ballad not only reflects the northern landscape and the nomadic spirit, but also conveys a conflicting attitude towards the classical Confucian expectation of womanhood ${ }^{577}$ As the daughter disguised herself as a man to answer the court's military draft of her elderly father, she should be praised for her

\footnotetext{
${ }^{575}$ Some of the other examples are “The Song of Li Bo's Younger Sister” (Libo xiaomei ge 李白小妹歌) and “The Black-Tailed Red Horse" (Ziliu ma 紫騮馬), all presenting poeticized images of horsewomen that were distinct from the ideal of a gentle and graceful lady celebrated in the Confucian literary tradition; see Lan 2003, p. 232.

${ }^{576}$ One of the best examples of military women holding a high social status and hierarchical rank supported by archaeological evidence is the tomb of Lady Fu Hao 婦好, consort of the Shang 商 king Wu Ding 武丁 (r. ? - 1192 BCE). Based on her tomb contents, she has been described as a military leader, outfitted with weapons and other quite distinctive non-Shang objects. These items identify Fu Hao with the peoples who lived outside of the Shang political realm, but within the sphere of contact, who raised horses and were aligned with the clans in northern Asia who probably controlled routes of trade for metal ores and other goods. Based on a reading of these objects, it has been determined that Fu Hao was most likely not a Shang elite but had been given all the luxury of a royal Shang burial as the wife of King Wu Ding. At the same time, she still maintained her identity as an outsider as marked by the artifacts of frontier manufacture and style in her tomb; see Linduff 2002, pp. 265-267; also Linduff 1996.

577 Although on the surface it appears to be a very straightforward ballad that celebrates a daughter's filial piety and bravery, Sufen Lai argues that, when analyzed closely, each section reveals a tension between the expected ideals of Confucian womanly virtues and the masculine world of warrior valor expected of Mulan in daily reality; see Lai 1999, p. 82.
} 
filiality and patriotism. Nonetheless, to have a woman on the frontline, roaming the wilderness in the company of her opposite sex, was certainly an indiscretion as far as the proper behavior expected of a Confucian lady was concerned. As such, Mulan perhaps best epitomizes the notion of a "dual presence", embodied within the social and cultural milieu of the Northern Wei period. Aptly phrased by Feng Lan, "the genesis of the Mulan poem was actually due to the absence of Confucian influence rather than to a desire to celebrate Confucian values." ${ }^{578}$ Such a literary character-turned-cultural icon could come into being only in a specific social locale and at a particular historical moment, when new practices and values were formed in juxtaposition of existing classical teachings, as a result of tremendous social changes.

Emerging from the rich Chinese tradition of tales and legends, Mulan's utter lack of supernatural demonstrations or interventions in her path to becoming a heroine might appear somewhat mundane by comparison. The main character, Mulan, simply puts on her father's armor and assumes a male identity to go to battle. However, the very feasibility of this action is what makes this story so compelling, even revolutionary. ${ }^{579}$ Here, transformation is not about divine intervention, but a simple yet deliberate act of changing clothes by which the identity of Mulan could be reinvented. ${ }^{580}$ This emphasis on returning to the basics of life becomes a notable recurring feature of this period, much like the development of the visual repertoire represented in tomb murals as we have previously discussed in chapter four. The prevalent use of omens and classical motifs in the Han

\footnotetext{
${ }^{578}$ Lan 2003, p. 232.

${ }^{579}$ Kwa and Idema 2010, p. xi.

${ }^{580}$ The notion that physical appearance is a powerful mediation of social identities and that it is commonly used to signal how individuals are to be placed within society, as well as symbolizing changes in their status, is explored by Sorensen as having derived from the readability of one's appearance, which contains codes that can be interpreted. This identity-image of a person is affected by the costume being worn, and becomes a role that one could take on; see Sorensen 1997.
} 
imagery was seen to have been gradually replaced by a growing predominance of scenes taken from everyday life that began to emerge in the Wei-Jin period, and was fully developed by the early Northern Wei.

This matter-of-fact transition undertaken by Mulan from one identity to another ${ }^{581}-\mathrm{a}$ woman to a man, a daughter to the Khagan's warrior - draws our attention to how much role-playing is a part of life, and the situational nature of how a person's identity is to be constructed. In evaluating our previous discourses on the many faces of the Tuoba, Stephen Greenblatt's discussion of man's self-fashioning in sixteenth-century England becomes a useful viewpoint for us to understand how the "self" is constantly and deliberately shaped in the formation and expression of one's identity. ${ }^{582}$ In fact, the notion of a truly autonomous act of self-fashioning does not exist in Greenblatt's view, since identity was never about free choice, but a cultural artifact. ${ }^{583}$ Even if there appears to be traces of an individual's volition, such as in the case of Mulan's ease in gender-crossing, the choice was certainly among a range of possibilities strictly prescribed by the social system in which the actions were carried out. As sovereigns of a multi-ethnic realm of both nomadic and sedentary traditions, practical conditions necessitated that the Tuoba had to learn to put on the many faces in their self-fashioning as the emperor of the Northern Wei.

This multiplicity of a person's identity is best demonstrated in the second to last stanza, where Mulan was not only a daughter to her parents, but also a younger sister to her elder sister and an elder sister to her little brother. This is no different from the same ways in

\footnotetext{
${ }^{581}$ Kwa and Idema 2010, p. xii.

582 Greenblatt interpreted the Renaissance version of self-fashioning as the control mechanisms for the governing of behavior, the cultural system of meanings that creates specific individuals by governing the passage from abstract potential to historical embodiment; see Greenblatt 2005, pp. 1-3.

${ }^{583}$ Greenblatt 2005, pp. 255-257.
} 
which Lady Poduoluo had been identified within Shaling M7 as the mother of a Northern Wei general in the epitaph text, and depicted visually in the tomb murals as the wife of her husband. As a member of the Northern Wei society, her "being" was defined within a system of relations that made Lady Poduoluo the lady she was, an elite woman who lived in Pingcheng and mother of a general in the Northern Wei army. In much of the same manner, the dual embodiment of the "Khagan/Son of Heaven" in the "Ballad of Mulan" demonstrates the absence of conflict in the ways in which the Tuoba ruler of this period regarded himself as a sovereign in both the Central Asian and Chinese traditions alike. The ease in which these two identities could be interchanged and applied with familiarity is the very feature of the Northern Wei Pingcheng period emphasized in this thesis, one that was conceived with the ingenuity of the Tuoba.

\section{LEGACIES OF THE TUOBA}

The versatility of "Mulan" - the girl as a heroine as well as the female values embodied in the story - in later literary and performative renditions has earned its iconic status in today's popular culture. In much of the same way, we should regard the Tuoba's cultural achievements in the Northern Wei as having had just as much influence on later Chinese periods. The Yuan 元 dynasty (1271-1368 CE) historian Hu Sanxing 胡三省 (1230-1302 CE) commented incisively in his annotated edition of Sima Guang’s 司馬光 Zizhi tongjian 資治通鋻 (Comprehensive Mirror for Aid in Government) on this particular juncture in history:

拓跋珪興而南、北之形定矣。南、北之形既定, 卒之南為北所並。鳴呼! 自 隋以後, 名稱揚於時者, 代北之子孫十居六七矣。584

${ }^{584}$ Zizhi tongjian, juan 108, p. 3429. 
The rise of Tuoba Gui led to the hardening of the North-South partition, which in turn led to the eventual absorption of the South by the North. Alas, from the Sui era onward, sixty to seventy percent of those who were prominent in their times have been descendants of the northern Dai region, [namely the Tuoba and other Xianbei and Xiongnu groups led by the Tuoba] $!^{585}$

Building on this argument, Chen Sanping further makes the claim that, from this point on, the Tuoba and their descendants had pretty much set the course of Chinese history for nearly a millennium before the Mongols swept much of the Asian continent in the thirteenth and fourteenth centuries. ${ }^{586}$

As two of the most culturally vibrant periods in China's pre-modern history, the Tang (618-907 CE) and the Yuan 元 (1271-1368 CE) have been perceived to be sharply different. The former is commonly viewed by the Chinese themselves as a "native" dynasty, whereas the latter is generally regarded as the conquest of China by a nomadic power. One of the main reasons for this difference is, if we had to give this statecraft a name, the "Sinitic façade" that the Tang ruling house had woven for itself, thereby obscuring the ethnic and cultural origins of the $\mathrm{Li}$ 李 imperial family. However, as this thesis has attempted to demonstrate, less politically and more culturally, the extraordinary vibrancy of the Tang dynasty had its roots in the Northern Wei, driven by the contribution of the Tuoba, for which they have received little recognition. As such, we should see that the Northern Wei reconfiguration of material culture during the Pingcheng period, as this thesis had previously discussed, produced enduring legacies in the practices and experiences that shaped what now defines our understanding of what is considered to be

\section{"Chinese".}

\footnotetext{
${ }^{585}$ English translation is based on the work of Dr. Chung-mo Kwok as cited in Chen Sanping 2012, p. 2, with slight modifications made by the author.

${ }^{586}$ Chen Sanping 2012, p. 2.
} 
The "open air" setting that was prominently featured in the Pingcheng tomb murals finds its continuation into the later periods. The late sixth century Sogdian tomb of Yu Hong 虞 弘, ${ }^{587}$ who lived and served under the contemporaneous states of the Northern Qi 北齊 (550-577 CE) and Northern Zhou 北周 (557-581 CE), and held the position of sabao 薩保 (Caravan-Chief) in the Sui dynasty (589-618 CE), contains a stone sarcophagus covered in reliefs. One of the stone panels depicts an outdoor banquet scene tucked in a corner of the garden walls, under the shade of foliage and accompanied by all sorts of birds and beasts. ${ }^{588}$ (fig. 98) Subsequently by the Tang dynasty, a fashion for landscape paintings on screens was established also in tomb furnishings. The late tenth century tomb of the military governor Wang Chuzhi 王處直 contains a full landscape painting mounted as a screen, which is painted onto the rear wall of the front chamber. (figs. 99a, b) The screen serves as a medium for providing a universe against which the individuals seated in front of it are to be viewed, often finding themselves within a complex landscape, traveling through time and space. ${ }^{589}$

An audacious attempt at revising the development of the Chinese history of art might consider treating Northern Wei tomb murals as a continuation of the landscape pictorial

\footnotetext{
${ }^{587}$ For a detailed report on the tomb of Yu Hong, see Shanxi sheng kaogu yanjiusuo, Taiyuan shi kaogu yanjiusuo and Taiyuan shi Jinyuan qu wenwu lüyouju 2005.

${ }_{588}$ These tomb furnishings were not uncommon in fifth to seventh century northern China when artefacts and customs from Central Asia became a new taste as trade routes to Central Asia fostered foreign communities in the capitals. Other contemporary examples include the coffin bed of Anjia, a Sogdian, and the stone couch of Kang Ye, described as coming from Samarkand, both under the Northern Zhou period (557-581). The tomb decorations of these foreigners emphasize on banqueting and dancing in the open air; entertainment among hills and trees were particularly favored, most likely on account of their nomadic backgrounds. It was precisely these representations from the burial context that Jessica Rawson has explored as most likely to be among the factors contributing to the role of landscape settings in later Chinese tombs. Especially scenes on the slabs around Kang Ye's stone couch, the emphasis of subject matter on weeping willows, rocks and rivers as a setting marks a further step towards making landscape a central position in tomb representations; see Rawson 2012, pp. 31-32.

${ }^{589}$ Rawson 2002b, pp. 7, 16.
} 
representation that had originated in the earlier Qin 秦 (221-206 BCE) and Han 漢 (206 BCE-220 CE) dynasties. A strikingly new complex of images had suddenly appeared at this time in the decoration of exotic goods from the northern frontier where most contact had been made with the steppe nomads. These scenes centered on wild animals in flight and archers on horseback, all positioned within a mountainous context (figs. 100a, b), in Esther Jacobson's view, represent the earliest Chinese images of landscape as terrain. ${ }^{590}$ Michael Sullivan attributes the cultural environment within which these landscapes emerged to the poetic focus on the natural world that had already developed in the late Zhou 周 (1046-256 BCE), followed by the early Han fascination with Daoism, alchemy, magic mountains and elaborate hunting parks. ${ }^{591}$ As nomadic goods and imagery penetrated into the Chinese sphere, absorption of new pictorial and conceptual elements into the development of a pictorial Chinese landscape representation demonstrated the meeting of the two worlds.

In time, a new practice of enlarging the majesty of the mountains would develop to confer a sense of focus and narrative force onto the figures moving through the depicted landscape. ${ }^{592}$ Incidentally, the use of mountains in Chinese landscape tradition as derived from the burial context, which functioned as a marker of an open-air setting in the

\footnotetext{
${ }^{590}$ Unlike some of the stylized bronze incisions of the Zhou dynasty that represented signs of a natural context, these Qin and Han images offer the first pictorial representation of the human figure within a landscape setting; Jacobson 1985, pp. 133-135.

${ }^{591}$ Sullivan, following an earlier study by Alexander Soper, turned to Achaemenid art for the source of the visual motifs of mounted archers and the theme of chasing after animals on horseback as found in the Qin and Han dynasties. They believe that contemporary Chinese fascination with landscape stimulated these imported visual elements to be combined with the indigenously developed depiction methods of the running line. Unfortunately, there are no extant indications of these Achaemenid sources, except what was later echoed by the Sassanians; see Sullivan 1962, p. 44; also Soper 1941, p. 147. Rather, Jacobson suggests looking at recent archaeological finds that effectively serve to bring this nomadic landscape to the borders of Han China, documenting the Chinese-nomad relations in the last centuries BCE. These archaeological records are more solid than the hypothetical relations between the Chinese and Western Asia; see Jacobson 1985, pp. 142-143.

${ }^{592}$ Jacobson 1985, p. 146-147.
} 
Northern Wei tombs, is suggested by Jessica Rawson as having the effect of establishing a perpetual physical environment for the individual, so that what was depicted in the image accrued to the individual. ${ }^{593}$ One could even say that the Yungang grottoes were a landscape representation in itself, using the mountain range as backdrop for the imperial portraits in the face of Buddha. The combination of Buddhist iconography, stone and new notions of imperial commemoration at the hands of the Tuoba opened up a new sculptural practice in China much embraced by imperial households of the northern tradition.

This practice was so firmly embodied that, with the relocation of the Northern Wei capital to Luoyang in 494 and throughout the Tang dynasty, the Longmen grottoes 龍門石窟 (next to the Yi River, 12 kilometers south of present-day Luoyang, Henan province), although carved in a new sculptural style, continued to embody imperial agency while receiving patronage from emperors, empresses and members of both the Tuoba Wei and the Li Tang ruling houses. The completion of the Vairocana Buddha of Fengxiansi 奉先寺 (fig. 101) at Longmen in 676 marked a new imperial era for the Tang dynasty as Empress $\mathrm{Wu}$ Zetian 武則天 created a new center of Longmen at the southern end of the mountain range. This physical move carried political and ideological significance. Empress $\mathrm{Wu}$ not only distanced herself from the children of Tang Taizong 唐太宗 ${ }^{594}$ who were active patrons of the northern caves, she also left behind the Pure Land iconography for the Huayan school of the Vairocana assembly at Fengxiansi. ${ }^{595}$ Though the question of whether or not Empress Wu had intended the Vairocana Buddha to be carved in her resemblance remains a romanticized popular surmise, there is no doubt that the Longmen

\footnotetext{
${ }^{593}$ Rawson 2002b, p. 14.

${ }^{594}$ Taizong 太宗 is the temple name for Li Shimin 李世民 (r. 626-649). Empress Wu Zetian had originally entered the Tang palace as a concubine of Taizong. After his death, she became the consort to Taizong's son and successor Gaozong, Li Zhi 李治 (r. 649-683), and was later made empress.

${ }^{595}$ McNair 1994, p. 78.
} 
grottoes of the Tang dynasty followed in the footsteps of Yungang in embodying the religious, political and imperial landscape of the current imperial household.

What has often been neglected is how these earlier nomadic conquests stimulated the transfer of peoples, objects, and certainly ideas across the Eurasian continent in the ancient world. In the Northern Wei Pingcheng period, the iconography of Buddhism, architectural sets in stone and notions of an imperial monument best epitomize the result of a strategic relocation of conquered subjects, concentrating their "soft power" at Pingcheng. As rulers who presided over a culturally vibrant region, the Tuoba maintained a "dual presence" in northern China through a practice of working with new material forms and generating individual variations within preexisting traditions, such as those in the context of Yungang and tomb burials. Ultimately, sculptures, paintings and figurines created a new cultural vocabulary for the Tuoba, one that (re)negotiated and (re)defined what we have now come to appreciate as "Chinese" culture.

\section{BACK TO THE GAXIAN CAVE}

On July 30, 1980, three Chinese archaeologists from Hulunbeier, Neimenggu province discovered a stone cave (fig. 102a) on the east side of the northern section of the Daxing'an Mountains 大興安嶺 in northeastern China. ${ }^{596}$ Inside the cave (known today as the Gaxian cave 嘎仙洞), on a granite rock face, is an inscription dated to the fourth year of the Taiping Zhenjun reign (443 CE) under Emperor Taiwu. (fig. 102b) This discovery,

\footnotetext{
${ }^{596}$ For the archaeological report on this discovery, see Mi Wenping 1981.
} 
or rather confirmation, of the inscription's existence vindicated the historical accuracy of the Wei shu. ${ }^{597}$

According to the Wei shu, in the year 443, a contingent of horsemen known as the Wuluohou 烏洛侯 asked for an audience with Emperor Taiwu. ${ }^{598}$ They informed him that their people had heard of a cave located in what is now the Elunhchun Autonomous Banner in northeastern Neimenggu province, which had been known as the Xianbei's ancestral shrine. Local inhabitants frequently worshipped at this cave since it has proven to be efficacious. This news from afar convinced Emperor Taiwu to send an emissary, led by Li Chang 李敞, to verify the report and to conduct ceremonies on behalf of the emperor himself to worship the imperial ancestors. If we compare dedication text preserved in the Wei shu to the inscriptions discovered by archaeologists in the Gaxian Cave in 1980, there exists a seemingly minor but noteworthy discrepancy between the two. The cave inscriptions provide us with a more complete version of the dedication as the text had been modified as it was recorded into the Wei shu. The inscription reads:

維太平真君四年, 癸未歲七月廿五日, 天子臣壽使謁者僕射庫立官中書侍郎 李敞、傅雀用駿足, 一元大武, 柔毛之牲, 敢昭告於皇天之神:

启闢之初, 佑我皇祖, 於彼土田, 歷載億年。聿來南遷, 應受多福。光宅中 原, 惟祖惟父。拓定四邊, 慶流後胤, 延及冲人。㘓揚玄風, 增构崇堂。克 翦凶刃，威暨四荒。幽人忘遐，稽首來王。始聞舊墟，爰在彼方。悠悠之 懷, 希仰余光。王業之興, 起自皇祖。綿綿瓜瓜, 時惟多祜。歸以謝施, 推 以配天。子子孫孫, 福禄永延。

\footnotetext{
${ }^{597}$ As some might challenge the authenticity of the inscription, only further studies using microscopic and chemical analysis of the rock surface can possibly provide a more definitive answer. However, the overall archaeological potential of Gaxian Cave at the Daxing'an Mountains can hardly be exaggerated.

${ }^{598}$ Wei shu, juan 108, pp. 2738-2739.
} 
薦於：皇之帝天、皇之后土

以皇祖先可寒配, 皇妣先可敦配。

尚飨!

東作帥使念丵。599

On the twenty-fifth day of the seventh month in the fourth year of the Taiping Zhenjun reign, the year of guiwei, the Son of Heaven [and your] servant [Tuoba] Tao had the emissaries, Li Chang, Supervisor of the Storehouse and Vice Director of the Secretariat, and Fu Que, use fine horses, sacrificial cattle, and sheep to humbly proclaim before the deities of the Heaven:

Since the opening [of heaven] and the clearing [of the earth], our imperial ancestors have been blessed on this piece of land for tens of thousands of years. Up to [our] southern migration, [we have] indeed received much blessing. [Those who have] pacified the Central Plains were my forefathers. [They had] expanded and settled [the lands] in the four directions, [allowing] the success to flow to posterity, arriving at [the time of] my youth. The "winds of mysticism" were expounded and promoted; venerated halls were added and constructed. Having conquered and vanquished [with] fierce blades, [our] might reached the four wildernesses. The people of Youzhou ${ }^{600}$ disregarded the distance; bowed their heads to pay reverence to the sovereign. For the first time, $[\mathrm{I}]$ hear of the ancient site, which is in that region. Endless are my thoughts, in the hopes of relying on [our ancestors'] lingering glories. The rise of [the Wei] rulership began with our forefathers. The tenacious continuity of our lineage had, throughout the years, been much blessed. [I] return [to this place] in order to show gratitude for what has been granted to us, and [I] present [my ancestors] as correlatives [in the sacrifice] to Heaven, so that future generations [will receive] endless blessings and bounty.

Presented forth to: Great Heaven and Sovereign Earth.

Using the imperial father, the former Khagan, and the imperial mother, the former Khatun, as correlatives [in the sacrifice].

Wish [for your] enjoyment!

Carved [at my] wishes by the leading emissary dispatched to the east. ${ }^{601}$

First and foremost, the discovery of this inscription in the Gaxian Cave helped identify the original homeland of the Tuoba (or rather, what was contemporaneously accepted as their native grounds) and vindicated the credibility of the Wei shu as a reliable textual source. Its additional value lies in testifying to the avoidance of the official Chinese term Huangdi

\footnotetext{
${ }^{599}$ Text of the cave inscription after Tong Zhuchen 1981, p. 36.

${ }^{600}$ Youzhou consisted of present-day northern Hebei province and parts of Liaoning province, the region over which the ancestors of the Tuoba had first laid claim.

${ }^{601}$ Author's trans.
} 
皇帝 or $D i$ 帝 for “emperor” by the Tuoba themselves in this period. Not only was the imperial father addressed as the Kehan 可寒 ${ }^{602}$ (Khagan), the imperial mother was addressed by the equivalent designation Kedun 可敦 (Khatun). In doing so, Emperor Taiwu declared himself the proud heir of a ruling household that clearly kept to its own imperial tradition, down to the use of nomenclature, despite its new residence in the Chinese sphere. In this light, the different notions and agencies of kingship explored by the Tuoba at Yungang would not have been so unexpected.

For one reason or another, both the salutation and the final section of the inscription, beginning with "Presented forth to", were left out of the imperial dedication as recorded in the Wei shu. Incidentally, among other slight variations and inconsistencies between the inscription and the transmitted text, this omission on the part of the latter greatly changed the tone of the sacrificial dedication carried out in the year 443. In the inscription, the humble attitude of Emperor Taiwu, the "Son of Heaven", in calling himself "your servant" by using the designation chen 臣 before the Great Heaven and Sovereign Earth was removed from the transmitted text. This discrepancy should not be brushed aside slightly as the mere omission on the part of the court historian. I believe that this demonstrates the multiple faces of Emperor Taiwu, having learned to manipulate his rhetoric as a means of statecraft. At the Gaxian Cave, the emperor's intended recipients of his dedication, apart from the Heaven above, were the Tuoba ancestors, for whom he added a personal touch in the choice of rhetoric.

\footnotetext{
${ }^{602}$ Despite the different characters, the usage of 可寒 and 可汗 are both transliterations of the designation Khagan.
} 
This deliberate act of identifying oneself with a particular collective through the use of rhetoric parallels Song Shaozu's differential use of figural representations in his tomb - the choice of nomadic dress for the clay figurines, while preferring a Han-Chinese apparel in the depiction of murals on the inside of the sarcophagus. In doing so, I have argued in chapter four that the tomb occupant compartmentalized his public and private affiliations through the application of different visual markers. Similarly, Emperor Taiwu appears to have adopted the same concept in separating his dynastic and familial associations, demonstrating a personal touch in the rhetoric applied in the sacrificial inscription. The ability to crossover between different social spheres and becoming adept at assuming distinct roles as the situation arises is, what I believe to be, the key to the Tuoba's success in managing China's first multi-ethnic dynasty under one ruling house. ${ }^{603}$ Simply speaking, the Tuoba had mastered the skillful interchange of imperial façades that served as a means to an end, which was very much similar to the function of Mulan's war gown.

It is in the delicate maintenance of a "dual presence" as they acted as sovereigns, not only as "Son of Heaven" to the conquered subjects in northern China, but also carrying over practices that befit a Khagan in the Central Asia tradition, that the Tuoba successfully developed a new imperial tradition. As we arrive at the end of this thesis, it is my hope that the reader will no longer revere the great Buddhas at Yungang or listen to the story of Mulan without being reminded of the ingenuity of the Tuoba in their making of the Northern Wei dynasty.

\footnotetext{
${ }^{603}$ The Tuoba's ability to compartmentalize the separate identities and usefulness of their subjects had taken as precedent the Murong Xianbei's methods of separating a nomadic army from a Chinese styled administration in their rule of the Yan 燕 states in the fourth century Sixteen Kingdoms period. The Murong Xianbei people of the north east were a semi-sedentary people who lived in a mixture of forest villages, agricultural communities, and nomadic camps. However, the Tuoba were eventually successful in uniting the entire northern China under one ruling house, owing to their ability to transform loyalty to a leader in the traditional nomadic tribal practice into loyalty to a dynasty; see Lewis 2009, pp. 74, 79.
} 


\section{Appendix A: Northern Wei Emperors of the Pingcheng Period}

\begin{tabular}{|c|c|c|c|}
\hline $\begin{array}{c}\text { Personal and Posthumous } \\
\text { Names, } \\
\text { and Date of Reign }\end{array}$ & Temple Names & Reign Names & $\begin{array}{l}\text { Years of } \\
\text { Reign }\end{array}$ \\
\hline \multirow{4}{*}{$\begin{array}{c}\text { Tuoba Gui 拓跋硅 } \\
\text { (Emperor Daowu 道武帝, } \\
\text { r. 386-409) }\end{array}$} & \multirow{4}{*}{ Taizu 太祖 } & Dengguo 登國 & $386-396$ \\
\hline & & Huangshi 皇始 & $396-398$ \\
\hline & & Tianxing 天興 & $398-404$ \\
\hline & & Tianci 天賜 & 404-409 \\
\hline \multirow{3}{*}{$\begin{array}{c}\text { Tuoba Si 拓跋嗣 } \\
\text { (Emperor Mingyuan 明元帝, } \\
\text { r. 409-423) }\end{array}$} & \multirow{3}{*}{ Taizong 太宗 } & Yongxing 永興 & $409-413$ \\
\hline & & Shenrui 神瑞 & $414-416$ \\
\hline & & Taichang 泰常 & $416-423$ \\
\hline \multirow{6}{*}{$\begin{array}{c}\text { Tuoba Tao 拓跋壽 } \\
\text { (Emperor Taiwu 太武帝, } \\
\text { r. 424-452) }\end{array}$} & \multirow{6}{*}{ Shizu 世祖 } & Shiguang 始光 & $424-428$ \\
\hline & & Shenjia 神鹿 & $428-431$ \\
\hline & & Yanhe 延和 & $432-435$ \\
\hline & & Taiyan 太延 & $435-440$ \\
\hline & & $\begin{array}{c}\text { Taiping zhenjun } \\
\text { 太平真君 }\end{array}$ & $440-451$ \\
\hline & & Zhengping 正平 & $451-452$ \\
\hline $\begin{array}{c}\text { Tuoba Yu 拓跋余 } \\
\text { (Prince Nan'an 南安王, } \\
\text { r. 452)* }\end{array}$ & NA & Yongping 永平 & 452 \\
\hline \multirow{4}{*}{$\begin{array}{c}\text { Tuoba Jun 拓跋濬 } \\
\text { (Emperor Wencheng 文成帝, } \\
\text { r. 452-465) }\end{array}$} & \multirow{4}{*}{ Gaozong 高宗 } & Xing'an 興安 & $452-454$ \\
\hline & & Xingguang 興光 & $454-455$ \\
\hline & & Taian 太安 & $455-459$ \\
\hline & & Heping 和平 & $460-465$ \\
\hline \multirow{2}{*}{$\begin{array}{c}\text { Tuoba Hong 拓跋弘 } \\
\text { (Emperor Xianwen 獻文帝, } \\
\text { r. 466-471) }\end{array}$} & \multirow{2}{*}{ Xianzu 顯祖 } & Tian'an 天安 & $466-467$ \\
\hline & & Huangxing 皇興 & $467-471$ \\
\hline \multirow{3}{*}{$\begin{array}{c}\text { Tuoba Hong 拓跋宏 } \\
\text { (Emperor Xiaowen 孝文帝, } \\
\text { r. 471-499)** }\end{array}$} & \multirow{3}{*}{ Gaozu 高祖 } & Yanxing 延興 & $471-476$ \\
\hline & & Chengming 承明 & 476 \\
\hline & & Taihe 太和 & $477-499$ \\
\hline
\end{tabular}

* Tuoba Yu was not given a posthumous name or a temple name upon his death, after a brief interim as Northern Wei emperor, since he was succeeded by Tuoba Jun, son of Tuoba Huang 拓跋晃 (428-451). Tuoba Huang was formerly recognized as crown prince by Tuoba Tao, but died before he could succeed the throne. When Tuoba Tao was killed in 452, his other son, Tuoba Yu took the throne instead, but died in the same year. Tuoba Jun honored his own father instead of Tuoba Yu with the funerary rights of an emperor.

** Tuoba Hong relocated the capital from Pingcheng to Luoyang in the eleventh month of 494, marking the end of Northern Wei Pingcheng era. 


\section{Appendix B: Figures}

The figure originally presented here cannot be made freely available via ORA for copyright reasons.

Figs. 1a, b

Top, boundary of early Northern Wei when the southern court was held by the Song regime (420-479 CE).

Bottom, boundary of late Northern Wei when the southern court was held by the Qi regime (479-502 CE).

After Tan Qixiang 1982, pp. 17-20.

The figure originally presented here cannot be made freely available via ORA for copyright reasons. 
Appendix B: Figures

The figure originally presented here cannot be made freely available via ORA for copyright reasons.

\section{Fig. 2}

Map of the different states in northern and southern China circa 366 CE. The Murong state of the Former Yan occupied the Manchurian frontier. At this time, the Tuoba had yet to change the name of their state from Dai to Wei.

After Lewis 2009, p. 78. 
The figure originally presented here cannot be made freely available via ORA for copyright reasons.

\section{Fig. 3}

Migratory route of the Tuoba's southward move.

After Xiong 2003, fig. 1; based on Su Bai 1977a, p. 43. 


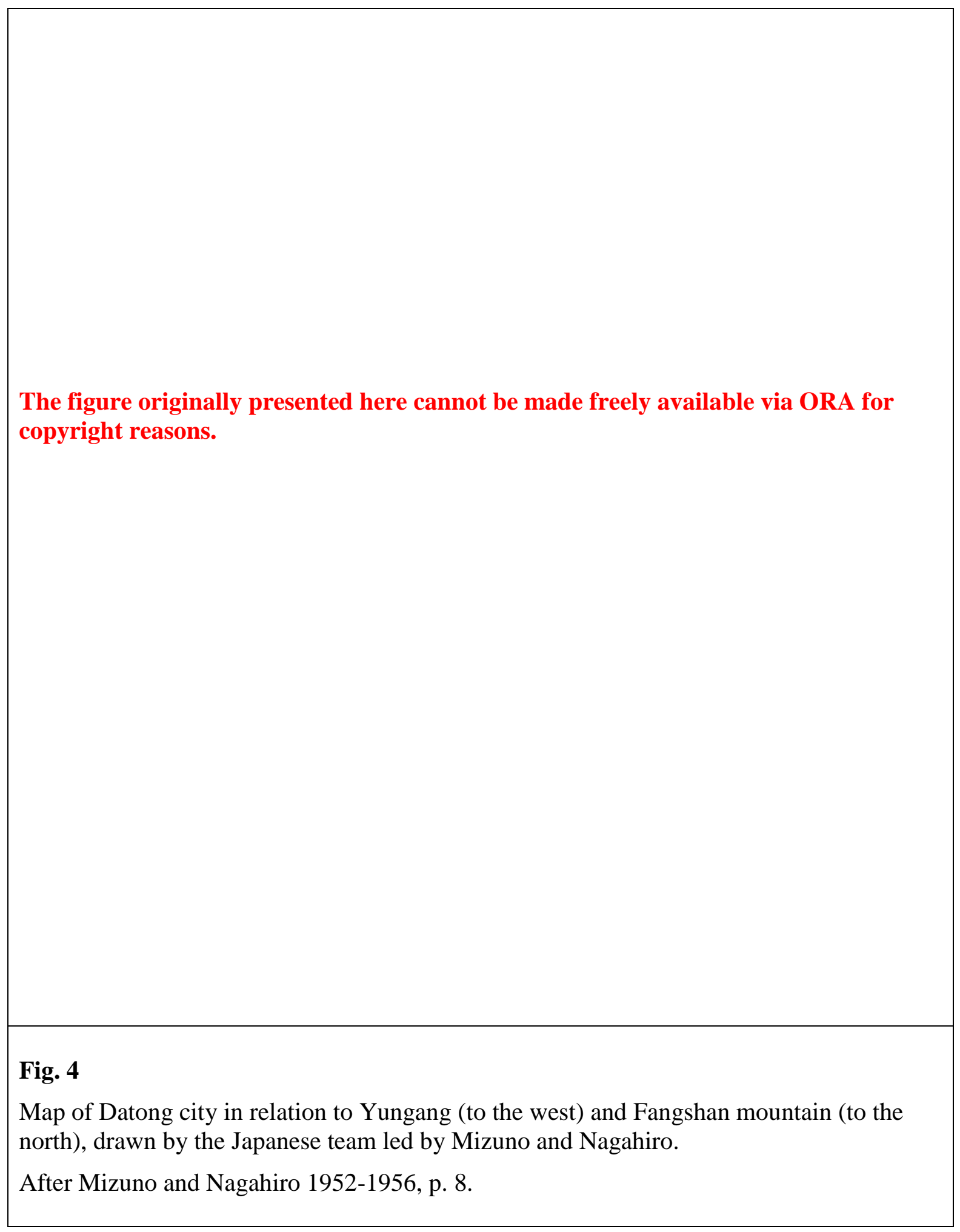


Appendix B: Figures

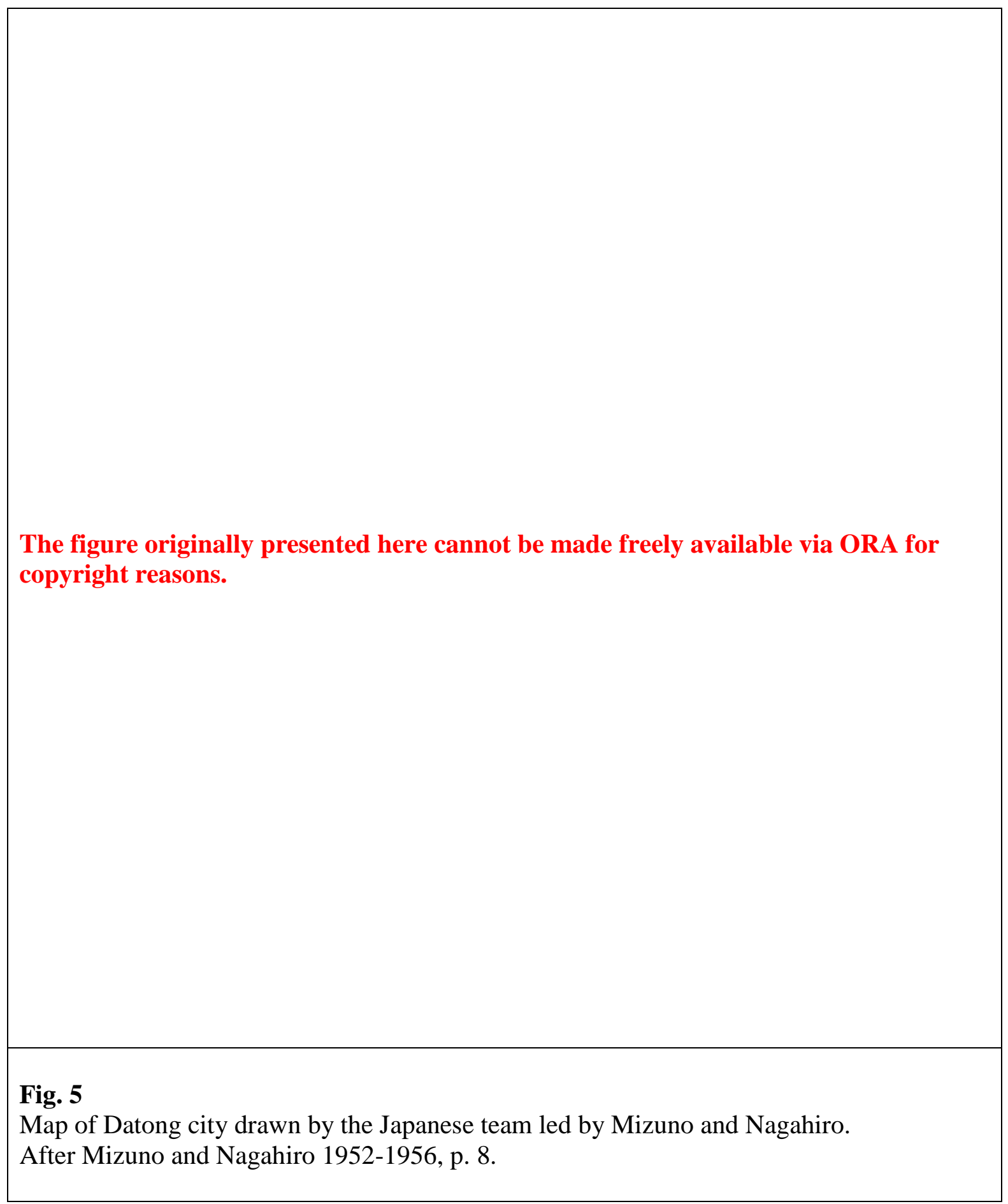


Appendix B: Figures

The figure originally presented here cannot be made freely available via ORA for copyright reasons.

\section{Fig. 6}

Drawing by Cao Chenming 曹臣民 (then Deputy Director of the Datong Municipal Museum) for explaining the hypothesized location of the northern great wall, which enclosed the northern mountain pass between the Baideng (to the right) and Leigong (to the left) Mountains. The Caochangcheng palace site is to the north of the Pingcheng city site.

Right to use this sketch for the purpose of this thesis has been obtained from Cao Chenming in March 2009. 
Appendix B: Figures

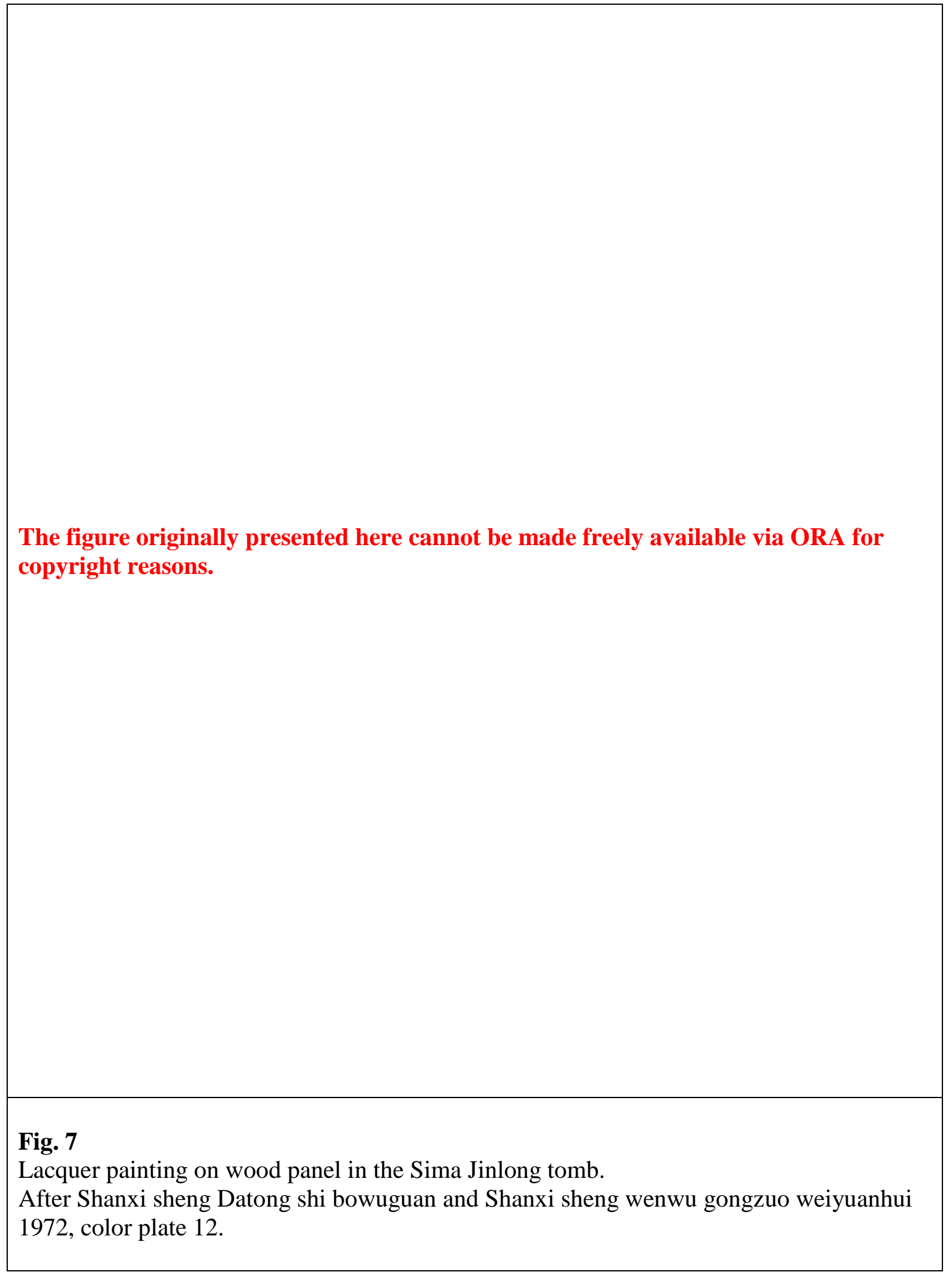


Appendix B: Figures

The figure originally presented here cannot be made freely available via ORA for copyright reasons.

\section{Fig. 8}

My own photograph of the glazed figurines in the Sima Jinlong tomb, assembled and stored in the Datong Municipal Museum, Datong, Shanxi province. 


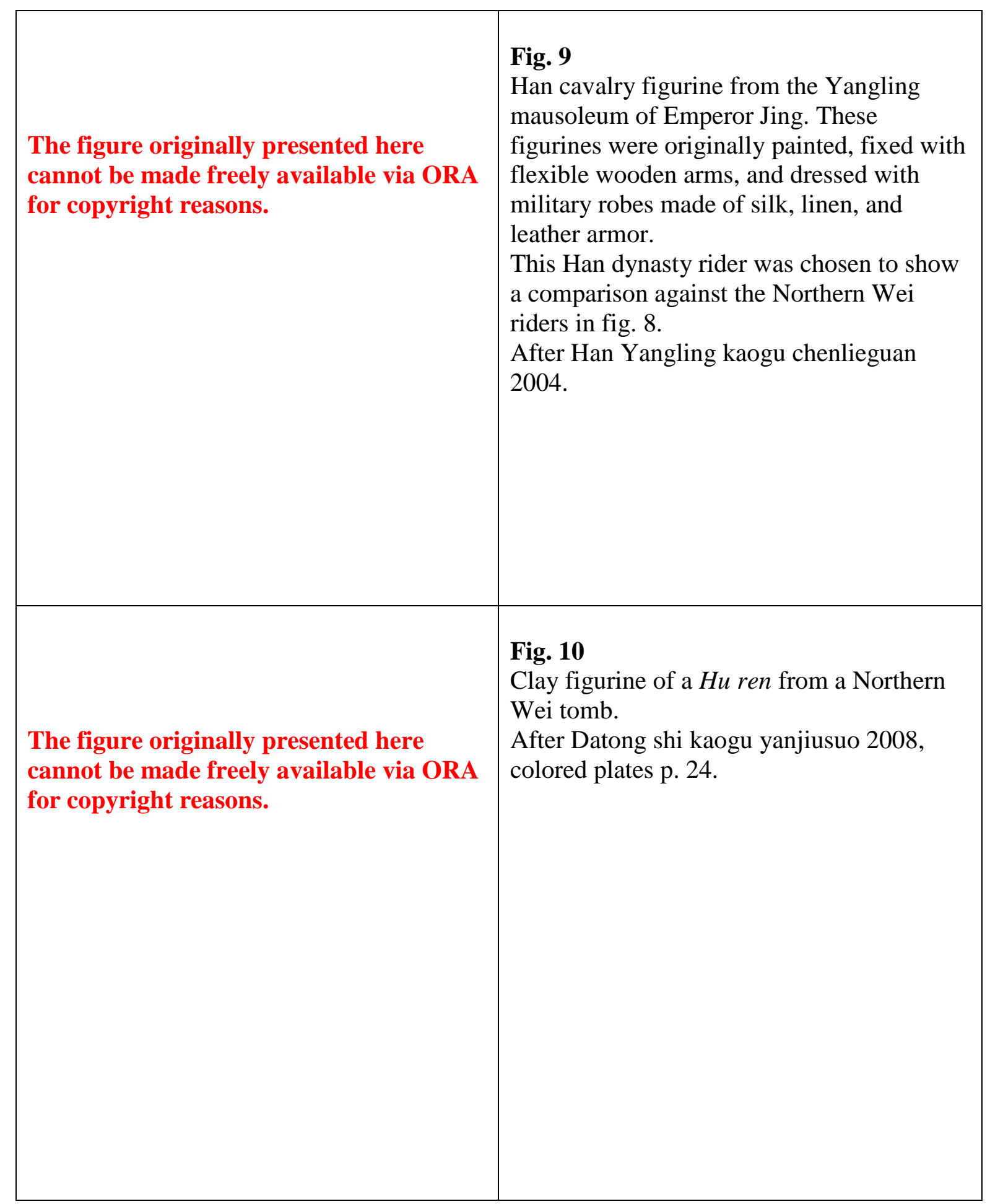


Appendix B: Figures

The figure originally presented here cannot be made freely available via ORA for copyright reasons.

\section{Fig. 11}

Plan of Pingcheng (present-day Datong, Shanxi province) in the Northern Wei, fourth to fifth century. Drawing dated to the Qing dynasty by Yang Shoujing in the Shuijing zhu tu, based on Li Daoyuan's descriptions in the Shuijing zhu.

After Shuijing zhu tu, p. 77b. 
Appendix B: Figures

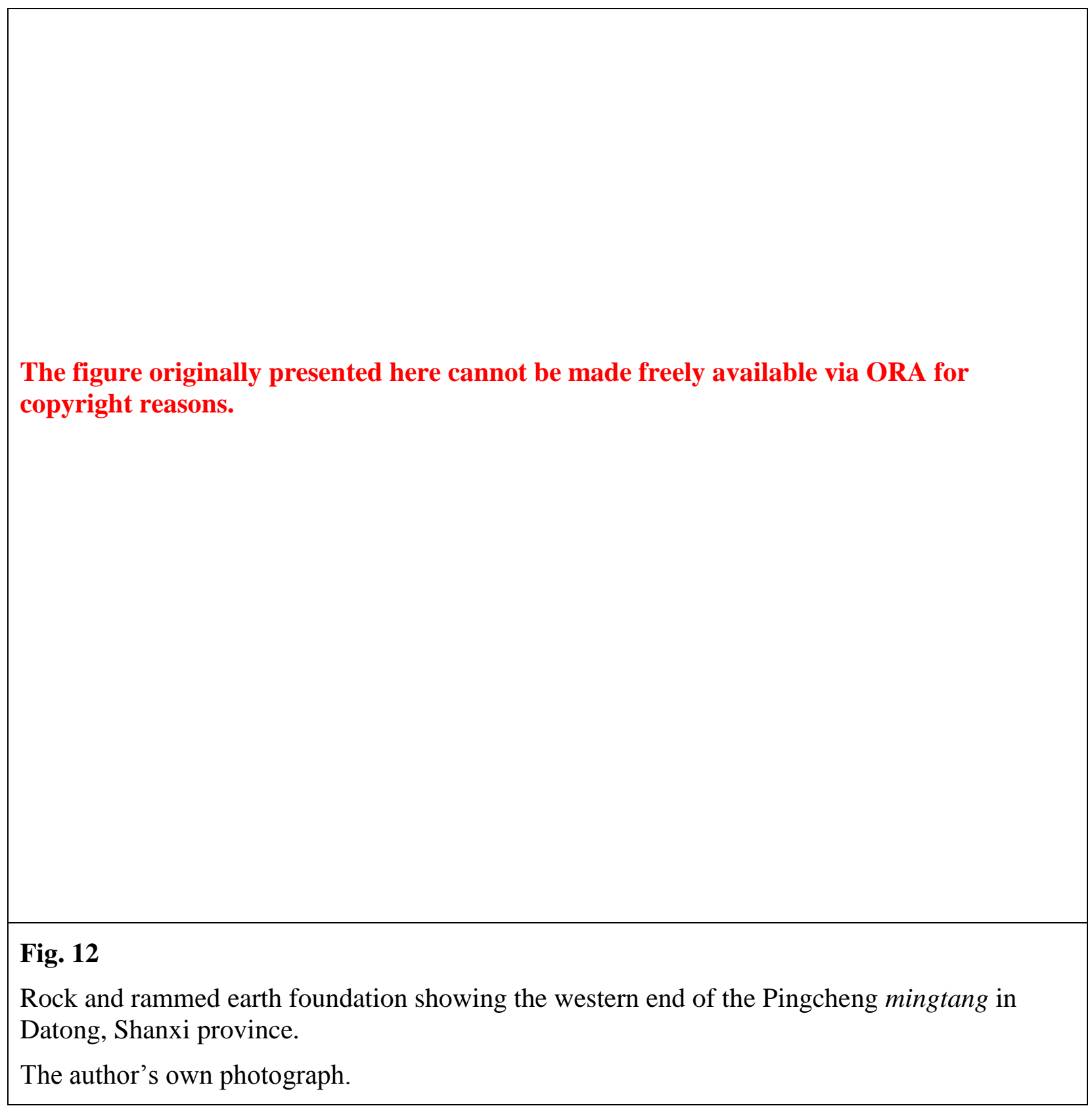


Appendix B: Figures

The figure originally presented here cannot be made freely available via ORA for copyright reasons.

Fig. 13

Sketch of the hypothesized layout of the Pingcheng mingtang based on the excavated rammed earth foundation to the west.

After Wang Yintian, Cao Chenming and Han Shengcun 2001, p. 27, fig. 2. 
Appendix B: Figures

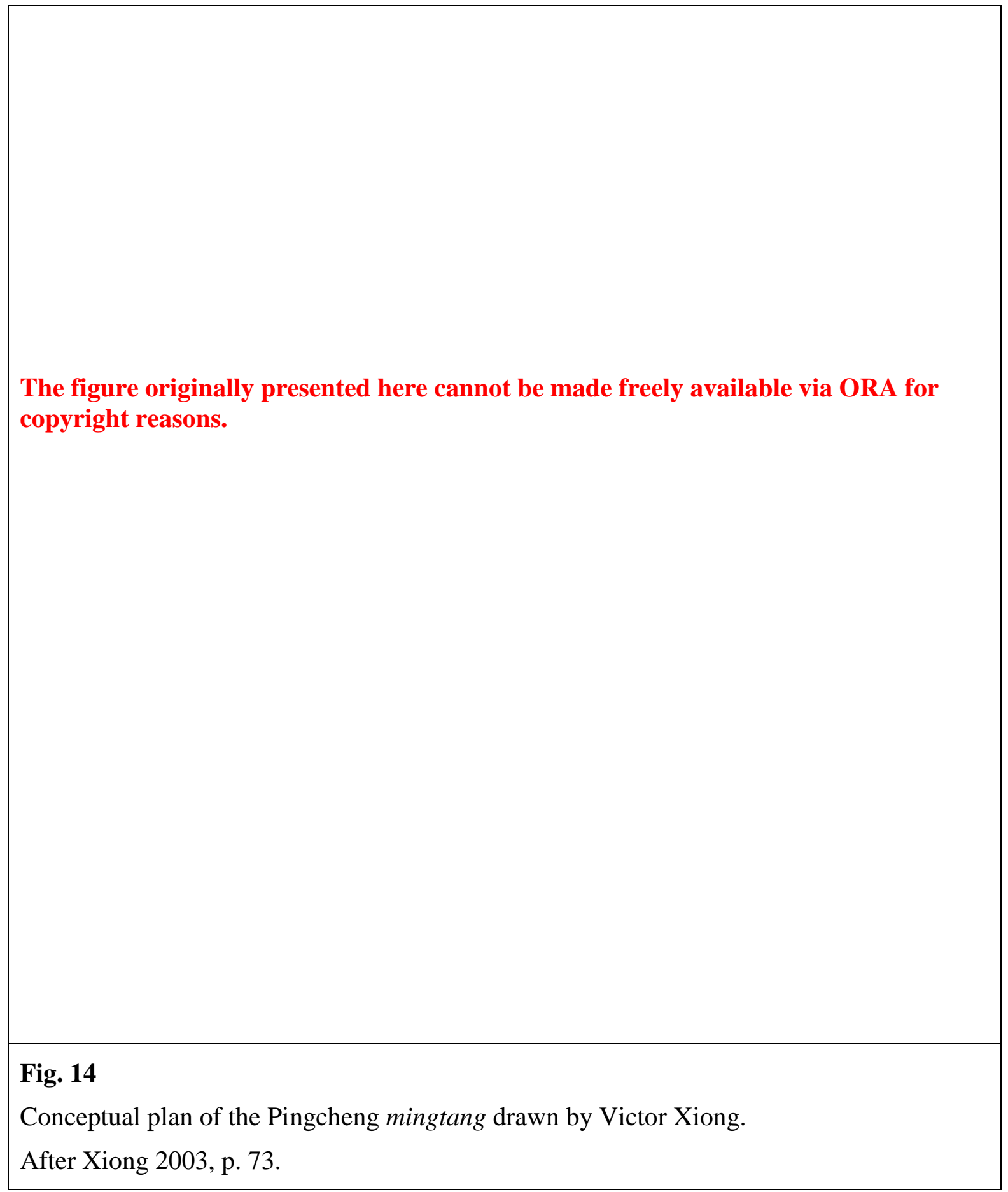


The figure originally presented here cannot be made freely available via ORA for copyright reasons.

\section{Figs. 15a, b}

a) Top, ceiling of the Kizil cave temple.

b) Bottom, painted ceiling of Dunhuang cave 101, dated to the late fifth century, Northern Wei period

After Soper 1947, figs. 10, 15.

The figure originally presented here cannot be made freely available via ORA for copyright reasons. 
Appendix B: Figures

The figure originally presented here cannot be made freely available via ORA for copyright reasons.

Fig. 16

Drawing by Yin Xian 殷憲 (local Datong scholar on the Northern Wei period) allocating the hypothesized relational positions of the mingtang, Pingcheng palace, and the Deer Park (within the greater encloses of the Northern Garden), in relation to the Ruhun River.

Right to use this sketch for the purpose of this thesis has been obtained from Yin Xian in March 2009. 


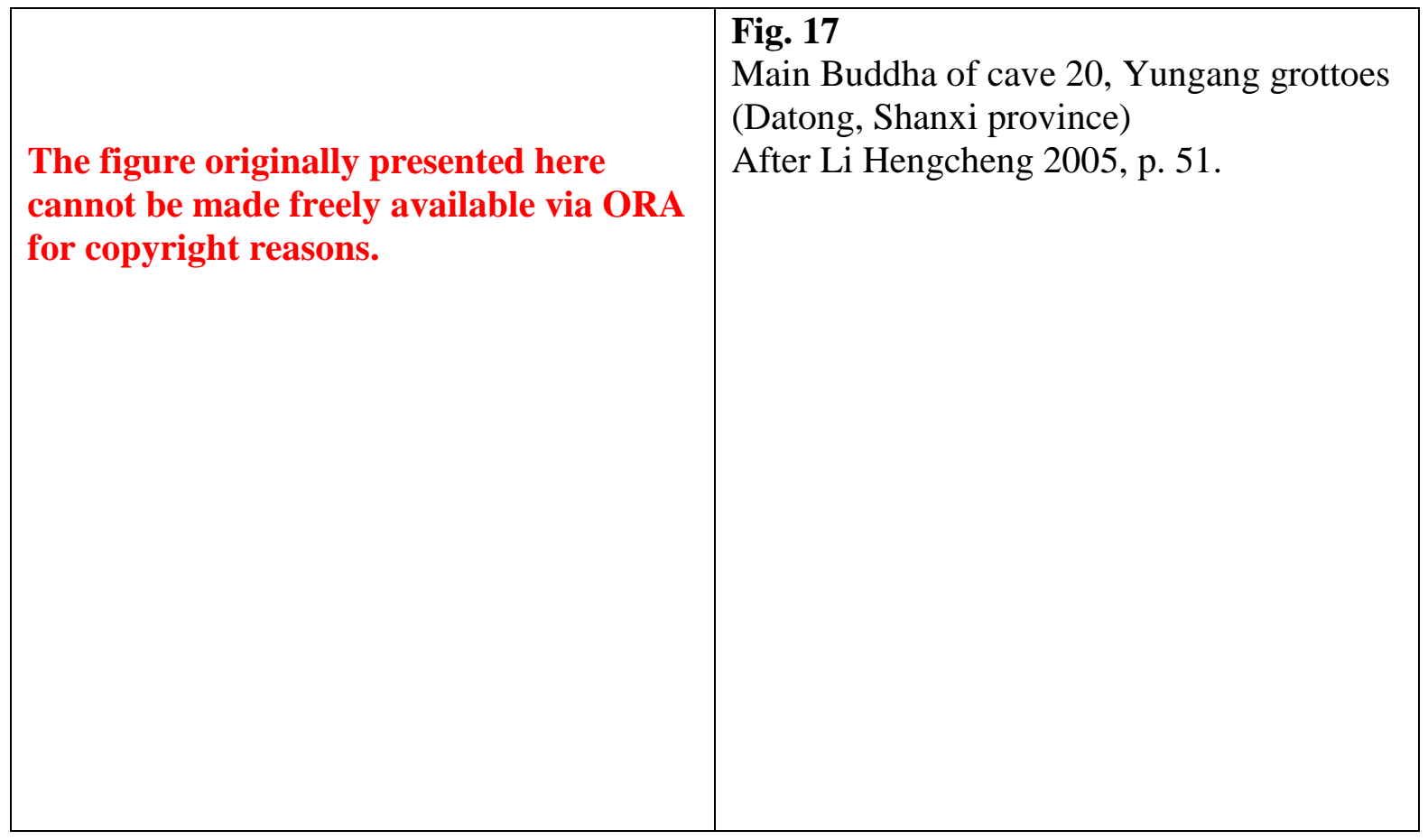

The figure originally presented here cannot be made freely available via ORA for copyright reasons.

The figure originally presented here cannot be made freely available via ORA for copyright reasons.

Fig. 18

(a) Top, panoramic view of the central caves at Yungang. The exposed Buddha is in cave 20. After Yungang shiku yanjiuyuan 2008, pp. 88-89.

(b) Bottom, plan of Yungang grottoes. The Tan Yao caves (no. 20-16) are circled in red. After Soper 1960, pp. 64-65. 
The figure originally presented here cannot be made freely available via ORA for copyright reasons.
The figure originally presented here cannot be made freely available via ORA for copyright reasons.

\section{Fig. 19}

Main Buddha sculptures in the Five Caves of Tan Yao.

a) Top left, cave 20

b) Top right, cave 19

c) Bottom left, cave 18

d) Bottom center, cave 17

e) Bottom right, cave 16

Caves 20,17 and 16 are after Yungang shiku yanjiuyuan 2008 .

Caves 19 and 18 are after Li Hengcheng 2005, pp. 37, 42.

\begin{tabular}{|l|l|l|}
\hline $\begin{array}{l}\text { The figure originally } \\
\text { presented here cannot be } \\
\text { made freely available via } \\
\text { ORA for copyright reasons. }\end{array}$ & $\begin{array}{l}\text { The figure originally } \\
\text { presented here cannot be } \\
\text { made freely available via } \\
\text { ORA for copyright reasons. }\end{array}$ & $\begin{array}{l}\text { The figure originally } \\
\text { presented here cannot be } \\
\text { made freely available via } \\
\text { ORA for copyright reasons. }\end{array}$ \\
& & \\
& & \\
\end{tabular}




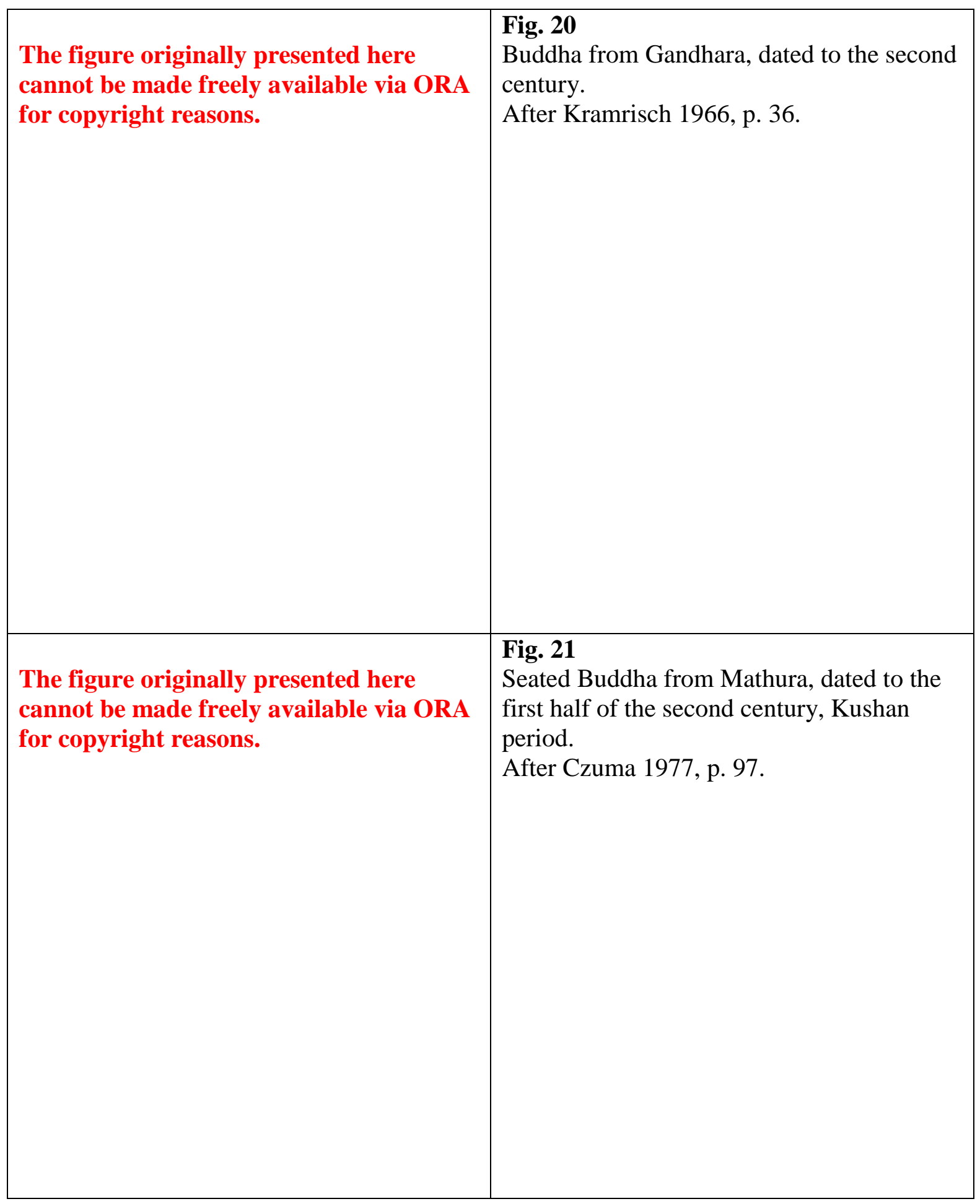


The figure originally presented here cannot be made freely available via ORA for copyright reasons.

Fig. 22

View of the northeastern portion of the site of Naqsh-e Rostam, Iran.

After Canepa 2010, p. 575, fig. 9.

The figure originally presented here cannot be made freely available via ORA for copyright reasons.

Fig. 23

The large grotto of Taq-e Bostan, Iran.

After Peck 1969, Pl. 1. 


\begin{tabular}{|c|c|}
\hline $\begin{array}{l}\text { The figure originally presented here cannot be made } \\
\text { freely available via ORA for copyright reasons. }\end{array}$ & $\begin{array}{l}\text { Fig. } 24 \\
\text { Arch of Galerius in Thessaloniki, } \\
\text { Greece. Completed ca. } 303 \text { CE. } \\
\text { View of the east face. } \\
\text { After Canepa } 2009, \text { p. } 86 .\end{array}$ \\
\hline $\begin{array}{l}\text { The figure originally presented here cannot be made } \\
\text { freely available via ORA for copyright reasons. }\end{array}$ & $\begin{array}{l}\text { Fig. } 25 \\
\text { Denarius of Octavian before } 31 \\
\text { BCE. On one side Octavian is } \\
\text { portrayed as Jupiter Feretrius, } \\
\text { and on the other Octavian sits on } \\
\text { a curule seat, wearing a toga, } \\
\text { with Victoria perched on his } \\
\text { hand: magistrate and ruler in one. } \\
\text { After Zanker 1988, p. 56, fig. } 44 .\end{array}$ \\
\hline $\begin{array}{l}\text { The figure originally presented here cannot be made } \\
\text { freely available via ORA for copyright reasons. }\end{array}$ & $\begin{array}{l}\text { Fig. } 26 \\
\text { Rubbing of the Yishan text (bei). } \\
\text { This stone inscription was one of } \\
\text { seven set up by Qin Shihuang } \\
\text { following his conquest of the } \\
\text { various states into which China } \\
\text { had been divided. The stone has } \\
\text { not survived and the rubbing is } \\
\text { made from a copy dated to } 993 \\
\text { CE. The text is written in seal } \\
\text { script, the script devised by the } \\
\text { Qin state to unify the Chinese } \\
\text { writing system. It proclaims the } \\
\text { majesty and greatness of the first } \\
\text { emperor in making his conquests. } \\
\text { After Rawson } 2007 b, p .26 \text {. }\end{array}$ \\
\hline
\end{tabular}


The figure originally presented here cannot be made freely available via ORA for copyright reasons.

Fig. 27

Middle panel of the Battle of Milvian Bridge scene on the Arch of Constantine. After Speidel 1986, p. 261, fig. 2.

The figure originally presented here cannot be made freely available via ORA for copyright reasons.

Fig. 28

Rock relief of Shapur I and the Roman emperor Phillip in submission at Naqsh-e Rostam. After Canepa 2009, p. 64. 
The figure originally presented here cannot be made freely available via ORA for copyright reasons.

Fig. 29a

General view of the inscriptions and reliefs on Mount Behistun, Iran. The relief depicts Darius I conquering the rebels.

After British Museum et al. edt. 1907, Pl. III.

The figure originally presented here cannot be made freely available via ORA for copyright reasons.

Fig. 29b

Drawing of the relief and a key to the positions of the Persian, Susian, and Babylonian epigraphs on the rock of Behistun.

After British Museum et al. edt. 1907, Pl. XIII. 


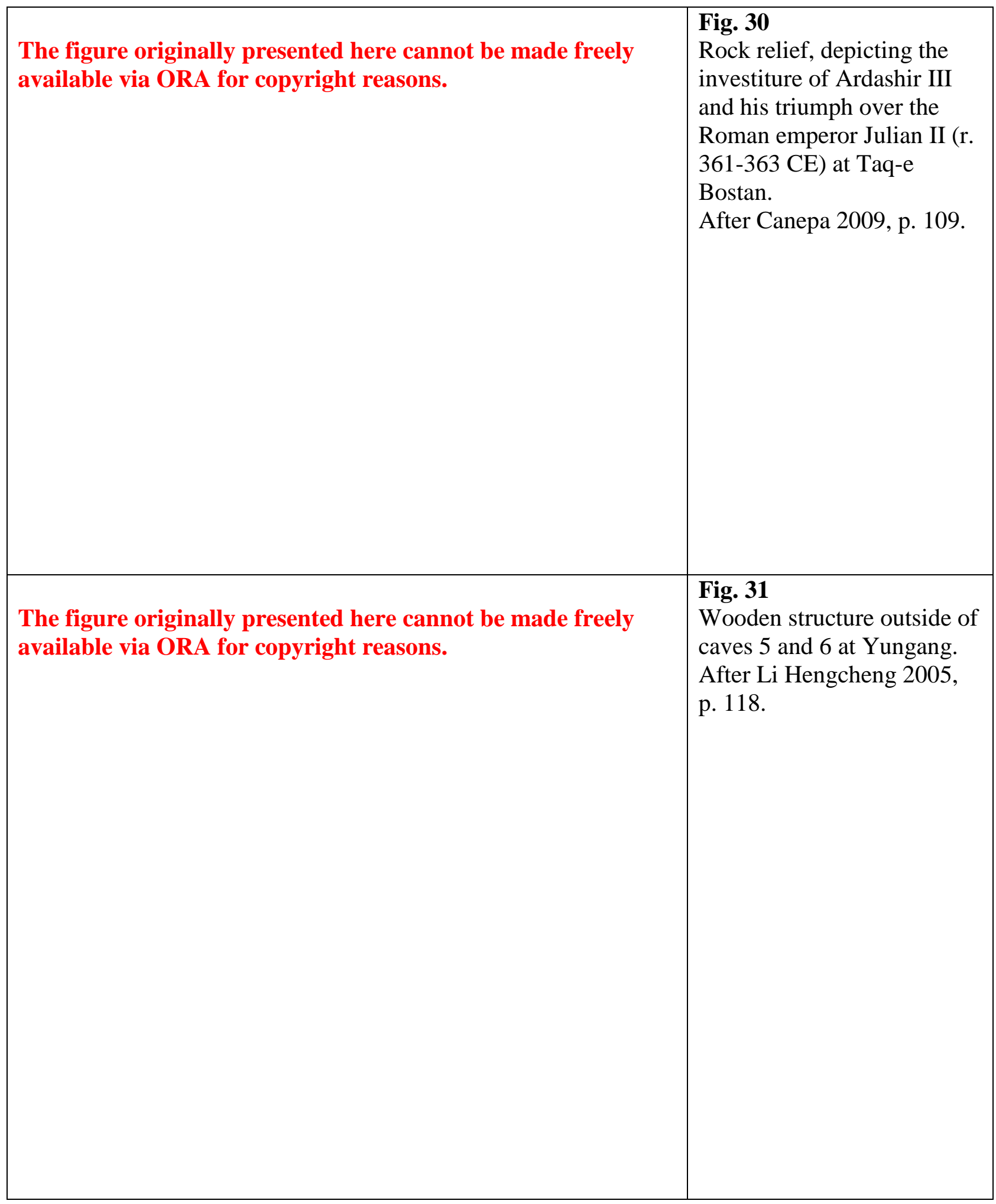




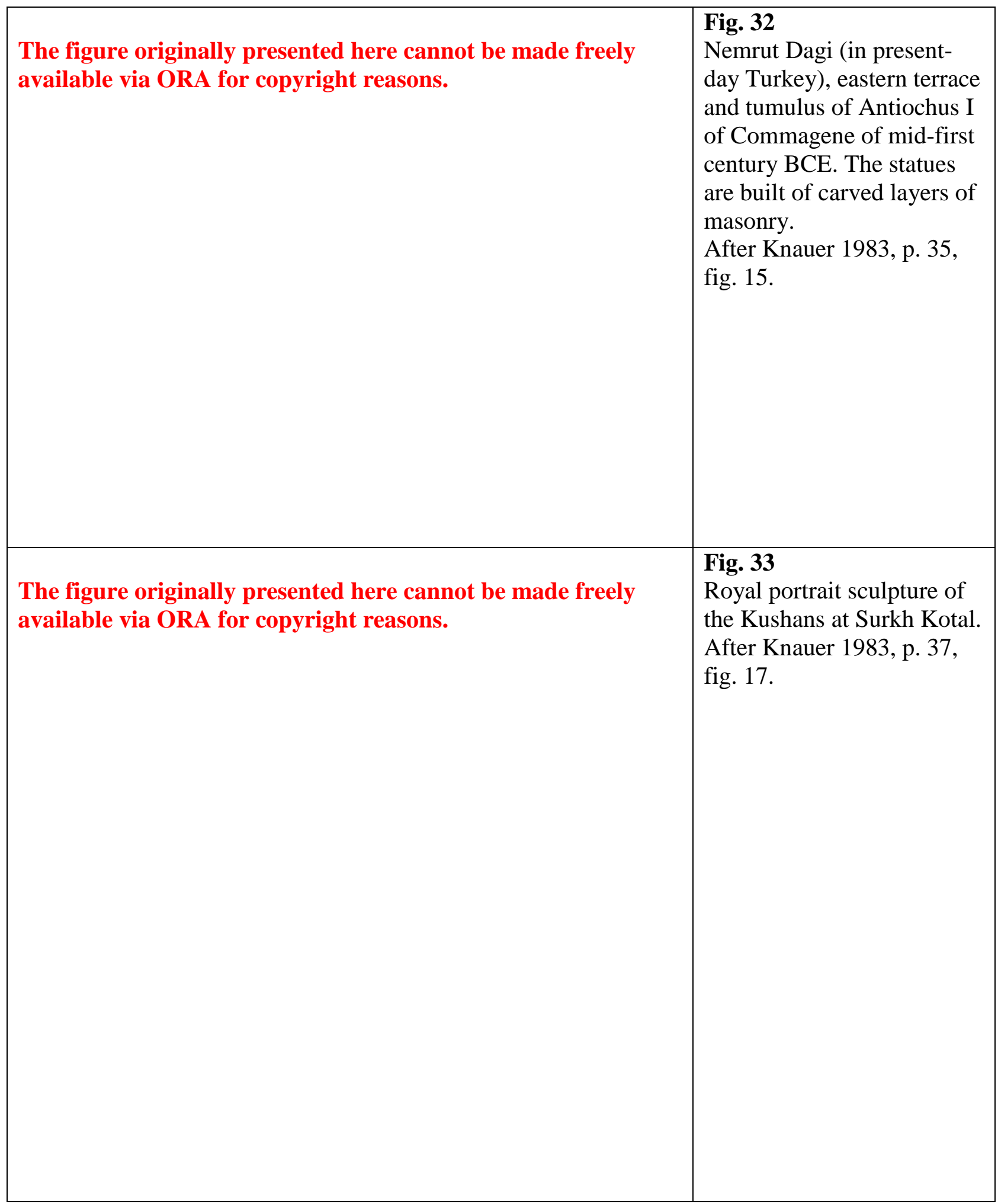


Appendix B: Figures

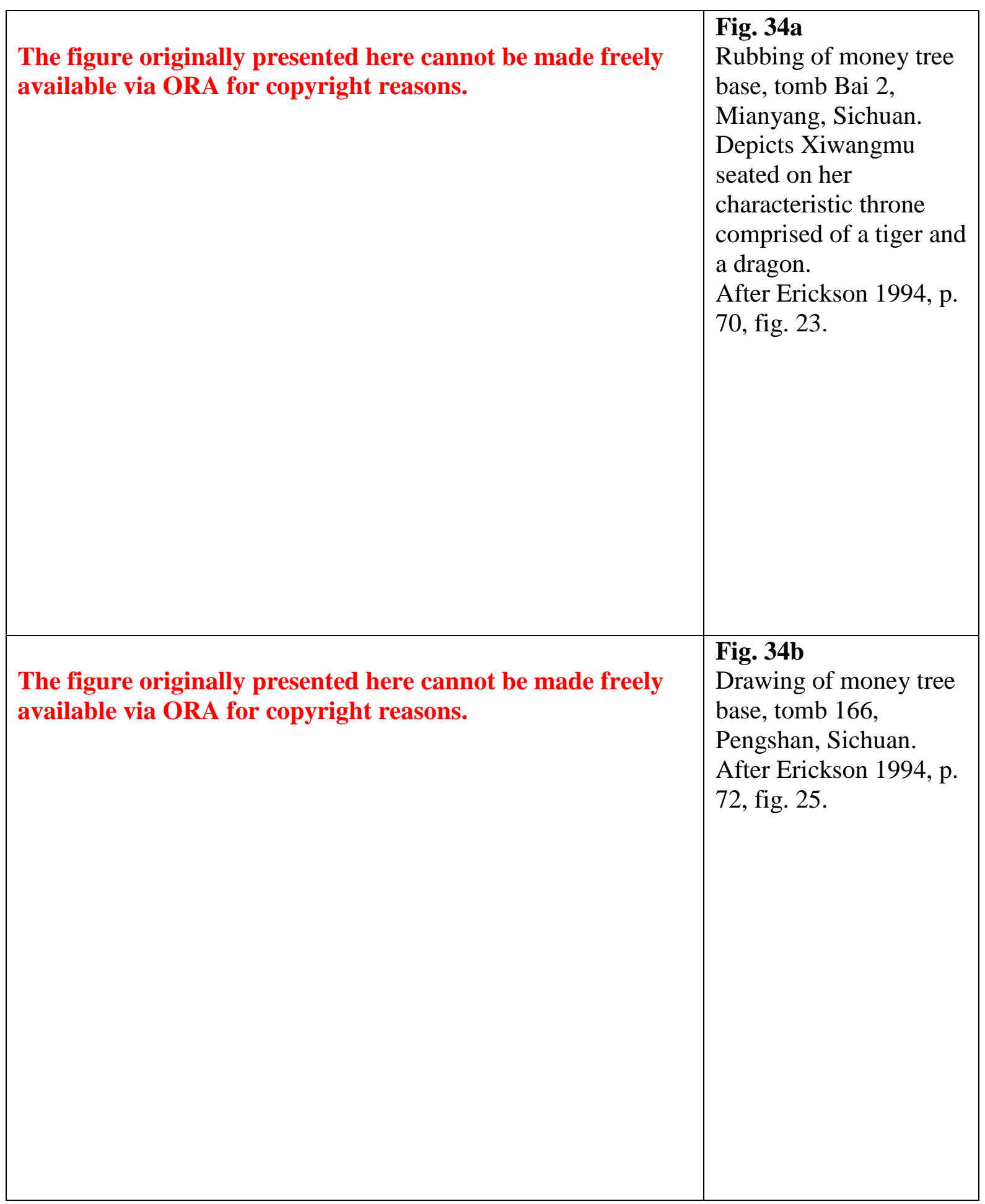




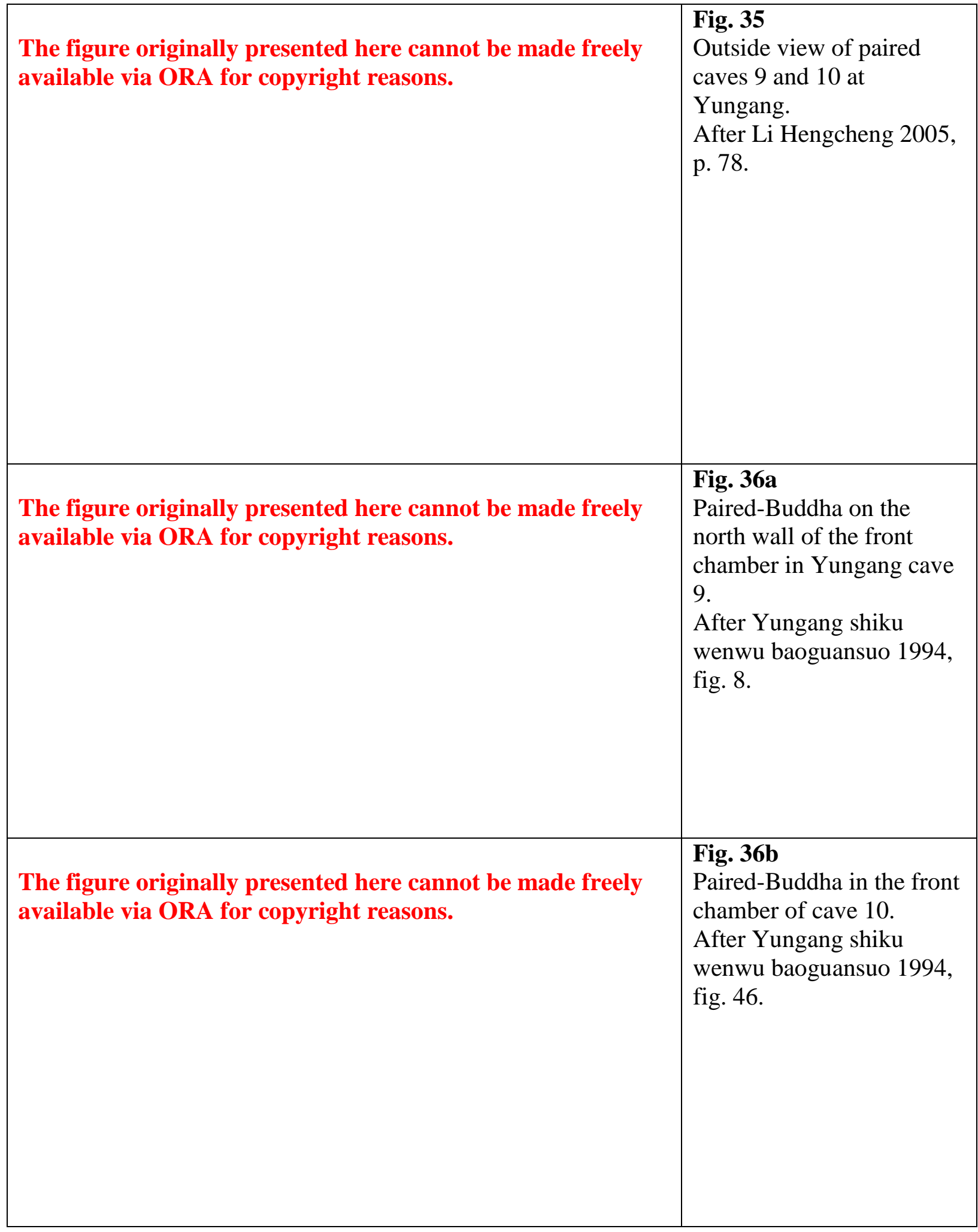




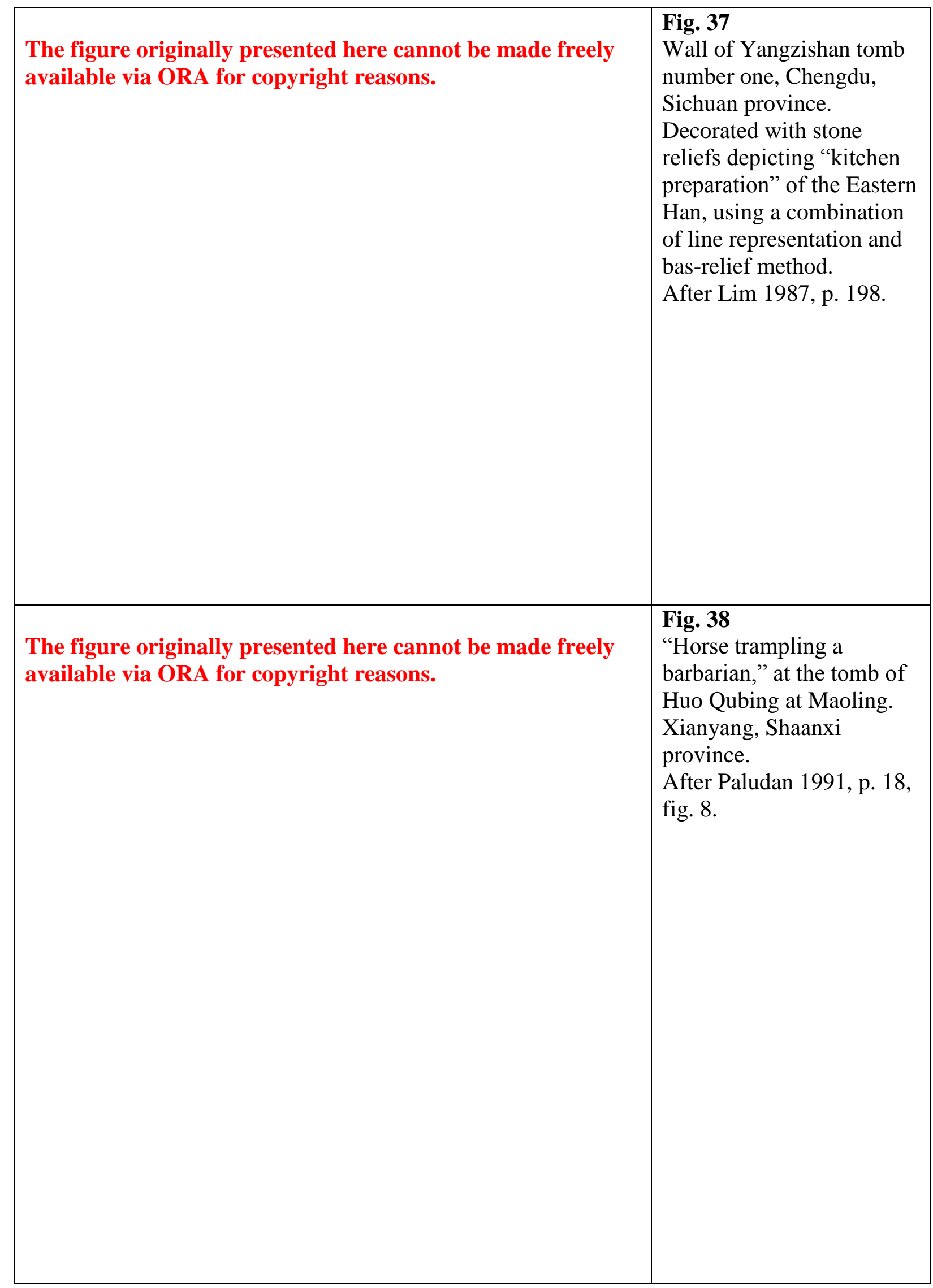


Fig. 39

Statuaries along the spirit road to tomb of Liang prince Xiao Ji (d. 529). Nanjing, Jiangsu province.

After Paludan 1991, p. 55, fig. 51.

The figure originally presented here cannot be made freely available via ORA for copyright reasons.

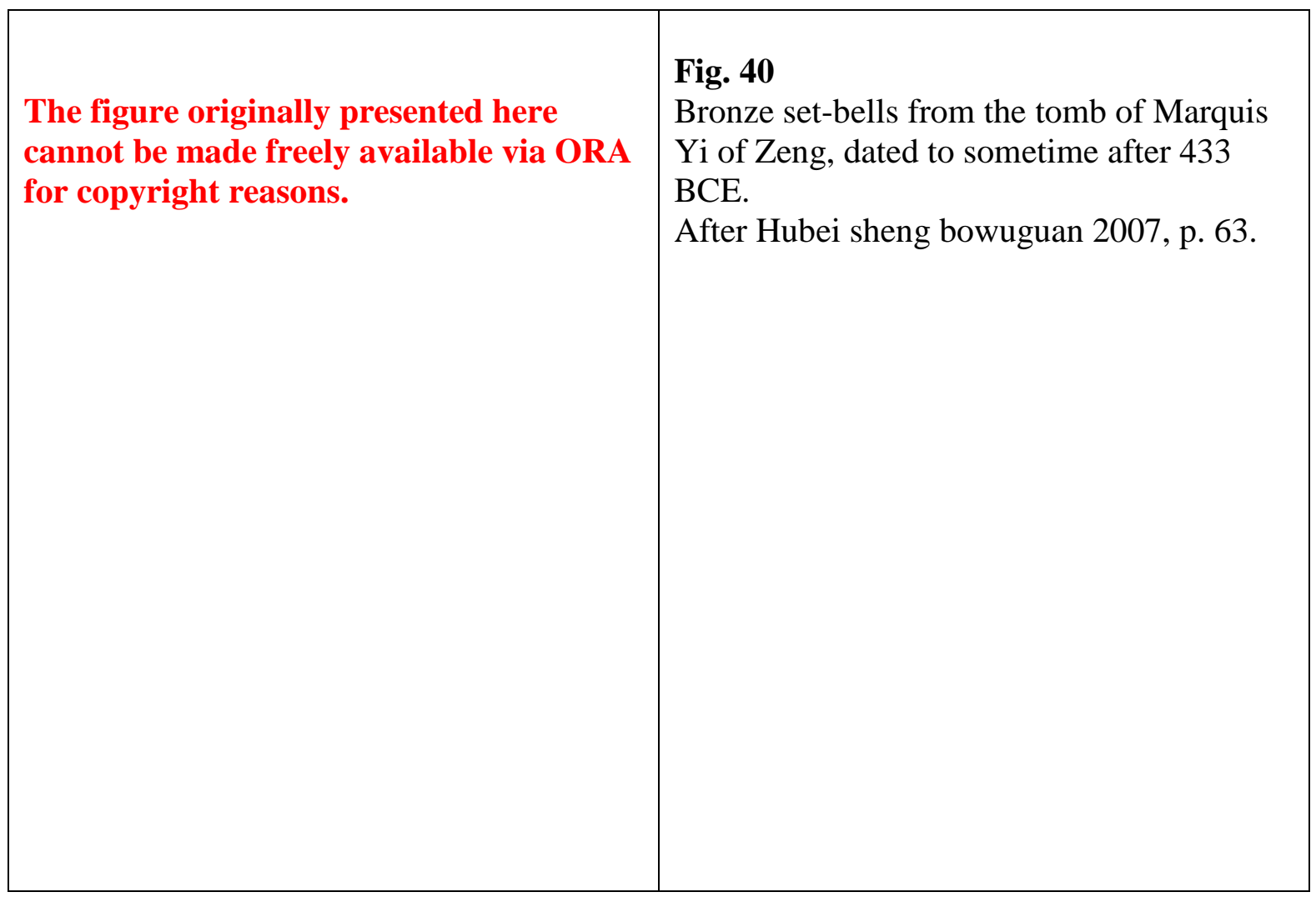


Appendix B: Figures

The figure originally presented here cannot be made freely available via ORA for copyright reasons.

Fig. 41

Map of northern China dated to 409 CE, during the Sixteen Kingdoms period. After Tan Qixiang 1982. 


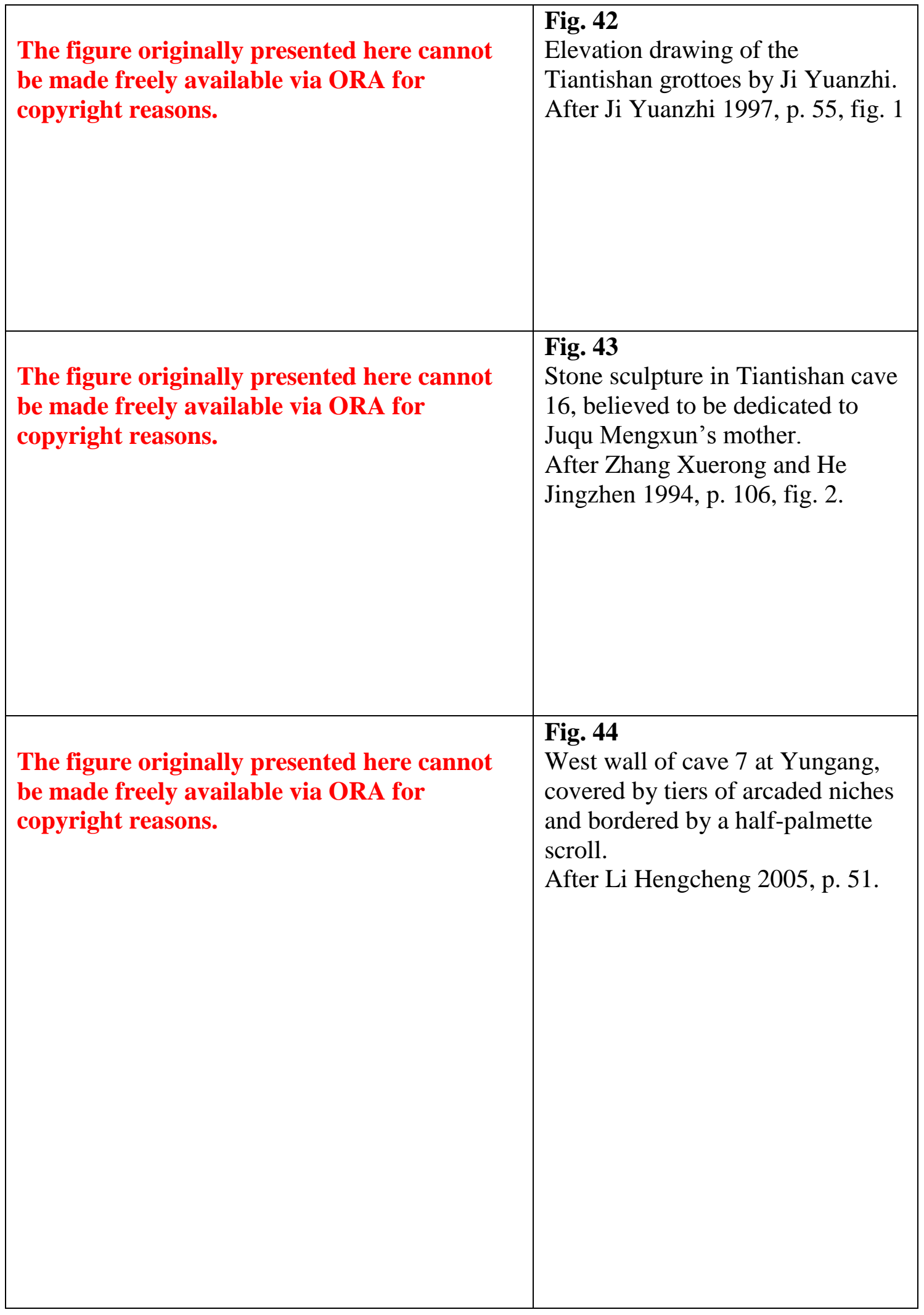


The figure originally presented here cannot be made freely available via ORA for copyright reasons.

\section{Fig. 45}

Pieces of architectural wood-carving decorated in Gandhara style, from ruined Buddhist shrine, Lop-nor site.

After Stein 1912, fig. 122.

The figure originally presented here cannot be made freely available via ORA for copyright reasons.

The figure originally presented here cannot be made freely available via ORA for copyright reasons.

The figure originally presented here cannot be made freely available via ORA for copyright reasons.

\section{Fig. 46a}

Border of palmettes on a running stem, on a hydria. Athens, dated to 510-500 BCE.

After Rawson 1984, p. 215.

\section{Fig. 46b}

Door jamb slate. Gandhara, dated to third century CE. After Rowland 1965, p. 122.

\section{Fig. 46c}

Half-palmette borders below the Buddha's niche on the north wall of the front chamber in Yungang cave 10 .

After Yungang shiku wenwu baoguansuo 1994, vol. 1, fig. 50. 
Appendix B: Figures

The figure originally presented here cannot be made freely available via ORA for copyright reasons.

Fig. 47a

Lacquer peeling from the Shaling tomb.

After Datong shi kaogu yanjiusuo 2006a, fig. 20.

The figure originally presented here cannot be made freely

\section{Fig. 47b}

Stone pillar base from the available via ORA for copyright reasons.

Sima Jinlong tomb. After

Shanxi sheng Datong shi bowuguan and Shanxi sheng wenwu gongzuo weiyuanhui 1972 , plate 14, fig. 4.

\section{Fig. 47c}

The figure originally presented here cannot be made freely Stone coffin bed from the available via ORA for copyright reasons. Song Shaozu tomb. After Datong shi kaogu yanjiusuo 2008 , plate 63 , fig. 1 


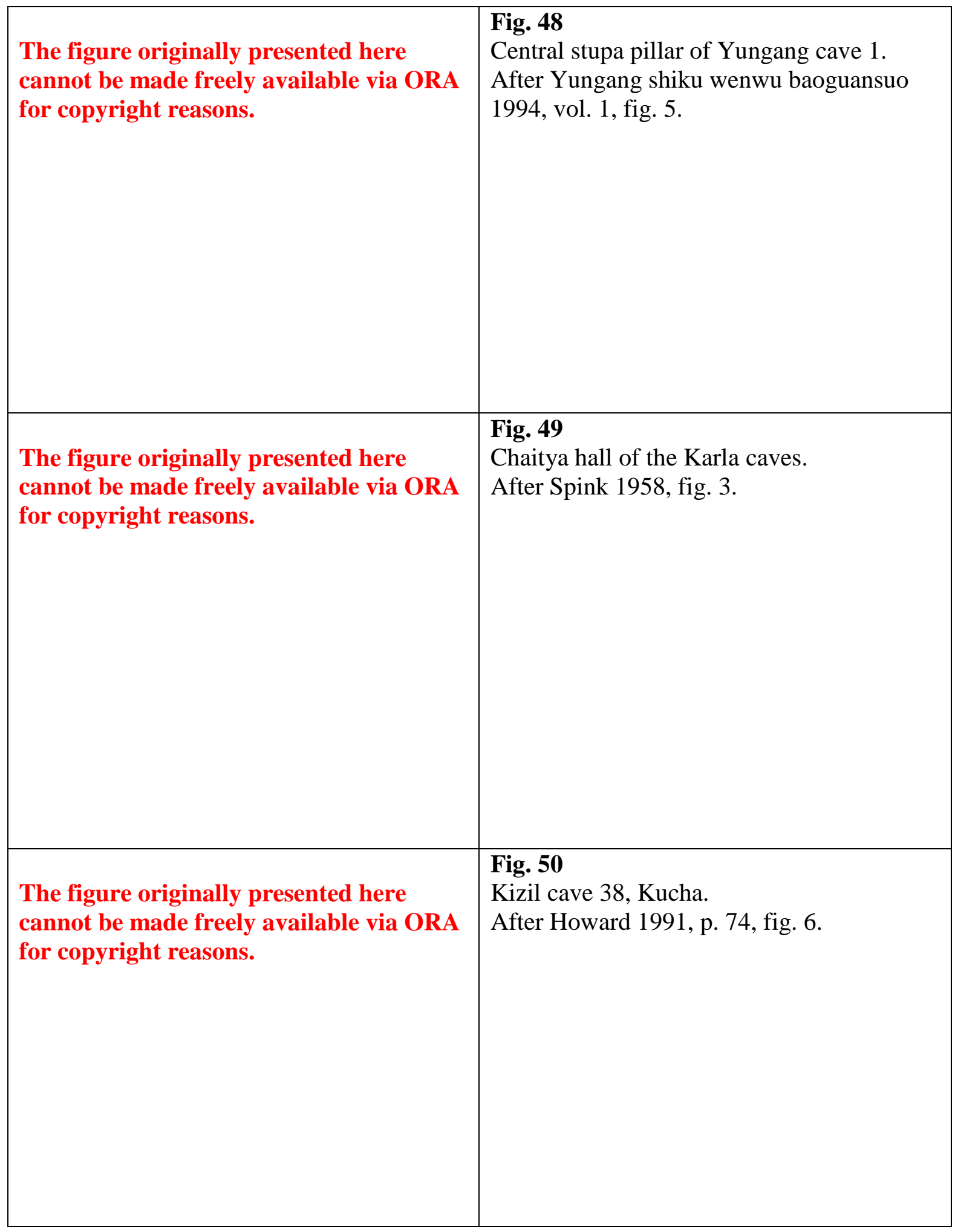


Appendix B: Figures

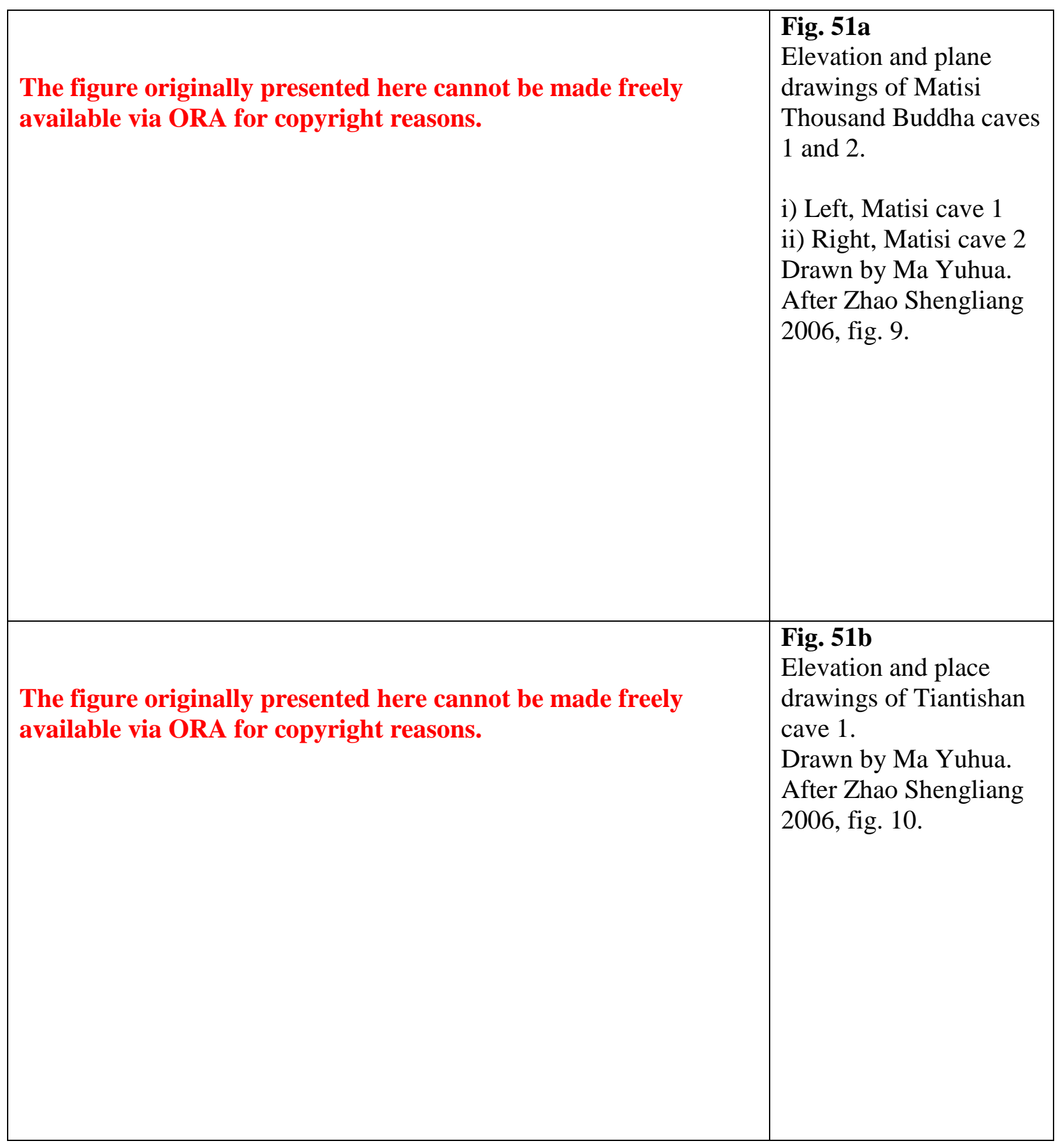




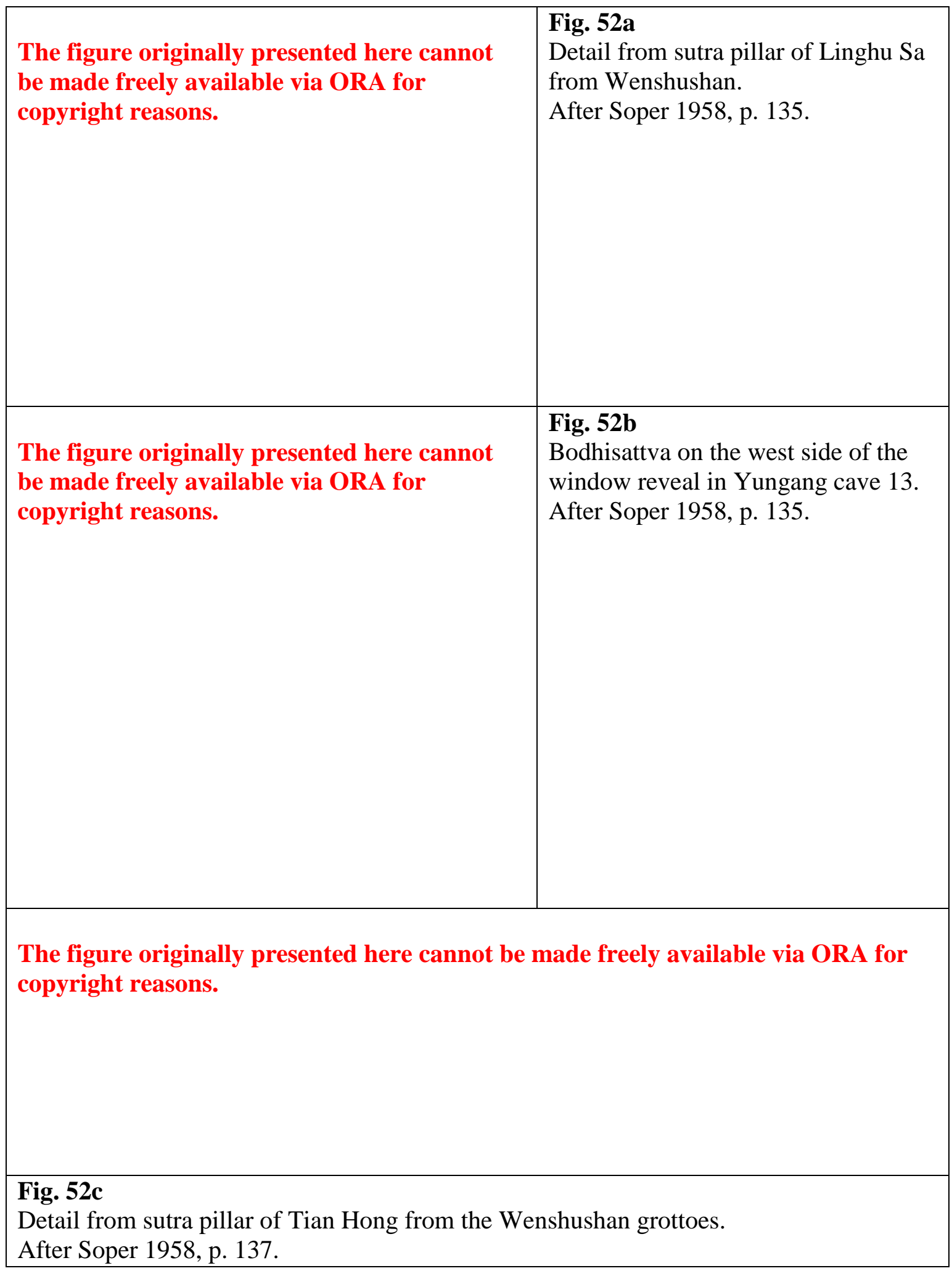


Appendix B: Figures

The figure originally presented here cannot be made freely

Fig. 53a available via ORA for copyright reasons.

South wall of Yungang cave 6 . After Li Hengcheng 2005.

\section{Fig. 53b}

The figure originally presented here cannot be made freely available via ORA for copyright reasons.

West wall of Yungang cave 9.

After Li Hengcheng 2005. 
Appendix B: Figures

Fig. 54

Map of Northern Wei and neighbors as of 449 CE. After Tan Qixiang 1982.

The figure originally presented here cannot be made freely available via ORA for copyright reasons. 
Appendix B: Figures

The figure originally presented here cannot be made freely available via ORA for copyright reasons.

\section{Fig. 55a}

Mural painting of the tomb occupant seated as a couple on the east wall of Shaling M7. After Datong shi kaogu yanjiusuo 2006a, p. 19. 
Appendix B: Figures

The figure originally presented here cannot be made freely available via ORA for copyright reasons.

Figs. 55b, c

b) Top, campsite banquet on the south wall of Shaling M7.

c) Bottom, military procession on the north wall of Shaling M7.

After Datong shi kaogu yanjiusuo 2006a, pp. 16, 19.

The figure originally presented here cannot be made freely available via ORA for copyright reasons. 
The figure originally presented here cannot be made freely available via ORA for copyright reasons.

\section{Fig. 56a}

Mural painting of the tomb occupant seated as a couple (only a corner of the lady's gown remains visible) on the east wall of Yunbolilu M1.

After Datong shi kaogu yanjiusuo 2011b, p. 17.

The figure originally presented here cannot be made freely available via ORA for copyright reasons.

Fig. 56b

East wall of Yunbolilu M1.

After Datong shi kaogu yanjiusuo 2011b, p. 21. 
The figure originally presented here cannot be made freely available via ORA for copyright reasons.

Figs. 57a, b, c, d

Drawings of the Zhijiabao sarcophagus murals painted on the inside of the wall panels. a) Top: north wall; b) Center left: west wall; c) Center right: east wall; d) Bottom: south wall After Wang Yintian and Liu Junxi 2001, p.43.

The figure originally presented here cannot be made freely available via ORA for copyright reasons.

The figure originally presented here cannot be made freely available via ORA for copyright reasons.

The figure originally presented here cannot be made freely available via ORA for copyright reasons. 
Appendix B: Figures

The figure originally presented here cannot be made freely available via ORA for copyright reasons.

Fig. 58

Figurine set of Yanbei Shiyuan M5, in Datong Museum, Shanxi province.

After Datong shi kaogu yanjiusuo 2008, color plate 50. 
The figure originally presented here cannot be made freely available via ORA for copyright reasons.

Fig. 59

a) Top, stone sarcophagus of Yanbei Shiyuan M5.

After Datong shi kaogu yanjiusuo 2008, color plate 51.

Bottom left and right, drawings of the stone sarcophagus in b) profile and c) birds-eye view.

After Datong shi kaogu yanjiusuo 2008, pp. 78, 83.

The figure originally presented here cannot be made freely available via ORA for copyright reasons.
The figure originally presented here cannot be made freely available via ORA for copyright reasons. 
The figure originally presented here cannot be made freely available via ORA for copyright reasons.

Fig. 60

Drawing of the Zhijiabao M1 sarcophagus.

After Wang Yintian and Liu Junxi 2001, p. 41.

The figure originally presented here cannot be made freely available via ORA for copyright reasons.
The figure originally presented here cannot be made freely available via ORA for copyright reasons.

\section{Fig. 61}

Drawings of the Yuchi Dingzhou M1 sarcophagus, in front and profile view.

After Datong shi kaogu yanjiusuo 2011a, pp. 8-9. 
The figure originally presented here cannot be made freely available via ORA for copyright reasons.

\section{Fig. 62}

Horizontal section drawing of Shaling M7.

After Datong shi kaogu yanjiusuo 2006a, p. 7.

The figure originally presented here cannot be made freely available via ORA for copyright reasons.

Fig. 63

Profile drawing of Shaling M7.

After Datong shi kaogu yanjiusuo 2006a, p. 7. 
The figure originally presented here cannot be made freely available via ORA for copyright reasons.

Fig. 64a, b

a) Top, mural banquet scene in the Dahuting M2 brick-and-stone chamber tomb, Mixian, Henan province.

b) Bottom, relief carvings on the walls of Dahuting M1 brick-and-stone chamber tomb, Mixian, Henan province.

After Henan sheng wenwu yanjiusuo 1993, color plate 43 of Dahuting M2 and plate 30 of Dahuting M1.

The figure originally presented here cannot be made freely available via ORA for copyright reasons. 
Appendix B: Figures

The figure originally presented here cannot be made freely available via ORA for copyright reasons.

\section{Fig. 65}

Rubbing of a relief carving depicting exemplar stories in the Yinan stone chamber tomb, Shandong province.

After Zeng Zhaoyu, Jiang Baogeng and Li Zhongyi 1956, plate 53. 
The figure originally presented here cannot be made freely available via ORA for copyright reasons.

Fig. 66

Drawing of the mural bricks lining the east wall of the front chamber of Jiayuguan Xincheng M5, Gansu province. Drawing by Zheng Yan.

After Zheng Yan 2002, p. 150.

The figure originally presented here cannot be made freely available via ORA for copyright reasons.

Fig. 67

Drawing of the mural bricks depicting a banquet scene in Jiayuguan Xincheng M6, Gansu province.

After Guo Yongli 2008, p. 83. 
The figure originally presented here cannot be made freely available via ORA for copyright reasons.

Fig. 68

Rubbing from Jiaxiang, Shandong province.

After Zhu Xilu 1992, fig 62.

The figure originally presented here cannot be made freely available via ORA for copyright reasons.

Fig. 69

Mural bricks depicting two separate banquet scenes for the men and the women in Jiayuguan Xincheng M5, Gansu province.

After Jiayuguan shi wenwu guanlisuo 1985, plate 58. 
The figure originally presented here cannot be made freely available via ORA for copyright reasons.
The figure originally presented here cannot be made freely available via ORA for copyright reasons.

\section{Figs. 70a, b}

a) Left, rubbing of three stone slabs stacked together to form an image with several registers. From the pillar-gate at Wuzhaishan, Jiaxiang, Shandong province.

After Barbieri-Low 2007, p. 95. Photo courtesy of Shandong Fine Arts Publishing House.

b) Right, rubbing of a pictorial stone relief from Xuzhou, Jiangsu province After Jiangsu sheng wenwu guanli weiyuanhui 1959, fig 73.

The figure originally presented here cannot be made freely available via ORA for copyright reasons.

\section{Fig. 71}

Infrastructural section of Dingiazha M5, depicting the entire pictorial scheme with the use of three registers across the walls.

After Wu Hung 2010, p. 34. 
Appendix B: Figures

The figure originally presented here cannot be made freely available via ORA for copyright reasons.

Fig. 72

Relief carving of a Buddha at the center flanked by Vimalakirti (right) and Manjusri (left), the bodhisattva of wisdom.

After Li Zhiguo 1999, p. 63. 


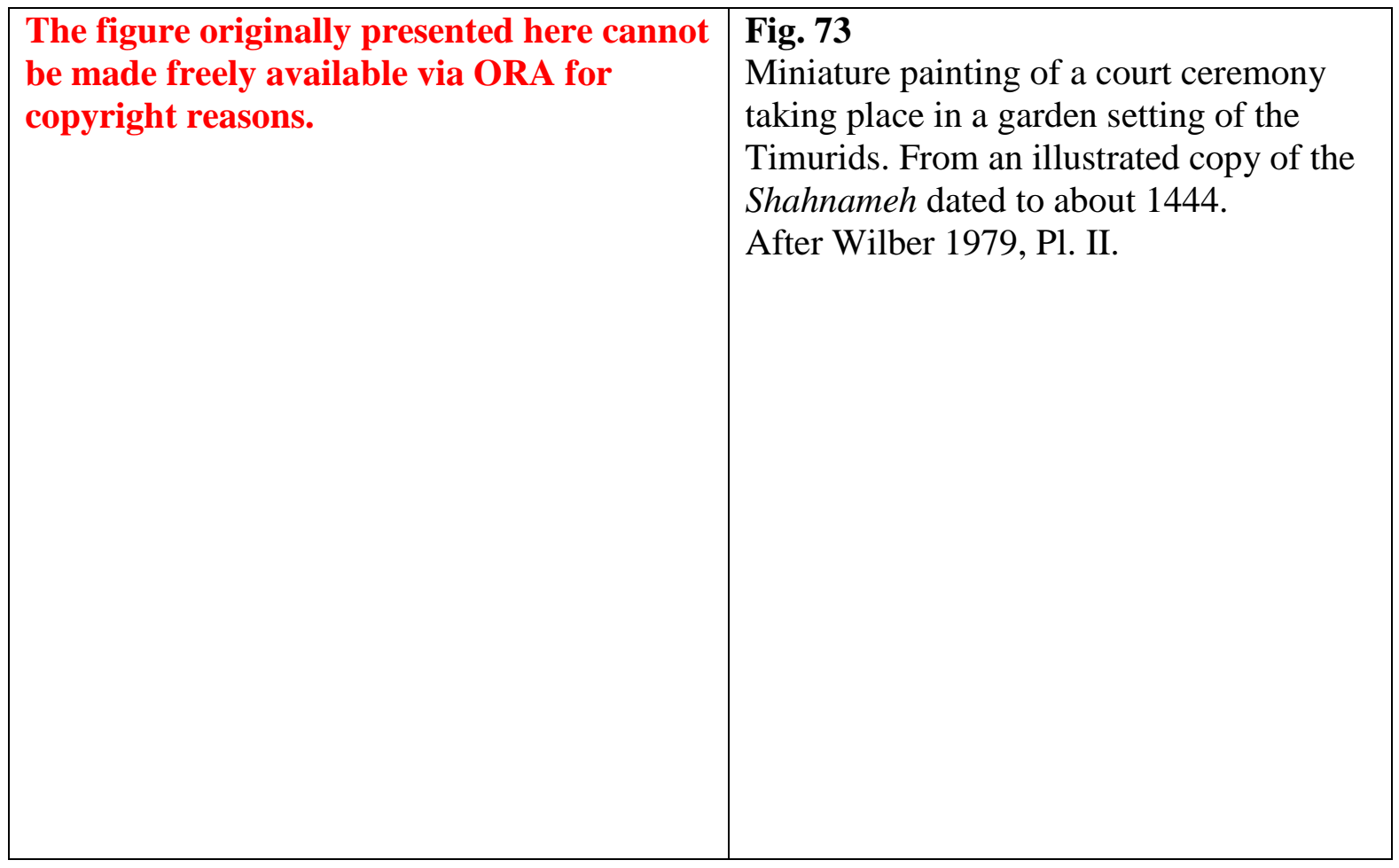

The figure originally presented here cannot be made freely available via ORA for copyright reasons.

\section{Fig. 74}

Miniature painting of the Mughal emperor Shah Jahan seated in his court tent which is pitched in front of the Hall of Private Audience at Delhi. Dated to around 1648. After Andrews 1987, p. 162, fig. 12. 
The figure originally presented here cannot be made freely available via ORA for copyright reasons.

Fig. 75

Close up of the butcher scene on the south wall of Shaling M7.

After Datong shi kaogu yanjiusuo 2006a, p. 20.

The figure originally presented here cannot be made freely available via ORA for copyright reasons.

\section{Fig. 76}

Drawing of the mural painted on one of the wooden coffin boards in Zhijiabao M2.

After Liu Junxi and Gao Feng 2004, p. 44, fig. 15. 
The figure originally presented here cannot be made freely available via ORA for copyright reasons.

\section{Fig. 77}

Clay figurine of what appears to be a yurt cart from Yanbei Shiyuan M5.

After Datong shi kaogu yanjiusuo 2008, color plate 95.

The figure originally presented here cannot be made freely available via ORA for copyright reasons.

\section{Fig. 78}

Close up of the drummers and other musicians at the front of the military procession. After Datong shi kaogu yanjiusuo 2006a, p. 18, fig. 37. 
The figure originally presented here cannot be made freely available via ORA for copyright reasons.
The figure originally presented here cannot be made freely available via ORA for copyright reasons.

\section{Fig. 79}

Close up of horseman and foot soldier on the north wall of Shaling M7. After Datong shi kaogu yanjiusuo 2006a, p. 18.

The figure originally presented here cannot be made freely available via ORA for copyright reasons.

\section{Fig. 80}

Rubbing of a stone relief from the west wall of the shrine at Xiaotangshan, Shandong province, depicting the battle between Han forces and those of the northern $h u$ nomadic tribes, dated to the Eastern Han, ca. 76-88 CE.

After Barbieri-Low 2007, pp. 176-177, fig. 5.8. 
The figure originally presented here cannot be made freely available via ORA for copyright reasons.

\section{Fig. 81}

Fuxi and Nüwa painted onto the underside of the arch above the tomb corridor.

After Datong shi kaogu yanjiusuo 2006a, p. 21.

The figure originally presented here cannot be made freely available via ORA for copyright reasons.

Fig. 82

Horizontal section and profile views of Yanbei Shiyuan M5.

After Datong shi kaogu yanjiusuo 2008, p. 72. 
The figure originally presented here cannot be made freely available via ORA for copyright reasons.

\section{Fig. 83}

Horizontal section view of Yanbei Shiyuan M5 tomb chamber with indications of the figurine distribution.

After Datong shi kaogu yanjiusuo 2008, p. 74.

\begin{tabular}{|l|l|}
\hline $\begin{array}{l}\text { The figure originally presented here } \\
\text { cannot be made freely available via } \\
\text { ORA for copyright reasons. }\end{array}$ & $\begin{array}{l}\text { Fig. 84 } \\
\text { Epitaph brick of Yanbei Shiyuan M5, } \\
\text { introducing the tomb occupant to be Song } \\
\text { Shaozu from the Dunhuang commandery, and } \\
\text { dating the tomb to } 477 \text { CE. } \\
\text { After Datong shi kaogu yanjiusuo 2008, color } \\
\text { plate 65. }\end{array}$ \\
\end{tabular} \mid




\begin{tabular}{|l|l|l|}
\hline $\begin{array}{l}\text { The figure originally } \\
\text { presented here cannot be } \\
\text { made freely available via } \\
\begin{array}{l}\text { ORA for copyright } \\
\text { reasons. }\end{array}\end{array}$ & $\begin{array}{l}\text { The figure originally } \\
\text { presented here cannot be } \\
\text { made freely available via } \\
\text { ORA for copyright } \\
\text { reasons. }\end{array}$ & $\begin{array}{l}\text { Fig. 85 } \\
\text { Front and back of the clay } \\
\text { figurine of a female attendant } \\
\text { wearing the "distinctive Xianbei } \\
\text { gear," in Yanbei Shiyuan M5, } \\
\text { Datong, Shanxi province. } \\
\text { After Datong shi kaogu } \\
\text { yanjiusuo 2008, color plate 85. }\end{array}$ \\
& & \\
& & \\
& & \\
&
\end{tabular}

The figure originally presented here cannot be made freely available via ORA for copyright reasons.

Fig. 86

Front, profile and back view of a flag bearer figurine, with chin-straps.

After Datong shi kaogu yanjiusuo 2008, p. 143. 


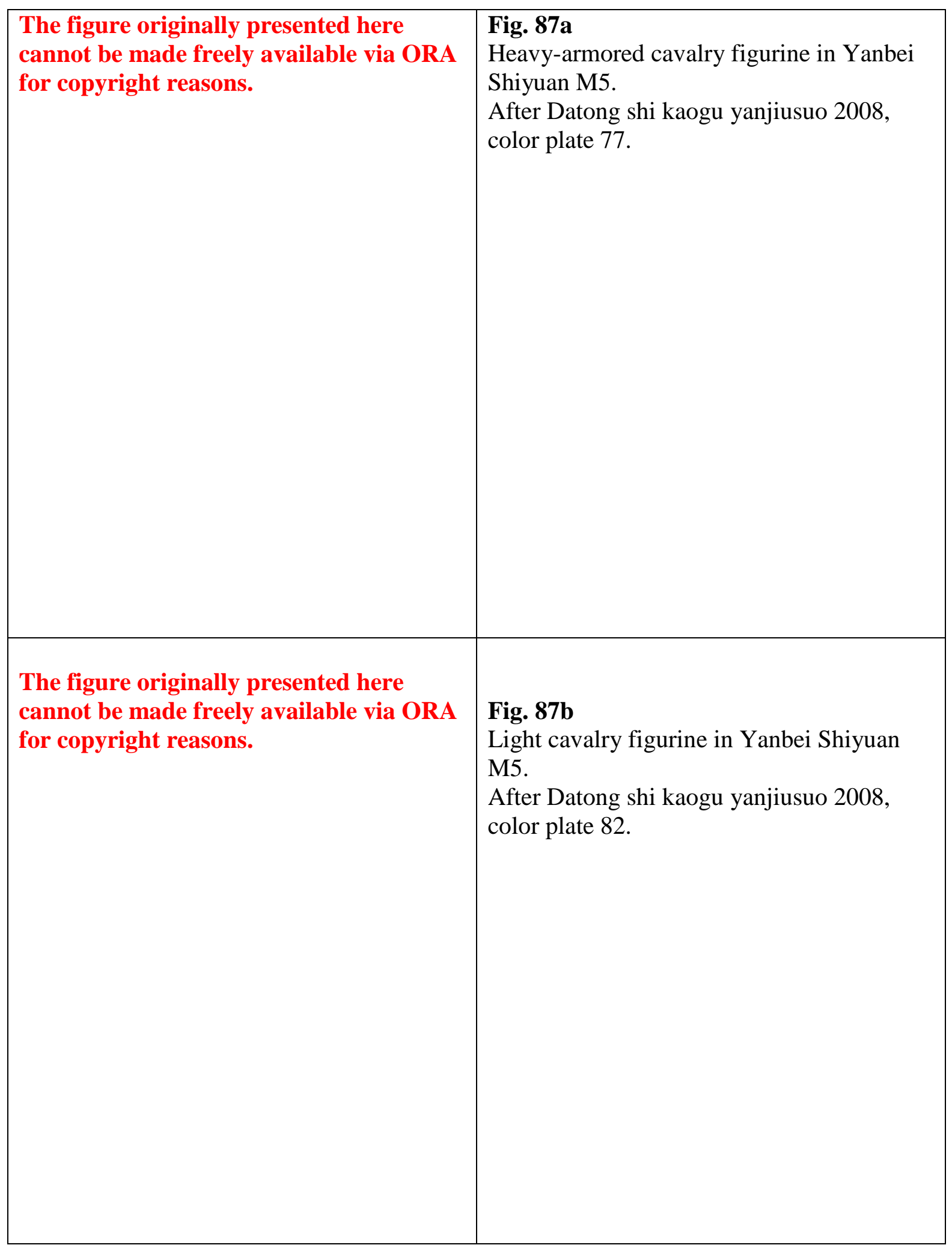


Appendix B: Figures

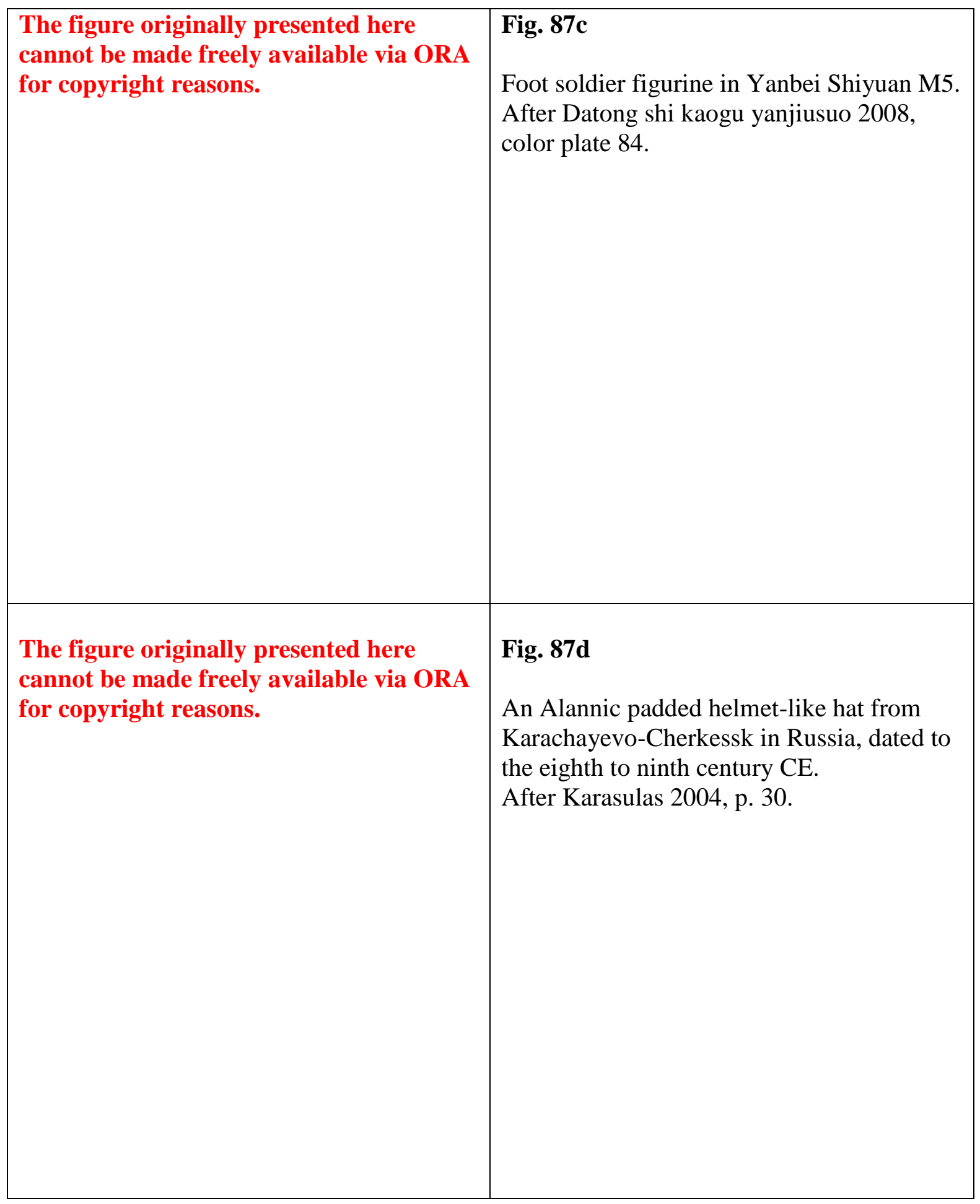


Appendix B: Figures

The figure originally presented here cannot be made freely available via ORA for copyright reasons.

Fig. 88

Terracotta warriors of the First Emperor Qin Shihuang at Lishan, Shaanxi province.

After Michaelson 2010, p. 41. 
The figure originally presented here cannot be made freely available via ORA for copyright reasons.

\section{Fig. 89a}

Drawing of a stone sarcophagus carved out of a solid block of stone from the Tuogouzui cliff tomb at Leshan, Sichuan province. Shown in three perspectives.

After Luo Erhu 2000, p. 32.

The figure originally presented here cannot be made freely available via ORA for copyright reasons.

Fig. 89b

Sarcophagus of the Mourning Women, date to the fourth century BCE. At the Archaeological Museum, Istanbul.

After Rawson 1984, p.43, fig. 18. 
The figure originally presented here cannot be made freely available via ORA for copyright reasons.

Fig. 90a

Roman stone sarcophagus with engraved columns, niches framed by moulding, and a halfopened door with a female figure hurrying out of it.

After Haarlov 1977, fig. 37.

The figure originally presented here cannot be made freely available via ORA for copyright reasons.

Fig. 90b

Drawings of the images depicted on all sides of the stone sarcophagus, found in Wang Hui's brick-chamber tomb at Shiyangshangcun, Lushan county, Sichuan province. Dated to $211 \mathrm{CE}$ in the Eastern Han.

After Luo Erhu 2000, p. 42. 


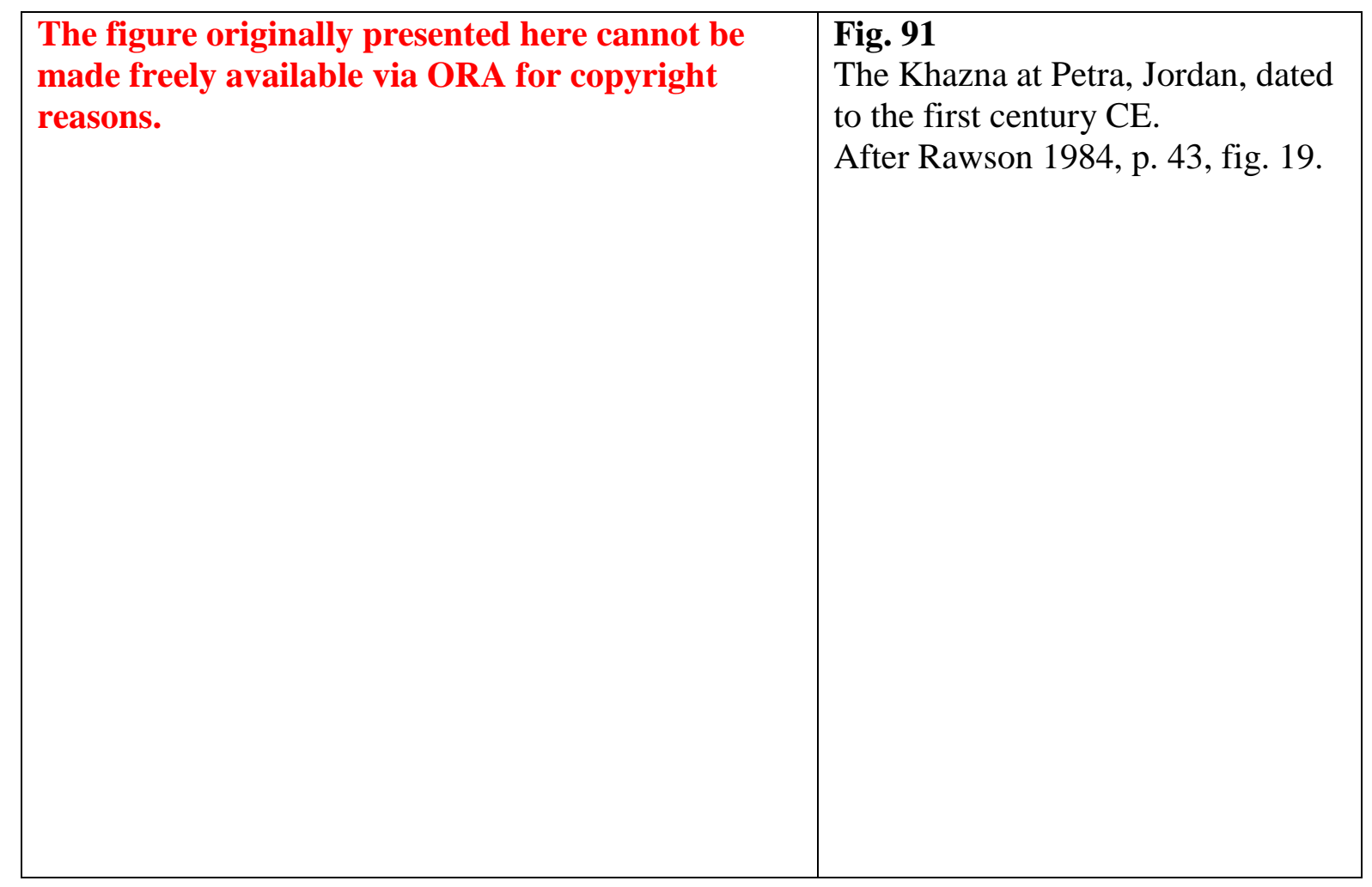

The figure originally presented here cannot be made freely available via ORA for copyright reasons.

\section{Fig. 92}

The Bimaran religuary from Gandhara, dated to the second to the third centuries, in the British Museum collection.

After Rawson 1984, p. 49. 
The figure originally presented here cannot be made freely available via ORA for copyright reasons.

\section{Fig. 93a}

Drawing of the arcade design that decorates the side of the Bimaran reliquary.

After Rowland 1946, fig. 4.

The figure originally presented here cannot be made freely available via ORA for copyright reasons.

Fig. 93b

The arcade reliefs of an early Christian stone sarcophagus, in the Musee Lapidaire, Arles. After Rowland 1946, fig. 5. 
The figure originally presented here cannot be made freely available via ORA for copyright reasons.

\section{Figs. 94a, b}

a) Top, southwestern coffin bed leg panel from Yanbei Shiyuan M5.

b) Bottom, southeastern coffin bed leg panel from Yanbei Shiyuan M5, with three decorative images highlighted in red. From left to right: animal combat, beast's face, and palmette.

After Datong shi kaogu yanjiusuo 2008, color plates 62, 63.

The figure originally presented here cannot be made freely available via ORA for copyright reasons.

The figure originally presented here cannot be made freely available via ORA for copyright reasons.

\section{Fig. 95}

A bronze openwork belt-buckle plaque depicting two mythological raptors attacking two tigers joined at the shoulder. Attributed to southern Siberia, dated to the third to second century BCE. In the Eskenazi collection, London.

After Bunker 2002, p. 102, fig. 70. 


\begin{tabular}{|c|c|}
\hline $\begin{array}{l}\text { The figure originally presented here cannot be made freely } \\
\text { available via ORA for copyright reasons. }\end{array}$ & $\begin{array}{l}\text { Fig. 96a } \\
\text { Drawing of the mural } \\
\text { on the inside of the } \\
\text { north wall of Yanbei } \\
\text { Shiyuan M5 } \\
\text { sarcophagus. Two } \\
\text { musicians, one } \\
\text { playing a qin and the } \\
\text { other playing a ruan. } \\
\text { After Datong shi } \\
\text { kaogu yanjiusuo } \\
2008, \text { p. 129, fig. } \\
\text { 132. }\end{array}$ \\
\hline $\begin{array}{l}\text { The figure originally presented here cannot be made freely } \\
\text { available via ORA for copyright reasons. }\end{array}$ & $\begin{array}{l}\text { Fig. } 96 \mathbf{b} \\
\text { Drawing of the mural } \\
\text { on the inside of the } \\
\text { west wall (on the } \\
\text { south end) of Yanbei } \\
\text { Shiyuan M5 } \\
\text { sarcophagus. Three } \\
\text { male dancers, } \\
\text { holding some sort of } \\
\text { jingles in their hands. } \\
\text { After Datong shi } \\
\text { kaogu yanjiusuo } \\
2008, \text { p. 129, fig. } \\
133 .\end{array}$ \\
\hline $\begin{array}{l}\text { The figure originally presented here cannot be made freely } \\
\text { available via ORA for copyright reasons. }\end{array}$ & $\begin{array}{l}\text { Fig. 96c } \\
\text { Drawing of the mural } \\
\text { on the inside of the } \\
\text { west wall (on the } \\
\text { north end) of Yanbei } \\
\text { Shiyuan M5 } \\
\text { sarcophagus. Two } \\
\text { male dancers, one is } \\
\text { leaping in mid-air } \\
\text { while the other lies } \\
\text { face-up on the floor. } \\
\text { After Datong shi } \\
\text { kaogu yanjiusuo } \\
\text { 2008, p. 130, fig. } \\
\text { 134. }\end{array}$ \\
\hline
\end{tabular}


Appendix B: Figures

The figure originally presented here cannot be made freely available via ORA for copyright reasons.

Fig. 97

Drawing of the layout of the four side slabs (only three has carved depictions) of the stone sarcophagus in the Wanzhai tomb of Xuzhou, Jiangsu province, dated to late Western Han (202 BCE - 9CE).

After Xin Lixiang 2000, p. 205. 
The figure originally presented here cannot be made freely available via ORA for copyright reasons.

\section{Fig. 98}

Drawing of a stone panel relief from the sarcophagus in the tomb of Yu Hong, in Taiyuan, Shanxi province.

After Shanxi sheng kaogu yanjiusuo, Taiyuan shi kaogu yanjiusuo and Taiyuan shi Jinyuan qu wenwu lüyouju 2001, p. 37, fig. 19. 
The figure originally presented here cannot be made freely available via ORA for copyright reasons.

Figs. 99a, b

a) Top, view of the front chamber of the tomb of Wang Chuzhi.

b) Bottom, landscape screen painted on the rear wall of the front chamber.

After Hebei sheng wenwu yanjiusuo 1998, plate 13:2.

The figure originally presented here cannot be made freely available via ORA for copyright reasons. 
The figure originally presented here cannot be made freely available via ORA for copyright reasons.

\section{Figs. 100a, b}

Top, surface of an impressed tile from Lintong, Shaanxi province, with deer, dogs and mounted archers in pursuit. Dated to the Qin dynasty.

Bottom, pattern on a Han silk fabric unearthed at Loulan (present-day Xinjiang province), with a rider wearing the distinctive headgear of a nomad, displayed amidst animals in both realistic and fantastic forms against a mountainous background.

After Jacobson 1985, p. 162, figs. 1, 2.

The figure originally presented here cannot be made freely available via ORA for copyright reasons. 
Appendix B: Figures

The figure originally presented here cannot be made freely available via ORA for copyright reasons.

Fig. 101

Fengxiansi sculpture assemblage at the Longmen grottoes, Luoyang, Henan province.

After Longmen grottoes official website.

http://www.longmen.com 
The figure originally presented here cannot be made freely available via ORA for copyright reasons.

Figs. 102a, b

a) Top, external view of the Gaxian Cave in the Daxing'an Mountains, Elunhchun Autonomous Banner, Neimenggu province.

After Mi Wenping 1981, p. 1.

b) Bottom, rubbing of the cave inscription.

After Ji Faxi 1985, p. 73.

The figure originally presented here cannot be made freely available via ORA for copyright reasons. 


\section{Appendix C: Bibliography}

\section{Chinese Primary Sources}

\section{Bei Qi shu}

Li Baiyao 李百藥 (565-648). Bei Qi shu 北齊書, 50 juan, 636 CE. Beijing: Zhonghua shuju, 1972.

\section{Bei shi}

Li Yanshou 李延壽 (ca. $7^{\text {th }}$ century). Bei shi 北史, 100 juan, 659 CE. Beijing: Zhonghua shuju, 1974.

\section{Fayuan zhulin}

Shi Daoshi 釋道世 $(?-683)$. Fayuan zhulin 法苑珠林, 100 juan, 668 CE. Beijing: Zhonghua shuju, 2003.

\section{Gaoseng zhuan}

Hui Jiao 慧盿 (497-554). Gaoseng zhuan 高僧傳, 14 juan, 519 CE. Beijing: Zhonghua shuju, 1992.

\section{Guanzi}

Liu Xiang 劉向 (77-6 BCE) edt. Guanzi 管子, 86 juan, 26 BCE. Translated from Chinese by Zhai Jiangyue 翟江月 in the Library of Chinese Classics series, vol. 3. Guilin: Guangxi Shifan daxue chubanshe, 2005.

Guang hongming ji (T.52, no.2103)

Shi Daoxuan 釋道宣 (596-667). Guang hongming ji 廣弘明集, 30 juan, early $7^{\text {th }}$ century. Collected in the Taisho Tripitaka 大正新修大正藏經, vol. 52, no. 2103.

\section{Han shu}

Ban Gu 班固 (32-92) et al. Han shu 漢書, 120 juan, early $2^{\text {nd }}$ century. Beijing: Zhonghua shuju, 1962.

\section{Hou Han shu}

Fan Ye 范曄 (398-445) et al. Hou Han shu 後漢書, 90 juan, 445 CE. Beijing: Zhonghua shuju, 1965.

\section{Kaogongji}

Kaogongji 考工記, in Guanzhong congshu 關中叢書, vol. 6, juan 1-2. 


\section{Miaofa lianhua jing (T.9, no.262)}

Translated from Sanskrit into Chinese by Kumarajiva 鳩摩羅什 (343/344-413 CE). Miaofa lianhua jing 妙法蓮華經. Collected in the Taisho Tripitaka 大正新修大正藏經, vol. 9, no. 262.

\section{Nan Qi shu}

Xiao Zixian 蕭子顯 (487-537). Nan Qi shu 南齊書, 59 juan, 509-519 CE. Beijing: Zhonghua shuju, 1972.

\section{Nan shi}

Li Yanshou 李延壽 (ca. $7^{\text {th }}$ century). Nan shi 南史, 80 juan, 659 CE. Beijing: Zhonghua shuju, 1975.

\section{Shi ji}

Sima Qian 司馬遷 (145 BCE - ?). Shi ji 史記, 130 juan, ca. 91 BCE. Beijing: Zhonghua shuju, 1959.

\section{Shuijing zhu}

Li Daoyuan 麗道元 (470-527). Shui jing zhu 水經注, 40 juan, early $6^{\text {th }}$ century. Annotated by Chen Qiaoyi 陳橋驛. Hangzhou: Zhejiang guji chubanshe, 2000.

\section{Shuijing zhu tu}

Yang Shoujing 楊守敬 (1839-1915). Shuijing zhu tu 水經注圖, 1905 CE. Taipei: Wenhai Press, 1966.

\section{Song shu}

Shen Yue 沈約 (441-513). Song shu 宋書, 100 juan, 488 CE. Beijing: Zhonghua shuju, 1974.

\section{Sui shu}

Wei Zheng 魏征 (580-643) et al. Sui shu 隋書, 85 juan, 636 CE. Beijing: Zhonghua shuju, 1973.

\section{Taiping yulan}

Li Fang 李昉 (925-996) et al. Taiping yulan 太平御覽, 1000 juan, 983 CE. Beijing: Zhonghua shuju, 1960.

\section{Wei shu}

Wei Shou 魏收 (505-572). Wei shu 魏書, 114 juan, 554 CE. Beijing: Zhonghua shuju, 1974.

\section{Wen xuan}

Xiao Tong 蕭統 (501-531) edt. Wen xuan 文選, 30 juan, 522 CE. Annotated by Li Shan 李善 (630-689). Beijing: Zhonghua shuju, 1990.

\section{Yu Zishan ji}

Yu Xin 座信 (513-581). Yu Zhishan ji 庵子山集, 16 juan, late $6^{\text {th }}$ century. Collected in the Sibu congkan 四部叢刊. Shanghai: Shangwu yinshuguan, 1929. 


\section{Yuefu shiji}

Guo Maoqian 郭茂倩 (1041-1099). Yuefu shiji 樂府詩集, 100 juan, late $11^{\text {th }}$ century.

Beijing: Zhonghua shuju, 1979.

\section{Yushi jiaozhu}

Ye Changzhi 葉昌熾 (1849-1917). Yushi jiaozhu 語石校注, 10 juan, early $20^{\text {th }}$ century. Annotated by Han Rui 韓銳. Beijing: Jinri Zhongguo chubanshe, 1995.

\section{Zizhi tongjian}

Sima Guang 司馬光 (1019-1086) et al. Zizhi tongjian 資治通鋻, 294 juan, 1084 CE. Beijing: Zhonghua shuju, 1956.

\section{Chinese Language Sources}

\section{Bo Juncai 2010}

Bo Juncai 柏俊才. “Ping Liang hu yu Bei Wei ruxue de fuxing” 平涼戶與北魏儒學的復 興, Lanzhou xuekan 蘭州學刊 2010.10, pp. 164-167.

\section{Cao Chenming 2004}

Cao Chenming 曹臣明. “Pingcheng kaogu ruogan diaocha cailiao de yanjiu yu tantao" 平 城考古若干調查材料的研究與探討, Wenwu shijie 文物世界 2004.4, pp. 9-12.

\section{Chen Gengling and Ma Qinglin 2002}

Chen Gengling 陳庚齡 and Ma Qinglin 馬清林. “Jiuquan Dingjiazha wuhao bihuamu xianzhuang diaocha” 酒泉丁家閘五號壁畫墓現狀調查, Sciences of Conservation and Archaeology 文物保護與考古科學 14:1(2002), pp. 23-28.

\section{Chen Yinque 1954}

Chen Yinque 陳寅恪. Sui Tang zhidu yuanyuan luelun gao 隋唐制度淵源略論稿. Beijing: Sanlian shudian, 1954.

\section{Chen Youbing 1996}

Chen Youbing 陳友冰. Liang Han Nan-Bei chao yuefu jianshang 兩漢南北朝樂府鑑賞. Taipei: Wunan tushu chuban youxiangongsi, 1996.

\section{Cui Dayong 1997}

Cui Dayong 崔大庸. “Shuangrushan yihao Hanmu yihao mache de fuyuan yu yanjiu” 雙 乳山一號漢墓一號馬車的復原與研究, Kaogu 考古 1997.3, pp. 208-218.

\section{Datong shi bowuguan 1989}

Datong shi bowuguan 大同市博物館. “Datong dongjiao Bei Wei Yuan Shu mu” 大同東 郊北魏元淑墓, Wenwu 文物 1989.8, pp. 57-65. 


\section{Datong shi bowuguan 2007}

Datong shi bowuguan 大同市博物館, “Datong Bei Wei Fangshan Siyuan fosi yizhi fajue baogao”大同北魏方山思遠佛寺遺址發掘報告, Wenwu 文物 2007.4, pp. 4-26.

\section{Datong shi bowuguan and Ma Yuji 1983}

Datong shi bowuguan 大同市博物館 and Ma Yuji 馬玉基. “Datong shi Xiaozhancun Huagetatai Bei Wei mu qingli jianbao” 大同市小站村花圪塔台北魏墓清理簡報, Wenwu 文物 1983.8, pp. 1-4.

Datong shi bowuguan and Shanxi sheng wenwu gongzuo weiyuanhui 1978

Datong shi bowuguan 大同市博物館 and Shanxi sheng wenwu gongzuo weiyuanhui 山西 省文物工作委員會, “Datong Fangshan Bei Wei Yongguling”大同方山北魏永固陵, Wenwu 文物 1978.7, pp. 29-33.

\section{Datong shi kaogu yanjiusuo 2004}

Datong shi kaogu yanjiusuo 大同市考古研究所. “Shanxi Datong Xiashenjing Bei Wei mu fajue jianbao” 山西大同下深井北魏墓發掘簡報, Wenwu 文物 2004.6, pp. 29-34.

\section{Datong shi kaogu yanjiusuo 2006a}

Datong shi kaogu yanjiusuo 大同市考古研究所, “Shanxi Datong Shaling Bei Wei bihu mu fajue jianbao” 山西大同沙嶺北魏壁畫墓發掘簡報, Wenwu 文物 2006.10, pp. 4-24.

\section{Datong shi kaogu yanjiusuo 2006b}

Datong shi kaogu yanjiusuo 大同市考古研究所. “Shanxi Datong Qilicun Bei Wei muqun fajue jianbao” 山西大同七里村北魏墓群發掘簡報, Wenwu 文物 2006.10, pp. 25-49.

\section{Datong shi kaogu yanjiusuo 2006c}

Datong shi kaogu yanjiusuo 大同市考古研究所. “Shanxi Datong Yingbin dadao Bei Wei muqun”山西大同迎賓大道北魏墓群, Wenwu 文物 2006.10, pp. 50-71.

\section{Datong shi kaogu yanjiusuo 2008}

Datong shi kaogu yanjiusuo 大同市考古研究所. Datong Yanbei shiyuan Bei Wei muqun 大同雁北師院北魏墓群, edt. Liu Junxi 劉俊喜. Beijing: Wenwu chubanshe, 2008.

\section{Datong shi kaogu yanjiusuo 2011a}

Datong shi kaogu yanjiusuo 大同市考古研究所. “Shanxi Datong Yanggao Bei Wei Yuchi Dingzhou mu fajue jianbao” 山西大同陽高北魏尉遲定州墓發掘簡報, Wenwu 文物 2011.12, pp. 4-12.

\section{Datong shi kaogu yanjiusuo 2011b}

Datong shi kaogu yanjiusuo 大同市考古研究所. “Shanxi Datong Yunboli lu Bei Wei bihua mu fajue jianbao” 山西大同雲波里路北魏壁畫墓發掘簡報, Wenwu 文物 2011.12, pp. 13-25. 


\section{Datong shi kaogu yanjiusuo 2011c}

Datongshi kaogu yanjiusuo 大同市考古研究所. “Shanxi Datong Wenyinglu Bei Wei bihuamu fajue jianbao” 山西大同文瀛路北魏壁畫墓發掘簡報, Wenwu 文物 2011.12, pp. 26-36.

\section{Du Doucheng 2009}

Du Doucheng 杜斗城. Hexi fojiao shi 河西佛教史. Beijing: Zhongguo shehui kexue chubanshe, 2009.

\section{Feng Hanji and Zhongguo kexueyuan kaogu yanjiusuo 2002}

Feng Hanji 馮漢驥 and Zhongguo kexueyuan kaogu yanjiusuo 中國科學院考古研究所. Qian Shu Wang Jian mu fajue baogao 前蜀王建墓發掘報告. Beijing: Wenwu chubanshe, 2002.

\section{Gao Ping 1999}

Gao Ping 高平. “Tuoba Wei wang jingshi Pingcheng daguimo qianxi renkou de shuzi, yuanyin ji qi yingxiang” 拓跋魏往京師平城大規模遷徙人口的數字、原因及其影響, Beichao yanjiu 北朝研究 1999.1, pp. 62-81.

\section{Gu Hongfei 1995}

Gu Hongfei 古鴻飛. “Guanyu Bei Wei Pingcheng chengjian de chutan”關於北魏平城城 建的初探, Beichao yanjiu 北朝研究 1995.2, pp. 9-14.

\section{Guo Moruo 1936}

Guo Moruo 郭沫若. Xian-Qin tiandaoguan zhi jinzhan 先秦天道觀之進展. Shanghai: Shangwu yinshuguan, 1936.

\section{Guo Yongli 2008}

Guo Yongli 郭永利, “Hexi Wei-Jin Shiliuguo bihua mu yanyin chuxing tu de leixing ji qi yanbian” 河西魏晉十六國壁畫墓宴飲、出行圖的類型及其演變, Kaogu yu wenwu 考古 與文物 2008.3, pp. 81-86.

\section{Han Fu 2004}

Han Fu 韓府. “Luelun “Taiwu miefo' de yuanyin” 略論 “太武滅佛” 的原因, Beichao yanjiu 北朝研究 2004.4, pp. 77-87.

\section{Han Shengcun 2005}

Han Shengcun 韓生存. “Bei Wei Pingcheng mingtang yizhi de faxian ji qi yiyi” 北魏平城 明堂遺址的發現及其意義, Journal of Datong Vocational College 大同職業技術學院學 報 19.1 (2005), pp. 37, 43 .

\section{Han Shengcun, Cao Chengming and Hu Ping 1996}

Han Shengcun 韓生存, Cao Chengming 曹承明 and Hu Ping 胡平. “Datong chengnan Jinshumeichang Bei Wei muqun”大同城南金屬鎂厰北魏墓群, Beichao yanjiu 北朝研究 1996.1, pp. 60-70. 


\section{Han Yangling kaogu chenlieguan 2004}

Han Yangling kaogu chenlieguan 漢陽陵考古陳列館. Han Yangling kaogu chenlieguan 漢陽陵考古陳列館. Beijing: Wenwu chubanshe, 2004.

\section{He Yuping 2004}

He Yuping 賀玉萍. “Mulan ci chuangzuo shidai yu zuozhe zhi tanjiu” 《木蘭辭》創作時 代與作者之探究, Journal of Luoyang University 洛陽大學學報 19:1(2004), pp. 20-21.

\section{Hebei sheng wenwu yanjiusuo 1998}

Hebei sheng wenwu yanjiusuo 河北省文物研究所. Wudai Wang Chuzhi mu 五代王處直 墓. Beijing: Wenwu chubanshe, 1998.

\section{Henan sheng wenwu yanjiusuo 1986}

Henan sheng wenwu yanjiusuo 河南省文物研究所. Xinyang Chu mu 信陽楚墓. Beijing: Wenwu chubanshe, 1986.

\section{Henan sheng wenwu yanjiusuo 1993}

Henan sheng wenwu yanjiusuo 河南省文物研究所. Mixian Dahuting Han mu 密縣打虎 亭漢墓. Beijing: Wenwu chubanshe, 1993.

\section{Hu Zhuoxue and Hu Hailong 2011}

Hu Zhuoxue 胡卓學 and Hu Hailong 胡海龍. “Mulan shi shidai kaolun” 《木蘭詩》時代 考論, Journal of Chinese Verse Studies 中國韻文學刊 25:3(2011), pp. 7-13.

\section{Huang Xiaofen 2003}

Huang Xiaofen 黃曉芬. Hanmu de kaoguxue yanjiu 漢墓的考古學研究. Changsha: Yueli shushe, 2003.

\section{Huang Zhanyue 1960}

Huang Zhanyue 黃展岳. “Han Chang'an cheng nanjiao lizhi jianzhu de weizhi ji qi youguan wenti” 漢長安城南郊禮制建築的位置及其有關問題, Kaogu 考古 1960.9, pp. 53-58.

\section{Huang Zhanyue and Zhang Jianmin 1960}

Huang Zhanyue 黃展岳 and Zhang Jianmin 張建民. “Han Chang'an cheng nanjiao lizhi jianzhu yizhi xue fajue jianbao” 漢長安城南郊禮制建築遺址學發掘簡報, Kaogu 考古 1960.7, pp. 36-39.

\section{Hubei sheng bowuguan 2007}

Hubei sheng bowuguan 湖北省博物館. Tomb of Marquis Yi of Zeng: Ritual-and-music Civilization in the Early Warring States Period 曾侯乙墓-戰國早期的禮樂文明. Beijing: Wenwu chubanshe, 2007.

\section{Hui Fuping and Wang Siming 2005}

Hui Fuping 惠富平 and Wang Siming 王思明. “Han dai xibei nongyequ kaituo jiqi shengtai huanjing yingxiang” 漢代西北農業區開拓及其生態環境影響, Gujin nongye 古 今農業 2005.1, pp. 80-85. 
Appendix C: Bibliography

\section{Ji Faxi 1985}

Ji Faxi 吉發習. “Gaxian dong diaocha buji” 嘎仙洞調查補記, Neimenggu Shida xuebao 内蒙古師大學報 1985.1, pp. 71-78.

\section{Ji Yuanzhi 1997}

Ji Yuanzhi 暨遠志. “Wuwei Tiantishan zaoqi shiku fenqi shilun” 武威天梯山早期石窟分 期試論, Dunhuang yanjiu 敦煌研究 1997.1, pp. 42-56.

\section{Jia Wenli 2010}

Jia Wenli 賈文麗. “Han chao zai Hexi de fangyu yu zhanlue yanbian” 漢朝在河西的防禦 與戰略演變, Nandu xuetan 南都學墰 30:4(2010), pp. 5-11.

\section{Jiayuguan shi wenwu guanlisuo 1985}

Jiayuguan shi wenwu guanlisuo 嘉峪關市文物管理所. Jiayuguan bihuamu fajue baogao 嘉峪關壁畫墓發掘報告. Beijing: Wenwu chubanshe, 1985.

\section{Jiang Yingju and Yang Aiguo 2001}

Jiang Yingju 蔣英炬 and Yang Aiguo 楊愛國. Handai huaxiangshi yu huaxiangzhuan 漢 代畫像石與畫像塼. Beijing: Wenwu chubanshe, 2001.

\section{Jiangsu sheng wenwu guanli weiyuanhui 1959}

Jiangsu sheng wenwu guanli weiyuanhui 江蘇省文物管理委員會. Jiangsu Xuzhou Han huaxiangshi 江蘇徐州漢畫像石. Beijing: Kexue chubanshe, 1959.

\section{Kang Le 1995}

Kang Le 康樂. Cong xijiao dao nanjiao: Guojia jidian yu Bei Wei zhengzhi 從西郊到南 郊: 國家祭典與北魏政治. Taipei: Daohe chubanshe, 1995.

\section{Leshan shi yamu bowuguan 1993}

Leshan shi yamu bowuguan 樂山市崖墓博物館. “Sichuan Leshan shi Tuogouzui Dong Han yamu qingli jianbao” 四川樂山市沱溝嘴東漢崖墓清理簡報, Wenwu 文物 1993.1, pp. 40-50.

\section{Li Gaocai, Yin Xian and Gao Ping 1990}

Li Gaocai 力高才, Yin Xian 殷憲 and Gao Ping 高平. “Bei Wei Pingcheng jingji diming kaoshi (xia)” 北魏平城京畿地名考釋 (下), Beichao yanjiu 北朝研究 1990.3, p. 115.

\section{Li Hai, Hou Junhai and Zhang Lanying 1996}

Li Hai 李海, Hou Junhai 侯峻梅 and Zhang Lanying 張蘭英. “Bei Wei Pingcheng mingtang chubu yanjiu” 北魏平城明堂初步研究, Science, Technology and Dialectics 科 學技術與辯證法 13.5 (1996), pp. 35-37.

\section{Li Hengcheng 2005}

Li Hengcheng 李恆城. Yungang shiku yu Bei Wei shidai 云岡石窟與北魏時代. Taiyuan: Shanxi kexue jishu chubanshe, 2005. 


\section{Li Ping 2000}

Li, Ping 李馮. Bei Wei Pingcheng shidai 北魏平城時代. Beijing: Shehui kexue wenxian chubanshe, 2000.

\section{Li Qingling 2009}

Li Qingling 李清淩, "Wei-Jin Shiliuguo Beichao xibei ge zhengquan de rencai xingguo" 魏晉十六国北朝西北各政權的人才興国, The Silk Road 絲綢之路 2009.18, pp. 23-28.

\section{Li Xueqin and Li Lifen 2006}

Li Xueqin 李雪芹 and Li Lifen 李立芬. Jiedu Yungang 解讀云岡. Beijing: Xueyuan chubanshe, 2006.

\section{Li Zhiguo 1999}

Li Zhiguo 李治國, edt. Yungang shiku 雲崗石窟. Beijing: Renmin Zhongguo chubanshe, 1999.

\section{Lin Chaomin 2005}

Lin Chaomin 林超民. “Han zu yimin yu Yunnan tongyi” 漢族移民與雲南統一, Yunnan minzu daxue xuebao 雲南民族大學學報 22:3(2005), pp. 106-113.

\section{Lin Lüzhi 1967}

Lin Lüzhi 林旅芝. Xianbei shi 鮮卑史. Hong Kong: Zhonghua wenhua shiye gongsi, 1967.

\section{Lin Shengzhi 2010}

Lin Shengzhi 林聖智. “Zhongguo zhonggu shiqi de muzang kongjian yu tuxiang” 中國中 古時期的墓葬空間與圖像, in Yan Juanying edt., Zhongguoshi xinlun - meishu yu kaogu fence 中國史新論 --- 美術與考古分冊 (Taipei: Lianjing chubangongsi, 2010), pp. 143202.

\section{Lin Shiwei 2009}

Lin Shiwei 林世偉. “Bei Wei Chaishan gong de weizhi yu gongyong kaoxi” 北魏豺山宮 的位置與功用考析, Shidi yanjiu 史地研究 2009.12, pp. 1-18.

\section{Lin Wo 2007}

Lin Wo 林斡. Dong Hu shi 東胡史. Hohhot: Neimenggu renmin chubanshe, 2007.

\section{Liu Jingcheng 1995}

Liu Jingcheng 劉精誠. “Bei Wei Xiaowendi shiqi de Han hua zhengce”北魏孝文帝時期 的漢化政策, Beichao yanjiu 北朝研究 1995.2, pp. 58-71.

\section{Liu Junxi and Gao Feng 2004}

Liu Junxi 劉俊喜 and Gao Feng 高峰. “Datong Zhijiabao Bei Wei muguan banhua” 大同 志家堡墓棺板畫, Wenwu 文物 2004.12, pp. 35-47.

\section{Liu Junxi and Zhang Zhizhong 2001}

Liu Junxi 劉俊喜 and Zhang Zhizhong 張志忠. “Datong shi Bei Wei Song Shaozu mu fajue jianbao”大同市北魏宋紹祖墓發掘簡報, Wenwu 文物 2001.7, pp. 19-39. 


\section{Liu Kangle and Han Lin 2008}

Liu Kangle 劉康樂 and Han Lin 韓琳. “Bei Wei zongjiao guanli tizhi chutan.” 北魏宗教 管理體制初探, Zongjiao xue yanjiu 宗教學研究 2008.3, pp. 198-200.

\section{Liu Xueyao 1994}

Liu Xueyao 劉學銚. Xianbei shi lun 鮮卑史論. Taipei: Nantian shuju, 1994.

\section{Liu Zhiyuan 1958}

Liu Zhiyuan 劉志遠. “Chengdu Tianhuishan yamu qingli ji” 成都天回山崖墓清理記, Kaogu xuebao 考古學報 1958.1, pp. 87-103.

\section{Lu Kanru and Feng Yuanjun 1968}

Lu Kanru 陸㑆如 and Feng Yuanjun 馮沅君. Zhongguo shishi 中國詩史. Hong Kong: Guwen shuju, 1968.

\section{Lu Qingfu 1994}

Lu Qingfu 陸慶夫. “Wu Liang fojiao ji qi dong chuan”五涼佛教及其東傳, Dunhuang xue jikan 敦煌學輯刊 1994.1, pp. 8-18.

\section{Lu Yaodong 2006}

Lu Yaodong 逯耀東. Cong Pingcheng dao Luoyang 從平城到洛陽. Beijing: Zhonghua shuju, 2006.

\section{Luan Guichuan 1995}

Luan Guichuan 戀貴川. “Bei Wei Taiwu mifo yanjiu erti” 北魏太武滅佛研究二題, Beichao yanjiu 北朝研究 1995.1, pp. 57-62.

\section{Luo Erhu 2000}

Luo Erhu 羅二虎. “Handai huaxiang shiguan yanjiu” 漢代畫像石棺研究, Kaogu xuebao 考古學報 2000.1, pp. 31-61.

\section{Lü Wenping 2007}

Lv Wenping 呂文平. “Sima Jinlong mu pingfeng qihua shangxi” 司馬金龍墓屏風漆畫賞 析, Wenwu shijie 文物世界 2007.5, pp. 38-40, 44.

\section{Ma Changshou 1962}

Ma Changshou 馬長壽. Wuhuan yu Xianbei 烏桓與鮮卑. Shanghai: Shanghai renmin chubanshe, 1962.

\section{Ma Shichang 2003}

Ma Shichang 馬世長. Kezi'er shiku zhongxinzhuku yanjiu 克孜爾石窟中心柱窟研究, in Zhongguo fojiao xueshu lundian 中國佛教學術論典, vol 85. Taiwan: Foguangshan wenjiao jijinhui, 2003.

\section{Maeda 1994}

Maeda, Masana 前田正名, Pingcheng lishi dili xue yanjiu 平城歷史地理學研究. Translated from Japanese by Li Ping et al. Beijing: Shumu wenxian chubanshe, 1994. 


\section{Mi Wenping 1981}

Mi Wenping 米文平. “Xianbei shishi de faxian yu chubu yanjiu” 鮮卑石室的發現與初步 研究, Wenwu 文物 1981.2, pp. 1-7, 99.

\section{Qin Dashu 2005}

Qin Dashu 秦大樹. “Shishu Hexi Liangzhou shiku he Yungang shiku de guanxi” 試述河 西涼州石窟和雲岡石窟的關係, in Yungang shiku wenwu yanjiusuo 雲岡石窟文物研究 所 edt. Yungang bainian lunwen xuanji (1) 雲岡百年論文選集（一) (Beijing: Wenwu chubanshe, 2005), pp. 246-250.

Qiu Yongsheng, Wei Ming, Li Xiaohui and Li Yinde 1988

Qiu Yongsheng 邱永生, Wei Ming 魏鳴, Li Xiaohui 李曉暉 and Li Yinde 李銀德. “Xuzhou Beidongshan Xi Han mu fajue jianbao" 徐州北洞山西漢墓發掘簡報, Wenwu 1988.2, pp. 2-18, 68.

\section{Ren Xianghong 1997}

Ren Xianghong 任相宏. “Shuangrushan yihao Hanmu muzhu kaolue” 雙乳山一號漢墓墓 主考略, Kaogu 考古 1997.3, pp. 202-207.

Shaanxi sheng wenguanhui, Shaanxi sheng bowuguan and Xianyang shi bowuguan Yangjiawan Han mu fajue xiaozu 1977

Shanxi sheng wenguanhui 陝西省文管會, Shaanxi sheng bowuguan 陝西省博物館 and Xianyang shi bowuguan Yangjiawan Han mu fajue xiaozu 咸陽市博物館楊家灣漢墓發 掘小組. “Xianyang Yangjiawan Han mu fajue baogao”咸陽楊家灣漢墓發掘報告, Wenwu 文物 1977.10, pp. 10-21, 95-97.

\section{Shandong daxue kaoguxi, Shandong sheng wenwuju and Changqing xian wenhuaju 1997}

Shandong daxue kaoguxi 山東大學考古係, Shandong sheng wenwuju 山東省文物句 and Changqing xian wenhuaju 長清縣文化局. “Shandong Changqing xian Shuangrushan yihao Hanmu fajue jianbao” 山東長清縣雙乳山一號漢墓發掘簡報, Kaogu 考古 1997.3, pp. 193-201, 218.

\section{Shandong wenwu kaogu yanjiusuo 1982}

Shandong wenwu kaogu yanjiusuo 山東文物考古研究所. Qufu Luguo gucheng 曲阜魯國 故城. Jinan: Qilu shushe, 1982.

Shanxi daxue lishi wenhua xueyuan, Shanxi sheng kaogu yanjiusuo and Datong shi bowuguan 2006

Shanxi daxue lishi wenhua xueyuan 山西大學歷史文化學院, Shanxi sheng kaogu yanjiusuo 山西省考古研究所 and Datong shi bowuguan 大同市博物館. Datong Nanjiao Bei Wei muqun 大同南郊北魏墓群. Beijing: Science Press, 2006. 
Appendix C: Bibliography

Shanxi sheng Datong shi bowuguan and Shanxi sheng wenwu gongzuo weiyuanhui 1972

Shanxi sheng Datong shi bowuguan 山西省大同市博物館 and Shanxi sheng wenwu gongzuo weiyuanhui 山西省文物工作委員會, “Shanxi Datong Shijiazhai Bei Wei Sima Jinlong mu” 山西大同石家寨北魏司馬金龍墓, Wenwu 文物 1972.3, pp. 20-29, 64.

\section{Shanxi sheng Datong shi kaogu yanjiusuo 2004}

Shanxi sheng Datong shi kaogu yanjiusuo 山西省大同市考古研究所. “Datong Hudong Bei Wei yihao mu”大同湖東北魏一號墓, Wenwu 文物 2004.12, pp. 26-34.

\section{Shanxi sheng kaogu yanjiusuo and Datong shi bowuguan 1992}

Shanxi sheng kaogu yanjiusuo 山西省考古研究所 and Datong shi bowuguan 大同市博物 館. “Datong Nanjiao Bei Wei muqun fajue jianbao”大同南郊北魏墓群發掘簡報, Wenwu 文物 1992.8, pp. 1-11.

Shanxi sheng kaogu yanjiusuo and Datong shi kaogu yanjiusuo 2001

Shanxi sheng kaogu yanjiusuo 山西省考古研究所 and Datong shi kaogu yanjiusuo 大同 市考古研究所. “Datong shi Bei Wei Song Shaozu mu fajue jianbao” 大同市北魏宋紹祖 墓發掘簡報, Wenwu 文物 2001.7, pp. 19-39.

Shanxi sheng kaogu yanjiusuo, Taiyuan shi wenwu kaogu yanjiusuo, and Taiyuan shi Jinyuan qu wenwu lüyouju 2005

Shanxi sheng kaogu yanjiusuo 山西省考古研究所, Taiyuan shi wenwu kaogu yanjiusuo 太原市文物考古研究所 and Taiyuan shi Jinyuan qu wenwu lüyouju 太原市晉源區文物 旅遊局. Taiyuan Sui Yu Hong mu 太原隋虞弘墓. Beijing: Wenwu chubanshe 2005.

\section{Su Bai 1977a}

Su Bai 宿白. “Shengle, Pingcheng yidai de Tuoba Xianbei Bei Wei yiji: Xianbei yiji jilu zhi yi” 盛樂、平城一帶的拓跋鮮卑北魏遺跡：鮮卑遺跡輯錄之一, Wenwu 文物 1977.5, pp. 42-54.

\section{Su Bai 1977b}

Su Bai 宿白. “Shengle, Pingcheng yidai de Tuoba Xianbei Bei Wei yiji: Xianbei yiji jilu zhi er” 盛樂、平城一帶的拓跋鮮卑北魏遺跡：鮮卑遺跡輯錄之二, Wenwu 文物 1977.11, pp. 38-46.

\section{Su Bai 1986}

Su, Bai 宿白. Liangzhou shiku yiji he “Liangzhou moshi” 涼州石窟遺跡和“涼州模式”, Kaogu xuebao 考古學報 1986.4, pp. 435-446.

\section{Su Bai 1994}

Su Bai 宿白. “Pingcheng shili de jiju he 'Yungang moshi' de xingcheng yu fazhan” 平城 實力的集聚和 “雲崗模式” 的形成與發展, Beichao yanjiu 北朝研究 1994.2-3, pp. 2347. 
Appendix C: Bibliography

\section{Sun Wei 2007}

Sun Wei 孫危. Xianbei kaoguxue wenhua yanjiu 鮮卑考古學文化研究. Beijing: Science Press, 2007.

\section{Tan Qixiang 1982}

Tan, Qixiang 譚其驤 edt. Zhongguo lishi ditu ji 中國歷史地圖集, vol 4. Shanghai: Ditu chubanshe, 1982.

\section{Tang Yongtong 2008}

Tang Yongtong 湯用娅. Han Wei liang Jin Nanbeichao fojiao shi 漢魏兩晉南北朝佛教 史. Wuhan: Wuhan daxue chubanshe, 2008.

\section{Tong Zhuchen 1981}

Tong Zhuchen 佟柱臣. “Gaxian dong Tuoba Tao zhuwen shike kao” 嘎仙洞拓跋壽祝文 石刻考, Lishi yanjiu 歷史研究 1981.6, pp. 36-42.

\section{Wang Guowei 1940}

Wang Guowei 王國維. Guantang jilin 觀堂集林. Shanghai: Shangwu yinshuguan, 1940.

\section{Wang Heng 2000}

Wang Heng 王恒. “Sima Jinlong mu: shidiao yueji yueqi yanjiu” 司馬金龍墓: 石雕樂伎 樂器研究, Wenwu shijie 文物世界 2000.5, pp. 32-35.

\section{Wang Jianshun 2006}

Wang Jianshun 王建舜. "Yungang shiku shuangku zaoxiang de shenmei wenhua yanjiu moshi, fenjie yu duicheng, hubu” 雲岡石窟雙窟造像的審美文化研究 - 模式、分解與 對稱、互補, in Yungang shiku yanjiuyuan 雲岡石窟研究院 edt. 2005 nian Yungang guoji xueshu yantaohui lunwenji (yanjiu juan) 2005 年雲岡國際學術研討會論文集（研 究卷) (Beijing: Wenwu chubanshe, 2006), pp. 722-729.

\section{Wang Jianshun 2008}

Wang Jianshun 王建舜. “Yungang shiku de wenhua pinzhi yu shenmei tedian” 雲岡石窟 的文化品質與審美特點, Dunhuang yanjiu 敦煌研究 2008.1, pp. 21-26.

\section{Wang Jianzhong 2001}

Wang Jianzhong 王建中. Han dai huaxiangshi tonglun 漢代畫像石通論. Beijing: Zijincheng chubanshe, 2001.

\section{Wang Kelin 1979}

Wang Kelin 王克林. “Bei Qi Kudi Huiluo mu” 北齊庫狄迴洛墓, Kaogu xuebao 考古學 報 1979.3, pp. 377-401.

\section{Wang Lei 2004}

Wang Lei 王否. "Xianshi de tisheng - Jiayuguan Xincheng Wei-Jin mushi bihua ticai zhong suo fanying de xianshi wenti” 現實的提升--- 嘉峪關新城魏晉墓室壁畫題材中所 
反映的現實問題, Sheji yishu (Shandong gongyi meishu xueyuan xuebao) 設計藝術（山 東工藝美術學院學報）, 2004.2, p. 24.

\section{Wang Mingke 2006}

Wang Mingke 王明珂. Hua Xia bianyuan 華夏邊緣. Beijing: Shehui kexue wenxian chubanshe, 2006.

\section{Wang Rubi 1984}

Wang Rubi 王汝㟲. Yuefu sanlun 樂府散論. Xi’an: Shaanxi renmin chubanshe, 1984.

\section{Wang Tingmei 2008}

Wang Tingmei 王婷梅. “Qianlun Xi Han Hexi sijun sheli de zhongyao xing” 淺論西漢河 西四郡設立的重要性, Chengde minzu shizhuan xuebao 承德民族師專學報 28:3(2008), pp. 34-35.

\section{Wang Yanqing 2008}

Wang Yanqing 王雁卿. “Yungang shiku de rendongwen zhuangshi” 雲岡石窟的忍冬紋 裝飾, Dunhuang yanjiu 敦煌研究 2008.4, pp. 43-48.

\section{Wang Yintian 1989}

Wang Yintian 王銀田. “Yuan Shu muzhi kaoshi - fu Bei Wei Gao Kun muzhi kao” 元淑 墓誌考釋 - 附北魏高琨墓誌考, Wenwu 文物 1989.8, pp. 66-68.

\section{Wang Yintian 2000}

Wang Yintian 王銀田. “Bei Wei Pingcheng mingtang yizhi zai yanjiu” 北魏平城明堂遺 址再研究, Beichao yanjiu 北朝研究 2000.2, p. 159.

\section{Wang Yintian, Cao Chenming and Han Shengcun 2001}

Wang Yintian 王銀田, Cao Chenming 曹臣明 and Han Shengcun 韓生存. “Shanxi Datong shi Bei Wei Pingcheng mingtang yizhi 1995 nian de fajue” 山西大同市北魏平城 明堂遺址 1995 年的發掘, Kaogu 考古 2001.3, pp. 26-34.

\section{Wang Yintian and Han Shengcun 1995}

Wang Yintian 王銀田 and Han Shengcun 韓生存. “Datong shi Qijiapo Bei Wei mu fajue jianbao”大同市齊家坡北魏墓發掘簡報, Wenwu jikan 文物季刊 1995.1, pp. 14-18.

\section{Wang Yintian and Liu Junxi 2001}

Wang Yintian 王銀田 and Liu Junxi 劉俊喜. “Datong Zhijiabao Bei Wei mu shiguo bihua” 大同智家堡墓石槨壁畫, Wenwu 文物 2001.7, pp. 40-51.

\section{Wang Yunxi 1962}

Wang Yunxi 王運熙. Yuefu shi luncong 樂府詩論叢. Beijing: Zhonghua shuju, 1962.

\section{Wu Suqin 1996}

Wu Suqin 武素琴. “Xi Han yulin shulun” 西漢羽林述論, Yindu xuekan 殷都學刊 1996.1, pp. 57-61. 
Appendix C: Bibliography

\section{Xiang Shiling 2004}

Xiang Shiling 向世陵. Zhongguo xueshu tongshi: Wei-Jin Nanbeichao juan 中國學術通 史: 魏晉南北朝卷. Beijing: Renmin chubanshe, 2004.

\section{Xie Chongguang 1990}

Xie Chongguang 謝重光. “Zhonggu fojiao siyuan wei shehui wenhua zhongxin shuo” 中 古佛教寺院為社會文化中心說, Beichao yanjiu 北朝研究 1990.3, pp. 56-65.

\section{Xin Lixiang 2000}

Xin Lixiang 信立祥. Han dai huaxiangshi zonghe yanjiu 漢代畫像石綜合研究, Beijing: Wenwu chubanshe, 2000.

\section{Xing Bingyan 1983}

Xing Bingyan 刑丙彥. “Ping Qi min yu Ping Qi hu shishi shangque” 平齊民與平齊戶試 釋商榷, Shanghai shifan daxue xuebao 上海師範大學學報, 1983.4, pp. 72-75.

\section{Xu Fuqian 1982}

Xu Fuqian 許福謙. “Ping Qi min yu Ping Qi hu shishi” 平齊民與平齊戶試釋, Beijing shiyuan xuebao 北京師院學報, 1982.4, pp. 54-62.

\section{Xu Pingfang 1981}

Xu Pingfang 徐苹芳. “Zhongguo Qin Han Wei Jin Nanbeichao shidai de lingyuan he yingyu” 中國秦漢魏晉南北朝時代的陵園和塋域, Kaogu 考古 1981.6, pp. 526-527.

\section{Xu Runqing 2011}

Xu Runqing 徐潤慶. “Cong Shaling bihuamu kan Bei Wei Pingchng shiqi de sangzang meishu” 從沙嶺壁畫墓看北魏平城時期的喪葬美術, in Wu Hung and Zheng Yan edts., Gudai muzang meishu yanjiu 古代墓葬美術研究, vol. 1 (Beijing: Wenwu chubanshe, 2011), pp. 163-190.

\section{Yang Shengzhi 1985}

Yang Shengzhi 楊生枝. Yuefu shi shi 樂府詩史. Xining: Qinghai renmin chubanshe, 1985.

\section{Yang Yimin and Tang Xiaojun 1998}

Yang Yimin 楊益民 and 唐曉軍. “Sunan xian Wenshushan shiku siyuan”肅南縣文殊山 石窟寺院, Sichou zhi lu 絲綢之路 1998.1, pp. 49-53.

\section{Yao Dali 2005}

Yao Dali 姚大力. “Lun Tuoba Xianbei bu de zaoqi lishi - du Weishu xuji” 論拓跋鮮卑部 的早期歷史 - 讀《魏書・序紀》, Fudan Journal (Social Sciences) 復旦學報（社會科學 版） 2005.2 , pp. 19-27.

\section{Yin Xian 2002}

Yin Xian 殷憲. “Datong Bei Wei gongcheng diaocha zhaji” 大同北魏宮城調查札記, Beichao yanjiu 北朝研究 2002.4, pp. 147-157.

\section{Yin Xian 2006}


Yin Xian 殷憲. “Yungang shiku suo fanying de yixie Bei Wei zhengzhi shehui qingzhuang” 雲岡石窟所反映的一些北魏政治社會情狀, in Yungang shiku yanjiuyuan 雲岡石窟研究院 edt. 2005 nian Yungang guoji xueshu yantaohui lunwenji (yanjiu juan) 2005 年雲岡國際學術研討會論文集（研究卷）(Beijing: Wenwu chubanshe, 2006), pp. 416-42.

\section{Yin Xian and Liu Junxi 2006}

Yin Xian 殷憲 and Liu Junxi 劉俊喜. “Yungang di 20 ku yuanshi kuxing chutan”雲岡第 20 窟原始窟形初探, in Yungang shiku yanjiuyuan 雲岡石窟研究院 edt. 2005 nian Yungang guoji xueshu yantaohui lunwenji (yanjiu juan) 2005 年雲岡國際學術研討會論 文集（研究卷）(Beijing: Wenwu chubanshe, 2006), pp. 339-343.

\section{Yu Yizhi 2008}

Yu Yizhi 喻意志. “Gujin yuelu kao”《古今樂錄》考, Zhongguo yinyuexue 中國音樂學, 2008.3, pp. 81-87.

\section{Yungang shiku wenwu baoguansuo 1994}

Yungang shiku wenwu baoguansuo 雲岡石窟文物保管所. Zhongguo shiku: Yungang shiku, 2 vols. 中國石窟: 雲岡石窟 (共二卷). Beijing: Wenwu chubanshe, 1994.

\section{Yungang shiku wenwu yanjiusuo 2005}

Yungang shiku wenwu yanjiusuo 雲岡石窟文物研究所 edt. Yungang baohu wushi nian 雲岡保護五十年. Beijing: Wenwu chubanshe, 2005.

\section{Yungang shiku yanjiuyuan 2008}

Yungang shiku yanjiuyuan 雲岡石窟研究院. Yungang shiku 雲岡石窟. Beijing: Wenwu chubanshe, 2008.

\section{Zeng Zhaoyu, Jiang Baogeng and Li Zhongyi 1956}

Zeng Zhaoyu 曾昭燏, Jiang Baogeng 蔣寶庚 and Li Zhongyi 黎忠義. Yinan gu huaxiangshi mu fajue baogao 沂南古畫像石墓發掘報告, Beijing: Wenhuabu wenwu guanliju, 1956.

\section{Zhan Li and Zhou Shiqu 1977}

Zhan Li 展力 and Zhou Shiqu 周世曲. “Shitan Yangjiawan Han mu qibingyong - dui Xi Han qianqi qibing wenti de tantao” 試探楊家灣漢墓騎兵俑 - 對西漢前期騎兵問題的探 討, Wenwu 文物 1977.10, pp. 22-26.

\section{Zhang Jihao 2003}

Zhang Jihao 張繼昊. Cong Tuoba dao Bei Wei-Bei Wei wangchao chuangjian lishi de kaocha 從拓跋到北魏 - 北魏王朝創建歷史的考察. Taipei: Daoxiang chubanshe, 2003.

\section{Zhang Jinlong 1997}

Zhang Jinlong 張金龍. “Bei Wei Xiaowendi zhengzhi sixiang sanlun” 北魏孝文帝政治思 想散論, Beichao yanjiu 北朝研究 1997.2, pp. 3-19.

\section{Zhang Jinlong 2002}


Zhang Jinlong 張金龍. Bei Wei zhengzhi yu zhidu lungao 北魏政治與制度論稿. Lanzhou: Gansu jiaoyu chubanshe, 2002.

\section{Zhang Longchun 2005}

Zhang Longchun 張龍春. “Qin Han shiqi zhongyuan yimin dui Lingnan de kaifa ji yingxiang” 秦漢時期中原移民對嶺南的開發及影響, Hetian shifan zhuanke xuexiao xuebao 和田師範專科學校學報 25:6(2005), pp. 194-195.

\section{Zhang Pengchuan 1979}

Zhang Pengchuan 張朋川. “Jiuquan Dingjiazha gumu bihua yishu” 酒泉丁家閘古墓壁畫 藝術, Wenwu 文物 1979.6, pp. 18-21.

\section{Zhang Qingjie 2008}

Zhang Qingjie 張慶捷. “Datong xinfaxian yipi Bei Wei muzang” 大同新發現一批北魏墓 葬. Zhongguo wenwu bao 中國文物報, 26 Sep 2008, p.5.

\section{Zhang Qingiie 2010}

Zhang Qingjie 張慶捷. Minzu huiju yu wenming hudong - Beichao shehui de kaoguxue guancha 民族匯聚與文明互動 - 北朝社會的考古學觀察. Beijing: Shangwu yinshuguan, 2010 .

\section{Zhang Qingjie and Liu Junxi 2011}

Zhang Qingjie 張慶捷 and Liu Junxi 劉俊喜. "Datong xin faxian liangzuo Bei Wei bihuamu niandai chutan”大同新發現兩座北魏壁畫墓年代初探, Wenwu 文物 2011.12, pp. 52-54.

\section{Zhang Xuerong 1993}

Zhang Xuerong 張學榮. “Liangzhou shiku ji youguan wenti” 涼州石窟及有關問題, Dunhuang yanjiu 敦煌研究 1993.4, pp. 47-60.

\section{Zhang Xuerong and He Jingzhen 1994}

Zhang Xuerong 張學榮 and He Jingzhen 何靜珍. “Lun Liangzhou fojiao ji Juqu Mengxun de chongfo zunru” 論涼州佛教及沮渠蒙遜的崇佛尊儒, Dunhuang yanjiu 敦煌研究 1994.2, pp. 98-110.

\section{Zhang Yan 2005}

Zhang Yan 張艷. “Yungang shiku zhong de erfo bingzuo he Wenshu wenji”雲崗石窟中 的二佛並坐和文殊問疾, Wenwu shijie 文物世界 2005.4, pp. 16-19.

\section{Zhang Zhizhong 2008}

Zhang Zhizhong 張志忠. “Datong Bei Wei Song Shaozu mu taoche moxing qianyi” 大同 北魏宋紹祖墓陶車模型淺議, Shoucangjia 收藏家 2008.2, pp. 81-84.

\section{Zhao Chunsheng and Wu Jian 1992}

Zhao Chunsheng 趙春生 and Wu Jian 武健. “Shandong Jining Shizhuan Xi Han muqun qingli jianbao” 山東濟寧師專西漢墓群清理簡報, Wenwu 文物 1992.9, pp. 22-36. 
Appendix C: Bibliography

\section{Zhao Shengliang 2006}

Zhao Shengliang 趙聲良. “Dunhuang Beichao shiku xingzhi zhu wenti” 敦煌北朝石窟形 制諸問題, Dunhuang yanjiu 敦煌研究 2006.5, pp. 1-15.

\section{Zhao Wucheng 2005}

Zhao Wucheng 趙吳成. “Hexi mushi bihua zhong 'Fuxi, Nuwa' he 'niushou renshen, jishou renshen” tuxiang qianxi” 河西墓室壁畫中 “伏羲、女嗗” 和 “牛首人身、雞首 人身” 圖像淺析, Kaogu yu wenwu 考古與文物 2005.4, pp. 66-70.

\section{Zhao Xueye 2007}

Zhao Xueye 趙雪野. “Cong huaxiang zhuan kan Hexi Wei-Jin shehui shenghuo” 從畫像 塼看河西魏晉社會生活, Kaogu yu wenwu 考古與文物 2007.5, pp. 81-84.

\section{Zheng Yan 1998}

Zheng Yan 鄭岩. “Muzhi huaxiang yanjiu” 墓主畫像研究 in Shandong daxue kaoguxi 山 東大學考考古系 edt., Liu Dunyuan xiansheng jinian wenji 劉敦愿先生紀念文集. (Ji'nan: Shandong daxue chubanshe, 1998.

\section{Zheng Yan 2001}

Zheng Yan 鄭岩. “Qingzhou Bei Qi huaxiangshi yu ruhua Suteren meishu” 青州北齊畫像 石與入華粟特人美術, in Wu Hung edt., Han Tang zhijian wenhua yishu de hudong yu jiaorong 漢唐之間文化藝術的互動與交融 (Beijing: Wenwu chubanshe, 2001), pp. 73106.

\section{Zheng Yan 2002}

Zheng Yan 鄭岩. Wei Jin Nanbeichao bihua mu yanjiu 魏晉南北朝壁畫墓研究. Beijing: Wenwu chubanshe, 2002.

\section{Zheng Yan 2003}

Zheng Yan 鄭岩. “Bei Qi Xu Xianxiu mu muzhu huaxiang youguan wenti” 北齊徐顯秀墓 墓主畫像有關問題, Wenwu 文物 2003.10, pp. 58-62.

\section{Zheng Yan 2011}

Zheng Yan 鄭岩. “Shizhe de mianju - zai lun Bei Zhou Kang Ye mu shiguanchuang huaxiang” 逝者的面具 - 再論北周康業墓石棺床畫像 in Wu Hung and Zheng Yan edts. Gudai muzang meishu yanjiu 古代墓葬美術研究, vol. 1 (Beijing: Wenwu chubanshe, 2011), pp. 217-242.

\section{Zhu Xilu 1992}

Zhu Xilu 朱锡禄. Jiaxiang Han huaxiangshi 嘉祥漢畫像石. Jinan: Shandong meishu chubanshe, 1992.

\section{Zou Qingquan 2010}

Zou Qingquan 鄒清泉. “Bei Wei zuota Weimo huaxiang yuanliu kaoshi” 北魏坐榻維摩 畫像源流考釋, Dunhuang yanjiu 敦煌研究 2010.4, pp. 67-73. 


\section{Western Language Sources}

\section{Allsen 2006}

Allsen, Thomas T. The Royal Hunt in Eurasian History. Philadelphia: University of Pennsylvania Press, 2006.

\section{Andrews 1987}

Andrews, Peter Alford. "The Generous Heart or the Mass of Clouds: The Court Tents of Shah Jahan.” Muqarnas 4(1987), pp. 149-165.

\section{Anthony 1995}

Anthony, David W. "Horse, wagon \& chariot: Indo-European languages and archaeology." Antiquity 69(1995), pp. 554-565.

\section{Bagley 1998}

Bagley, Robert. "Review: Monumentality in Early Chinese Art and Architecture by Wu Hung," Harvard Journal of Asiatic Studies 58:1(1998), pp. 221-256.

\section{Barbieri-Low 2007}

Barbieri-Low, Anthony J. Artisans in Early Imperial China. Seattle: University of Washington Press, 2007.

\section{Barfield 1989}

Barfield, Thomas J. The Perilous Frontier: Nomadic Empires and China. Oxford: Basil Blackwell, 1989.

\section{Barth 1969}

Barth, Fredrik, ed. Ethnic Groups and Boundaries: The Social Organization of Ethnic Difference. Boston: Little, Brown and Company, 1969.

\section{Barthes 1977}

Barthes, Roland. Image, Music, Text. Translated by Stephen Heath. London: Fontana Press, 1977.

\section{Berman 1983}

Berman, Harold J. Law and Revolution: The Formation of the Western Legal Tradition. Cambridge, Massachusetts and London: Harvard University Press, 1983.

\section{Bodde 1942}

Bodde, Derk. "Dominant Ideas in the Formation of Chinese Culture." Journal of the American Oriental Society 62:4(1942), pp. 293-299.

\section{Boodberg 1979}

Boodberg, Peter A. "The Language of the T'o-Pa Wei" in Alvin P. Cohen compiled, Selected Works of Peter A. Boodberg (Berkeley and Los Angeles: University of California Press, 1979), pp. 221-239.

\section{Borglum 1930}

Borglum, Gutzon. "First Survey and the Development of the Memorial," in Mount Rushmore National Memorial Commossion edt., Mount Rushmore National Memorial: A 
Monument Commemorating the Conception, Preservation and Growth of the Great American Republic. Peter Norbeck Papers, University of South Dakota Archives, 1930.

\section{Bourdieu 1977}

Bourdieu, Pierre. Outline of a Theory of Practice. Trans. Richard Nice. Cambridge:

Cambridge University Press, 1977.

\section{Bourdieu 1991}

Bourdieu, Pierre. "Genesis and Structure of the Religious Field." Trans. Jenny B. Burnside, Craig Calhoun and Leah Florence, Comparative Social Research 13(1991), pp. 1-44.

\section{Bourdieu 2010}

Bourdieu, Pierre. Distinction: A Social Critique of the Judgement of Taste. Trans. Richard Nice. London: Routledge, 2010.

\section{Brashier 2005}

Brashier, K. E. "Text and Ritual in Early Chinese Stelae," in Martin Kern edt., Text and Ritual in Early China (Seattle: University of Washington Press, 2005), pp. 249-284.

\section{Brashier 2011}

Brashier, K. E. Ancestral Memory in Early China. Cambridge, Massachusetts and London: Harvard University Asia Center, 2011.

\section{British Museum et al. 1907}

British Museum et al. edt. The Sculptures and Inscription of Darius the Great on the Rock of Behistun in Persia. London: British Museum Press, 1907.

\section{Bunker 2002}

Bunker, Emma C. edt. Nomadic Art of the Eastern Eurasian Steppe: The Eugene V. Thaw and other New York Collections. New York: The Metropolitan Museum of Art, 2002.

\section{Cameron 1987}

Cameron, Averil. "The construction of court ritual: the Byzantine Book of Ceremonies," in David Cannadine and Simon Price edts. Rituals of Royalty: Power and Ceremonial in Traditional Societies (Cambridge: Cambridge University Press, 1987), pp. 106-136.

\section{Canepa 2009}

Canepa, Matthew P. The Two Eyes of the Earth: Art and Ritual of Kingship between Rome and Sasanian Iran. Berkeley, California: University of California Press, 2009.

\section{Canepa 2010}

Canepa, Matthew P. "Preface: Theorizing Cross-Cultural Interaction Among Ancient and Early Medieval Visual Cultures," Orientalis 38(2010), pp. 7-30.

\section{Cannadine 1987}

Cannadine, David. "Introduction: divin rites of kings," in David Cannadine and Simon Price edts. Rituals of Royalty: Power and Ceremonial in Traditional Societies (Cambridge: Cambridge University Press, 1987), pp. 1-19. 
Appendix C: Bibliography

\section{Chen Xin 2011}

Chen Xin. Miniature Buildings in the Liao (907-1125) and the Northern Song (960-1127) Periods. DPhil thesis. Oxford: University of Oxford, 2011.

\section{Chen Sanping 2012}

Chen Sanping. Multicultural China in the Early Middle Ages. Philadelphia: University of Pennsylvania Press, 2012.

\section{Cheng 2003}

Cheng, Bonnie. Fabricating Life out of Death: Sixth Century Funerary Monuments and the Negotiation of Cultural Traditions. DPhil thesis. Chicago: The University of Chicago, 2003.

\section{Cheng 2010}

Cheng, Bonnie. "The space between: Locating "culture" in artistic exchange," Orientalis 38(2010), pp. 81-120.

\section{Clauson 1960}

Clauson, Gerard. "Turk, Mongol, Tungus," Asia Minor 8:1(1960), pp. 105-123.

\section{Cole 1999}

Cole, Mary Hill. The Portable Queen: Elizabeth I and the Politics of Ceremony. Amherst: University of Massachusetts Press, 1999.

\section{Coomber 2011}

Coomber, Neil. The Performative Construction of Identity in the Shang and Zhou dynasties. DPhil thesis. Oxford: University of Oxford, 2011.

\section{Creel 1970}

Creel, Herrlee G. The Origins of Statecraft in China, vol. 1. Chicago: University of Chicago Press, 1970.

\section{Czuma 1977}

Czuma, Stanislaw. "Mathura Sculpture in the Cleveland Museum Collection," The Bulletin of the Cleveland Museum of Art 64:3(1977), pp. 83-114.

\section{Deng Fei 2010}

Deng, Fei. Understanding efficacy: a study of decorated tombs in northern Song China (960-1127). DPhil thesis. Oxford: University of Oxford, 2010.

\section{Dien 1981}

Dien, Albert E. "A Study of Early Chinese Armor," Artibus Asiae 43:1/2 (1981), pp. 5-66.

\section{Dien 1986}

Dien, Albert E. "The Stirrup and Its Effect on Chinese Military History," Ars Orientalis, vol. 16, 1986, pp. 33-56. 


\section{Dien 1992}

Dien, Albert E. "A New Look at the Xianbei and their Impact on Chinese Culture" in George Kuwayama edt., Ancient Mortuary Traditions of China: Papers on Chinese Ceramic Funerary (Los Angeles: Far Eastern Art Council, 1992), pp. 40-59.

\section{Dien 2007}

Dien, Albert E. Six Dynasties Civilization. New Haven: Yale University Press, 2007.

\section{Dobson 1963}

Dobson, W. A. C. H. (Trans.) Mencius. Toronto: University of Toronto Press, 1963.

\section{Donald 1993}

Donald, Merlin. Origins of the Modern Mind: Three Stages in the Evolution of Culture and Cognition. Cambridge, Massachusetts: Harvard University Press, 1993.

\section{Dunnell and Millward 2004}

Dunnell, Ruth W. and James A. Millward. "Introduction," in James A. Millward, Ruth W. Dunnell, Mark C. Elliott and Philippe Forêt edts., New Qing Imperial History: The Making of Inner Asian Empire at Qing Chengde (New York: RoutledgeCurzon, 2004), pp. 1-12.

\section{Eberhard 1952}

Eberhard, Wolfram. Conquerors and Rulers. Leiden: Brill, 1952.

\section{Erickson 1994}

Erickson, Susan N. "Money Trees of the Eastern Han Dynasty," Bulletin of the Museum of Far Eastern Antiquities 66(1994), pp. 5-115.

\section{Falkenhausen 1993}

Falkenhausen, Lothar von. "On the Historiographical Orientation of Chinese Archaeology." Antiquity 67 (1993), pp. 839-849.

\section{Falkenhausen 1995}

Falkenhausen, Lothar von. "The regionalist paradigm in Chinese archaeology," in Philip L. Kohl and Clare Fawcett edts. Nationalism, politics, and the practice of archaeology (Cambridge: Cambridge University Press, 1995), pp. 198-217.

\section{Forêt 2000}

Forêt, Philippe. Mapping Chengde: the Qing landscape enterprise. Honolulu: University of Hawai'i Press, 2000.

\section{Foucault 1972}

Foucault, Michel. Archaeology of Knowledge. Translated from French by A. M. Sheridan Smith. New York: Pantheon, 1972.

\section{Foucault 1977}

Foucault, Michel. Discipline and Punish: The Birth of the Prison. Translated from French by Alan Sheridan. London: Penguin Books, 1977. 


\section{Fowler and Fowler 2008}

Fowler, Jeaneane D. and Merv Fowler. Chinese Religions: Beliefs and Practices. Portland: Sussex Academic Press, 2008.

\section{Frankel 1976}

Frankel, Hans H. The Flowering Plum and the Palace Lady: Interpretations of Chinese poetry. New Haven: Yale University Press, 1976.

\section{Freedberg 1989}

Freedberg, David. The Power of Images: Studies in the History and Theory of Response. Chicago: The University of Chicago Press, 1989.

\section{Gao 1987}

Gao Wen. "A Brief Overview of the Han Tomb Reliefs from Sichuan" trans. Jessie Bunnin, in Lucy Lim edt. Stories from China's Past: Han dynasty pictorial tomb reliefs and archaeological objects from Sichuan (San Francisco: Chinese Culture Foundation of San Francisco, 1987), pp. 46-50.

\section{Geertz 1973}

Geertz, Clifford. The Interpretation of Cultures. New York: Basic Books, 1973.

\section{Geertz 1983}

Geertz, Clifford. Local Knowledge. New York: Basic Books, 1983.

\section{Gell 1998}

Gell, Alfred. Art and Agency: An Anthropological Theory. Oxford, Oxford University Press, 1998.

\section{Gernet 1995}

Gernet, Jacques. Buddhism in Chinese Society: An Economic History from the Fifth to the Tenth Centuries, translated from French by Franciscus Verellen. New York: Columbia University Press, 1995.

\section{Gilbert 1987}

Gilbert, Michelle. "The person of the king: ritual and power in a Ghanaian state," in David Cannadine and Simon Price edts. Rituals of Royalty: Power and Ceremonial in Traditional Societies (Cambridge: Cambridge University Press, 1987), pp. 298-330.

\section{Glass 1994}

Glass, Matthew. "Producing Patriotic Inspiration at Mount Rushmore," Journal of the American Academy of Religion 62:2(1994), pp. 265-283.

\section{Gosden 2004}

Gosden, Chris. Archaeology and Colonialism: Cultural Contact from 5000 BC to the Present. Cambridge: Cambridge University Press, 2004.

\section{Greenblatt 2005}

Greenblatt, Stephen. Renaissance self-fashioning: from More to Shapespeare. Chicago: The University of Chicago Press, 2005. 


\section{Grousset 1970}

Grousset, Rene. The Empire of the Steppe: a History of Central Asia. Trans. Naomi Walford. New Brunswick: Rutgers University Press, 1970.

\section{Haarlov 1997}

Haarlov, Britt. The Half-Open Door: A Common Symbolic Motif within Roman Sepulchural Sculpture. Odense: Odense University Press, 1977.

\section{Halbwachs 1992}

Halbwachs, Maurice. On Collective Memory. Translated by Lewis A. Cosner. Chicago: The University of Chicago Press, 1992.

\section{Hall 1992}

Hall, Stuart. "The West and the Rest," in Stuart Hall and Bram Gieben edts. Formations of Modernity (Cambridge: Polity Press/The Open University, 1992), pp. 275-332.

\section{Hall 1997}

Hall, Stuart. "The Work of Representation," in Stuart Hall edt. Representation: Cultural Representations and Signifying Practices (London: Open University, 1997), pp. 13-74.

\section{Halsall 2007}

Halsall, Guy. Barbarian Migrations and the Roman West 376-568. Cambridge: Cambridge University Press, 2007.

\section{Heather 2009}

Heather, Peter. Empires and Barbarians: Migration, Development and the Birth of Europe. London: Macmillan, 2009.

\section{Henning 1952}

Henning, W. B. "A Farewell to the Khagan of the Aq-Aqatärān," Bulletin of the School of Oriental and African Studies, University of London 14:3(1952), pp. 501-522.

\section{Ho 1967}

Ho, Ping-Ti. "The Significance of the Ch'ing Period in Chinese History." The Journal of Asian Studies 26:2(1967), pp. 189-195.

\section{Ho 1998}

Ho, Ping-Ti. "In Defense of Sinicization: A Rebuttal of Evelyn Rawski's 'Reenvisioning the Qing'." The Journal of Asian Studies 57:1(1998), pp. 123-155.

\section{Holmgren 1982}

Holmgren, Jennifer. Annals of Tai: Early T'o-pa history according to the first chapter of the Wei-shu. Canberra: Faculty of Asian Studies in association with Australian National University Press, 1982.

\section{Holmgren 1989}

Holmgren, Jennifer. "Northern Wei as a Conquest Dynasty: Current Perceptions; Past Scholarship". Papers on Far Eastern History, vol. 40, 1989.9, pp. 1-50. 


\section{Howard 1991}

Howard, Angela F. "In Support of a New Chronology for the Kizil Mural Paintings," Archives of Asian Art 44(1991), pp. 68-83.

\section{Hung 1989}

Hung, Chang-Tai. "Female Symbols of Resistance in Chinese Wartime Spoken Drama." Modern China 15:2(1989), pp. 149-177.

\section{Huntington 1986}

Huntington, John C. "The Iconography and Iconology of the 'Tan Yao' Caves at Yungang." Oriental Art 32:2(1986), pp. 142-160.

\section{Hurvitz 1956}

Hurvitz, Leon, trans. "Wei Shou, Treatise on Buddhism and Taoism: An English Translation of the Original Chinese Text of Wei shu CXIV and the Japanese Annotation of Tsukamoto Zenryū." In Yun-kang: The Buddhist Cave Temples of the Fifth Century A.D. in North China. Vol. 16. Kyoto: Kyoto University, Institute of Humanities, 1956.

\section{Jacobson 1985}

Jacobson, Esther. "Mountains and Nomads: A Reconsideration of the Origins of Chinese Landscape Representation." Museum of Far Eastern Antiquities Bulletin 57(1985), pp. 133-180.

\section{James 1989}

James, Jean M. "Some Iconographic Problems in Early Daoist-Buddhist Sculptures in China." Archives of Asian Art, 42(1989), pp. 71-76.

\section{James 1998/1999}

James, Jean M. "The Eastern Han Offering Shring: A Functional Study," Archives of Asian Art 51(1998/1999), pp. 16-29.

\section{Jenkins 2008}

Jenkins, Richard. Social Identity. London: Routledge, 2008.

\section{Jones 1917}

Jones, H. L. The Geography of Strabo, vol. 3. London: W. Heinemann, 1917.

\section{Karasulas 2004}

Karasulas, Antony. Mounted Archers of the Steppe 600 BC-AD 1300. Oxford: Osprey Publishing, 2004.

\section{Keay 2008}

Keay, John. China: A History. London: HarperPress, 2008.

\section{Keightley 1984}

Keightley, David N. "Late Shang Divination: The Magico-Religious Legacy," in Henry Rosemon Jr. edt. Explorations in Early Cosmology. Journal of the American Academy of Religion Studies 50:2(Chicago, California: Scholars Press, 1984), pp. 11-34. 


\section{Keightley 2000}

Keightley, David N. The Ancestral Landscape: Time, space, and community in late Shang China, ca. 1200-1045 B.C. Berkeley: Institute of East Asian Studies, 2000.

\section{Keightley 2004}

Keightley, David N. "The Making of the Ancestors: Late Shang Religion and Its Legacy," in John Lagerwey edt. Religion and Chinese Society (Hong Kong: Chinese University Press, 2004), pp. 3-64.

\section{Kern 2000}

Kern, Martin. The Stele Inscription of Ch'in Shih-huang: text and ritual in early Chinese imperial representation. New Haven: American Oriental Society, 2000.

\section{Kern 2008}

Kern, Martin. "Announcements from the Mountains: The Stele Inscriptions of the Qin First Emperor," in Fritz-Heiner Mutschler and Achim Mittag edts., Conceiving the Empire: China and Rome Compared (Oxford: Oxford University Press, 2008), pp. 217-240.

\section{Kieschnick 1997}

Kieschnick, John. The Eminent Monk: Buddhist ideals in medieval Chinese hagiography. Honolulu: University of Hawai'i Press, 1997.

\section{Kieschnick 2003}

Kieschnick, John. The Impact of Buddhism on Chinese Material Culture. Princeton: Princeton University Press, 2003.

\section{Knauer 1983}

Knauer, Elfriede Regina. "The Fifth Century A.D. Buddhist Cave Temples at Yun-kang, North China," Expedition, 25:4(1983), pp. 27-47.

\section{Knecht 2008}

Knecht, Robert J. The French Renaissance Court. New Haven: Yale University Press, 2008 .

\section{Knechtges 1996}

Knechtges, David R. (Trans.) Wen xuan, vol. two. Princeton: Princeton University Press, 1996.

\section{Kohn 1995}

Kohn, Livia. Laughing at the Tao: debates among Buddhists and Taoists in medieval China. Princeton: Princeton University Press, 1995.

\section{Kramrisch 1966}

Kramrisch, Stella. "Image of Buddha from Gandhara," Philadelphia Museum of Art Bulletin 61:289(1966), pp. 36-39.

\section{Kris and Kurz 1979}

Kris, E. and O. Kurz. Legend, Myth, and Magic in the Image of the Artist: A Historical Experiment. New Haven: Yale University Press, 1979. 


\section{Kwa and Idema 2010}

Kwa, Shiamin and Wilt L. Idema. Mulan: Five Versions of a Classic Chinese Legend, with Related Texts. Indianapolis: Hackett Publishing Company, Inc., 2010.

\section{Lai 1999}

Lai, Sufen Sophia. "From Cross-dressing Daughter to Lady Knight-errant: The origin and evolution of Chinese women warriors," in Sherry J. Mou edt. Presence and Presentation: women in the Chinese literati tradition (Basingstoke: Macmillian, 1999), pp. 77-108.

\section{Lan 2003}

Lan, Feng. "The Female Individual and the Empire: A Historicist Approach to Mulan and Kingston's Woman Warrior," Comparative Literature 55:3(2003), pp. 229-245.

\section{Leach 1970}

Leach, E. R. Political Systems of Highland Burma: A study of Kachin Social Structure. London: Athlone Press, 1970.

\section{Ledderose 2000}

Ledderose, Lothar. Ten Thousand Things: Module and Mass Production in Chinese Art. Princeton: Princeton University Press, 2000.

\section{Legge 1967}

Legge, James. Li Chi: Book of Rites, 2 vols. New Hyde Park: University Books, 1967.

\section{Lehmann 1945}

Lehmann, Karl. “The Dome of Heaven.” The Art Bulletin 27:1(1945), pp. 1-27.

\section{Le May 1943}

Le May, Reginald. "The Bimaran Casket," The Burlington Magazine 182(1943), pp. 122123.

\section{Lendon 2006}

Lendon, J. E. "The Legitimacy of the Roman Emperor: Against Weberian Legitimacy and Imperial 'Strategies of Legitimation'" in Herausgegeben von Anne Kolb edt., Herrschaftsstrukturen und Herrschaftspraxis: Konzepte, Prinzipien und Strategien der Administration im romischen Kaiserreich (Berlin: Akademie, 2006), pp. 53-63.

\section{Lewis 1999}

Lewis, Mark Edward. Writing and Authority in Early China. Albany: State University of New York Press, 1999.

\section{Lewis 2009}

Lewis, Mark Edward. China between Empires: The Northern and Southern Dynasties. Cambridge (MA): Belknap Press of Harvard University Press, 2009.

\section{Li 1990}

$\mathrm{Li}$, Yinde. "The "Underground Palace" of a Chu Prince at Beidongshan." Orientations 21:10(1990), pp. 57-61. 
Appendix C: Bibliography

\section{Ligeti 1970}

Ligeti, Louis. "Le Tabghatch: Un dialecte de la langue sien-pi" in Louis Ligeti edt., Mongolian Studies (Budapest : Akadémiai Kiadó, 1970), pp. 265-308.

\section{Lim 1987}

Lim, Lucy. "Form and Content in Early Chinese Pictorial Art" in Lucy Lim edt. Stories from China's Past: Han dynasty pictorial tomb reliefs and archaeological objects from Sichuan (San Francisco: Chinese Culture Foundation of San Francisco, 1987), pp. 51-53.

\section{Lim 1989}

Lim, Lucy. The Northern Wei Tomb of Ssu-ma Chin-lung and Early Chinese Figure Painting. DPhil thesis. New York: New York University, 1989.

\section{Linduff 1996}

Linduff, Katheryn M. "Art and Identity: The Chinese and Their 'Significant Others' in the Shang," in Michael Gervers and Wayne Schlepp edts., Cultural Contact, History, and Ethnicity in Inner Asia (Toronto: Toronto Studies in Central and Inner Asia, Joint Centre for Asia Pacific Studies, 1996), pp. 12-48.

\section{Linduff 2002}

Linduff, Katheryn M. "Women's Lives Memorialized in Burial in Ancient China at Anyang," in Sarah Milledge Nelson and Myriam Rosen-Ayalon edts., In Pursuit of Gender: Worldwide archaeological approaches (Oxford: Rowman \& Littlefield, 2002), pp. 257288.

\section{Liu 2005}

Liu, Cary Y. "The 'Wu Family Shrine' as a Recarving of the Past," in Cary Y. Liu, Michael Nylan, and Anthony Barbieri-Low edt., Recarving China's Past: Art, Archaeology, and Architecture of the "Wu Family Shrines" (Princeton: Princeton University Art Museum, 2005), pp. 23-74.

\section{Liu, Nylan and Barbieri-Low 2005}

Liu, Cary Y., Michael Nylan, and Anthony Barbieri-Low edts., Recarving China's past: Art, archaeology, and architecture of the "Wu Family Shrines". Princeton: Princeton University Art Museum, 2005.

\section{Mair 1994}

Mair, Victor H. The Columbia Anthology of Traditional Chinese Literature. New York: Columbia University Press, 1994.

\section{Mair and Bender 2011}

Mair, Victor H. and Mark Bender, edts. The Columbia Anthology of Chinese Folk and Popular Literature. New York: Columbia University Press, 2011.

\section{Mayr-Harting 1972}

Mayr-Harting, Henry. The Coming of Christianity to Anglo-Saxon England. London: B.T. Batsford Ltd., 1972. 


\section{McNair 1994}

McNair, Amy. "Early Tang Imperial Patronage at Longmen.” Ars Orientalis 24(1994), pp. 65-81.

\section{Michaelson 2010}

Michaelson, Carol. "Introduction to the Terracotta Army" in Jessica Rawson and Kristian Goransson edts., China's terracotta army (Stokholm: Ostasiatiska Museet, 2010), pp. 3846.

\section{Miller 2010}

Miller, Daniel. Stuff. Cambridge: Polity Books, 2010.

\section{Mitchell 1994}

Mitchell, W. J. T. "Introduction," in W. J. T. Mitchell edt. Landscape and Power (Chicago: University of Chicago Press, 1994), pp. 1-4.

\section{Mitchell 1996}

Mitchell, W. J. T. “What Do Pictures 'Really’ Want?” October 77(1996), pp. 71-82.

\section{Mizuno and Nagahiro 1952-1956}

Mizuno, Seiichi 水野清一 and Toshio Nagahiro 長広敏雄. Yun-kang, the Buddhist CaveTemples of the Fifth Century A.D. in North China, 16 vols. Kyoto: Kyoto University Jimbun kagaku kenkyusho, 1952-1956.

\section{Müller 2002}

Müller, Shing. "The Nomads of the Fifth Century: The Tuoba Xianbei" in Annette L. Juliano and Judith A. Lerner edts., Nomads, Traders and Holy Men Along China's Silk Road (Turnhout, Belgium: Brepols Publishers, 2002), pp. 33-44.

\section{Müller 2003}

Müller, Shing. "Chin-Straps of the Early Northern Wei: New Perspectives on the TransAsiatic Diffusion of Funerary Practices." Journal of East Asian Archaeology 5:1-4(2003), pp. 27-71.

\section{Nylan 2003}

Nylan, Michael. "Ordinary mysteries: Interpreting the Archaeological Record of Han Sichuan." Journal of East Asian Archaeology 5:1-4(2003), pp. 375-400.

\section{Nylan 2008}

Nylan, Michael. "The Rhetoric of 'Empire' in the Classical Era in China," in Fritz-Heiner Mutschler and Achim Mittag edts., Conceiving the Empire: China and Rome Compared (Oxford: Oxford University Press, 2008), pp. 39-66.

\section{O'Kane 1993}

O'Kane, Bernard. "From Tents to Pavilions: Royal Mobility and Persian Palace Design," Ars Orientalis 23(1993), pp. 249-268.

\section{Olmstead 1935}

Olmstead, A. T. "Darius as Lawgiver." The American Journal of Semitic Languages and Literatures 51:4(1935), pp. 247-249. 


\section{Paludan 1991}

Paludan, Ann. The Chinese Sprit Road: the classical tradition of stone tomb statuary. New Haven: Yale University Press, 1991.

\section{Paludan 2006}

Paludan, Ann. Chinese sculpture: A great tradition. Chicago: Serindia Publications, 2006.

\section{Panofsky 1964}

Panofsky, Erwin. Tomb Sculptures. New York: Harry N. Abrams, Inc., 1964.

\section{Parker 1896}

Parker, Edward Harper. "The Origin of the Turks," The English Historical Review 11:43(1896), pp. 431-445.

\section{Peck 1969}

Peck, Elsie Holmes. "The Representation of Costumes in the Reliefs of Taq-i-Bustan," Artibus Asiae 31:2/3(1969), pp. 101-146.

\section{Piggott 1992}

Piggott, Stuart. Wagon, Chariot and Carriage: symbol and status in the history of transport. London: Thames and Hudson, 1992.

\section{Powers 1991}

Powers, Martin J. Art \& Political Expression in Early China. New Haven: Yale University Press, 1991.

\section{Pulleyblank 1983}

Pulleyblank, E. G. "The Chinese and Their Neighbors in Prehistoric and Early Historic Times" in David N. Keightley edt., The Origins of Chinese Civilization (Berkeley and Los Angeles: University of California Press, 1983), pp. 411-466.

\section{Qian 2001}

Qian, Nanxiu. Spirit and Self in Medieval China: The Shih-shuo hsin-yu and its Legacy. Honolulu: University of Hawai'i Press, 2001.

\section{Rawski 1996}

Rawski, Evelyn S. "Reenvisioning the Qing: The Significance of the Qing Period in Chinese History." The Journal of Asian Studies 55:4(1996), pp. 829-850.

\section{Rawson 1984}

Rawson, Jessica. Chinese Ornament: The Lotus and the Dragon. London: British Museum Publications Ltd, 1984.

\section{Rawson 1989}

Rawson, Jessica. "Statesmen or Barbarians? The Western Zhou as Through Their Bronzes." Proceedings of the British Academy LXXV(1989), pp. 71-95. 


\section{Rawson 1998}

Rawson, Jessica. "Chinese Burial Patterns: Sources of Information on thought and Belief" in Colin Renfrew and Christopher Scarre edts., Cognition and Material Culture: The Archaeology of Symbolic Storage. (Cambridge, England: McDonald Institute for Archaeological Research, 1998), pp. 107-133.

\section{Rawson 1999}

Rawson, Jessica. "Eternal Palaces of the Western Han: A New View of the Universe," Artibus Asiae 59:1 (1999), pp. 5-58.

\section{Rawson 2001}

Rawson, Jessica. "Tombs and Tomb Furnishings of the Eastern Han Period (AD 25-220)," in Robert Bagley edt., Ancient Sichuan: Treasures from a Lost Civilization (Seattle: Seattle Art Museum, 2001), pp. 253-308.

\section{Rawson 2002a}

Rawson, Jessica. "The Power of Images: the model universe of the First Emperor and its legacy" Historical Research 75:188(2002), pp. 123-154.

\section{Rawson 2002b}

Rawson, Jessica. "The Origins of Chinese Mountain Painting: Evidence from Archaeology." Proceedings of the British Academy 117(2002), pp. 1-48.

\section{Rawson 2006a}

Rawson, Jessica. "Reviving Ancient Ornament and the Presence of the Past: Examples from Shang and Zhou Bronze Vessels", paper delivered at Re-inventing the Past: Antiquarianism in East Asian Art and Visual Culture (Conference in two parts organized by the Center for the Art of East Asia, University of Chicago, May and November 2006), pp. 47-76. Publication of conference papers is in preparation

\section{Rawson 2006b}

Rawson, Jessica. "The Chinese Hill Censer, boshanlu: a note on Origins, Influences and Meanings," Ars Asiatiques, Volume en homage á Madame Michéle Pirazzoli t'Serstevens, 61 (2006), pp. 75-86.

\section{Rawson 2006c}

Rawson, Jessica. "Ornament as System: Chinese Bird-and-Flower Design," The Burlington Magazine, 148:1239(2006), pp. 380-389.

\section{Rawson 2007a}

Rawson, Jessica. "The Agency of, and the Agency for, the Wanli Emperor" in Robin Osborne and Jeremy Tanner edts., Art's Agency and Art History (Oxford: Blackwell, 2007), pp. 95-113.

\section{Rawson 2007b}

Rawson, Jessica edt. The British Museum Book of Chinese Art. London: British Museum Press, 2007. 


\section{Rawson 2012}

Rawson, Jessica. "Inside out: Creating the exotic within early Tang dynasty China in the seventh and eighth centuries," World Art 2:1(2012), pp. 25-45.

\section{Rowland 1935}

Rowland, Benjamin. "Chinese Sculpture of the Pilgrimage Road," Bulletin of the Fogg Art Museum, 4:2(1935), pp. 22-28.

\section{Rowland 1937}

Rowland, Benjamin. "Notes on the Dated Statues of the Northern Wei Dynasty and the Beginnings of Buddhist Sculpture in China." The Art Bulletin, 19:1(1937), pp. 92-107.

\section{Rowland 1946}

Rowland, Benjamin. "Gandhara and Early Christian Art: The Homme-Arcade and the Date of the Bimaran Reliquary.” The Art Bulletin, 28:1(1946), pp. 44-47.

\section{Rowland 1965}

Rowland, Benjamin. "A Cycle of Gandhara," Bulletin of the Museum of Fine Arts 63:333(1965), pp. 114-129.

\section{Russell 2011}

Russell, Ben. "The Roman Sarcophagus 'Industry': A Reconsideration," in Jas Elsner and Janet Huskinson edts., Life, Death and Representation: Some new work on Roman Sarcophagi (Berlin: de Gruyter, 2011), pp. 119-147.

\section{Samman 1995}

Samman, Neil. "The Progresses of Henry VIII, 1509-1529," in Diarmaid MacCulloch etd., The Reign of Henry VIII: Politics, Policy and Piety (London: Macmillan Press, 1995), pp. 59-74.

\section{Schafer 1968}

Schafer, Edward H. "Hunting Parks and Animal Enclosures in Ancient China." Journal of the Economic and Social History of the Orient 11(1968), pp. 318-343.

\section{Schama 1995}

Schama, Simon. Landscape and Memory. New York: Knopf, 1995.

\section{Schechla 1993}

Schechla, Joseph. "Ideological Roots of Population Transfer," Third World Quarterly 14:2(1993), pp. 239-275.

\section{Schmitt 1998}

Schmitt, Jean-Claude. Ghosts in the Middle Ages: The Living and the Dead in Medieval Society. Chicago: University of Chicago Press, 1998.

\section{Sekino and Tokiwa 1926-1938}

Sekino, Tadashi and Tokiwa, Daijo. Buddhist Monuments in China. Tokyo: Bukkyoshiseki kenkyu-kwai, 1926. 


\section{Sewell 1960}

Sewell, Jack. "Gandhara Sculpture," The Art Institute of Chicago Quarterly, 54:3(1960), p. 10.

\section{Si 2010a}

Si, Han. "The Smiling Empire - Terracotta figurines from the Han Yangling mausoleum," in Jessica Rawson and Kristian Goransson edts., China 's terracotta army (Stokholm: Ostasiatiska Museet, 2010), pp. 91-100.

\section{Si 2010b}

$\mathrm{Si}$, Han. "The General's Soldiers from Yangjiawan” in Jessica Rawson and Kristian Goransson edts., China's terracotta army (Stokholm: Ostasiatiska Museet, 2010), pp. 119122.

\section{Skaff 2004}

Skaff, Jonathan Karam. "Survival in the Frontier Zone: Comparative Perspectives on Identity and Political Allegiance in China's Inner Asian Borderlands during the Sui-Tang Dynastic Transition (617-630)." Journal of World History 15:2(2004), pp. 117-153.

\section{Soothill 1951}

Soothill, William. The Hall of Light: A Study of Early Chinese Kingship. London: Lutterworth Press, 1951.

\section{Soper 1947}

Soper, Alexander Coburn. “The 'Dome of Heaven' in Asia." The Art Bulletin 29:4(1947), pp. 225-248.

\section{Soper 1941}

Soper, Alexander. "Early Chinese Landscape Painting." Art Bulletin 23:2(1941), pp. 141164.

\section{Soper 1958}

Soper, Alexander Coburn. "Northern Liang and Northern Wei in Kansu." Artibus Asiae 21:2(1958), pp. 131-164.

\section{Soper 1959}

Soper, Alexander Coburn. Literary Evidence for Early Buddhist Art in China. Ascona: Artibus Asiae, 1959.

\section{Soper 1960}

Soper, Alexander Coburn. "South Chinese Influence on the Buddhist Art of the Six Dynasties Period." Bulletin of the Museum of Far Eastern Antiquities, Stockholm 1960.32, pp. 47-112.

\section{Soper 1966}

Soper, Alexander Coburn. "Imperial Cave-Chapels of the Northern Dynasties: Donors, Beneficiaries, Dates.” Artibus Asiae 28:4(1966), pp. 241-270. 


\section{Sorensen 1997}

Sorensen, Marie Louise Stig. "Reading Dress: The Construction of Social Categories and Identities in Bronze Age Europe," Journal of European Archaeology, 5:1(1997), pp. 93114.

\section{Speidel 1986}

Speidel, M. P. "Maxentius and His 'Equites Singulares' in the Battle at the Milvian Bridge.” Classical Antiquity 5:2(1986), pp. 253-262.

\section{Spink 1958}

Spink, Walter M. "On the Development of Early Buddhist Art in India," The Art Bulletin 40:2(1958), pp. 95-104.

\section{Spink 2007}

Spink, Walter M. Ajanta: History and Development. Leiden: Brill, 2007.

\section{Steane 1999}

Steane, John. The Archaeology of the Medieval English Monarchy. London: Routledge, 1999.

\section{Stein 1912}

Stein, Aurel Sir. Ruins of desert Cathay: personal narrative of explorations in Central Asia and westernmost China, vol. 1. London: Macmillan, 1912.

\section{Steinhardt 1990}

Steinhardt, Nancy Shatzman. Chinese Imperial City Planning. Honolulu: University of Hawai'i Press, 1990.

\section{Sullivan 1962}

Sullivan, Michael. The Birth of Landscape Painting in China. Berkeley and Los Angeles: The University of California Press, 1962.

\section{Sullivan 1969}

Sullivan, Michael. The Cave-Temples of Maichishan. London: Faber and Faber, 1969.

\section{Symons 2004}

Symons, Van J. "Qianlong on the road: The imperial tours to Chengde," in James A. Millward, Ruth W. Dunnell, Mark C. Elliott and Philippe Forêt edts., New Qing Imperial History: The Making of Inner Asian Empire at Qing Chengde (New York:

RoutledgeCurzon, 2004), pp. 55-65.

\section{Thomas 1981}

Thomas, Charles. Christianity in Roman Britain to AD 500. London: Batsford Academic and Educational Ltd., 1981.

\section{Tomita 1942}

Tomita, Kojiro. "A Chinese Sacrificial Stone House of the Sixth Century A.D." Bulletin of the Museum of Fine Arts, 242(1942), pp. 998-110. 


\section{Twitchett 1992}

Twitchett, Denis. The Writing of Official History Under the T'ang. Cambridge, UK:

Cambridge University Press, 1992.

\section{Walker and Lucero 2000}

Walker, William H. and Lisa J. Lucero. "The depositional history of ritual and power," in Marcia-Anne Dobres and John E. Robb edts., Agency in Archaeology (London: Routledge, 2000), pp. 130-147.

\section{Ware 1932}

Ware, James R. "Notes on the History of the Wei shu". Journal of the American Oriental Society, 52:1(1932), pp. 35-45.

\section{Ware 1933a}

Ware, James R. “Wei Shou on Buddhism”. T'oung Pao, 30(1933), pp. 100-181.

\section{Ware 1933b}

Ware, James R. "The Wei shu and the Sui shu on Taoism". Journal of the American Oriental Society, 53:3(1933), pp. 215-250.

\section{Watson 1993}

Watson, Burton. (Trans.) The Lotus Sutra. New York: Columbia University Press, 1993.

\section{Watson 1997}

Watson, Burton. (Trans.) The Vimalakirti Sutra. New York: Columbia University Press, 1997.

\section{Weber 1978}

Weber, Max. Economy and Society: An outline of interpretive sociology, vol 2. Berkeley and London: University of California Press, 1978.

\section{Wechsler 1985}

Wechsler, Howard. Offerings of Jade and Silk. New Haven: Yale University Press, 1985.

\section{Wenley 1947}

Wenley, A. G. (Archibald Gibson). "The Grand Empress Dowager Wen Ming and the Northern Wei Necropolis at Fang Shan”. Freer Gallery of Art, Occasional Papers, vol. 1, no. 1. Washington: Smithsonian Institution, 1947.

\section{Wilber 1979}

Wilber, Donald N. "The Timurid Court: Life in Gardens and Tents." Iran 17(1979), pp. 127-133.

\section{Wilbur 1943}

Wilbur, Martin C. "Industrial Slavery in China During the Former Han Dynasty (206 BCAD 25)." The Journal of Economic History, 3:1(1943), pp. 56-69.

\section{Wittfogel and Feng 1949}

Wittfogel, Karl A. and Feng Chia-sheng. History of Chinese Society, Liao (907-1125). Philadelphia: American Philosophical Society, 1949. 


\section{Wong 2003}

Wong, Dorothy C. "Ethnicity and Identity: Northern nomads as Buddhist art patrons during the period of Northern and Southern dynasties" in Nicola Di Cosmo and Don J. Wyatt edts., Political Frontiers, Ethnic Boundaries, and Human Geographies in Chinese History (London: RoutledgeCurzon, 2003), pp. 80-118.

\section{Wright 1959}

Wright, Alfred. Buddhism in Chinese History. Stanford: Stanford University Press, 1959.

\section{Wu Hung 1986}

Wu Hung. "Buddhist Elements in Early Chinese Art ( $2^{\text {nd }}$ and $3^{\text {rd }}$ centuries A.D.)," Artibus Asiae 47:3/4(1986), pp. 263-303, 305-352.

\section{Wu Hung 1989}

Wu Hung. The Wu Liang Shrine: The ideology of early Chinese pictorial art. Stanford: Stanford University Press, 1989.

\section{Wu Hung 1996}

Wu Hung. Monumentality in Early Chinese Art and Architecture. Stanford: Stanford University Press, 1996.

\section{Wu Hung 1997}

Wu Hung. "The Prince of Jade Revisited: Material Symbolism of Jade as Observed in the Mancheng Tombs," in Rosemary E. Scott edt., Chinese Jades: Colloquies on Art and Archaeology in Asia (London: Percival David Foundation of Chinese Art, 1997), pp. 147169.

\section{Wu Hung 2002}

Wu Hung "A Case of Cultural Interaction: House-shaped sarcophagi of the Northern Dynasties," Orientations 34.5(2002), pp. 34-41.

\section{Wu Hung 2010}

Wu Hung. The Art of the Yellow Springs: Understnading Chinese Tombs. London: Reaktion Books, 2010.

\section{Xiong 2003}

Xiong, Victor. "Ritual Architecture under the Northern Wei" in Wu Hung edt. Between the Han and Tang: Visual and Material Culture in a Transformative Period. Beijing: Wenwu chubanshe, 2003, pp.31-92.

\section{Zanker 1988}

Zanker, Paul. The Power of Images in the Age of Augustus, trans. by Alan Shapiro. Ann Arbor: The University of Michigan Press, 1988.

\section{Zurcher 2007}

Zurcher, Erik. The Buddhist Conquest of China: the spread and adaptation of Buddhism in early medieval China. $3^{\text {rd }}$ ed. Leiden: Brill, 2007. 
Appendix C: Bibliography

\section{Zwalf 1985}

Zwalf, W, edt. Buddhism: art and faith. London: British Museum Publications, 1985.

\section{Japanese Language Sources}

\section{Egami 1950}

Egami, Namio 江上波夫. Yūrashia kodai hoppō bunka: Kyōdo bunkaronkō. ユウラシア 古代北方文化: 匈奴文化論考. Tokyo: Yamakawa shuppansha, 1950.

\section{Murata 1981}

Murata, Jiro 村田治郎. Chūgoku no teito. 中国の帝都. Kyoto: Sōgeisha, 1981.

\section{Tsukamoto 1942}

Tsukamoto, Zenryū 塚本善隆. Shina bukkyōshi kenkyū: Hokugi hen 支那佛教史研究 : 北魏篇. Tokyo: Kōbundō, 1942.

\section{Tsukamoto 1961}

Tsukamoto, Zenryū. Gisho Shakurō shi no kenkyū 魏書釋老志の研究. Kyoto: Bukkyō bunka kenkyūjo, 1961. 